\title{
UAB
}

Universitat Autònoma de Barcelona

\section{EL TRASPLANTE PULMONAR EN LA FIBROSIS QUÍSTICA Y LA INFLUENCIA DE LA CIRCULACIÓN EXTRACORPÓREA}

\author{
Alberto Jauregui Abularach
}

ADVERTIMENT. L'accés als continguts d'aquesta tesi queda condicionat a l'acceptació de les condicions d'ús establertes per la següent llicència Creative Commons:

(c) (i) (\$) $\fallingdotseq$ http://cat.creativecommons.org/?page_id=184

ADVERTENCIA. El acceso a los contenidos de esta tesis queda condicionado a la aceptación de las condiciones de uso establecidas por la siguiente licencia Creative Commons:

(c) (i) $\circledast$ ) http://es.creativecommons.org/blog/licencias/

WARNING. The access to the contents of this doctoral thesis it is limited to the acceptance of the use conditions set by the following Creative Commons license: (c) (i) (\$) $@$ https://creativecommons.org/licenses/?lang=en 


\title{
TESIS DOCTORAL
}

\section{EL TRASPLANTE PULMONAR EN LA FIBROSIS QUÍSTICA Y LA INFLUENCIA DE LA CIRCULACIÓN EXTRACORPÓREA}

Tesis presentada para optar al grado de Doctor

\author{
Doctorando: \\ Alberto Jauregui Abularach \\ Directores: \\ Dr. Juan Solé Montserrat \\ Prof. Manuel Armengol Carrasco \\ Tutor: \\ Prof. Manuel Armengol Carrasco
}
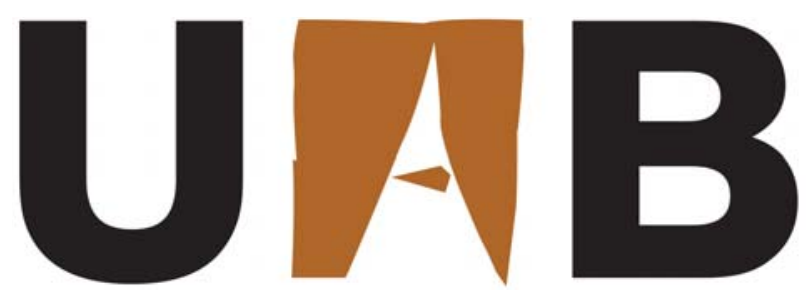

Universitat Autònoma de Barcelona

Programa de Doctorat en Cirurgia i Ciències Morfològiques

Departament de Cirurgia. Facultat de Medicina 

A Pedro, mi padre y amigo fraterno.

A Sonia, mi madre y amiga del alma. A Miguel, mi hermano y mi inspiración. Y sobre todo, a Carol, la luz de mis días 



\section{AGRADECIMIENTOS}

- Al Prof. Manuel Armengol Carrasco, Catedrático de Cirugía de la Universitat Autònoma de Barcelona y Director de la Tesis, por dedicar su tiempo y dedicación en la supervisión del presente trabajo.

- Al Dr. Juan Solé Montserrat, Jefe de servicio de Cirugía Torácica del Hospital Vall d'Hebron y Director de la Tesis, por toda la dedicación en mi formación de cirujano torácico, por la comprensión y por su amistad.

- A todos los cirujanos torácicos que forman y han formado parte del Servicio de Cirugía Torácica del Hospital Vall d'Hebron: Mercedes Canela, Joan Teixidor, Iker López, María Deu, Javier Pérez, Laura Romero, Joel Rosado, Irene Bello, Manuel Wong, Leire Sánchez, Fernando Ascanio, Pilar Montoya y Estefania San Gines, por compartir el trabajo diario y contribuir a los resultados presentados en este trabajo.

- A todos los integrantes del equipo de Neumología del Programa de Trasplante Pulmonar del Hospital Vall d'Hebron: Antonio Román, Carlos Bravo, Víctor Monforte, Manuel López-Messeguer, Cristina Berastegui y Berta Saez, por su profesionalidad en el manejo de los pacientes y por la colaboración prestada en la realización del presente trabajo.

- A Antonio Moreno, responsable del programa de Trasplante Pulmonar Infantil, por toda su colaboración en la revisión del presente trabajo.

- A Javier de Gracia, Antonio Álvarez y Mario Culebras, por compartir su gran experiencia en los pacientes con Fibrosis Quística y por la excelencia de su trabajo.

- A todos los integrantes de la Organización Catalana y Nacional de Trasplantes, y de los Servicios del Hospital Vall d'Hebron de Coordinación de Trasplantes, Medicina Intensiva, Anestesiología, Cirugía Cardíaca, Enfermedades Infecciosas, Rehabilitación, Anatomía Patológica, Radiología y a todo el equipo de Enfermería, por su imprescindible colaboración al éxito del Programa de Trasplante Pulmonar.

- A Santiago Pérez Hoyos, bioestadístico de la Unidad de Soporte Metodológico a la Investigación Biomédica (USMIB), por su colaboración fundamental en la elaboración del análisis estadístico. 



\section{ABREVIATURAS}

Las siguiente abreviaturas han sido utilizadas en este trabajo:

6WT

$\Delta \mathbf{F}_{508}$

ADN

ALG

ATG

AMPc

ATP

AZT

BCE

BTB

$\mathrm{Cl}^{-}$

CEC

CFTR

CMV

DM

DB

DCI

DPI

EB

ENaC

EPOC

FEV $_{1}$

FVC

FNTa

FQ

FPI

FNT

HTP

HR

IBM

IC

IMC

IL-1及

IL-6

IPE

ISHLT

IV

MMF

$\mathrm{Na}^{+}$

MNT

mmHg

OKT3

OMS

ON
Test de la marcha en 6 minutos

Deleción de nucleótidos que codifican fenilalanina en la posición 508

Ácido desoxirribonucleico

Globulina antilinfocítica

Globulina antitimocítica

Adenosina monofosfato cíclico

Adenosina trifosfato

Azatioprina

Bomba de circulación extracorpórea

Biopsia transbronquial

Cloro

Circulación extracorpórea

Cystic fibrosis transmembrane regulator

Citomegalovirus

Diabetes Mellitus

Dehiscencia bronquial

Disfunción crónica del injerto

Disfunción primaria del injerto

Estenosis bronquial

Canales de sodio epitelial

Enfermedad pulmonar obstructiva crónica

Volumen espiratorio forzado en el primer segundo

Capacidad vital forzada

Factor de necrosis tumoral alfa

Fibrosis quística

Fibrosis pulmonar idiopática

Factor de necrosis tumoral

Hipertensión pulmonar

Hazard Ratio

International business machines

Intervalo de confianza

Índice de masa corporal

Interleucina $1 \beta$

Interleucina 6

Insuficiencia pancreática exocrina

International Society for Heart and Lung Transplantation

Intravenoso

Micofenolato mofetil

Sodio

Micobacterias no tuberculosas

Milímetros de mercurio

Anticuerpo monoclonal Muromonab - CD3

Organización mundial de la salud

Óxido nítrico 


$\begin{array}{ll}\text { ONT } & \text { Organización nacional de trasplantes } \\ \text { PCR } & \text { Reacción en cadena de la polimerasa } \\ \text { PFR } & \text { Pruebas de función respiratoria } \\ \text { PaCO}_{2} & \text { Presión parcial de dióxido de carbono } \\ \text { PaO }_{2} & \text { Presión parcial de oxígeno } \\ \text { pH } & \text { Potencial hidrógeno } \\ \text { RA } & \text { Rechazo agudo } \\ \text { RC } & \text { Rechazo crónico } \\ \text { SRIS } & \text { Síndrome de respuesta inflamatoria sistémica } \\ \text { TBL } & \text { Trasplante bilobar } \\ \text { TBP } & \text { Trasplante bipulmonar } \\ \text { TP } & \text { Trasplante pulmonar } \\ \text { TUP } & \text { Trasplante unipulmonar } \\ \text { UCI } & \text { Unidad de cuidados intensivos } \\ \text { VIH } & \text { Virus de inmunodeficiencia humana } \\ \text { VM } & \text { Ventilación mecánica } \\ \text { VMNI } & \text { Ventilación mecánica no invasiva } \\ \text { VO } & \text { Vía oral }\end{array}$




\section{ÍNDICE}

Página

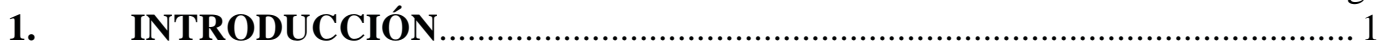

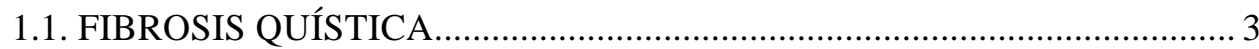

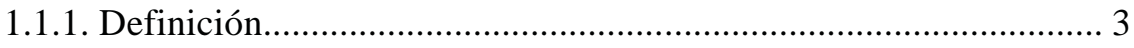

1.1.2. Patogénesis................................................................................. 3

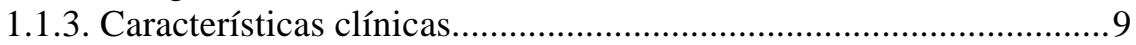

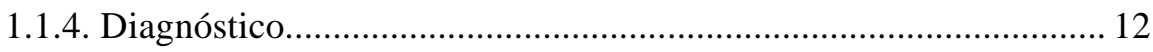

1.1.5. Tratamiento................................................................................ 13

1.2. EL TRASPLANTE PULMONAR EN LA FIBROSIS QUÍSTICA............... 17

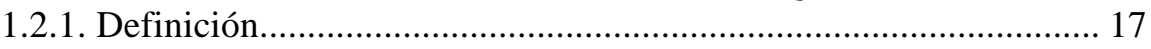

1.2.2. Tipos de trasplantes pulmonares.................................................. 17

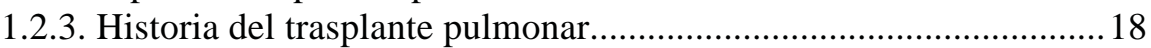

1.2.4. El trasplante pulmonar en España................................................... 19

1.2.5. El trasplante de pulmón por Fibrosis Quística..................................20

1.2.6. Selección del donante y receptor..................................................... 25

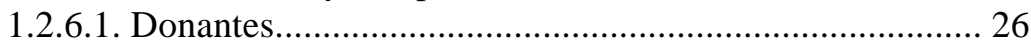

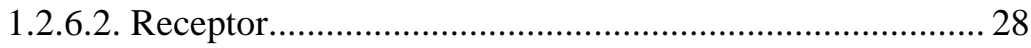

1.2.6.2.1. Contraindicaciones absolutas............................ 29

1.2.6.2.2. Contraindicaciones relativas............................ 31

1.2.7. Inmunosupresión en el trasplante pulmonar por Fibrosis Quística..32

1.2.7.1. Corticoesteroides.......................................................... 33

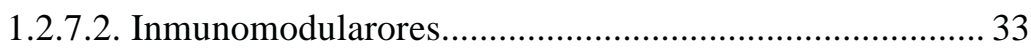

1.2.7.3. Antagonistas de la calcineurina........................................ 35

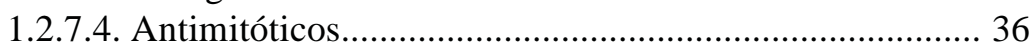

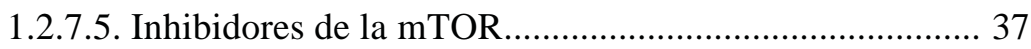

1.3. LA CIRCULACIÓN EXTRACORPÓREA.................................................. 38

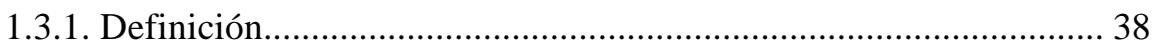

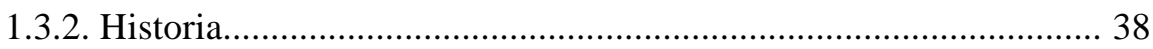

1.3.3. Funcionamiento de la máquina de CEC......................................... 40

1.3.4. Fisiopatología de la CEC................................................................. 45

1.4. INFLUENCIA DE LA CEC EN EL TRASPLANTE PULMONAR ...............50

1.4.1. CEC y la disfunción del injerto pulmonar........................................ 50

1.4.2. CEC como factor protector en el TP...............................................51

1.4.3. CEC y disminución de la supervivencia............................................53

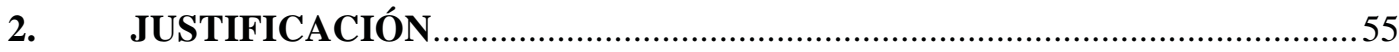

3. OBJETIVOS

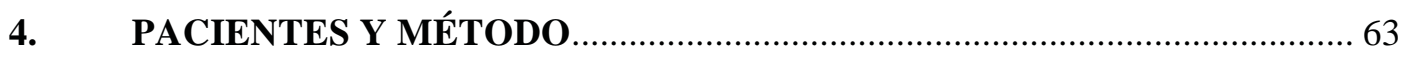

4.1. PACIENTES

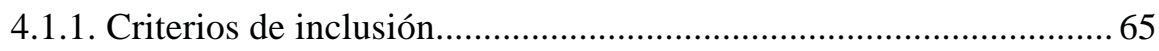

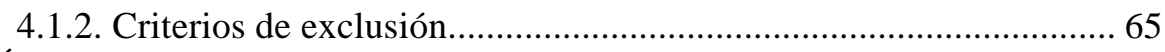

4.2. MÉTODO

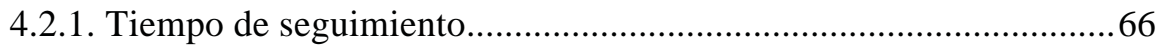

4.2.2. Extracción y preservación pulmonar................................................... 66

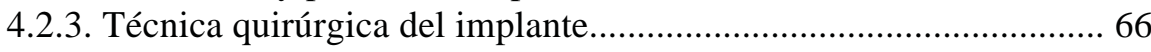

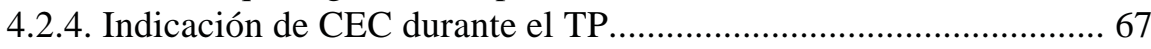




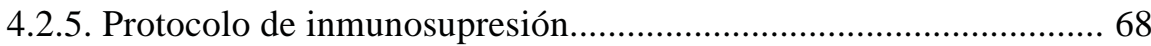

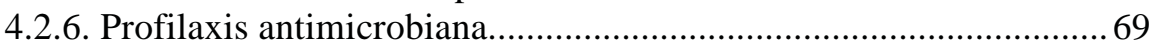

4.2.7. Evaluación de receptores y seguimiento postoperatorio.................. 70

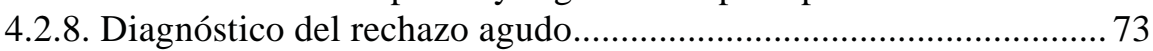

4.2.9. Diagnóstico de la disfunción crónica del injerto............................... 73

4.2.10. Variables del estudio.....................................................................74

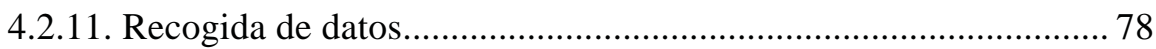

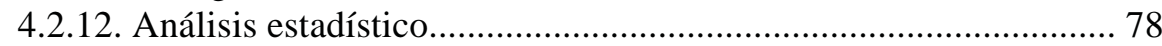

5. RESULTADOS

5.1. ANÁLISIS DESCRIPTIVO DE LA SERIE GLOBAL................................. 83

5.1.1. Análisis descriptivo previo al trasplante pulmonar.......................... 84

5.1.2. Análisis descriptivo del acto quirúrgico.......................................... 91

5.1.3. Análisis descriptivo del postoperatorio........................................... 92

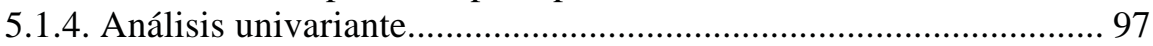

5.2. INFLUENCIA DE FACTORES SOBRE LA PROBABILIDAD DE CEC... 107

5.2.1. Análisis descriptivo previo al trasplante pulmonar......................... 108

5.2.2. Análisis descriptivo del acto quirúrgico......................................... 115

5.2.3. Análisis descriptivo del postoperatorio......................................... 116

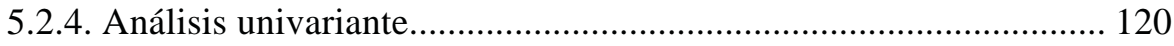

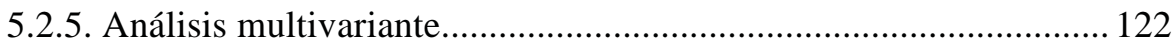

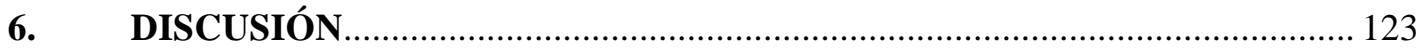

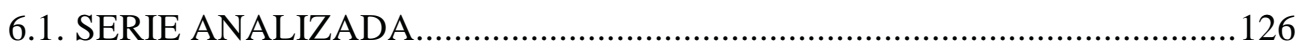

6.2. SOLUCIÓN DE PRESERVACIÓN............................................................. 127

6.3. CARACTERÍSTICAS DEMOGRÁFICAS................................................ 127

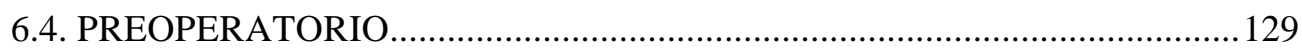

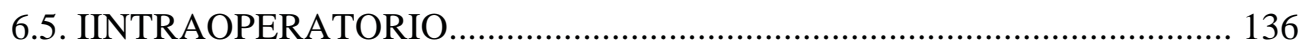

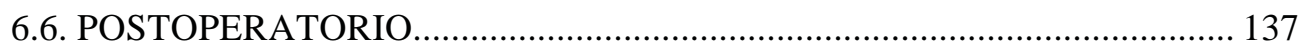

6.7. SUPERVIVENCIA DE LA SERIE GENERAL ......................................... 143

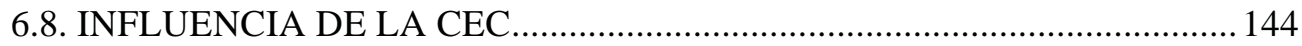

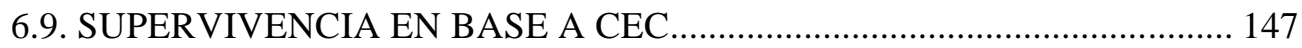

6.10. FACTORES DE RIESGO DE CEC......................................................... 148

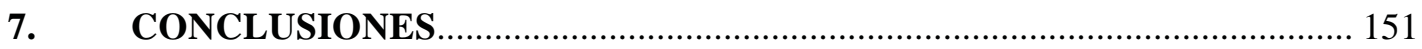

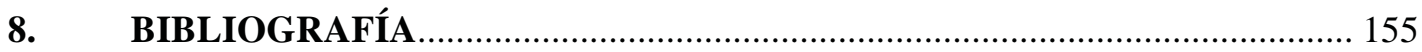


1. INTRODUCCIÓN 



\subsection{FIBROSIS QUÍSTICA}

\subsubsection{Definición}

La fibrosis quística (FQ) es un desorden mono genético que se presenta como enfermedad multisistémica. Es la enfermedad genética más frecuente en la raza blanca, con una frecuencia en nuestro medio de 1:5500 nacidos vivos ${ }^{1}$. Habitualmente los primeros síntomas aparecen en la infancia, pero un 7\% de los pacientes es diagnosticado en la edad adulta. Gracias a la mejora de los tratamientos, más del $36 \%$ de los pacientes llega a la edad adulta y un $12 \%$ sobrepasa los 30 años. La media de supervivencia está por encima de los 32 años para los hombres y 29 años para las mujeres con FQ. Por lo tanto, la FQ ya no es una enfermedad de la edad pediátrica. ${ }^{2}$

En España la tendencia de la FQ respecto a la edad sigue patrones parecidos, en un estudio realizado en España el año 2007 se aprecia dicha tendencia; en el año 1992, sólo el 5\% eran mayores de 18 años; pero en noviembre de 2006 el $42 \%$ eran mayores de 18 años. $^{3}$

Esta enfermedad se caracteriza por la infección crónica de las vías aéreas que ocasionan bronquiectasias y bronquioloectasias, insuficiencia pancreática exocrina, disfunción intestinal, función anormal de glándulas sudoríparas y disfunción urogenital.

\subsubsection{Patogénesis ${ }^{4}$}

\section{Consideraciones genéticas}

En el epitelio normal de los conductos, el cloro es transportado por canales de la membrana plasmática (canales de cloro). El defecto primario en la FQ se debe a una función anormal de una proteína del canal del cloro codificada por el gen regulador de 
la conductancia transmembrana de la FQ; CFTR o Cystic fibrosis transmembrane regulator en la banda cromosómica 7q31.2. La proteína codificada por el CFTR tiene dos dominios transmembrana, dos dominios de unión a nucleótidos citoplasmáticos y un dominio regulador (dominio R) que contiene lugares de fosforilación de las proteín cinasas A y C. Los dos dominios transmembrana forman un canal a través del cual pasa el cloro. La activación del canal del CFTR está mediada por aumentos inducidos por agonistas de la adenosina monofosfato cíclico (AMPc), seguidos de la activación de una proteín cinasa A que fosforila el dominio R. La unión y la hidrólisis de la adenosina trifosfato (ATP) tiene lugar en el dominio de unión de los nucleótidos y es esencial para la abertura y el cierre del poro del canal en respuesta a la señalización mediada por la AMPc.

Hay varios aspectos importantes de la función del CFTR que han surgido en los últimos años:

- El CFTR regula múltiples canales iónicos adicionales y procesos celulares. Aunque inicialmente se caracterizó como un canal de conductancia de cloro, actualmente se sabe que el CFTR puede regular múltiples canales iónicos y procesos celulares, principalmente a través de la interacción con su dominio de unión con los nucleótidos. ${ }^{5,6}$ Estos incluyen los denominados canales de cloro rectificados hacia fuera, los canales de potasio rectificados hacia dentro, los canales de sodio epitelial $(\mathrm{ENaC})$, canales de unión estrecha y los procesos celulares implicados en el transporte de ATP y la secreción de moco. De ellos, la interacción de CFTR con $\mathrm{ENaC}$ tiene posiblemente la mayor relevancia fisiopatológica en la FQ.

El ENaC está situado en la superficie apical de las células epiteliales exocrinas y es responsable del transporte de sodio intracitoplasmático desde el líquido luminal, haciendo que éste (el líquido luminal) pase a ser hipotónico. El ENaC es inhibido por el CFTR cuando éste funciona normalmente; pero, en la FQ, la actividad del ENaC aumenta, incrementando notablemente el transporte de sodio a través de la membrana apical. La única excepción a esta regla se produce en los conductos sudoríparos humanos, donde la actividad del ENaC disminuye 
como resultado de las mutaciones del CFTR, por lo tanto se forma un líquido luminal hipertónico que contiene sudor rico en cloro (la condición obligada de la FQ clásica) y en sodio. ${ }^{7}$ Esta es la base del sudor "salado" que las madres pueden detectar con frecuencia en sus hijos afectados.

Las funciones del CFTR son específicas de cada tejido; motivo por el que el impacto de una mutación en el CFTR es específico de cada tejido. Por ejemplo, la principal función del CFTR en los conductos de las glándulas sudoríparas es reabsorber iones de cloro luminales y aumentar la reabsorción de sodio a través del ENaC. Ocasionando la disminución de la reabsorción de cloruro sódico y la producción de un sudor hipertónico.

El canal del CFTR no sólo es responsable de la absorción de cloro. En el epitelio respiratorio e intestinal forma uno de los caminos más importantes para la secreción luminal activa de cloro. En estos lugares, las mutaciones del CFTR originan una pérdida o reducción de la secreción de cloro dentro de la luz. La absorción luminal activa de sodio también está aumentada debido a la pérdida de la inhibición de la actividad del $\mathrm{ENaC}$, estos dos cambios iónicos aumentan la reabsorción pasiva de agua desde la luz, disminuyendo el contenido en agua de la capa líquida superficial que recubre las células mucosas. ${ }^{8}$ De esta forma, al contrario que en los conductos sudoríparos, no hay diferencias en la concentración de sal de la capa líquida superficial que recubre las células mucosas respiratorias entre los individuos normales y los afectos de FQ. Así, la patogenia de las complicaciones respiratorias e intestinales en la $F Q$ parece originarse en que la capa líquida que recubre la mucosa es isotónica pero con bajo volumen. En los pulmones, la deshidratación origina una acción mucociliar defectuosa y acumulación de secreciones viscosas hiperconcentradas que obstruyen las vías aéreas y predisponen a infecciones pulmonares recurrentes (Figura 1). ${ }^{9}$ 


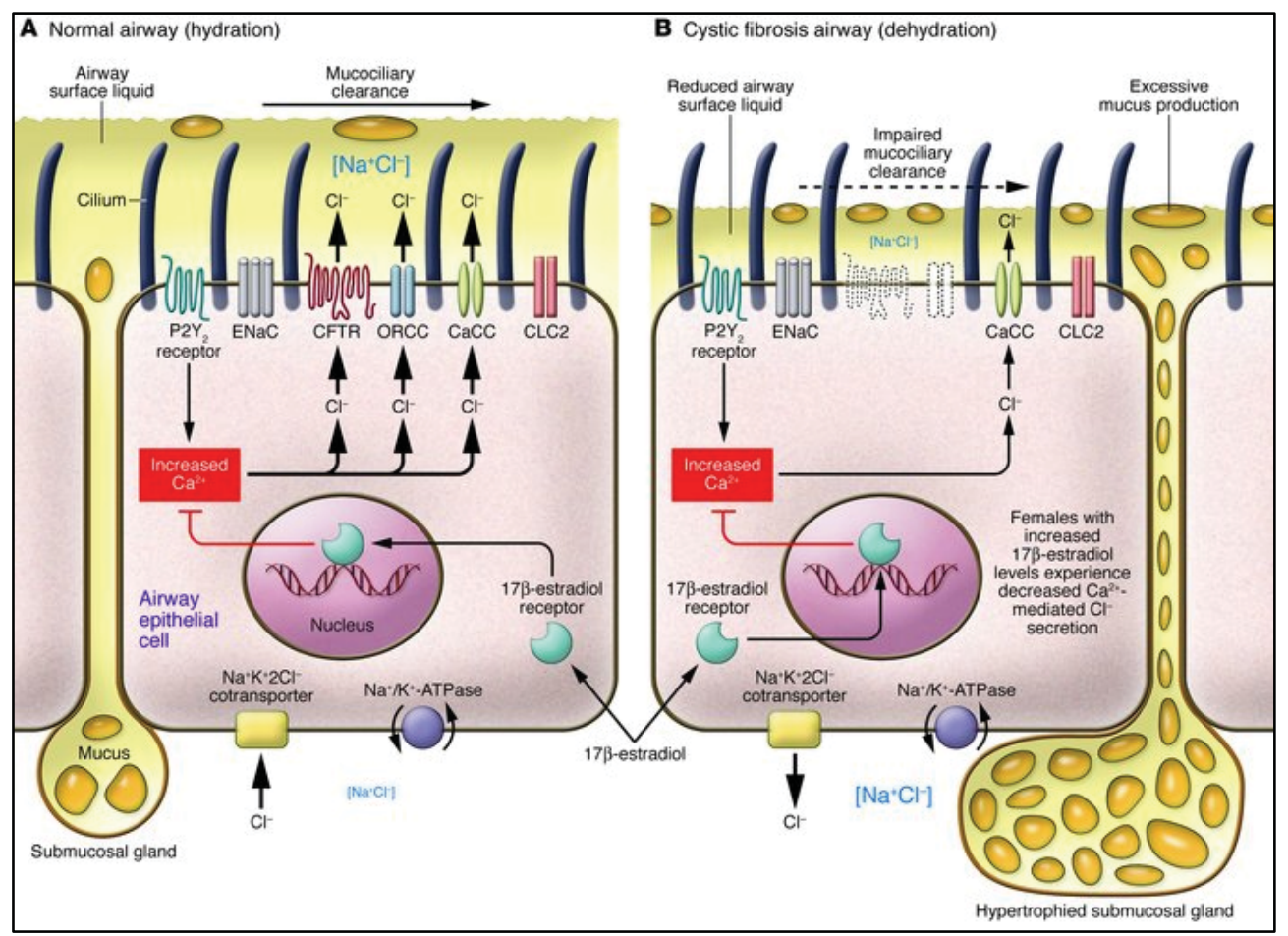

Figura 1. A: Vía aérea normal. B: Vía aérea de paciente con FQ; disminución de la secreción de cloro y un aumento en la reabsorción de sodio y agua, que dan lugar a la deshidratación de la capa de moco y formación de moco espeso de difícil eliminación. ${ }^{9}$

El CFTR media el transporte de iones de bicarbonato. Se ha demostrado recientemente que el CFTR puede transportar también iones de bicarbonato y que en algunas variantes mutantes de CFTR el transporte de cloro está total o sustancialmente conservado, mientras que el transporte de bicarbonato es claramente anormal. Los líquidos alcalinos son secretados por tejidos normales, mientras que los líquidos ácidos (debido a la ausencia de iones de bicarbonato) son secretados por epitelios que poseen estos CFTR mutantes. La disminución del $\mathrm{pH}$ luminal puede dar lugar a varios efectos adversos como aumento de la precipitación de mucina y obstrucción de conductos causando un incremento de la unión de bacterias a dichas mucinas. La insuficiencia pancreática, una característica de la FQ clásica, existe prácticamente siempre cuando hay mutaciones del CFTR con conductancia de bicarbonato anormal. 


\section{El gen de la $F Q$}

Desde que se clonó el gen CFTR en 1989 se han identificado más de 800 mutaciones causales de la enfermedad. Varias mutaciones se han agrupado en seis "clases" según su efecto sobre la proteína CFTR: ${ }^{10}$

Clase I: Sintesis de proteína defectuosa. Estas mutaciones se asocian con la falta completa de la proteína CFTR en la superficie apical de las células epiteliales.

Clase II: Plegamiento, procesamiento y circulación de la proteína anormales. Estas mutaciones dan lugar a un procesamiento defectuoso de la proteína desde el retículo endoplasmático hasta el aparato de Golgi; la proteína no está completamente plegada y glucosilada y en cambio es degradada antes de alcanzar la superficie celular. Las anomalías del gen de la FQ más frecuente es una mutación de clase II que da lugar a una deleción de tres nucleótidos que codifican la fenilalanina en la posición $508\left(\Delta \mathrm{F}_{508}\right)$. En todo el mundo, esta mutación puede encontrarse aproximadamente en el 68 a $70 \%$ de los pacientes con FQ. ${ }^{11}$ Las mutaciones de clase II se asocian también con una falta completa de proteína del CFTR en la superficie apical de las células epiteliales.

Clase III: Regulación defectuosa. Las mutaciones de esta clase evitan la activación del CFTR al impedir la unión y la hidrólisis del ATP, un prerrequisito esencial para el trasiego iónico. De esta forma, existe una cantidad normal de CFTR en la superficie apical pero que no es funcional.

Clase IV: Conductancia disminuida. Estas mutaciones ocurren típicamente en el dominio transmembrana del CFTR, que forma el poro iónico para el transporte de cloro. Existe una cantidad normal del CFTR en la membrana apical, pero con una función reducida. Esta clase suele asociarse con un fenotipo más leve de FQ. 
- $\quad$ Clase V: Abundancia disminuida. Estas mutaciones típicamente afectan a los lugares intrónicos de empalme o al promotor de CFTR, de forma que existe una cantidad reducida de proteína normal. Las mutaciones de clase V también se asocian con un fenotipo más leve de FQ.

Clase VI: Alteración de la regulación de canales iónicos separados. Como se ha descrito anteriormente, el CFTR está implicado en la regulación de múltiples canales iónicos celulares diferentes. Las mutaciones de esta clase afectan al papel regulador de CFTR. En algunos casos, una mutación determinada afecta a la conductancia de CFTR y la regulación de otros canales iónicos. Por ejemplo, la mutación $\Delta \mathrm{F}_{508}$ es una mutación de clase II y de clase VI.

Al ser la FQ una enfermedad autosómica recesiva, los individuos afectados poseen mutaciones en ambos alelos. Sin embargo, la combinación de mutaciones en los dos alelos puede tener un efecto destacado sobre el fenotipo global, además de causar manifestaciones específicas en los órganos afectados. Así pues, dos mutaciones "graves" (clase I, II y III) que producen una virtual ausencia de CFTR de membrana se asocian con el fenotipo de FQ clásica (insuficiencia pancreática, infecciones seno pulmonares y síntomas gastrointestinales), mientras que la presencia de una mutación "leve" (clases IV o V) en uno o ambos alelos da lugar a un fenotipo menos grave. Esta regla general de correlación genotipo - fenotipo es muy constante en la enfermedad pancreática, en la que la presencia de una mutación "leve" en un alelo puede revertir el fenotipo de insuficiencia pancreática conferido por homocigosidad de mutaciones "graves". Por el contrario, las correlaciones genotipo - fenotipo son mucho menos constantes en la enfermedad pulmonar, lo que refleja un efecto de modificadores secundarios.

Las pruebas genéticas para detectar las mutaciones de CFTR se han ampliado, por lo que cada vez se ha hecho más evidente que los pacientes que presentan una serie de fenotipos clínicos aparentemente no relacionados también pueden poseer mutaciones de CFTR. Entre ellos se encuentran individuos inicialmente diagnosticados con pancreatitis crónica idiopática, enfermedad pulmonar crónica de inicio tardío, bronquiectasias idiopáticas y azoospermia obstructiva. ${ }^{12}$ Estos subgrupos se clasifican 
como FQ no clásica o atípica, identificar a estos individuos es importante no sólo para el manejo posterior sino también con vistas al consejo genético.

\subsubsection{Características clínicas}

Muchos pacientes con FQ presentan signos y síntomas desde la infancia. Aproximadamente el 15\% de los pacientes presentan obstrucción intestinal en forma de íleo meconial en las primeras 24 horas de vida. Otra presentación frecuente durante el primer o segundo año de vida son los síntomas respiratorios; tos e infiltrados pulmonares recurrentes y estancamiento en el desarrollo pondoestatural. Una proporción significativa de pacientes (7\%) se diagnostican después de los 18 años. ${ }^{13}$

\section{Tracto respiratorio}

La enfermedad del tracto respiratorio superior es casi universal en los pacientes con FQ. La sinusitis crónica es común durante la infancia y usualmente se manifiesta como obstrucción nasal con rinorrea. La frecuencia de pólipos nasales es de un $25 \%$ y suele ser habitual que requieran tratamiento quirúrgico.

En el tracto respiratorio inferior el primer síntoma de FQ es la tos. Con el tiempo, la tos se vuelve persistente y con expectoración mucopurulenta. Inevitablemente los periodos de estabilidad clínica se interrumpen por exacerbaciones, definidas como un aumento de la tos, aumento en la cantidad de esputo, disminución de la función pulmonar y disminución de peso. Estas agudizaciones requieren terapia agresiva, incluyendo drenaje postural y antibioticoterápia oral o parenteral. Durante el transcurso de los años, las exacerbaciones se vuelven más frecuentes y la función pulmonar se deteriora progresivamente evolucionando hacia el fallo respiratorio.

Los pacientes con FQ tienen colonizaciones por gérmenes casi de forma constante. Haemophilus influenzae y Staphilococcus aureus son los gérmenes más frecuentes en los pacientes recién diagnosticados. ${ }^{13,14}$ Posteriormente suelen colonizarse por otros gérmenes tales como la Pseudomonas aeruginosa (el microorganismo predominante), Burkholderia cepacia (antes llamada Pseudomona cepacia), Xanthomonas, Proteus, Escherichia coli, y Klebsiella. En un $50 \%$ de los pacientes con FQ se aísla Aspergillus fumigatus en el esputo, y un $10 \%$ de estos pacientes puede desarrollar síndrome de aspergilosis alérgica broncopulmonar. La presencia de 
Mycobacterium tuberculosis es rara en pacientes con FQ, pero un 10 a $20 \%$ de los pacientes adultos con FQ tienen cultivos positivos en esputo de micobacterias no tuberculosas (MNT) que en algunos casos presentan enfermedad pulmonar. ${ }^{15}$

Dentro de la función pulmonar, la primera anomalía observada en niños con FQ es un aumento del volumen residual y de la capacidad pulmonar total, sugiriendo enfermedad de la pequeña vía aérea. A medida que progresa la enfermedad, existe una acumulación de secreciones, destrucción de las paredes de la vía aérea y bronquiolitis.

El cambio inicial en la radiografía de tórax es una hiperinsuflación, reflejando obstrucción de la pequeña vía aérea. Posteriormente se observan signos de impactación mucosa intraluminal, dilatación bronquial y por último bronquiectasias. Por razones que aún se desconocen, el lóbulo superior derecho suele ser el primero en afectarse y de forma más grave.

La afectación respiratoria en la FQ se asocia con muchas complicaciones intercurrentes. El neumotórax se presenta en más del 10\% de pacientes, la hemoptisis suele asociarse a las infecciones pulmonares, puede llegar a ser masiva y de difícil tratamiento, dedos en palillo de tambor y como eventos tardíos de la enfermedad el fallo respiratorio y el cor pulmonale.

\section{Tracto gastrointestinal}

La insuficiencia pancreática exocrina (IPE) es una de las características clínicas que se presentan con mayor frecuencia en los pacientes con FQ. Más del 50\% de los pacientes presentan signos clínicos de IPE durante los primeros días de vida y hasta el $90 \%$ los manifiestan dentro del primer año. Asimismo, es la causa principal de desnutrición y retardo en el crecimiento de los pacientes. La secreción pancreática es una solución con un volumen elevado de bicarbonato como respuesta a la estimulación por secretina y colecistoquinina. ${ }^{16-19} \mathrm{Su}$ función principal es neutralizar el pH ácido producido por las secreciones gástricas y permitir un funcionamiento óptimo de las enzimas pancreáticas. La FQ se caracteriza por una disminución en el volumen y en la concentración de bicarbonato de la secreción pancreática, lo cual genera un retardo en el flujo de la secreción y de las pro-enzimas digestivas a través de los conductos pancreáticos. Todo esto, ocasiona una activación prematura de las enzimas originando daño en el tejido 
pancreático por destrucción de las células acinares. El dañó crónico da lugar a la fibrosis del páncreas y a la insuficiencia del órgano. ${ }^{16}$ La IPE se manifiesta por una disminución o ausencia en la producción de enzimas pancreáticas exocrinas como la amilasa, proteasas, lipasa, colipasa y fosfolipasa. ${ }^{17}$ De forma característica, la IPE origina malabsorción de grasas que se evidencia clínicamente por dolor abdominal, esteatorrea, flatulencias, diarrea y disminución en la absorción de vitaminas liposolubles. Se estima que la función enzimática del páncreas debe disminuir a menos del $3 \%$ de lo normal para que se desarrollen datos clínicos de IPE. ${ }^{18}$

Debido a la mayor supervivencia de los pacientes con FQ, actualmente la diabetes mellitus (DM) es una de las comorbilidades más frecuentes en los sujetos que alcanzan la edad adulta. ${ }^{20}$ Típicamente se diagnostica en la adolescencia tardía, con una media al diagnóstico comprendida entre los 18 y 25 años. La prevalencia es difícil de establecer y a menudo resulta infra estimada. En Europa y Estados Unidos se estima una prevalencia global del 12 y 16,9\% respectivamente. ${ }^{21,22}$ En los pacientes con DM y FQ existe un declive de la función pulmonar mayor que en los pacientes normo glucémicos, en relación directa con el grado de déficit de insulina y con la severidad de la alteración del metabolismo hidrocarbonado. Expresado en otro modo, el grado de intolerancia a la glucosa se correlaciona directamente en la espirometria con un menor volumen espiratorio forzado durante el primer segundo $\left(\mathrm{FEV}_{1}\right)$ y una menor capacidad vital forzada $(\mathrm{FVC}){ }^{23}$

El síndrome de íleo meconial en los recién nacidos se presenta como distensión abdominal, obstrucción intestinal y vómitos. La radiografía simple de abdomen puede ser diagnóstica al apreciarse niveles hidroaéreos en intestino delgado con imágenes reticulares en su interior (meconio). En niños o adultos jóvenes se puede presentar un síndrome denominado íleo meconial equivalente. La presentación clínica suele ser en forma de dolor abdominal en cuadrante inferior, hiporéxia, vómitos y usualmente una masa abdominal palpable. Este síndrome puede ser confundido con apendicitis lo que ocurre frecuentemente en pacientes con FQ. Más del 90\% de los pacientes tiene insuficiencia pancreática, dando lugar a mala absorción de grasas con presencia de deposiciones frecuentes, voluminosas y mal olientes. ${ }^{24}$ 
Los signos y síntomas de mala absorción también se extienden a las vitaminas liposolubles, incluyendo vitaminas E y K. Las células Beta pancreáticas suelen estar conservadas en un principio pero disminuyen con el tiempo causando hiperglucemia y requerimiento de terapia con insulina en los pacientes mayores.

\section{Sistema genitourinario}

La pubertad tardía es frecuente en hombres y mujeres con FQ. Más del 95\% de los pacientes masculinos tienen azoospermia, debido a una obliteración de los vasos deferentes por una probable secreción de líquidos defectuosa. Hasta un $20 \%$ de las mujeres con FQ son infértiles por la presencia de moco cervical espeso que bloquea la migración espermática, y la posible anormalidad en el transporte de líquidos en la trompa de Falopio.

\subsubsection{Diagnóstico}

\section{Despistaje}

El despistaje se basa en la combinación de criterios clínicos y análisis del sudor con la medición de los valores de cloro $\left(\mathrm{Cl}^{-}\right)$. La concentración de sodio $\left(\mathrm{Na}^{+}\right)$y $\mathrm{Cl}^{-}$en el sudor varía con la edad, pero típicamente en adultos una concentración de $\mathrm{Cl}^{-}>70$ $\mathrm{mEq} / \mathrm{L}$ determina a los pacientes con $\mathrm{FQ}$ de los pacientes con otras enfermedades pulmonares. Entre 1 y $2 \%$ de los pacientes con síndrome clínico de FQ tienen valores normales de $\mathrm{Cl}^{-}$en el sudor. ${ }^{25}$

Aunque la determinación de mutaciones genéticas del CFTR ha dado una nueva dimensión al diagnóstico de FQ, el test del sudor, todavía se mantiene como el procedimiento estándar para confirmar el diagnostico de FQ. ${ }^{26}$

\section{Diagnóstico de certeza}

Debido al gran número de mutaciones de FQ, el análisis del ácido desoxirribonucleico $(\mathrm{ADN})$ no se suele utilizar para el diagnóstico de despistaje (screening).

Para la gran mayoría de pacientes con FQ, el test del sudor se mantiene como la mejor prueba diagnostica. Para los pacientes que tienen valores intermedios en el test del sudor, el estudio de ADN puede ayudar a definir el diagnostico. ${ }^{27}$ 
La relación entre genotipo y fenotipo todavía no está totalmente esclarecida para definir un pronóstico. La relación entre los homocigotos $\Delta \mathrm{F}_{508}$ y la insuficiencia pancreática esta establecida pero no así la relación entre homocigotos $\Delta \mathrm{F}_{508}$ y la enfermedad pulmonar.

\subsubsection{Tratamiento}

El principal objetivo del tratamiento de la FQ está dirigido al aclaramiento de las secreciones, control de las infecciones pulmonares, nutrición adecuada y prevenir la obstrucción intestinal. Últimamente la terapia genética podría convertirse en el tratamiento de elección.

\section{Enfermedad pulmonar.}

Las principales técnicas para el aclaramiento de las secreciones son la fisioterapia respiratoria, drenaje postural y percusión del tórax (clapping). Existe un interés cada vez mayor en la utilización de soluciones hipertónicas (3 al 7\%) de aerosoles para aumentar el aclaramiento de las secreciones. ${ }^{2}$

Más del $95 \%$ de los pacientes con FQ fallecen por complicaciones de infecciones pulmonares. Los antibióticos son el pilar sobre el que se basa el tratamiento de éstos pacientes y el espectro de acción está dirigido por los cultivos de esputo. Debido al aumento en el aclaramiento total corporal y la distribución de los antibióticos en pacientes con $\mathrm{FQ}$, las dosis requeridas suelen ser mayores que la de pacientes con infecciones pulmonares similares pero que no tienen $\mathrm{FQ}$.

El aumento de tos y expectoración suele tratarse con antibióticos orales. Típicamente los antibióticos utilizados contra especies de Staphylococcus incluyen a una penicilina semisintética o una cefalosporina. La ciprofloxacina oral puede ser eficaz contra Pseudomonas y controlar sus síntomas. Sin embargo su utilización puede estar limitada por la rápida aparición de cepas resistentes, por lo tanto el tratamiento debe ser intermitente (2 a 3 semanas) y no crónico. Las exacerbaciones más severas, o exacerbaciones con cepas resistentes a antibióticos orales suelen requerir la administración de antibióticos intravenosos (IV) de forma hospitalaria. Aunque actualmente es cada vez más frecuente la terapia antibiótica en régimen ambulatorio. 
Usualmente se administran dos drogas, una de ellas suele ser un aminoglucosido que suele utilizarse para "obstaculizar" la aparición de cepas resistentes. La dosis debería monitorizarse para que los niveles pico de gentamicina o tobramicina se mantengan alrededor de $10 \mu \mathrm{g} / \mathrm{mL}$. Las drogas de segunda línea suelen ser una cefalosporina, por ejemplo ceftazidima y/o un derivado de penicilina. Los antibióticos contra especies de Staphylococcus y/o Haemophilus influenzae se administran de acuerdo a los cultivos de esputo. Los antibióticos en aerosoles tienen un papel importante en el tratamiento de la infección pulmonar de pacientes con FQ. Dosis importantes de aminoglucosidos administrados vía aerosol como tobramicina $600 \mathrm{mg}$ dos veces al día pueden ser efectivas para retrasar las exacerbaciones. La administración en aerosoles también permite su utilización con otras drogas, por ejemplo colistina que suele ser inefectiva en su administración endovenosa.

La utilización de agentes para promover el aclaramiento como N-acetil-cisteína, que solubiliza las glicoproteínas del moco, no ha demostrado ser de utilidad clínica significativa sobre el aclaramiento de moco o sobre la función pulmonar. Sin embargo, la utilización de $\mathrm{ADN}$ recombinante, que degrada el ADN concentrado en el esputo, disminuye la viscosidad del esputo y aumenta el flujo aéreo durante su administración por períodos cortos de tiempo. Su utilización por períodos más largos (6 meses) ha demostrado aumentar el tiempo entre las exacerbaciones pulmonares. ${ }^{28,29}$ Muchos pacientes incluidos en estudios terapéuticos con ADN recombinante parecen demostrar beneficios objetivos. Actualmente se llevan a cabo estudios experimentales dirigidos a restaurar el contenido de sal y agua en las secreciones de estos pacientes. ${ }^{30,31}$

Los agonistas $\beta$ - adrenérgicos inhalados pueden ser útiles en el control de la broncoconstricción, parecen aumentar el flujo aéreo durante un corto período de tiempo, pero los beneficios a largo plazo no han sido demostrados. Los esteroides orales no son drogas de primera línea para controlar la broncoconstricción y no se ha demostrado su utilidad en la mejora de la función pulmonar. Si bien, se suelen utilizar para el tratamiento de la aspergilosis alérgica broncopulmonar.

El daño crónico de las paredes de la vía aérea refleja en cierta medida el efecto de enzimas inflamatorias generadas por células inflamatorias. Hasta la fecha no se han desarrollado terapias con antiproteasas que hayan demostrado ser efectivas. Sin 
embargo, en algunos pacientes adolescentes con FQ parece haber beneficio prolongado en tratamiento con altas dosis de antiinflamatorios no esteroideos (ibuprofeno). ${ }^{31}$

El tratamiento de algunas complicaciones pulmonares requiere intervenciones urgentes. La atelectasia suele tratarse mejor con fisioterapia respiratoria y terapia antibiótica. Los neumotórax que afectan a un $10 \%$ o menos del pulmón pueden ser tratados de forma expectante. En los pacientes que son tributarios de drenaje pleural, suele ser necesario mantener dichos drenajes por períodos más prolongados que en pacientes sin FQ por la enfermedad pulmonar de base y las fugas aéreas prolongadas. Aunque la utilización de agentes esclerosantes intrapleurales para conseguir pleurodesis no suele recomendarse por las complicaciones que puede causar en el postoperatorio de un trasplante pulmonar (TP), dichos procedimientos quirúrgicos, no se consideran actualmente una contraindicación para el trasplante. ${ }^{32}$ La hemoptisis de pequeña cuantía no requiere terapia específica aparte del tratamiento de la infección pulmonar y el control de la coagulación con administración de vitamina K. Si la hemoptisis es masiva, suele ser efectiva la embolización de arterias bronquiales. La mayor complicación pulmonar en pacientes con FQ son el fallo respiratorio y el cor pulmonale. La medida más efectiva contra estas condiciones suele requerir un tratamiento enérgico de la afectación pulmonar y oxígeno suplementario. La utilización de ventilación mecánica no invasiva (VMNI) con presión positiva puede ser útil como terapia adjunta.

Al final, el único tratamiento efectivo contra el fallo respiratorio suele ser el TP. La supervivencia a los 2 años supera el $60 \%$ y la muerte de estos pacientes suele ser por rechazo crónico del injerto en forma de bronquiolitis obliterante. Los pulmones trasplantados no desarrollan el fenotipo específico de FQ.

\section{Enfermedad Gastrointestinal.}

El mantenimiento de una nutrición adecuada es de importancia crítica para los pacientes con FQ. La mayoría (> 90\%) de los pacientes con FQ se benefician del tratamiento sustitutivo con enzimas pancreáticas. Las cápsulas generalmente contienen entre 4000 y 29000 unidades de lipasa. La dosis de las enzimas (típicamente no mayores de 20000 unidades/kg por comida) debería ajustarse al peso, sintomatología abdominal y características de las heces fecales. Usualmente es necesaria la administración de vitaminas liposolubles, particularmente vitamina E y K. Respecto al tratamiento de la 
DM relacionada con la FQ, actualmente se recomienda el tratamiento con insulina. ${ }^{33} \mathrm{El}$ uso de antidiabéticos orales no está recomendado. ${ }^{33,34}$

Para el tratamiento de la obstrucción intestinal debido a síndrome de íleo meconial equivalente se utilizan enemas de contrastes hipertónicos. Para el control de los síntomas suele utilizarse el ajuste de enzimas pancreáticas y la administración de soluciones con agentes osmóticos como lactulosa o propileneglicol. La persistencia de la sintomatología abdominal puede indicar la presencia de una neoplasia gastrointestinal cuya incidencia está aumentada en pacientes con FQ. La enfermedad hepática y de la vesícula biliar se suele tratar como en los pacientes sin diagnóstico de FQ. La enfermedad hepática terminal se puede tratar con el trasplante hepático que tiene una supervivencia a los 2 años mayor al $50 \% .^{25}$

\section{Problemática psicosocial.}

La FQ impone una importante carga emocional dada la limitación de la calidad de vida en estos pacientes. La salud, las opciones de empleo, la planificación familiar y la expectativa de vida son factores de gran trascendencia. Por lo tanto, la asistencia psicosocial de estos pacientes es de vital importancia para los servicios de salud. 


\subsection{EL TRASPLANTE PULMONAR EN LA FIBROSIS QUÍSTICA}

\subsubsection{Definición.}

Se define como trasplante el proceso en el que se extrae un injerto (células, tejidos $\mathrm{u}$ órganos) de un individuo (donante) y se implanta en otro paciente (receptor).

Se denomina trasplante ortotópico cuando el injerto se coloca en su localización anatómica habitual (corazón o pulmón) y heterotópico cuando se implanta en una zona diferente del organismo (riñón)

La relación genética entre donante y receptor se describe como:

- Singénica: cuando la relación se establece entre individuos de una cepa idéntica o gemelos homocigotos.

- Alogénica: entre individuos de la misma especie pero genéticamente diferentes.

-Xenotrasplante: cuando se realiza entre seres de diferentes especies (por ej. de cerdo a humano).

- Autotrasplante: cuando un injerto se trasplanta de un lugar a otro del organismo, en un mismo individuo.

En la actualidad, el trasplante pulmonar que se realiza de forma habitual es alogénico y ortotópico.

\subsubsection{Tipos de trasplantes pulmonares}

Los tipos de trasplante que se realizan en la actualidad son:

- Trasplante unipulmonar (TUP). Se trasplanta un solo pulmón, derecho o izquierdo.

- Trasplante bipulmonar (TBP). Se trasplantan los dos pulmones.

a. Trasplante bipulmonar en bloque. Se implantan ambos pulmones en bloque realizando una única anastomosis traqueal.

b. Trasplante bipulmonar secuencial. Se implanta primero un pulmón y posteriormente, el contralateral realizando una anastomosis bronquial y vascular independiente para cada pulmón. 
- Cardiopulmonar. Se reemplaza en bloque el corazón y ambos pulmones con anastomosis traqueal.

- Lobar. Se trasplantan un lóbulo o más frecuentemente dos lóbulos pulmonares, uno en cada hemitórax.

\subsubsection{Historia del trasplante pulmonar}

El trasplante pulmonar experimental se inicia en la Unión Soviética en 1946, cuando Demikhov realiza el primer trasplante cardiopulmonar en un perro. Un año más tarde efectuaría un trasplante unipulmonar. ${ }^{35}$

A principios de 1950, Metras publicó una serie de 20 trasplantes con una supervivencia de 3 semanas. ${ }^{36}$ Este autor introduce la técnica del trasplante pulmonar que actualmente se sigue habitualmente: anastomosis primero del bronquio, seguido de la arteria y finalmente de la aurícula izquierda.

En 1963 el grupo de Hardy publica el primer trasplante pulmonar realizado en humanos. ${ }^{37,38}$ Se practicó un trasplante pulmonar izquierdo y el paciente falleció a los 18 días, por insuficiencia renal. La terapia inmunosupresora no se había desarrollado en aquel momento y por lo tanto no se utilizó en el primer TP. En 1971, Derom (E.E.U.U) consiguió la mayor supervivencia hasta el momento en un TP con 8 meses, pero el receptor falleció por rechazo crónico, sepsis y estenosis bronquial. La mayoría de pacientes moría precozmente en las primeras semanas tras la intervención por fallo primario del injerto, sepsis o rechazo agudo. ${ }^{39}$

Entre los 38 primeros pacientes trasplantados, en los que la inmunosupresión se realizó con corticoides y azatioprina (desde 1963 a 1977) solo sobrevivieron 9 más de 15 días. La mayor parte de estos pacientes morían por infecciones o dehiscencia de la sutura de la vía aérea.

Tras varios intentos fallidos, Cooper inicia un programa de trasplante unipulmonar en pacientes afectos de fibrosis pulmonar que no se encontraran en una situación crítica. En 1983 consiguieron realizar el primer trasplante pulmonar que era dado de alta hospitalaria. Se trataba de un paciente de 58 años afecto de una fibrosis pulmonar que fue dado de alta a las seis semanas y falleció a los seis años y medio por una insuficiencia renal. ${ }^{40}$ 
El siguiente paso fue el TBP para patologías sépticas en las que estaba contraindicado el trasplante unipulmonar. Dark en Europa $(1986)^{41}$ y Patterson en E.E.U.U (1988) ${ }^{42}$ realizaron los primeros trasplantes bipulmonares en bloque mediante anastomosis traqueal. La dehiscencia de la sutura traqueal era el mayor problema de este tipo de trasplante y la causa de sus malos resultados. Por último, Noirclerc propugna la anastomosis bronquial bilateral en $1990 .{ }^{43}$ En 1991 Pasque (Saint Louis) publicaron 24 casos de trasplante pulmonar bilateral secuencial en pacientes con fibrosis quística y enfisema pulmonar. ${ }^{44}$ Actualmente, esta es la técnica utilizada universalmente para el trasplante bipulmonar.

\subsubsection{El trasplante pulmonar en España}

El trasplante pulmonar se inicia en España en la década de los años 90. El primer trasplante pulmonar con éxito se realiza en 1990 en el Hospital Vall d’Hebron de Barcelona y posteriormente inician su actividad los restantes grupos de trasplante pulmonar españoles. El Hospital Puerta de Hierro de Madrid realizó el primer trasplante en 1991. El Hospital La Fe de Valencia en 1992; el Hospital Reina Sofía de Córdoba en 1993, el Hospital Marqués de Valdecillas de Santander en 1997, el Hospital Juan Canalejo de La Coruña en 1999 y en 2009 el Hospital 12 de octubre de Madrid.

El número de TP que se realizan en España se ha incrementado progresivamente, hasta alcanzar los 294 TP en el año 2015 según datos de la Organización Nacional de Trasplante (ONT). (Figura 2)

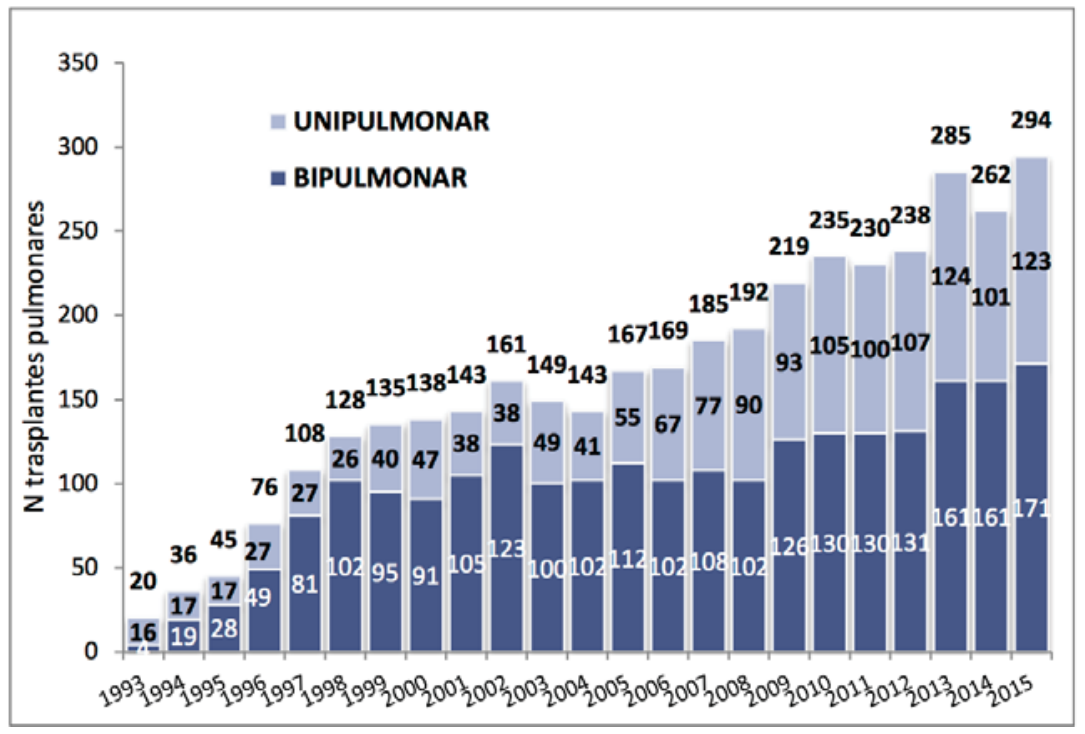

Figura 2. Número de trasplantes pulmonares por año en España. Datos de la organización Nacional de Trasplante (Estadística de la ONT. Disponible en www.ont.es). 


\subsubsection{El trasplante de pulmón por Fibrosis Quística. ${ }^{45}$}

Como se comentó previamente, la FQ es la enfermedad genética más frecuente en la raza blanca y cuya mortalidad está estrechamente relacionada con la afectación broncopulmonar.

Según datos proporcionados por la ONT, desde el año 2002 hasta el 2015 se han realizado $380 \mathrm{TP}$ en pacientes con FQ. (Figura 3)

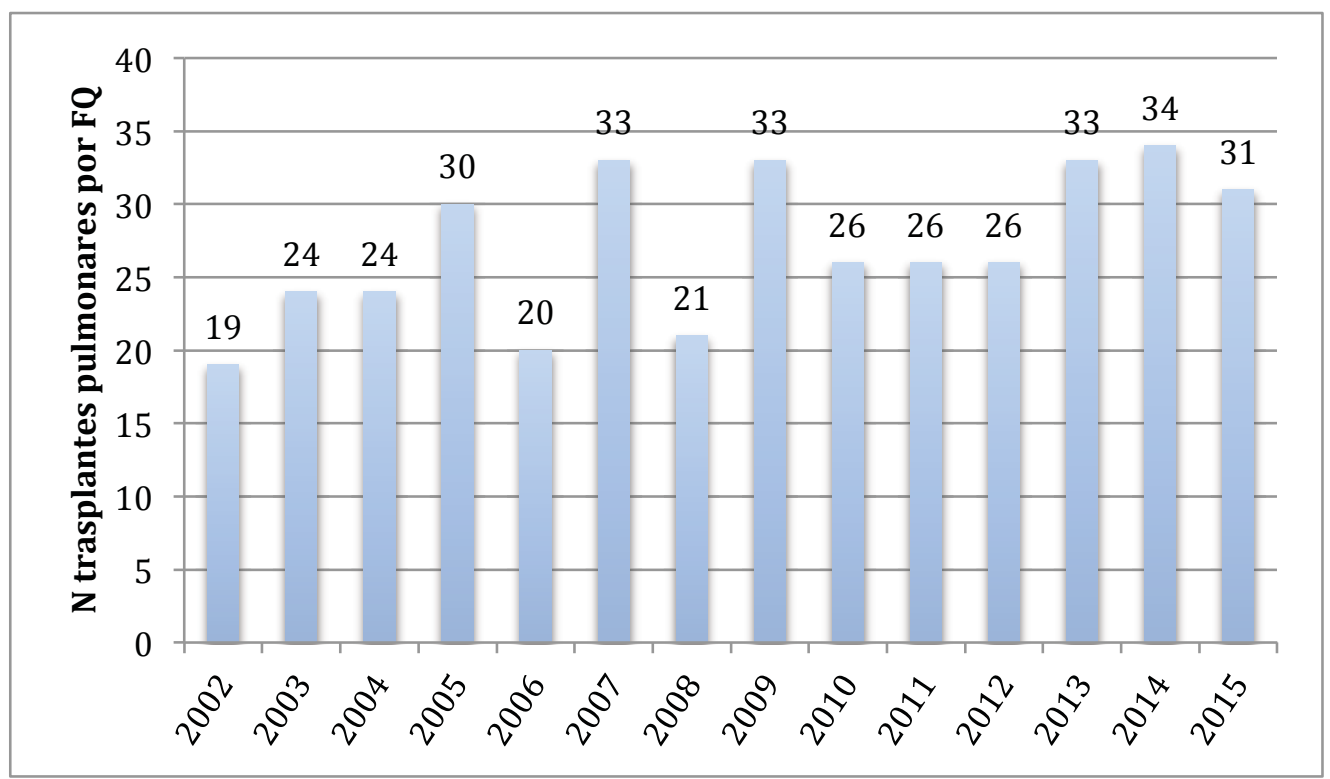

Figura 3. Número de trasplantes pulmonares por FQ en España. Datos de la organización Nacional de Trasplante (Estadística de la ONT. Disponible en www.ont.es).

La enfermedad pulmonar es la principal causa de mortalidad en el $80 \%$ de los pacientes afectos de FQ y la única terapia que ha demostrado mejorar la supervivencia en los pacientes con enfermedad pulmonar avanzada es el TP. ${ }^{46}$ Este procedimiento cada vez ha ganado mayor aceptación desde la primera vez que se empleó en 1983 al realizar un trasplante cardiopulmonar en un paciente afecto de FQ y pocos años después el primer TBP. ${ }^{47,48}$ Desde entonces la técnica quirúrgica ha cambiado notablemente, mientras el TP bilateral se ha convertido en la técnica de elección, el trasplante cardiopulmonar se reserva para pacientes con FQ que además tienen algún tipo de afectación cardíaca significativa. ${ }^{49,50}$

Al igual que en el trasplante de otros órganos sólidos, existen más receptores que donantes. Más aún, el TP no es una cura para la enfermedad pulmonar de la FQ; con 
una supervivencia media para adultos después del TP de 6.4 años. ${ }^{51}$ Por lo tanto, la correcta elección para incluir en lista de espera de TP a los pacientes con FQ tiene que basarse en: (i) La situación de la enfermedad permita a los pacientes sobrevivir el tiempo de permanencia en lista de espera; y (ii) que el TP pueda ofrecer al paciente con FQ algún "beneficio" real, usualmente medido como tiempo de supervivencia. ${ }^{52,53}$

Los pacientes con FQ candidatos a TP poseen una complejidad especial al ser pacientes que tienen una patología séptica a nivel pulmonar y que usualmente están colonizados por especies de Pseudomonas aeruginosa, Burkholderia cepacia y aspergillus spp, muchos de ellos multirresistentes y de difícil tratamiento. A pesar del potencial riesgo de sepsis de estos pacientes, especialmente en el contexto de la inmunosupresión posterior al trasplante, los pacientes con FQ tienen las mejores tasas de supervivencia comparada con otros grupos de etiologías que se someten a un TP, llegando a tener supervivencias de $91 \%, 83 \%$ y $76 \%$ al año, tres y cinco años respectivamente en algunas series publicadas. ${ }^{54,55}$ Pese a estos resultados esperanzadores, entre un $19 \%$ y un $41 \%$ de los pacientes con FQ fallecen en la lista de espera de TP. ${ }^{56-58}$

Se ha descrito en la literatura que la calidad del injerto pulmonar tiene un papel importante en la supervivencia posterior al TP (donantes con criterios extendidos en comparación con donantes considerados estándar, la utilización de ventilación protectora y la preservación pulmonar). ${ }^{59-63}$ La implementación de la perfusión retrógrada ha demostrado mejorar la calidad del injerto al mantener la baja temperatura y eliminar los detritos o material embolico que se puedan haber formado durante la extracción. Además, la perfusión retrógrada del injerto parece distribuir de forma más uniforme la solución de preservación y disminuye la pérdida de surfactante pulmonar. ${ }^{64-}$ 66

Como se ha mencionado previamente, la técnica quirúrgica más empleada es el TBP porque al igual que otras enfermedades pulmonares supurativas, el objetivo, es evitar la contaminación del pulmón recién implantado por el pulmón nativo. Existen reportes de casos aislados en la literatura de pacientes con FQ en los que se realizó un TUP por neumonectomia previa, aunque es una técnica a considerar, los resultados no parecen satisfactorios. ${ }^{67-69}$ 
Una de las características que tienen los pacientes con FQ como potenciales candidatos a TP es que, aunque los pacientes en edades infantiles no han padecido trastornos de la cavidad pleural que motiven la necesidad de cirugías previas, los pacientes adultos pueden tener una afectación pleural intensa por las infecciones bacterianas recurrentes o episodios de neumotórax de repetición. Algunos de los pacientes en los que se ha realizado algún tipo de pleurodesis por neumotórax de repetición pueden presentar una mayor complejidad quirúrgica, pero sin afectar a la supervivencia. ${ }^{32,70,71}$

Debido al escaso número de donantes pulmonares, la mortalidad en lista de espera y las usualmente pequeñas medidas torácicas que suelen tener estos pacientes, lo que dificulta en ocasiones obtener órganos adecuados, nuevas alternativas al TBP han aparecido en los últimos años. Una de ellas es el trasplante bilobar (TBL), técnica que consiste en implantar lóbulos pulmonares a partir de dos donantes vivos, aunque también se pueden implantar lóbulos de donantes en muerte encefálica. Generalmente esta técnica se utiliza cuando los pacientes con FQ no se espera que sobrevivan el tiempo necesario en lista de espera. El TBL requiere dos donantes sanos, compatibilidad de grupos sanguíneos, que no tengan contraindicaciones para toracotomías y que tengan medidas torácicas mayores que las del receptor. La operación se realiza bajo circulación extracorpórea (CEC) con técnica similar a la de un TBP. Usualmente se implanta el lóbulo inferior izquierdo bajo CEC completa y posteriormente el lóbulo inferior derecho bajo CEC parcial. Sin embargo, la supervivencia de los pacientes trasplantados con esta técnica es menor a la del TBP con un $37.5 \%$ a los 5 años y en la actualidad se realiza en pocos centros a nivel mundial. ${ }^{72,73}$

Otra técnica recientemente descrita es la del trasplante bilobar con la técnica de partición (Split). Descrita en 1997 por Couetil y cols ${ }^{74,75}$, consiste en separar los dos lóbulos del pulmón izquierdo donante, implantar el lóbulo inferior izquierdo en el hemitórax izquierdo y el lóbulo superior izquierdo en el hemitórax derecho del receptor. El implante en el hemitórax derecho requiere girar el lóbulo $180^{\circ}$ sobre su eje vertical y suturar el bronquio del lóbulo superior para implantar el lóbulo donado en el bronquio intermediario. (Figura 4) 
Mediante esta técnica del split, se puede aprovechar el pulmón derecho donante para otro receptor que necesite un trasplante unipulmonar.

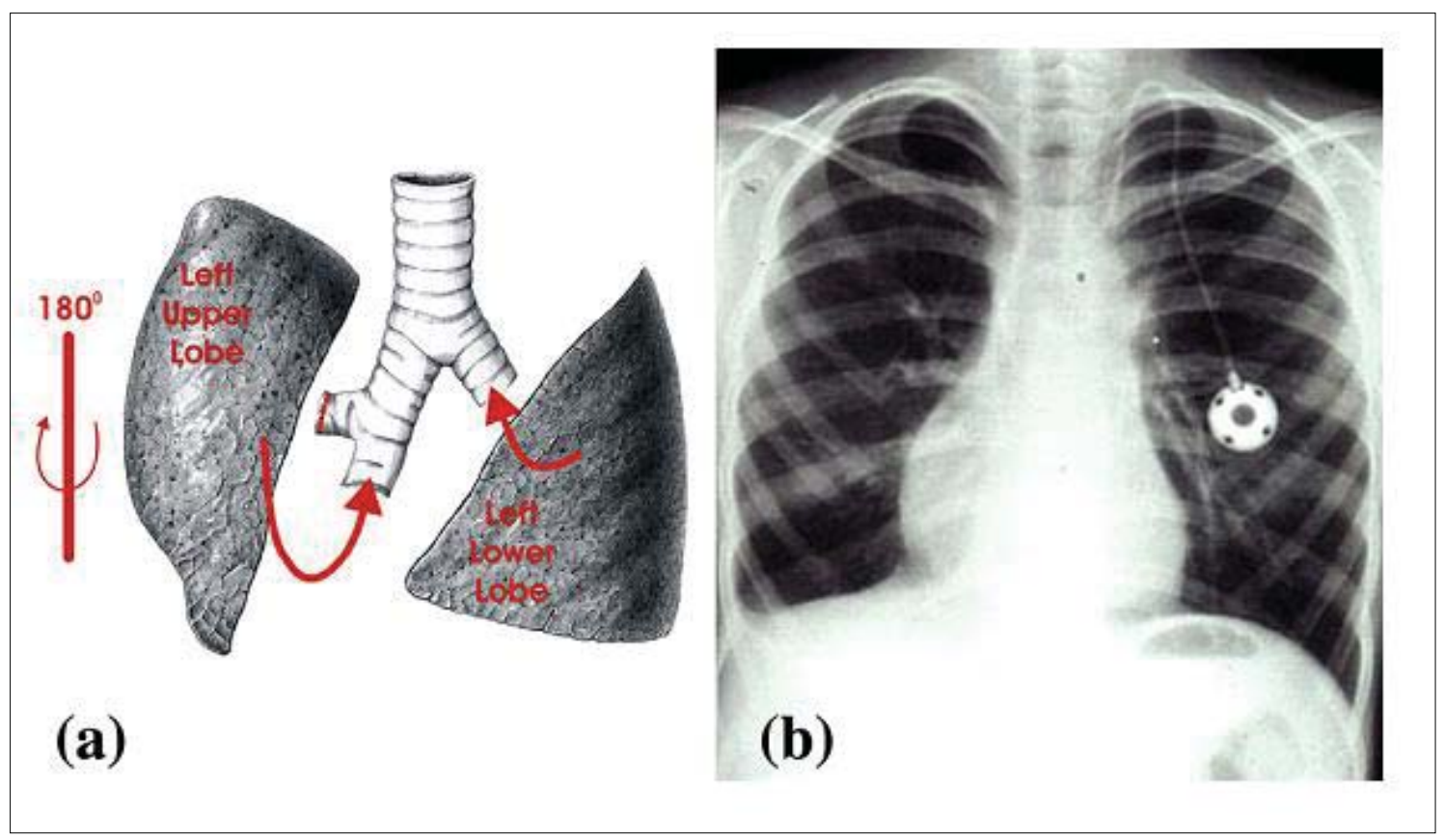

Figura 4. Trasplante bilobar mediante la técnica de split. (a) El lóbulo inferior es implantado en el hemitórax izquierdo del receptor, mientras que el lóbulo superior izquierdo es implantado en el hemitórax derecho después de rotarlo $180^{\circ}$ sobre su eje vertical y realizar una sutura del bronquio del lóbulo superior derecho. (b) Radiografía de tórax postoperatoria en la que se aprecia ligero desplazamiento cardiaco hacia la derecha sin repercusión hemodinámica. $^{76}$

Todavía no se disponen de resultados a largo plazo, pero pese al escaso número de pacientes trasplantados con esta técnica y su aparente buena evolución postoperatoria, podría convertirse en una técnica habitual para paliar el escaso número de donantes y su utilización en pacientes con medidas torácicas pequeñas. ${ }^{77}$

En 2007 se publica un estudio retrospectivo que demostraba que solo 5 de los 514 pacientes infantiles (menores de 18 años) con FQ en lista de espera de TP tendrían una mejora en la supervivencia después del trasplante, por lo tanto, el aparente beneficio del TP en pacientes con FQ se ponía en entredicho. ${ }^{78}$ Sin embargo se ha sugerido que dicho estudio podría interpretar solo el resultado de los pacientes que estaban en peores condiciones físicas pre trasplante y en consecuencia no es representativo de la mayoría de pacientes con FQ en lista de espera que suelen estar en condiciones físicas aceptables, además el estudio no presenta resultados sobre la calidad de vida de los pacientes trasplantados que probablemente, después de la supervivencia, sea el objetivo más importante de todo procedimiento terapéutico. ${ }^{79}$ 
El TP debe ser considerado en paciente con FQ que tienen una supervivencia esperada a los 2 años $<50 \%$ y con limitación funcional clasificada como III o IV según la New York Heart Association. Pero, predecir la supervivencia usando información objetiva ha sido difícil debido a que no se ha encontrado ningún factor que de por si, pueda predecir una diminución de la supervivencia en éstos pacientes.

La mayoría de la información proviene de estudios con cohortes relativamente pequeñas. La determinación de la función pulmonar para evaluar el grado de progresión de la enfermedad se ha considerado un factor predictor muy valorado. ${ }^{80} \mathrm{El} \mathrm{FEV}_{1}$ ha sido la variable más utilizada para la evaluación de la mortalidad. En 1992, se reporta que el $\mathrm{FEV}_{1}<30 \%$ del predicho se asociaba a una mortalidad a los 2 años del $40 \%$ en hombres y del $55 \%$ en mujeres. ${ }^{81}$

Mayer-Hamblett y cols ${ }^{82}$ crearon un modelo para identificar los mejores predictores de mortalidad en pacientes con FQ con la base de la Cystic Fibrosis Foundation. Determinaron que la edad, altura, $\mathrm{FEV}_{1}$, aislamientos microbiológicos respiratorios, número de hospitalizaciones y el número de episodios de antibioticoterápia endovenosa ambulatoria eran predictores significativos de mortalidad a $\operatorname{los} 2$ años.

Augarten y cols ${ }^{83}$ evaluaron a pacientes con FQ derivados para TP a 4 centros trasplantadores, entre los resultados, los autores reportaron que la relación de $\mathrm{FEV}_{1}<$ $30 \%$ del predicho y una presión parcial de dióxido de carbono $\left(\mathrm{PaCO}_{2}\right)>50 \mathrm{~mm} \mathrm{Hg} \mathrm{se}$ correlaciona con mortalidad temprana.

Con los datos de la Cystic Fibrosis Foundation, Liou y cols $^{84}$ desarrollaron un modelo de supervivencia a 5 años. Los autores evaluaron el impacto de diferentes variables sobre la supervivencia y lo correlacionaron con los cambios del $\mathrm{FEV}_{1}$. El sexo femenino, la DM, infección por B. Cepacia y el número de exacerbaciones afectaba la supervivencia de los pacientes con $\mathrm{FQ}$, mientras que el $\mathrm{FEV}_{1}$ por si solo no era un predictor suficiente de mortalidad temprana.

Otras características preoperatorias que parecen afectar la supervivencia después del TP son la tolerancia al esfuerzo y la hipertensión pulmonar (HTP). Un Test de la marcha de 6 minutos (6WT) menor de $400 \mathrm{~m}$ y la HTP han sido asociados con un peor pronóstico. ${ }^{85-88}$ La presencia de neumotórax y de infecciones por MNT se ha reportado 
que disminuye la función pulmonar y se relaciona con la mortalidad en pacientes con enfermedad pulmonar avanzada. ${ }^{89,90}$

Según el registro de la Sociedad Internacional de Trasplante de Corazón y Pulmón (ISHLT). ${ }^{91}$ Los pacientes trasplantados con FQ obtienen el mejor resultado global (supervivencia media de 7.1 años) y los pacientes con HTP el peor (4,9 años). No obstante, cuando analizamos los resultados condicionados a sobrevivir el primer año, el resultado de la HTP se equipara a la FQ (9,3 años de supervivencia media) y los peores resultados corresponden a la Enfermedad Pulmonar obstructiva crónica (EPOC) y a la Fibrosis pulmonar (FP) (6,6 y 6,7 años de supervivencia media respectivamente), relacionado con la mayor edad de los pacientes en el momento del trasplante.

\subsubsection{Selección del donante y receptor}

Debido a las particularidades que presentan los pacientes con FQ, existen ciertas consideraciones a valorar previas al TP, entre las cuales 2 escenarios han aumentado el interés de la comunidad científica en los últimos años:

Infecciones por MNT: Se ha observado un aumento en la incidencia de aislamientos de MNT en los pacientes con FQ. ${ }^{89}$ En estos casos la ISHLT hace una serie de recomendaciones, aunque especifica, que dichas recomendaciones se basan en series de $\operatorname{casos}^{92,93}$ :

- $\quad$ Todos los pacientes con FQ que sean derivados para trasplante deben ser evaluados de infecciones por MNT.

- Los pacientes con infecciones por MNT que están siendo evaluados para TP deberían tener el aislamiento del microorganismo de acuerdo a las guías microbiológicas y recibir tratamiento previo a la entrada en lista de espera.

- El tratamiento debería ser realizado por o en colaboración con un experto en el tratamiento de éstos pacientes.

- $\quad$ Enfermedad pulmonar o extrapulmonar por MNT que progresa a pesar de tratamiento optimo o la imposibilidad de tolerar dicho tratamiento es una contraindicación para entrar en lista de espera de TP. 
- $\quad$ Infección por B. Cepacia complex: Se ha visto que los pacientes con FQ infectados por B. cepacia complex suelen tener un descenso más rápido del $\mathrm{FEV}_{1}$. También tienen un mayor riesgo posterior al TP, aunque dicho riesgo se ha atribuido sobre todo a pacientes infectados con $B$. cenocepacia. ${ }^{94-96}$ Las recomendaciones son:

Todos los pacientes con FQ que sean derivados para trasplante deben ser evaluados de infecciones por B. cepacia.

- Pacientes con especies diferentes a B. cenocepacia no tienen un aumento del riesgo de mortalidad posterior al TP y pueden entrar en lista.

Pacientes con B. cenocepacia tienen un aumento de riesgo de mortalidad secundario a la persistencia de la enfermedad posterior al TP. Se recomienda que los centros que continúan aceptando pacientes con ésta infección tengan un programa activo de investigación para prevenir y controlar la infección y además tener experiencia en el tratamiento de éstos pacientes. Se recomienda, además, que el paciente con ésta infección, sea informado sobre el aumento de riesgo que conlleva el TP.

\section{1..2.6.1. Donante}

Las organizaciones autonómicas de trasplante centralizan y coordinan todo el proceso de donación y trasplante de órganos en España. Ante un potencial donante, tras la constatación de la muerte cerebral y la aceptación por parte de la familia de la donación, la ONT informa de los datos clínicos y antropométricos del donante al Centro de Coordinación de Trasplantes del Hospital en el que se realizará el implante de los órganos. El equipo de cirujanos de este hospital que llevará a cabo el trasplante debe valorar las características del donante y tras considerarlo adecuado poner en marcha la cadena de trabajo que dará lugar al trasplante.

En el cuadro 1 se aprecian las características que deben reunir los donantes para TP. ${ }^{97-99}$ 
Edad $<$ a 55 años

Compatibilidad AB0

Radiografía de tórax normal

$\mathrm{PaO}_{2}>300 \mathrm{mmHg}$ con $\mathrm{FiO}_{2}$ de $100 \%$ y Presión positiva espiratoria final (PEEP) de $5 \mathrm{mmHg}$

Exposición de tabaco $<20$ paquetes/año

Ausencia de traumatismo torácico

No evidencia de broncoaspiración

No cirugía previa cardiopulmonar

Ausencia de gérmenes en esputo (tinción de Gram)

Ausencia de secreciones purulentas valoradas por fibrobroncoscopia

Cuadro 1. Criterios de selección de los donantes pulmonares

Actualmente, las listas de espera de los grupos de trasplante pulmonar están aumentando considerablemente porque la disponibilidad de pulmones para el trasplante es insuficiente para el aumento de indicaciones. De todos los donante multiorgánicos, sólo en el 10-15\% de los pulmones son aptos para su implante, probablemente porque es el órgano más vulnerable y está expuesto desde un primer momento a la agresión de la ventilación mecánica y al riesgo de la infección por la intubación orotraqueal.

Esta escasez de pulmones viables para el trasplante pulmonar ha hecho que se reconsideren las características del donante ideal y se utilicen pulmones denominados "subóptimos" que son aquellos que no cumplen todos los criterios anteriormente expuestos.

Se han realizado muchos estudios basados en el trasplante de pulmones subóptimos por diversas causas con resultados muy dispares y contradictorios. ${ }^{100-103}$ Como se expone en la amplia revisión realizada por Orens y cols ${ }^{104}$ sobre los criterios 
de aceptación del donante, estos criterios se basan en general en impresiones clínicas más que en sólidas evidencias médicas. Por lo tanto, la aceptación del donante se debe realizar analizando cada caso de forma individual y sin aplicar estos criterios con rigidez para evitar la pérdida de pulmones válidos para el trasplante.

\subsubsection{Receptor}

Hay una serie de condiciones que debe cumplir el receptor para ser evaluado en un centro trasplantador y por último ser considerado un candidato válido para el TP. Dichas condiciones aparecen reflejadas en el documento de consenso para la selección de candidatos de Trasplante Pulmonar de la ISHLT ${ }^{45}$. Estas son las siguientes:

Criterios para remitir a un centro trasplantador

- $\quad$ Disminución del $\mathrm{FEV}_{1}$ hasta el $30 \%$ o paciente con enfermedad avanzada y caída rápida del $\mathrm{FEV}_{1}$ pese a tratamiento médico óptimo (especialmente en pacientes de sexo femenino), infectados con MNT, B. cepacia complex y/o DM.

- $\quad$ Distancia del 6WT menor a 400 metros.

- Desarrollo de HTP en ausencia de exacerbaciones hipóxicas (definida como presión sistólica de arteria pulmonar $>35 \mathrm{~mm} \mathrm{Hg}$ en el ecocardiograma o medias $>25 \mathrm{~mm} \mathrm{Hg}$ medidas por cateterismo cardiaco derecho.

- Deterioro clínico caracterizado por aumento en la frecuencia de exacerbaciones asociado con:

- $\quad$ Episodios de fallo respiratorio agudo que requieran VMNI.

- $\quad$ Aumento en la resistencia antibiótica y disminución en la recuperación tras las exacerbaciones.

- $\quad$ Deterioro del estado nutricional pese a seguir una dieta suplementaria.

- Neumotórax.

- Hemoptisis masiva pese a embolización bronquial. 
Criterios para entrar en lista de espera de TP

- Insuficiencia respiratoria crónica.

- Con hipoxia (Presión parcial de oxígeno $\left[\mathrm{PaO}_{2}\right]<60$ mm Hg).

. Con hipercapnia $\left(\mathrm{PaCO}_{2}>50 \mathrm{~mm} \mathrm{Hg}\right)$.

- $\quad$ Terapia de VMNI de forma crónica

$-\quad$ HTP

- $\quad$ Hospitalizaciones frecuentes

- $\quad$ Disminución rápida de la función pulmonar

- $\quad$ Clase funcional IV de la Organización mundial de la Salud (OMS).

\subsection{Contraindicaciones absolutas}

Las contraindicaciones absolutas para el TP se encuentran reflejadas en el documento de consenso de la ISHLT ${ }^{45}$ y son las siguientes:

- El TP no debería plantearse en pacientes adultos con antecedentes recientes de enfermedades neoplásicas. Se considera razonable, un período libre de enfermedad de 2 años combinado con un bajo riesgo de recurrencia después del TP, por ejemplo, en el cáncer de piel diferente al melanoma que ha sido tratado de forma apropiada. Aun así, en la mayoría de los casos, un período de 5 años libre de enfermedad se considera prudente, en particular, pacientes con antecedentes de neoplasias hematológicas, sarcoma, melanoma, cáncer de mama, vejiga o renal. Desafortunadamente, para una proporción importante de pacientes con antecedentes neoplásicos el riesgo de recurrencia es muy alto para indicar el TP, incluso después de un período de 5 años libre de enfermedad.

- Disfunción significativa e intratable de otro órgano (corazón, hígado, riñón, cerebro, etc.) excepto cuando exista la posibilidad de realizar un trasplante combinado. 
- Enfermedad ateroesclerótica no corregida, con sospecha o diagnóstico confirmado de isquemia y/o enfermedad coronaria no subsidiaria de revascularización.

- Inestabilidad médica aguda, incluyendo, sepsis, infarto de miocardio y fallo hepático.

- Diátesis hemorrágica intratable.

- Infección crónica con gérmenes altamente virulentos y/o gérmenes resistentes difícilmente controlables previos al TP.

- $\quad$ Evidencia de infección activa por Mycobacterium tuberculosis.

- Deformidad significativa de la caja torácica que pueda ser una causa de restricción severa posterior al $\mathrm{TP}$.

- $\quad$ Obesidad clase II o III (Índice de masa corporal [IMC] $\geq 35.0 \mathrm{~kg} / \mathrm{m}$

- La no adherencia al tratamiento médico o antecedentes de no adherencia a tratamientos que puedan aumentar el riesgo posterior al TP.

- Condiciones psiquiátricas o psicológicas asociadas con la imposibilidad de cooperar con su equipo médico o que no existan las garantías de poder asumir el tratamiento médico posterior al TP.

- $\quad$ Ausencia de soporte social adecuado.

- Severa limitación funcional con poco potencial de rehabilitación posterior.

- Abuso de sustancias o dependencia a dichas sustancias (alcohol, tabaco, marihuana u otras sustancias ilícitas). En muchos casos, es necesario terapias dirigidas previas al TP para asegurar la abstinencia. Pruebas sanguíneas o en orina pueden ser utilizados para verificar la abstinencia de la sustancia. 


\subsection{Contraindicaciones relativas}

Las contraindicaciones relativas para el TP por FQ son:

- Malnutrición progresiva o severa.

- $\quad$ Osteoporosis severa y sintomática.

- Cirugía torácica previa extensa con resección pulmonar.

- Ventilación mecánica y/o soporte extracorpóreo. Aun así, la selección cuidadosa de algunos candidatos a TP sin otra afectación en el resto de órganos puede ser valorado para TP.

- $\quad$ En pacientes con hepatitis B y/o C, el TP se puede considerar si no existen signos clínicos de cirrosis o hipertensión portal y que se encuentran de forma estable. El TP debería realizarse en centros con unidades de hepatología experimentadas.

- Para pacientes infectados por el virus de la inmunodeficiencia humana (VIH), el TP se puede considerar en pacientes con enfermedad controlada, con carga de VIH indetectable y con tratamiento retroviral adecuado. El TP en pacientes con VIH debería realizar en centros con experiencia en el tratamiento de pacientes VIH positivos.

- Infección por Burkholderia cenocepacia, Burkholderia gladioli, y gérmenes multirresistentes como Mycobacterium abscessus. $\mathrm{Si}$ se considera el trasplante en éstos pacientes, debería realizarse en centros con experiencia en el tratamiento de éstas infecciones y el paciente tiene que estar informado del aumento de riesgo que conlleva el trasplante con éste tipo de infecciones. Los pacientes con afectación progresiva pulmonar o extrapulmonar por MNT pese a tratamiento óptimo o intolerancia a dicho tratamiento, se consideran contraindicación para el TP. ${ }^{45}$

- Enfermedad ateroesclerótica, excepto cuando pueda ser subsidiaria de revascularización previa o durante el TP. 
- $\quad$ Otras condiciones médicas que puedan derivar en daños orgánicos como la DM, hipertensión arterial, epilepsia, obstrucción venosa central, úlcera péptica y reflujo gastroesofágico que debería tratarse de forma óptima previo al TP.

\subsubsection{Inmunosupresión en el trasplante pulmonar por Fibrosis Quística}

La inmunosupresión en el trasplante de órganos sólidos es una de las bases sobre la que se sustenta el éxito de la terapia de trasplante. Sin inmunosupresión el cuerpo humano invariablemente rechazará el órgano trasplantado con la consiguiente pérdida del injerto. A lo largo de los últimos años se han experimentado cambios en el tratamiento inmunosupresor, se han descubierto nuevos fármacos con mayor acción y menor toxicidad.

Los pacientes con FQ trasplantados de pulmón pertenecen a un grupo que al principio de la era de los trasplantes se consideraba de alto riesgo al introducir fármacos que disminuían las defensas a pacientes que estaban, la gran mayoría, colonizados por gérmenes altamente virulentos. Por otro lado, eran pacientes que en fase terminal de su enfermedad y con indicación de trasplante eran rechazados por tener antecedentes de cirugía previas para el control de hemoptisis o neumotórax de repetición. ${ }^{105}$ A medida que fueron reportándose casos exitosos de trasplantes cardiopulmonar iniciales y posteriormente TBP, la aceptación del trasplante como tratamiento en estos pacientes prevaleció. ${ }^{106-111}$

El objetivo de la terapia inmunosupresora es la prevención del rechazo, tanto agudo como crónico, y el tratamiento del rechazo una vez instaurado. Existen cinco grupos de inmunosupresores que se utilizan en el trasplante de órganos sólidos:

- $\quad$ Corticoesteroides.

- Inmunomoduladores. Anticuerpos policlonales como la Globulina antitimocítica (ATG), la Globulina antilinfocítica (ALG) o el anticuerpo monoclonal Muromonab-CD3 (OKT3), y monoclonales como el basiliximab o el alemtuzumab.

- Anticalcineurínicos. Ciclosporina y Tacrolimus. 
- $\quad$ Antimitóticos. Azatioprina (AZA) y Micofenolato mofetil (MMF).

- $\quad$ Inhibidores de la mTOR. Sirolimus y Everolimus.

En el TP, la inmunosupresión habitual consiste en la asociación de 3 fármacos de familias distintas, habitualmente la combinación de corticoesteroides, calcineurínicos y un fármaco antimitótico, a la que se puede añadir un fármaco inmunomodulador como terapia de inducción. ${ }^{112}$

El objetivo de utilizar una triple terapia es la de actuar a diferentes niveles del mecanismo inmunológico del rechazo y además permite disminuir dosis de cada fármaco reduciendo así su toxicidad. El régimen más utilizado actualmente en el TP por FQ es la asociación de Tacrolimus, MMF y corticoesteroides.

\subsubsection{Corticoesteroides}

Los corticoesteroides se utilizan de rutina en todas las asociaciones de inmunosupresión en el TP por FQ. Actúan como moduladores de la inmunidad y la inflamación, bloquean la activación y proliferación de linfocitos, disminuyendo la secreción de citoquinas y produciendo la lisis de linfocitos $\mathrm{T}$ inmaduros. ${ }^{113} \mathrm{El}$ mantenimiento de éste grupo de inmunosupresores es de forma indefinida, aunque existen reportes de su retirada de forma exitosa en trasplantes de riñón, hígado o corazón. ${ }^{114-117}$

La dosis y vía de administración es de 500 - 1000 mg de metilprednisolona IV durante la cirugía (al desclampar la arteria pulmonar) y posteriormente $125 \mathrm{mg}$ de metilprednisolona IV durante tres días, $1 \mathrm{mg} / \mathrm{Kg} /$ día los próximos 10 días, 0,5 $\mathrm{mg} / \mathrm{Kg} /$ día entre 1 - 3 meses postoperatorios, $0,25 \mathrm{mg} / \mathrm{Kg} /$ día entre los 3 meses y el año para posteriormente mantener dosis de $0,15 \mathrm{mg} / \mathrm{Kg} /$ día de forma indefinida.

Entre los efectos adversos de los corticoesteroides se encuentra el hipercortisonismo, DM, cataratas, osteoporosis, miopatía proximal, acné, estrías cutáneas e hipertensión arterial. ${ }^{118}$

\subsubsection{Inmunomoduladores}

ATG y ALG con combinaciones de anticuerpos policlonales dirigidos contra los linfocitos B y T. No son específicos, sino que producen una inactivación de todos los linfocitos y una depleción de los mismos por lisis. La inducción con ATG es capaz de reducir la aparición de rechazo agudo en el TP en el primer año postrasplante. ${ }^{119} \mathrm{La}$ 
dosis y vía de administración suele ser 10 - 15 mg/Kg/día IV durante 7 a 10 días. Entre los efectos adversos se encuentra la leucopenia, fiebre, artralgias, enfermedad del suero y trombocitopenia.

OKT3, produce una inmunosupresión no selectiva mediante bloqueo de los linfocitos $\mathrm{T}$ por interacción con la molécula CD3 del receptor celular produciendo la lisis de la célula. Es un anticuerpo de origen animal (murino) muy efectivo, pero poco utilizado por los efectos secundarios. La dosis es de $5 \mathrm{mg}$ /día IV durante 7 a 10 días. Entre los efectos adversos puede producir fiebre, leucopenia, escalofríos, disnea, dolor torácico, vómitos, diarrea, temblores, encefalopatía y meningitis aséptica.

Basiliximab es un anticuerpo monoclonal quimérico que se une a la molécula CD25 del receptor de la IL-2 bloqueando su acción e impidiendo así la proliferación de los linfocitos T activados. Por lo tanto, produce una inmunosupresión selectiva ya que actúa únicamente sobre los linfocitos $\mathrm{T}$ activados. Ha demostrado su eficacia en la disminución de la frecuencia y severidad del rechazo agudo, sobre todo cuando se utiliza como terapia de inducción. ${ }^{120}$ La forma de administración es de 2 dosis de $20 \mathrm{mg}$ IV previo a la reperfusión del injerto y 4 días después del trasplante. Suele ser un medicamento bien tolerado con efectos adversos propios de la inmunosupresión como infecciones bacterianas y víricas.

Daclizumab es un anticuerpo monoclonal humanizado, que se une a la subunidad Tac del receptor de la IL-2 y bloquea su acción. Al igual que el anterior, su acción es selectiva sobre los linfocitos $\mathrm{T}$ activados. Tiene la ventaja de que, al ser humanizado, es menos inmunógeno y se puede administrar en más ocasiones sin que se desarrollen anticuerpos contra él. Se ha descrito una disminución significativa de la incidencia de rechazo agudo sin aumentar las complicaciones. ${ }^{121}$ Desde el año 2009 ha sido retirado del mercado europeo y norteamericano a raíz de un estudio realizado en trasplante cardíaco en el que se observó un aumento de la mortalidad con el daclizumab relacionada con las infecciones. Se administra en 5 dosis de $1 \mathrm{mg} / \mathrm{Kg}$ IV previo a la reperfusión del injerto y cada 14 días postrasplante. Los efectos adversos son similares al basiliximab.

Alemtuzumab es otro anticuerpo monoclonal humanizado anti-CD52. El antígeno CD52 se encuentra en los linfocitos, monocitos, macrófagos y eosinófilos. Una 
dosis de éste fármaco puede producir una supresión de los linfocitos CD4 y CD8 durante un año. Si se utiliza como terapia de inducción se puede reducir la dosis de otros inmunosupresores para minimizar los efectos secundarios sin aumentar la incidencia de rechazo agudo o la supervivencia. ${ }^{122,123}$ El tiempo libre de rechazo agudo es significativamente mayor en comparación con ATG o daclizumab. ${ }^{124}$ Se ha descrito su utilización en pacientes con rechazo agudo refractario y para el tratamiento del rechazo crónico. ${ }^{125}$ La dosis es de $30 \mathrm{mg}$ IV en infusión continua previo a la reperfusión del injerto. Los efectos adversos son similares a la de otros anticuerpos monoclonales.

\subsubsection{Antagonistas de la calcineurina}

Ciclosporina, es un polipéptido cíclico aislado en 1970 a partir del hongo Tolypocladium inflatum. Actúa penetrando en la célula para unirse a una proteína citoplasmática del grupo de las inmunofilinas denominada ciclofilina. El complejo formado por la ciclosporina-ciclofilina inhibe la calcineurina que interviene en la regulación de la transcripción de la IL-2 y otras citoquinas como la IL-4, el factor de necrosis tumoral (FNT) y el interferón gamma. De este modo se inhibe la producción de IL-2 y con ello se frena la proliferación de linfocitos T. Es un fármaco de absorción variable y rango terapéutico estrecho, por lo que se aconseja monitorizar sus niveles plasmáticos tres veces por semana. Además, al tener metabolismo hepático por la vía del citocromo p-450, sus niveles pueden variar por interacciones con otros fármacos como la cimetidina, claritromicina, cotrimoxazol, hormonas sexuales, metoclopramida, etc. La dosis es de 1,5 - $2 \mathrm{mg} / \mathrm{Kg} /$ día IV o 3 - $10 \mathrm{mg} / \mathrm{Kg}$ /día vía oral (VO). Los niveles plasmáticos hasta los 6 meses deben ser de 300 - $400 \mathrm{ng} / \mathrm{ml}$, entre los 6 meses y el año postrasplante de 250 - $300 \mathrm{ng} / \mathrm{ml}$ y a partir del año de $150-250 \mathrm{ng} / \mathrm{ml}$. Entre sus efectos adversos; hipertensión arterial, dislipemia, nefrotoxicidad, hepatotoxicidad, hirsutismo e hiperplasia gingival.

Tacrolimus, es un metabolito descubierto de 1984, derivado del actinomiceto Streptomyces tsukubaensis. Es una macrólido que inicialmente se llamó FK 506 y tiene un mecanismo de acción similar a la ciclosporina. Se une a la proteína citoplasmática FKBP, del grupo de las inmunofilinas, y juntas inhiben la calcineurina. Bloquean la producción de múltiples citoquinas entre las que se encuentra la IL-2 e inhiben la activación y proliferación de los linfocitos T y B. 
En estudios in vitro, el tacrolimus puede alcanzar un potencia 50 a 100 veces superior a la ciclosporina. ${ }^{126}$ Sin embargo en estudio clínicos no se han encontrado diferencias. Ensayos clínicos aleatorizados comparando la ciclosporina con el tacrolimus no han demostrado diferencias en la supervivencia, aunque, algún estudio observa una menor incidencia de rechazo agudo y bronquiolitis obliterante en el grupo de tacrolimus. ${ }^{127,128} \mathrm{La}$ dosis es de $0,01 \mathrm{mg} / \mathrm{Kg} /$ día IV o 0,1 - 0,15 mg/Kg/día VO. Los niveles plasmáticos entre 10 a $15 \mathrm{ng} / \mathrm{ml}$ los 6 primeros meses y posteriormente 10 a 12 ng/ml. Entre los efectos adversos; DM, hipertensión arterial, dislipemia, nefrotoxicidad, neurotoxicidad, erupciones pruriginosas, alopecia, hipercaliemia, hipomagnesemia y alteraciones gastrointestinales.

\subsubsection{Antimitóticos}

Azatioprina, es un análogo de las purinas, derivado de la 6-mercaptopurina, que inhibe la síntesis de $\mathrm{ADN}$ y su función, por lo tanto, impide la proliferación de todas las células que se encuentran en crecimiento. Inhibe la proliferación de los linfocitos T y B. Su monitorización se realiza mediante los leucocitos totales que deben estar por encima de $4000 / \mathrm{m}^{3}$. La dosis es de 1,5 a $2 \mathrm{mg} / \mathrm{Kg} /$ día IV o VO. Entre los afectos adversos; mielodepresión (leucopenia, trombocitopenia y anemia megaloblástica), hepatitis, ictericia colestásica y pancreatitis.

MMF, da lugar al ácido micofenólico que inhibe la enzima inosina monofosfato deshidrogenasa dando lugar a la inhibición de la síntesis de ADN. Existen dos vías en la síntesis de las purinas para formar $\mathrm{ADN}$ y en este caso se inhibe la síntesis de novo que es la que utilizan los linfocitos. Por lo tanto, el efecto antiproliferativo del micofenolato es más selectivo y los efectos secundarios menores. Tiene metabolismo hepático y el ácido micofenólico se convierte en micofenolato glucorónico que se excreta por la bilis. Parte de él es reconvertido a ácido micofenólico en el intestino produciendo recirculación entero-hepática y un pico plasmático secundario a las 6 a 12 horas de la administración. Los estudios no son concluyentes de la superioridad del micofenolato sobre la azatioprina, aunque la supervivencia al año parece ser mejor, no hay diferencias en cuanto al rechazo agudo o crónico. ${ }^{129}$ La dosis es de 1 a 4 g/día IV o VO y los niveles entre 2 a $5 \mu \mathrm{g} / \mathrm{ml}$. El afecto adverso más importante son las alteraciones gastrointestinales (dolor abdominal y diarreas), además puede producir leucopenia. Para reducir los efectos adversos a nivel digestivo, en los últimos años, se está cambiando la 
estrategia hacia la administración de ácido micofenólico que ha demostrado en algunos estudios disminuir los efectos adversos gastrointestinales. ${ }^{130}$

\subsubsection{Inhibidores de la mTOR}

La mTOR (mammalian Target of Rapamycin) es una enzima que participa en la regulación del inicio de la transcripción del ácido ribonucleico mensajero. Está implicada en el estímulo de crecimiento y progresión del ciclo celular.

Sirolimus, es un producto natural del actinomiceto (Streptomyces hygroscopicus) y tiene una estructura similar al tacrolimus pero con una acción diferente. El sirolimus no inhibe la calcineurina, por lo que carece de los efectos adversos que tiene la ciclosporina y tacrolimus como la nefrotoxicidad $\mathrm{o}$ neurotoxicidad. Se una a la inmunofilina FKBP12 en el citoplasma del linfocito y con ella inhibe la síntesis de proteínas y la proliferación celular a través de la mTOR. Paraliza el ciclo celular en la fase G1 y bloquea la proliferación de las células T, B y la producción de inmunoglogulinas. Una de sus funciones más importantes es su capacidad de inhibir las señales de los factores de crecimiento. Presenta propiedades antiproliferativas, que pueden ser útiles para frenar los fenómenos fibrótico que ocurren en la bronquiolitis obliterante y en caso de aparición de tumores. El sirolimus tiene un perfil de toxicidad tolerable, puede emplearse en caso de rechazo agudo refractario o como sustituto de los anticalcineurínicos para evitar los efectos secundarios. ${ }^{131}$ La dosis es de 3 a $6 \mathrm{mg} / d i ́ a$ VO. Entre los efectos adversos; leucopenia, trombocitopenia, hipertrigliceridemia, diarrea, acné, úlceras orales, neumonía intersticial y problemas en la cicatrización que podrían afectar a la sutura bronquial.

Everolimus tiene una estructura y acción similar al sirolimus. Inhibe los linfocitos, fibroblastos y las células del músculo liso a través del bloqueo de la mTOR. Éstas últimas células, son muy importantes en la remodelación que se produce en la bronquiolitis obliterante posterior al TP. El everolimus es un fármaco interesante para mejorar la función renal disminuyendo la dosis de anticalcineurínicos sin aumentar el riesgo de rechazo agudo. ${ }^{132,133} \mathrm{La}$ dosis es de $2 \mathrm{mg} /$ día VO y los efectos adversos son similares a los de sirolimus. 


\subsection{LA CIRCULACIÓN EXTRACORPÓREA}

\subsubsection{Definición}

La CEC permite que las enfermedades del corazón y/o pulmón que sean tributarias de tratamiento quirúrgico puedan realizarse manteniendo de forma temporal la función de bomba del corazón y la oxigenación del pulmón fuera del cuerpo humano. El funcionamiento básico de la CEC es drenar la sangre del corazón y los pulmones a un reservorio por cánulas venosas y retornar de forma oxigenada mediante cánulas arteriales utilizando una bomba y un "pulmón artificial" (oxigenador o intercambiador de gases). La tubuladura y las cánulas son de polivinilo clorídico, mientras que el oxigenador y las conexiones son de policarbonato. ${ }^{134}$

\subsubsection{Historia ${ }^{135}$}

En la primera mitad del siglo XX, la medicina cardiovascular tuvo muchos triunfos. Una anestesia eficaz, las condiciones antisépticas y los antibióticos propiciaron una cirugía más segura. El cateterismo cardíaco, la electrocardiografía y la fluoroscopia hicieron que fuera posible el diagnóstico no quirúrgico de las patologías cardiovasculares.

Antes del 1950, sin embargo, no existía una forma segura para el tratamiento quirúrgico de daños o defectos que afectaban al corazón. Para realizar dicha corrección, la función de éste órgano vital tenía que ser interrumpida. El problema era mantener los tejidos del cuerpo con vida mientras se operaba el corazón. Mientras algunos cirujanos practicaban la llamada "cirugía a ciegas", mediante la cual se introducía un dedo en el corazón a través de un orificio en la pared torácica sin poder ver lo que se intentaba corregir, otros intentaban parar el corazón sometiendo al cuerpo a temperaturas de congelación. Incluso, algunos cirujanos utilizaron la "circulación cruzada," en la cual la circulación del paciente se conectaba a la circulación de un donante. Todos estos intentos acarrearon importantes riesgos de hemorragia, daño tisular y muerte.

En febrero de 1931, John H. Gibbon (Figura 5) fue testigo de la muerte de una paciente cuya circulación pulmonar fue bloqueada por un coágulo de sangre. Dicha experiencia condujo a Gibbon a perseguir una línea de la investigación: una forma para oxigenar la sangre fuera del cuerpo humano. 


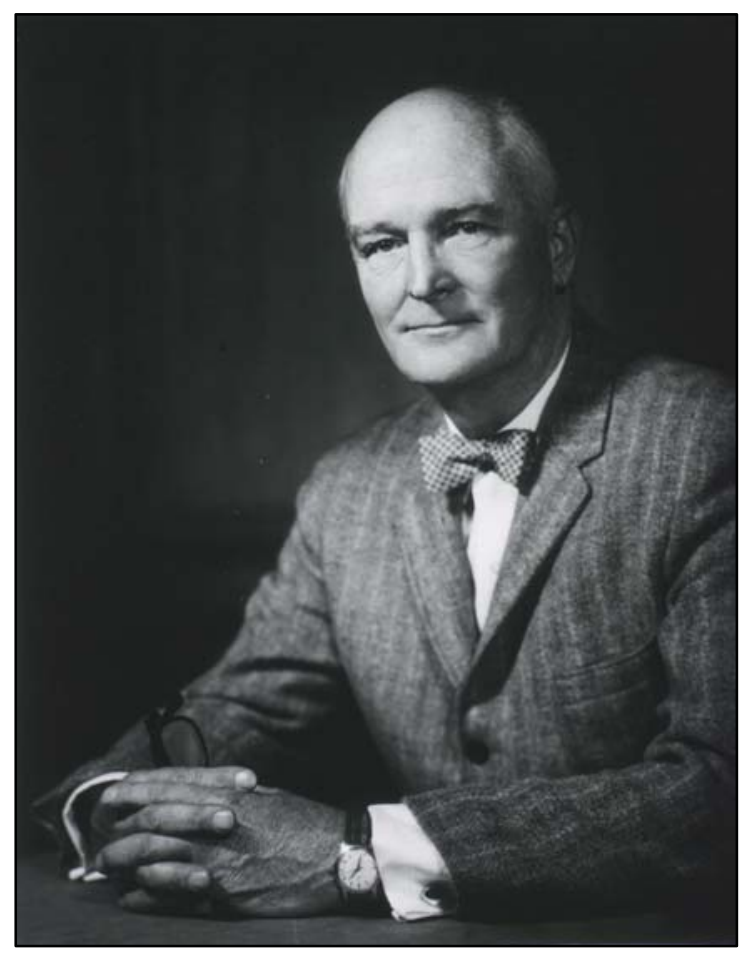

Figura 5. John H. Gibbon Jr., 1904 - 1973.

Gibbon comenzó su proyecto en 1934, cuando regresó al laboratorio de Edward D. Churchill en el Hospital General de Massachusetts con su segunda beca de investigación quirúrgica. En 1939, reporta que la supervivencia prolongada era posible en animales de experimentación.

La Segunda Guerra Mundial (1939-1945) interrumpe el progreso de su trabajo; que retoma en el Jefferson Medical College en 1944. Poco después, atrajo el interés de Thomas J. Watson, presidente de la International Business Machines (IBM), que proporcionó los servicios del laboratorio de física experimental de IBM, así como la asistencia de ingenieros. En los próximos siete años, IBM construye y modifica dos máquinas experimentales y contribuyó significativamente en la evolución de una máquina que pudiera ser utilizada en humanos.

El 6 de mayo de 1953, la máquina corazón-pulmón se utilizó por primera vez con éxito en Cecelia Bavolek. Seis meses antes de la cirugía, Bavolek había sido hospitalizada en tres ocasiones con síntomas de insuficiencia cardíaca debido a una comunicación interauricular. Durante la cirugía, su circulación se conectó a la máquina corazón-pulmón durante cuarenta y cinco minutos, el equipo quirúrgico dirigido por Gibbon fue capaz de cerrar la comunicación entre las aurículas y re-establecer la función normal del corazón. Dos meses más tarde, un examen del defecto reveló que 
estaba completamente cerrado; Bavolek reanudó su vida normal. La era de la cirugía a corazón abierto había comenzado.

\subsubsection{Funcionamiento de la máquina de $\mathrm{CEC}^{136}$}

El funcionamiento de la máquina de CEC consiste básicamente en unidades modulares integradas en grupo de 3 o 4 cuerpos (Figura 6); cada módulo tiene un motor eléctrico acoplado a un cabezal regulable conformado por dos rodillos metálicos. Estos giran contra una superficie denominada pista, por donde se instala un tubo colapsable de Silastic ${ }^{\circledR}$ por el que circula la sangre (Figura 7)

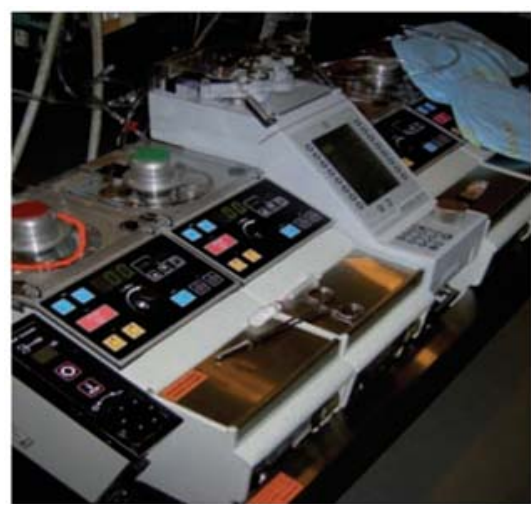

Figura 6. Bomba de CEC

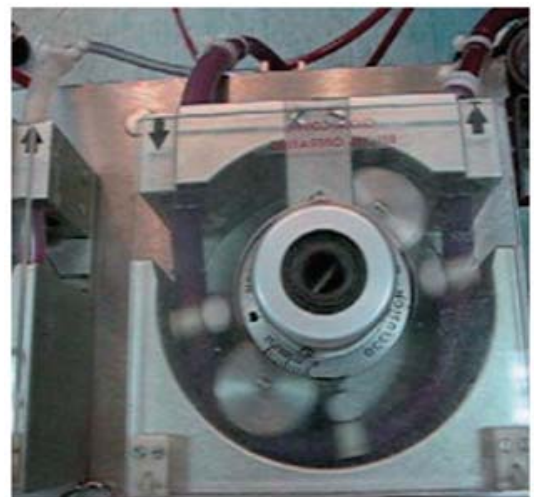

Figura 7. Bomba de rodillos

El tubo instalado tiene un calibre que determina un volumen interno. Cada giro del cabezal desplaza un volumen sanguíneo que, al multiplicar por el número de vueltas, permite determinar el flujo generado por la bomba de circulación extracorpórea (BCE). El ajuste de los rodillos contra el tubo y la pista es de suma importancia para evitar la destrucción de los glóbulos rojos. Esto se realiza con un registro manual antes de poner en marcha el sistema: se coloca un tubo con solución fisiológica ajustado entre el rodillo y la pista con una columna de un metro de altura, que debe descender un centímetro en un minuto. La calidad mecánica de la BCE influye en la facilidad y persistencia de la regulación efectuada. En los equipos nuevos, con sensores instalados, se puede observar en un "display" el efecto mecánico (volumen eyectado) de la BCE expresado en litros por minuto. Los perfusionistas con experiencia continúan utilizando, por seguridad, el viejo método manual para asegurar la veracidad de la información brindada por la máquina.

Lo arriba mencionado es el sistema de bombeo, mientras que el acople de un dispositivo descartable biocompatible, por donde también pasa el flujo sanguíneo, permite cumplir con la función de oxigenar la sangre (Figura 8). Este componente 
contiene un reservorio para la sangre, y un módulo instalado con una membrana artificial plegada con micro poros en una superficie equivalente al pulmón, de aproximadamente $1,8 \mathrm{~m}^{2}$ (sistema para adultos). Por lo tanto, el equipo tiene un orificio para entrada y salida de gases (aire comprimido/oxígeno); también tiene una serpentina por donde circula agua (fría o caliente según lo que el cirujano disponga).

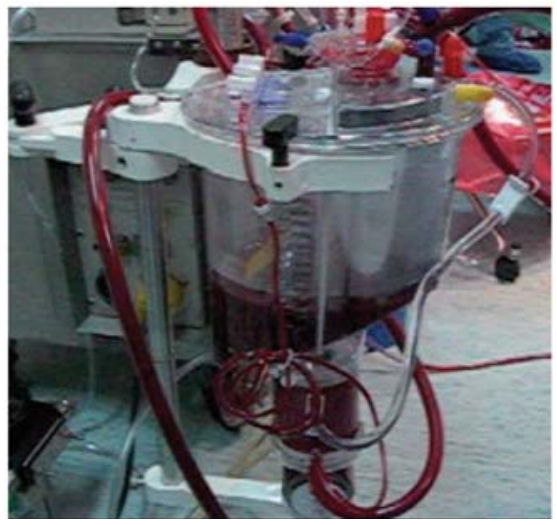

Figura 8. Oxigenador

El empleo de la BCE podría resumirse en ocho puntos fundamentales:

\section{Heparinización del sistema}

La anticoagulación es fundamental para que el contacto de la sangre con las tubuladuras y oxigenador no forme coágulos en el sistema circulatorio, que podrían generan oclusiones embolicas en cualquier territorio; ${ }^{137,138}$ las más críticas son las del sistema nervioso central y el túbulo renal. La coagulación masiva del sistema generaría una detención circulatoria total con posterior muerte del paciente. Esta última situación es un planteamiento teórico y ausente en la actualidad.

Como éste paso es crucial, algunos equipos quirúrgicos continúan inyectando la heparina (dosis de $2-3 \mathrm{mg} / \mathrm{Kg}$ de peso) directamente en la aurícula derecha para confirmar su acceso al torrente circulatorio. También puede administrarse por una vía central.

La actividad de la heparina se controla con un kit de determinación que se denomina ACTest (caolín) y se realiza en quirófano. Se determina un tiempo basal y luego de administrar el anticoagulante. Con algunas diferencias entre grupos, en general un tiempo de 480 segundos ( 8 minutos) se considera adecuado, no debiendo disminuirse a menos de 350 segundos. Antiguamente no se hacía esta determinación, por lo que se ignoraba la cantidad de heparina circulante posterior a la CEC. Dado que el tiempo de 
actividad es variable según cada individuo, muchos pacientes recibían neutralización inadecuada y esto generaba hemorragias postoperatorias por microagregados plaquetarios y/o eritrocitarios y exceso de protamina.

\section{Conexión del paciente al sistema extracorpóreo}

La membrana de intercambio gaseoso y las tubuladuras requieren un volumen líquido denominado "cebado" o "priming", para lo cual se utilizan soluciones cristaloides. Se deben eliminar las burbujas para evitar embolias gaseosas. Luego de administrada la heparina sistémica, se procede a colocar una cánula en la aurícula derecha del paciente para la salida de sangre hacia la BCE, y otra cánula para el retorno de la sangre, habitualmente en la aorta ascendente. Así, desde el paciente hacia la BCE la sangre (oscura) fluye por gravedad o diferencia de altura, mientras que el retorno hacia el paciente (sangre roja rutilante) se realiza de manera activa al comprimir el rodillo el tubo de Silastic ${ }^{\circledR}$. La diferencia del color de la sangre, producida al pasar por el oxigenador, asegura un funcionamiento correcto del sistema, por lo que el perfusionista suele asegurarse una adecuada iluminación para evaluar dicho proceso. Empero la confirmación se logra mediante una muestra gasométrica de dicha sangre. ${ }^{139}$

En pocos casos durante el TP es necesario realizar la CEC con parada cardíaca y la posterior necesidad de solución de preservación cardíaca (cardioplejia), si así lo requiriera el acto quirúrgico, el paso siguiente es la colocación de una pinza ("clamp") en la aorta ascendente que ocluye el ingreso de sangre en las arterias coronarias al tiempo que se inyecta la cardioplejia. Esto inicia el denominado tiempo de clampeo y termina al liberar la oclusión de la aorta. Se refiere al período que el corazón no recibe oxigenación y es protegido por las soluciones cardiopléjicas. ${ }^{140}$

\section{Hemodilución}

Un paciente adulto de peso promedio tiene una volemia aproximada de 5 litros. Si tenemos en cuenta que puede haber un volumen de "cebado" que puede llegar a 1,2 litros, es evidente que la masa globular sufrirá una dilución.

Inicialmente se pensó que utilizar sangre para el cebado del sistema era más fisiológico. Sin embargo, la dificultad al flujo por la viscosidad propia de la sangre, el efecto trombogénico de ésta y la posibilidad de contraer patologías motivó a que actualmente se empleen cristaloides. Así, la hemodilución obtenida al mezclar el cebado 
mejora la propiedad reológica de la sangre y el flujo capilar se encuentra optimizado. Sin embargo, se debe comprender que el organismo está en una situación no fisiológica. El flujo arterial es de tipo no pulsátil, el hematocrito es menor, la sangre no coagula por acción de la heparina y habitualmente la temperatura corporal está modificada.

Respecto del hematocrito, se considera adecuado durante la CEC un valor de 22 a $24 \% .{ }^{141}$ Pacientes anémicos, dependiendo del grado, es posible que requieran aporte de glóbulos rojos; en cambio, a un sujeto con poliglobulia se le extraerá parte de la masa globular, para ser re infundida luego de la CEC. Éste volumen presenta la ventaja de tener plaquetas preservadas de la acción nociva del rodillo de la BCE.

El ajuste adecuado de los rodillos contribuye a evitar la destrucción de los elementos formes de la sangre. Además, si se genera hemólisis, puede conducir a lesión de los túbulos renales por el depósito de hemoglobina. Así, en un paciente que presente hematuria posterior a la CEC, deberá diferenciarse si es debido a un fenómeno traumático local o se trata de hemoglobinuria.

\section{Flujo a suministrar}

Para estimar el requerimiento metabólico del individuo debemos recordar que se encuentra dormido y relajado por la acción anestésica. Utilizando como referencia la superficie corporal: se considera que un flujo de 2,5 litros/metro es óptimo, y como la superficie promedio es de 1,8 metros el flujo habitual ronda los 5 litros/minuto. ${ }^{142}$ En pacientes pequeños no existen mayores inconvenientes; en cambio, pacientes de gran tamaño pueden requerir altos flujos que podrían ocasionar lesiones hematológicas. Aquí encuentran su indicación otros sistemas de BCE, como los de acción centrífuga con otro tipo de cabezal. Pero más allá de la teoría, el flujo adecuado es aquel que mantiene al paciente con un pH normal y sin acidosis metabólica.

5. Recuperación de la sangre derramada en el pericardio y/o cavidad pleural Debido a la heparinización sistémica y a la presencia de líneas de aspiración durante la circulación extracorpórea, toda la sangre vertida en la cavidad pericárdica y pleural puede ser recuperada en forma inmediata y dirigida al reservorio del oxigenador para continuar en el torrente circulatorio. 
Debe tenerse en cuenta que tanto en la fase inicial previa a la administración de heparina, como al tiempo posterior a la neutralización con protamina, ya no puede aspirarse la sangre a excepción de la utilización de un sistema especial de recuperación (denominado "cell saver") ${ }^{143}$. Este sistema recupera glóbulos, que son lavados, y no sangre completa.

\section{Temperatura corporal}

La temperatura es muy importante en la cirugía cardíaca; la razón es la relación directa que la temperatura guarda con el consumo metabólico. Por cada grado que baja la temperatura corporal ocurre un descenso de aproximadamente 5-7\% en el consumo de oxígeno. Debido a que la CEC impacta directamente en el gasto cardíaco, esto es de vital importancia para preservar los tejidos.

Al entrar en CEC, con el paciente anestesiado y con el tórax abierto en un quirófano con temperatura menor que la corporal, sin actividad muscular y en contacto con las tubuladuras externas, lo habitual es que la temperatura corporal descienda. Esto se controla con el intercambiador de calor y se ajusta para que el finalizar la CEC el paciente se encuentre en normotermia. ${ }^{144}$

\section{Protección miocárdica}

Como se ha comentado previamente, la utilización de protección miocárdica durante el TP no suele ser necesario ya que la parada completa del corazón no suele ser habitual. En los casos en los que durante el TP sea necesario realizar algún tipo de cirugía cardíaca (por ejemplo; cierre del foramen oval permeable) o la técnica quirúrgica durante el TP demande la parada cardíaca para continuar con el procedimiento, entonces si estará indicada la utilización de cardioplejia.

8. Desconexión del sistema y neutralización de la anticoagulación

Cuando todos los parámetros vitales se encuentran en valores correctos, el perfusionista disminuye el flujo de la CEC; si el corazón mantiene sin problemas la circulación y la saturación de oxígeno, se procede a detener la BCE. En este punto el corazón se contrae por sus propios medios mientras el pulmón es ventilado mecánicamente. Se procede primero a retirar la línea de la aurícula derecha/cava devolviendo el volumen residual que haya quedado en el reservorio a través de la cánula aórtica. Es importante evitar la 
sobre distensión del ventrículo derecho, regulando el tiempo y magnitud de la sangre devuelta.

En este momento se calcula la cantidad de heparina circulante y se inicia la infusión de protamina para su inactivación a razón de 1 a 1.5 mg por cada 100 unidades $(1 \mathrm{mg})$ de heparina administrada. ${ }^{145}$ Una vez devuelto el volumen sanguíneo, se retira la cánula arterial efectuando una correcta hemostasia.

\subsubsection{Fisiopatología de la $\mathrm{CEC}^{146}$}

La cirugía sobre el corazón provoca una respuesta inflamatoria vigorosa, la cual tiene importantes implicaciones clínicas. En el reporte de la base de datos nacional de la Sociedad de Cirujanos Torácicos, el 20\% (22 000 pacientes) de los pacientes de bajo riesgo desarrollaron complicaciones postoperatorias. La incidencia de fracaso multiorgánico posterior a la CEC fue del $11 \%$, con una tasa de mortalidad del $41 \%$. El fracaso multiorgánico es el predictor más importante de mortalidad en los pacientes que requieren cirugía cardíaca y ventilación mecánica postoperatoria prolongada.

Los factores que influyen sobre la incidencia, severidad y la mejoría clínica de la respuesta inflamatoria no están bien establecidos. Tres perspectivas por separado contribuyen a nuestro entendimiento de la asociación entre la respuesta inflamatoria y las secuelas clínicas adversas.

- Primero: La interacción compleja de moléculas humorales pro inflamatorias o antiinflamatorias puede influenciar la presentación clínica y el curso del síndrome de respuesta inflamatorio sistémico (SRIS), donde el balance de las citoquinas (proinflamatorias - antiinflamatorias) determinan el curso clínico después de cirugía cardíaca.

- Segundo: Estados de hipoperfusión orgánica que se presentan en el postoperatorio de cirugías con CEC.

- Tercero: La inmunosupresión generalizada inducida por la CEC puede jugar un rol importante en el desarrollo de complicaciones infecciosas. 
Factores que activan la respuesta inflamatoria:

Entre los activadores no específicos de la respuesta inflamatoria se incluyen; el trauma quirúrgico, pérdida sanguínea, transfusiones de sangre e hipotermia. La CEC específicamente, puede activar la respuesta inflamatoria por tres mecanismos distintos (Figura 9). Un mecanismo que involucra directamente la "activación de contacto" del sistema inmune seguido a la exposición de la sangre a superficies extrañas de los circuitos de la CEC.

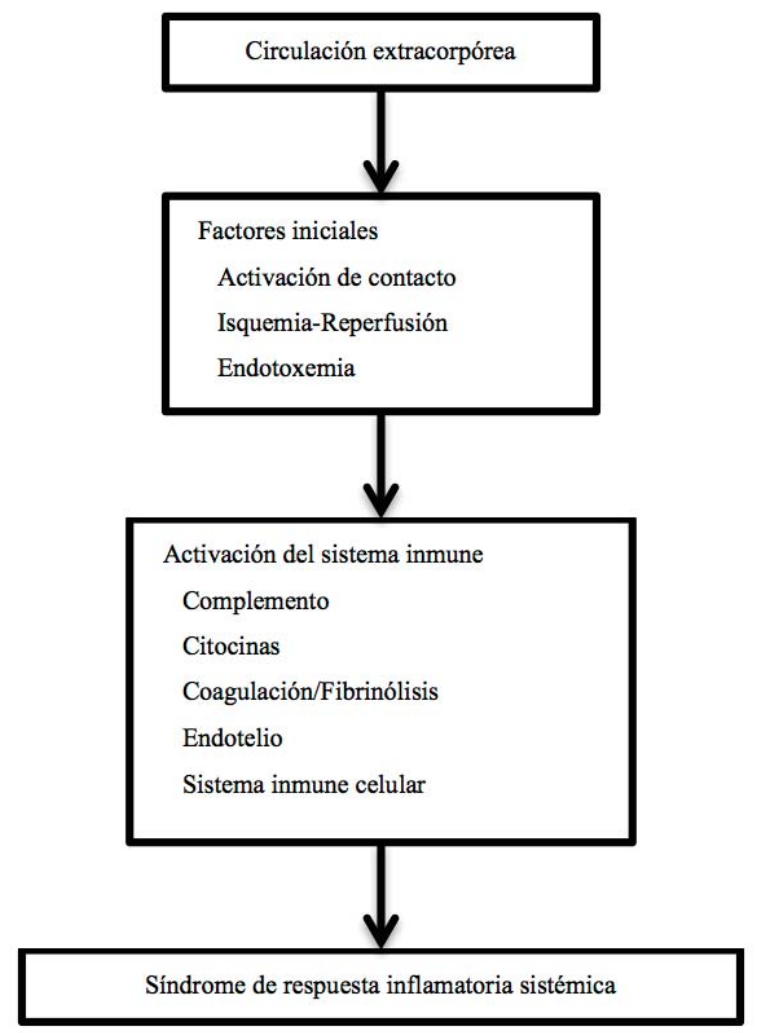

Figura 9. Diagrama de la secuencia de eventos que se producen por la CEC que pueden llevar al desarrollo del síndrome de respuesta inflamatoria sistémica. ${ }^{146}$

Un segundo mecanismo, involucra el daño isquemia-reperfusión al cerebro, corazón, pulmones, riñones e hígado como resultado del pinzamiento aórtico, si fuera necesario. La restauración de la perfusión al liberar el pinzamiento aórtico se asocia con la activación de la respuesta inflamatoria.

La endotoxemia puede indirectamente activar la cascada inflamatoria. La hipoperfusión esplácnica, un hallazgo común durante y después de la CEC, puede dañar la barrera mucosa, dando lugar a la translocación de endotoxinas intestinales. La concentración de endotoxinas sistémicas se correlaciona estrechamente con el grado de 
disfunción cardiovascular posterior a la CEC. Sin embargo, la importancia de las endotoxinas en estimular la respuesta inflamatoria en la CEC permanece en debate. En realidad, las endotoxinas pueden ser un contaminante de los líquidos, como la cardioplejía o el cebado de la CEC utilizados de forma rutinaria.

La CEC ha sido comparada con el SRIS; la activación del complemento, reactantes de fase aguda, activación de neutrófilos, sobre-regulación de moléculas de adhesión, cambios en la activación de neutrófilos pueden todos, contribuir a la compleja vasodilatación y a la disfunción sistémica multiorgánica. Las manifestaciones clínicas son complejas e incluyen sangrado, lesión isquemia-reperfusión, infecciones y disfunción multiorgánica, incluyendo la disfunción del sistema nervioso central. La activación de la coagulación ocurre con el daño tisular durante la cirugía y progresa cuando la sangre toma contacto con superficies no endoteliales de los circuitos de perfusión de la $\mathrm{CEC}$, dando lugar a trombosis y reacciones de defensa que son responsables de la morbilidad asociada con la cirugía. La CEC requiere heparina, siendo ésta un anticoagulante no ideal ya que requiere de un cofactor (antitrombina III) para su actividad, teniendo un margen muy limitado de actividad.

La exposición de sangre a superficies extrañas da lugar a una activación de la cascada del complemento, predominantemente por la vía alterna. La interface sangregas de los circuitos de CEC puede también jugar un papel importante para dicha activación. La formación de complejos heparina-protamina activan la cascada del complemento principalmente por la vía clásica $(\mathrm{C} 4 \mathrm{a})$. En los primeros cinco días después de la cirugía hay un segundo aumento retardado en los productos de la activación del complemento. Esta activación retardada del complemento parece estar mediada por la proteína $\mathrm{C}$ reactiva en respuesta a los complejos heparina-protamina.

El rol central del complemento en la respuesta inflamatoria a la cirugía con CEC ha sido demostrado por los efectos de los inhibidores específicos del complemento. El complemento soluble humano del tipo de receptores 1 atenúa el daño miocárdico y pulmonar, mientras que bloquear la formación de C3a previene la activación de neutrófilos, monocitos y plaquetas en modelos de CEC. Los anticuerpos monoclonales anti-C5a atenúan la disfunción pulmonar, miocárdica, mesentérica y microvascular mediada por la CEC. 
El grado de cortocircuitos pulmonares postoperatorios se correlaciona con la activación de la vía clásica por complejos protamina-heparina. Las concentraciones plasmáticas de $\mathrm{C} 3 \mathrm{a}$ postoperatorias pueden predecir la probabilidad de disfunción pulmonar, renal y hemostática.

Las citoquinas son otro grupo de moléculas que forman parte del complejo sistema de la respuesta inflamatoria. Éstas, son pequeñas proteínas que semejan hormonas y que una vez generadas y liberadas por las células lesionadas, son transportadas a lugares distantes del cuerpo y afectan a la función de otras células en localizaciones distintas. Las citoquinas son producidas en respuesta a una variedad de estímulos fisiológicos y patológicos. Las citoquinas proinflamatorias juegan un papel importante en los estímulos de los procesos inflamatorios. Concentraciones elevadas de citoquinas específicas, como la interleucina-1ß (IL-1ß) e interleucina-6 (IL-6), son predictivas de estados inflamatorios en pacientes críticamente enfermos. El factor de necrosis tumoral $\alpha$ (FNT $\alpha$ ) e IL-1ß se elevan de forma muy temprana después de la cirugía cardíaca y presentan picos tardíos de IL-6 e IL-8. Los pacientes que desarrollan SRIS demuestran elevaciones significativas de citoquinas comparados a pacientes no complicados con SRIS. Además, las concentraciones altas de IL-6 se correlacionan con la mortalidad en cirugía cardíaca pediátrica.

El óxido nítrico $(\mathrm{ON})$ puede tener efectos protectores dentro de la respuesta inflamatoria. La vasodilatación inducida por el ON puede prevenir la acumulación de mediadores que afecten al endotelio. El ON puede recoger radicales libres y prevenir la sobre-regulación de las moléculas de adhesión de los neutrófilos. El rol del ON en la respuesta inflamatoria es complejo, sin embargo, puede tener algunos efectos potenciales deletéreos. La disminución inducida por citoquinas de la función miocárdica parece estar relacionada a un aumento en la sintetasa del ON inducible, la cual es sobreregulada por la CEC. Las citoquinas, particularmente IL-1ß, juegan un papel importante en el proceso de la dilatación inflamatoria inducida por ON. La liberación de ON durante la CEC parece ser dependiente del tipo de flujo de la CEC, con atenuación de la liberación de $\mathrm{ON}$ basal durante el flujo no pulsátil, condicionando al cierre de capilares funcionales en órganos blanco como resultado de una disminución en el diámetro transversal del vaso. 
La prevención de la sobre-regulación de sintetasa del ON inducible reduce la inestabilidad hemodinámica después de la CEC, mientras que la inhibición de la sintetasa del ON puede revertir la hipotensión refractaria en el estado de shock establecido. El ON parece ser una poderosa toxina celular directa, inactivando enzimas involucradas en la glicólisis, el ciclo de Krebs, y la cadena transportadora de electrones, reduciendo el trifosfato de adenosina y concentraciones de antioxidantes, predisponiendo a la muerte celular.

La CEC parece causar un mayor estrés oxidativo en pacientes con DM, existiendo diferencias cualitativas en la respuesta inflamatoria del paciente diabético. Los pacientes diabéticos mal controlados pueden tener un aumento de la respuesta inflamatoria.

La apnea durante la CEC puede llevar a la activación de enzimas liposomales en la circulación pulmonar, las cuales se relacionan con el daño pulmonar agudo postoperatorio. Dicho proceso puede ser atenuado con una maniobra de capacidad vital realizada antes de la finalización de la CEC; sin embargo, la presión positiva continua de la vía aérea aplicada durante la CEC parece ser inefectiva.

La administración de opioides, como la morfina, puede reducir la liberación de ciertas citoquinas. Los derivados opioides han sido reportados como atenuantes de la disfunción posterior a la isquemia y la cardioplejía debido al efecto de apertura de los canales de KATP .

Los anestésicos volátiles pueden atenuar el daño pos isquémico. El pre tratamiento con anestésicos volátiles semejan el efecto benéfico del pre acondicionamiento isquémico; el efecto cardioprotector puede ser bloqueado por antagonistas de los canales de KATP, o por bloqueo de los receptores del subtipo de adenosina A1. 


\subsection{INFLUENCIA DE LA CEC EN EL TRASPLANTE PULMONAR}

No existe un consenso claro sobre el papel de la CEC en el TP. ${ }^{147-151}$ Con el aumento progresivo del trasplante pulmonar bilateral secuencial y la mejora en la técnica quirúrgica, las indicaciones para la CEC en el TP han disminuido.

\subsubsection{CEC y la disfunción del injerto pulmonar.}

Existen publicaciones que señalan que la respuesta inflamatoria sistémica causada por la propia CEC se ha visto implicada en la lesión pulmonar. ${ }^{152}$ Dado que el injerto está sometido a rechazo por parte del sistema inmune del receptor, la activación innecesaria del sistema inflamatorio sería contraproducente. ${ }^{153}$

La mayor desventaja de la CEC es la respuesta inflamatoria, mediada por el contacto de la sangre con el sistema extracorpóreo, con el riesgo que conlleva sobre la lesión pulmonar y el aumento del riesgo de sangrado. Esto es común a todos los pacientes que requieren CEC (no solo los pacientes de TP), y diversos estudios relacionan la CEC con una mayor activación de la respuesta inflamatoria y un aumento en la frecuencia de disfunción primaria del injerto (DPI) pulmonar. ${ }^{148-150,154-158}$

Un metanálisis de 11 estudios demuestra que la incidencia de DPI era significativamente mayor en los pacientes trasplantados pulmonares bajo CEC, atribuyendo un riesgo de 2.29 mayor de DPI si se trasplantan bajo CEC. ${ }^{155}$

Khan $y$ cols $^{159}$ reportan una serie de 99 pacientes trasplantados, en los cuales estudian los posibles factores relacionados con la DPI y concluyen que la utilización de CEC durante el TP se asocia con un aumento en la incidencia y gravedad de la DPI, lo cual aumentaba el tiempo de ventilación mecánica (VM) y la estancia en la unidad de cuidados intensivos (UCI) pero que no afectaba la supervivencia.

La existencia de DPI en el TP es de vital importancia gracias a su vinculación con una disminución de la supervivencia y la asociación como factor de riesgo para la disfunción crónica del injerto (DCI). ${ }^{160-162}$

Aunque un estudio que analiza la influencia y las posibles causas de la DPI en el TP observa que los pacientes trasplantados bajo CEC tiene mayor DPI (33\% vs. 22\%), 
dicho resultado no alcanzó la significación estadística. ${ }^{163}$

En un estudio en base a 100 pacientes trasplantados, la incidencia de DPI fue del 15\% y aunque se observó una tendencia a la utilización de CEC en los pacientes que posteriormente fueron diagnosticados de DPI (33\% vs. $22 \%$ ), dicha tendencia tampoco alcanzó la significación estadística. ${ }^{163}$

El grupo de trabajo sobre la DPI de la ISHLT publica que el uso de la CEC durante el TP parece aumentar la frecuencia de DPI, mayor tiempo de VM y de estancia en la UCI. Sin embargo, no parece influir en la supervivencia al año y 3 años del TP. ${ }^{164}$

Entre los trabajos en contra de la utilización de CEC, existen estudios experimentales que han demostrado una peor función pulmonar en animales que fueron trasplantados de pulmón bajo CEC. ${ }^{150,158}$

\subsubsection{CEC como factor protector en el TP.}

A diferencia de lo expuesto previamente, también se han publicado estudios que no encuentran un aumento en la incidencia de DPI en pacientes trasplantados bajo CEC.

En 1998 se publica una serie de 100 pacientes TP con una incidencia de DPI del $15 \%$. Entre los resultados, no se encontraron diferencias significativas en cuanto a la edad, sexo, diagnostico que motivo el TP, presión de arteria pulmonar previa al TP, tipo de TP, tiempos de isquemia o la utilización de CEC entre los pacientes que desarrollaron DPI y los que no. ${ }^{163}$

Una de las series más amplias de 983 TP (adultos e infantiles) y que evalúa la incidencia de DPI en el TP, no encuentra una mayor incidencia de DPI pese a que prácticamente todos los trasplantes infantiles fueron realizados bajo CEC. ${ }^{165}$

En el estudio de Huang y $\operatorname{cols}^{160}$ se evalúa la implicación de la DPI en la presencia de DCI. En la serie descrita, más del $20 \%$ de los pacientes se trasplantan bajo CEC. En su análisis univariante para potenciales factores de DCI, la CEC no alcanza la significación estadística $(\mathrm{RR}=1,42$ IC 95\% 0.98 - 2.06; $\mathrm{p}=0,07)$.

Existe controversia sobre la asociación entre CEC y DPI, independientemente de 
la patología pulmonar que motivó el TP. La CEC es más frecuente en pacientes con HTP que posteriormente pueden presentar DPI y por tanto podría asociarse erróneamente la vinculación entre CEC y DPI. ${ }^{166}$

Otros autores exponen que el aumento en la liberación de citoquinas se debe sobre todo a la isquemia y reperfusión del nuevo injerto más que a la utilización de la CEC. Marczin y cols ${ }^{167}$ reportan que la lesión microvascular causada por el estrés hidrostático que genera finalmente el dañó del injerto pulmonar, puede limitarse controlando el flujo de sangre hacia el nuevo pulmón gracias a la CEC.

Estudios a favor de la utilización de CEC durante el TP han demostrado que la mortalidad a los 30 días es similar entre los pacientes trasplantados bajo CEC y los que no y concluyen que la CEC durante el TP es un método efectivo de asistencia extracorpórea en un grupo de pacientes generalmente muy afectado. ${ }^{168,169}$

En un estudio publicado en 2002, Szeto y cols ${ }^{169}$ concluyen que no existen diferencias entre los pacientes trasplantados por EPOC con o sin CEC, tanto en el tiempo de ventilación mecánica, tiempo en UCI, supervivencia a los 30 días y al año, $\mathrm{FEV}_{1}$ al año e incidencia de DCI.

En cuanto al procedimiento quirúrgico del TP, existen publicaciones a favor de la utilización de la CEC, en cuanto previene el colapso hemodinámico que se produce cuando se realiza el clampaje de la arteria pulmonar para su posterior anastomosis con el injerto pulmonar. ${ }^{167}$

Incluso existen autores que sugieren que la CEC podría ser un factor protector inmunológico en el TBP para los pacientes con EPOC en los que la utilización de la CEC obtiene una mayor supervivencia al año (97\% vs. 77\%) y que los pacientes con 2 HLA-DR mismatches tuvieron una mejor supervivencia $(\mathrm{OR}=0,06 ; \mathrm{p}=0,02) .{ }^{170}$

Un estudio en base a 23 pacientes que recibieron un TBP por diversos diagnósticos, no encontró una mayor incidencia de DPI en los pacientes TP bajo CEC y tampoco encontraron una mayor afectación de la ventilación/perfusión en la gammagrafía pulmonar realizada durante el postoperatorio. ${ }^{171}$ 


\subsubsection{CEC y disminución de la supervivencia}

En 1994, Ryo y cols ${ }^{149}$ publican una serie de 100 trasplantes pulmonares y cardiopulmonares. Entre los resultados, detallan una menor supervivencia al mes en los pacientes que se trasplantaron bajo CEC y concluyen que sus resultados podrían sugerir que la interacción entre CEC y la lesión de preservación podría exagerar la disfunción pulmonar en el TP.

Algunos autores reportan que la utilización de la CEC, es una terapia necesaria para el TP y refieren que la elevada mortalidad a los 30 días (26\%), como el estudio de Hlozek y cols no se debe a la utilización de la CEC sino más bien a otros factores como las infecciones o el rechazo del injerto. ${ }^{168}$

Otros grupos han demostrado que en los receptores de TP, sin el diagnóstico de HTP, la CEC se asocia a un aumento de la mortalidad. ${ }^{172,173}$

Otra de las desventajas de la CEC incluye la utilización de heparina con el subsecuente aumento de riesgo de hemorragias. Wang y cols ${ }^{174}$ demostró que un tiempo mayor de CEC se correlacionaba con la necesidad de transfusiones sanguíneas. Existen otros estudios con la misma conclusión. ${ }^{175}$ La disfunción renal y neurológica también son otras posibles secuelas. El fallo renal agudo es particularmente importante en la población trasplantada porque algunas de las drogas inmunosupresoras son nefrotóxicas y por lo tanto, puede ser necesaria la modificación de las dosis en estas circunstancias. 153

También se ha relacionado la utilización de la CEC en el trasplante pulmonar con el retraso en el cierre de la toracotomía y un aumento de la mortalidad postoperatoria. $^{176,177}$

Existen reportes sobre la influencia de la CEC en trasplantados pulmonares por otras patologías pulmonares como la EPOC o la FP. ${ }^{147,169,172,178}$

No se han encontrado estudios en la literatura que evalúen la influencia de la CEC exclusivamente en el grupo de pacientes trasplantados pulmonares por FQ. 

2. JUSTIFICACIÓN 

Datos en la literatura constatan que la prevalencia, los fenotipos y los genotipos de pacientes con FQ varían de forma considerable entre países. Lo cual genera la necesidad de estudios sobre éste particular grupo de pacientes en cada territorio, ya que probablemente los resultados de trabajos publicados sobre pacientes con FQ en otros países no puedan ser completamente extrapolables a nuestro territorio. ${ }^{179-183}$

Existen múltiples series publicadas en la literatura sobre paciente con FQ receptores de TP, sobre las características previas al trasplante y datos sobre el postoperatorio y la supervivencia. ${ }^{53,54,56,184,185}$ Aunque algunas de las publicaciones son en base a series de números reducidos de casos. En nuestro país solo se han encontrado dos publicaciones sobre $\mathrm{TP}$ en pacientes con FQ, una de ellas en las que se engloba a los pacientes con FQ dentro de las enfermedades supurativas y otra en la que se sugiere que la CEC, entre otras causas, disminuye la supervivencia de los pacientes pediátricos con FQ que reciben un TP. ${ }^{186,187}$ Aunque dichas publicaciones presentan información muy valiosa, creemos que es necesario más información sobre éste grupo de pacientes sometidos a TP en nuestro territorio.

En 2014, la ISHLT publica los resultados de más de 47,000 receptores de TP. En dicho reporte la FQ representa al 16,4\% de todos los receptores con una supervivencia a los 5 años del $60 \%$ en comparación a la supervivencia del $50 \%$ cuando el diagnostico que motivó el TP no es la FQ. ${ }^{188}$

En nuestro medio, el Registro Español de trasplante Pulmonar publica en 2013 los resultados de los centros trasplantadores de España. Informan que para la serie general de TP la supervivencia a los 3 meses, al año y a los 3 años es del 71,7 y 60,1\% 
respectivamente. En el informe también se aprecia una mejor supervivencia de los pacientes con FQ en comparación con el resto de patologías. Además concluyen que los factores que más inciden en la supervivencia del paciente son la edad del receptor y el diagnóstico que indico el trasplante. ${ }^{189}$ Pese al gran valor del estudio, no presenta datos de supervivencia específicos de cada patología y la supervivencia a largo plazo.

Respecto a la CEC, no existe un consenso claro para su utilización en el TP, cómo se mencionó previamente. La mayor desventaja potencial para la utilización de CEC es la respuesta inflamatoria, mediada por el contacto de la sangre con el circuito extracorpóreo, con el consiguiente riesgo de lesión pulmonar y hemorragia. ${ }^{146,147,174}$

Por otro lado, los estudios que valoran la implicación de la CEC en el trasplante pulmonar son exclusivos de las patologías más prevalentes, EPOC y FP. ${ }^{147,169}$ Algunos estudios valoran la implicación de CEC en la DPI comparando dos grupos, con y sin CEC dentro de los que incluyen paciente con FQ entre otros diagnósticos. ${ }^{148,155,156}$

Existen argumentos a favor y en contra de la utilización de la CEC, pero la evidencia clínica es insuficiente. ${ }^{147}$

Los pacientes con FQ constituyen un grupo diferenciado de pacientes candidatos a TP tanto por las características de los pacientes (menor edad, patología séptica y afectación de otros órganos) como por la diferente evolución postoperatoria (tratamientos crónicos y mejor adherencia a tratamientos prolongados).

Por todo lo mencionado previamente, creemos que es importante identificar las características de los pacientes con FQ trasplantados en nuestro centro, analizar el resultado posterior al TP y la supervivencia a corto y largo plazo. Respecto a la CEC, debe evaluarse el grado de implicación que puede tener en la evolución de éste grupo de pacientes e identificar los posibles factores que puedan determinar qué pacientes son más susceptibles de requerir el soporte extracorpóreo durante el trasplante. 
3. OBJETIVOS 

Los objetivos del presente estudio fueron los siguientes:

1. Evaluar la supervivencia de los pacientes con FQ sometidos a TP en nuestro centro y las variables que pueden influir en la mortalidad.

2. Evaluar el impacto que tiene la CEC sobre la morbimortalidad peroperatoria y los resultados a largo plazo del TP por FQ en nuestro medio.

3. Identificar los factores que podrían influir en la utilización de CEC en este grupo de pacientes sometidos a trasplante pulmonar por Fibrosis Quística. 

4. PACIENTES Y MÉTODO 



\subsection{PACIENTES}

\subsubsection{Criterios de inclusión}

Desde agosto de 1990 hasta septiembre de 2011 se han realizado 592 trasplantes pulmonar en el Hospital Universitario Vall d'Hebron. En 1992 se trasplanta al primer paciente con FQ. Se han incluido en el estudio todos los pacientes con diagnóstico de FQ trasplantados de pulmón en el periodo entre el 1 de abril de 1992 y el 30 de septiembre 2011. En este período se han realizado 66 trasplantes pulmonares por FQ en nuestro centro.

\subsubsection{Criterios de exclusión}

Se han excluido del análisis global los siguientes pacientes:

- Retrasplantes. Se han excluido 2 pacientes que fueron retrasplantados durante el periodo del tiempo de estudio. El motivo de la exclusión se debe a que los retrasplantes son un tipo de trasplante que difiere significativamente respecto al resto en cuanto al riesgo quirúrgico y a la supervivencia posterior.

\subsection{MÉTODO}

En el presente trabajo se ha realizado un estudio observacional retrospectivo de todos los pacientes afectos de FQ trasplantados en el Hospital Vall d'Hebron. La recogida de datos se ha realizado mediante una revisión de todas las historias clínicas de los pacientes recogiendo todas las variables analizadas en el estudio. 


\subsubsection{Tiempo de seguimiento}

El seguimiento de los pacientes trasplantados se ha realizado hasta septiembre de 2014 , por lo que el tiempo mínimo de seguimiento posible, en caso de no haber fallecido antes, es de 3 años. Consideramos que es un tiempo adecuado para valorar los resultados del TP en los pacientes con FQ y la implicación de la CEC en la evolución posterior al trasplante.

\subsubsection{Extracción y preservación pulmonar}

La extracción pulmonar se ha realizado siguiendo la misma técnica quirúrgica en todos los trasplantes de la cohorte. En todas las extracciones se ha realizado perfusión anterógrada y retrógrada. Previo a la perfusión anterógrada, se administra $0.5 \mathrm{mg}$ de Epoprostenol sódico $\left(\right.$ Flolan $\left.^{\circledR}\right)$ en la arteria pulmonar, para producir dilatación vascular de la circulación pulmonar e inhibir la agregación plaquetaria. La preservación durante la primera época (1992 - 2002) se realizó con una solución con alto contenido en potasio (Euro-Collins ${ }^{\circledR}$ ), a partir del 2002, con una solución con dextrano y pobre en potasio $\left(\right.$ Perfadex $\left.^{\circledR}\right)$.

Desde el momento de la extracción hasta el implante, todos los injertos pulmonares se mantuvieron insuflados al $50 \%$ y en un baño de la solución de preservación correspondiente a $4^{\circ} \mathrm{C}$, envasados por separado, de forma estéril.

\subsubsection{Técnica quirúrgica del implante}

La técnica quirúrgica ha sido básicamente la misma en todos los procedimientos. Todos los trasplantes se han realizado a través de toracotomías antero laterales bilaterales con esternotomía transversa.

Para todas las anastomosis se utilizan suturas del calibre adecuado de acuerdo a las características antropométricas de los receptores. En primer lugar, se realiza la anastomosis bronquial termino-terminal con puntos sueltos de la porción cartilaginosa y sutura continua o discontinua en la porción membranosa. Se utiliza material bioabsorbible, un copolímero de poliglactina 910 monofilamento (Monocryl ${ }^{\circledR}$ ). Tras la anastomosis bronquial se realiza la anastomosis arterial mediante sutura continua con material sintético de polipropileno monofilamento e irreabsorbible (Prolene ${ }^{\circledR}$ ). Por 
último, se realiza la anastomosis del rodete de la aurícula izquierda conteniendo las dos venas pulmonares de cada pulmón, mediante sutura continua con polipropileno $\left(\right.$ Prolene $\left.^{\circledR}\right)$. Una vez finalizadas las anastomosis se procede a la reperfusión del injerto, realizando de-aireación y limpieza del líquido de preservación por la anastomosis de la aurícula izquierda antes del cierre definitivo de la sutura. Antes de la reperfusión de cada pulmón se administra una dosis de hasta $500 \mathrm{mg}$ de metilprednisolona endovenosa (10 $\mathrm{mg} / \mathrm{kg}$ en los pacientes pediátricos). Finalmente se procede a la re-expansión pulmonar. (Figura 10)

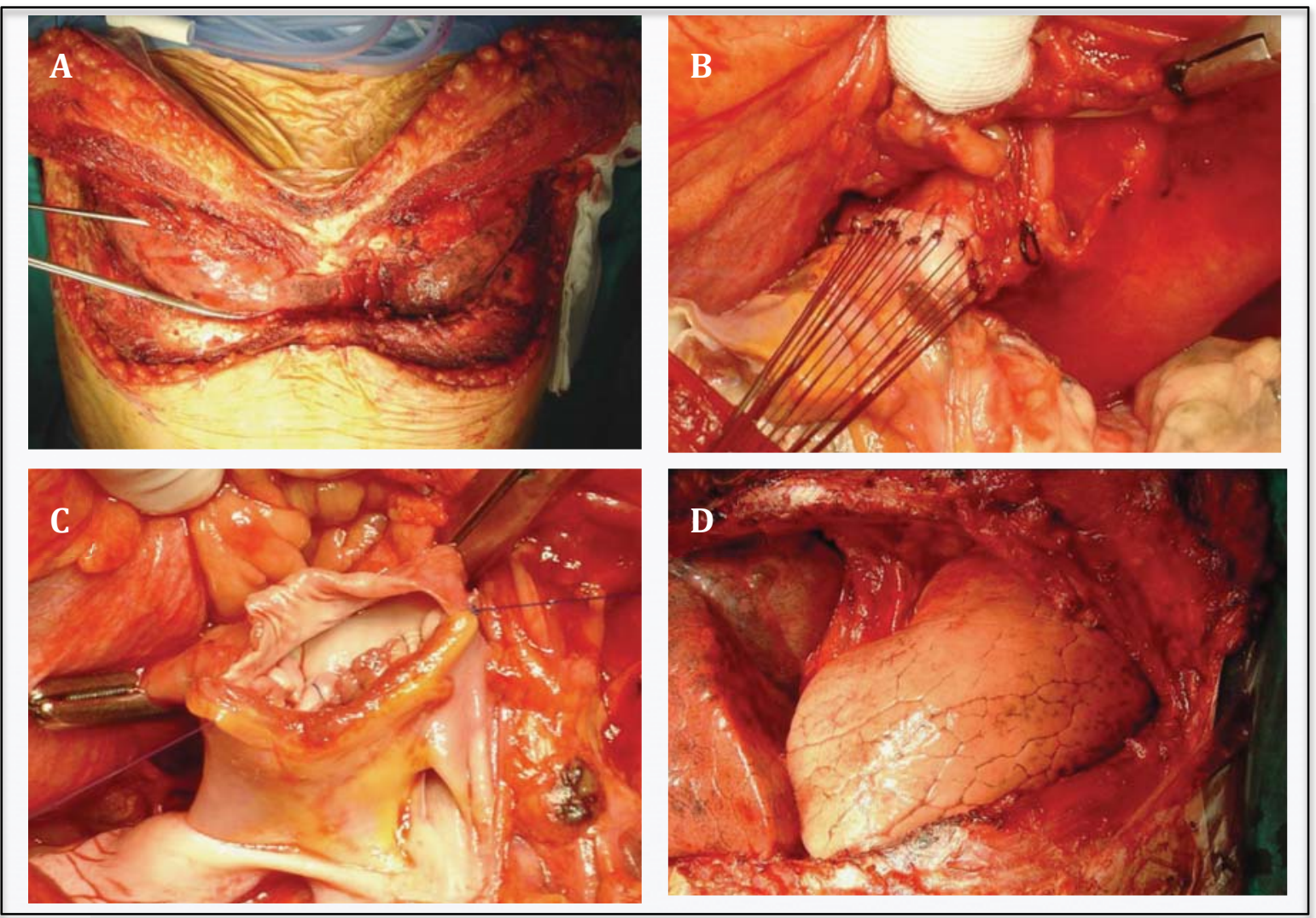

Figura 10. Técnica quirúrgica del implante pulmonar. A: Toracotomía antero lateral bilateral con sección transversa del esternón (Toracotomía tipo "Clamshell"). B: Aspecto final de la sutura bronquial. C: Sutura del rodete auricular. D: Visión final del implante del primer pulmón. Al fondo de la imagen el pulmón nativo.

\subsubsection{Indicación de CEC durante el TP}

En nuestra serie, la indicación para la utilización de CEC durante el TP en el Hospital Vall d'Hebron se ha realizado si existía algunos de los supuestos descritos a continuación y siguiendo las indicaciones publicadas en la literatura: ${ }^{190}$ 
- $\quad$ De forma programada; corrección de defectos cardíacos durante el TP

- $\quad$ Dificultades durante el acto quirúrgico; lesión de estructuras cardíacas o pulmonares, imposibilidad de colapso pulmonar, etc.

- $\quad$ Disfunción cardíaca y fallo del ventrículo derecho.

- Disfunción hiperaguda del injerto o edema pulmonar tras la implantación del primer pulmón.

- $\quad$ Índice cardíaco $<21 / \mathrm{min} / \mathrm{m}^{2}$.

- $\quad$ Saturación venosa mixta de oxígeno $<60 \%$.

- $\quad$ Saturación arterial de oxígeno $<85 \%$.

- $\quad$ Presión media de arteria pulmonar $<50$ - 60 mmHg.

$-\mathrm{pH}<7.00$

\subsubsection{Protocolo de inmunosupresión}

El régimen de inmunosupresión ha consistido en una triple terapia con corticoesteroides, un anticalcineurínico (cicloscoporina o tacrolimus) y un antimitótico (Azatioprina o Micofenolato mofetil). Hasta el año 2005, la combinación de mantenimiento más utilizada fue la formada por ciclosporina (tacrolimus en los pacientes pediátricos) y azatioprina, pero a partir de ese año se realizó un cambio en el protocolo y el tratamiento inmunosupresor de elección paso a ser tacrolimus y micofenolato mofetil.

El tratamiento con ciclosporina se iniciaba el primer día postrasplante por vía endovenosa y se ajustaba la dosis para mantener niveles entre 200 y $300 \mathrm{ng} / \mathrm{ml}$. Posteriormente, se realizaba el cambio a vía oral cuanto tolerara la ingesta. A largo plazo el objetivo eran mantener una concentración en sangre entre 100 y 200 ng/ml. En los casos en los que se utilizaba tacrolimus, empezaba también la administración por sonda nasogástrica el primer día del postoperatorio. Se ajustaba la dosis en función de los niveles sanguíneos valle con el objetivo de mantenerlos entre 8 y $15 \mathrm{ng} / \mathrm{ml}$ en el postoperatorio. A largo plazo el objetivo eran niveles entre 5 y $10 \mathrm{ng} / \mathrm{ml}$.

La dosis de azatioprina era de 1 a $3 \mathrm{mg} / \mathrm{Kg} /$ día dependiendo del recuento total de leucocitos, que no debía ser inferior a 4 × 109\% , y la administración comenzaba la segunda semana postoperatoria. El micofenolato mofetil se administraba también a partir de la segunda semana, a dosis de 1 a $3 \mathrm{~g} /$ día dividida en dos tomas $\left(600 \mathrm{mg} / \mathrm{m}^{2}\right.$ 
cada 12 horas en los pacientes pediátricos), manteniendo niveles entre 2 y $4 \mu \mathrm{g} / \mathrm{ml}$ y un recuento de leucocitos totales mayor de 4 × $10^{9} / 1$.

Las dos primeras dosis de metilprednisolona se administraban en el quirófano a dosis de $500 \mathrm{mg}$ (10 mg/kg en los pacientes pediátricos) antes de la perfusión de cada pulmón. Posteriormente se administraban $375 \mathrm{mg}$ el primer día $(1 \mathrm{mg} / \mathrm{kg} / \mathrm{día}$ en los pacientes pediátricos) y pauta descendente hasta alcanzar una dosis de mantenimiento de $0.1-0.2 \mathrm{mg} / \mathrm{Kg} /$ día el resto de la vida.

El sirolimus y el everolimus han sido utilizados como terapia de rescate en la disfunción crónica del injerto, en el rechazo agudo refractario o como sustituto de otros agentes inmunosupresores en caso de reacciones adversas.

El régimen inmunosupresor habitual no ha incluido la terapia de inducción con anticuerpos poli o monoclonales, salvo en los pacientes pediátricos en los que se ha utilizado basiliximab.

Los episodios de rechazo agudo, tanto el rechazo tisular como el rechazo humoral, se han tratado con bólus de 5 a metilprednisolona $10 \mathrm{mg} / \mathrm{Kg}$ IV tres días consecutivos. En caso de la persistencia de signos de rechazo agudo, se repetían los bólus de metilprednisolona y posteriormente, si no se resolvía el cuadro, se recurría a los anticuerpos monoclonales o a la plasmaféresis en caso de existir indicios de rechazo mediado por anticuerpos.

\subsubsection{Profilaxis antimicrobiana}

La profilaxis antimicrobiana se ha realizado mediante una triple terapia con antibacterianos, antifúngicos y antivirales.

En todos los pacientes con FQ el tratamiento se ha basado en los gérmenes aislados en los cultivos previos al TP, excepto en 2 pacientes de la serie que no tenían aislamientos microbiológicos previos al TP y en los cuales el tratamiento fue con amoxicilina - ácido clavulánico ( $2 \mathrm{~g}$ cada 8 horas IV). El tratamiento antimicrobiano y su duración, se adaptaba posteriormente en función de los cultivos obtenidos de los pulmones del donante y del receptor. Todos los pacientes recibieron profilaxis para el 
Pneumocystis jirovecii con cotrimoxazol desde el momento en el que toleraron la ingesta oral.

La profilaxis antifúngica para el aspergillus se ha realizado durante todo el periodo del estudio con anfotericina B nebulizada desde el primer día del postoperatorio. Hasta julio del año 2003, se utilizó la anfotericina B desoxicolato, con una pauta de $6 \mathrm{mg}(6 \mathrm{ml})$ cada 8 horas durante los primeros 120 días postoperatorios, posteriormente, una dosis al día el resto de la vida. A partir de julio de 2003, se sustituyó por anfotericina B liposomal que se administraba en dosis de $25 \mathrm{mg}(6 \mathrm{ml}) 3$ veces por semana los primeros 60 días pos trasplante, $25 \mathrm{mg}$ cada semana entre los días 60 y 180 y posteriormente $25 \mathrm{mg}$ cada 2 semanas a partir de los 180 días de forma indefinida.

La profilaxis para el citomegalovirus (CMV) se ha realizado mediante el ganciclovir o el valganciclovir. Hasta marzo de 2003 la profilaxis se realizó con ganciclovir IV a dosis de $5 \mathrm{mg} / \mathrm{Kg} / 12 \mathrm{~h}$ durante los primeros 21 días del postoperatorio y posteriormente con $3 \mathrm{~g} /$ día de ganciclovir vía oral hasta los 120 días en los pacientes con riesgo de infección por CMV intermedio o bajo, y hasta los 240 días en los de alto riesgo (donante seropositivo y receptor seronegativo). A partir de marzo de 2003, la profilaxis se basa en valganciclovir oral. En los primeros días del postoperatorio se administraba una dosis de $5 \mathrm{mg} / \mathrm{Kg} / 12 \mathrm{~h}$ de ganciclovir IV y posteriormente $900 \mathrm{mg} / \mathrm{día}$ de valganciclovir oral $(15 \mathrm{mg} / \mathrm{kg}$ en los niños o en los últimos años con la fórmula: dosis $(\mathrm{mg})=7 \mathrm{x}$ superficie corporal $\left(\mathrm{m}^{2}\right) \mathrm{x}$ aclaramiento de creatinina) cuando el paciente toleraba la ingesta. La dosis se ajustaba en función del aclaramiento de creatinina y se reducía si el recuento leucocitario total se situaba por debajo de $4 \mathrm{x}$ $10^{9} / \mathrm{L}$. La duración de la profilaxis fue la misma que en la primera época, 120 o 240 días en función del grupo de riesgo. En el año 2007, se amplió la duración de la profilaxis a un año en los pacientes de alto riesgo (Donantes seropositivos / Receptores seronegativos).

\subsubsection{Evaluación de receptores y seguimiento postoperatorio}

En la fase previa al trasplante, todos los candidatos fueron evaluados mediante visitas en consulta externa y una serie de exploraciones entre las que se incluyen el estudio de 
la función pulmonar, cardíaca, renal y hepática entre otras. Se obtuvieron muestras respiratorias para cultivo de bacterias, micobacterias y hongos, para decidir si era posible un tratamiento de erradicación previo al trasplante o ajustar la profilaxis en el postoperatorio. Tras completar ésta evaluación, se discutió cada caso en un comité multidisciplinar formado por miembros de los servicios de cirugía torácica, anestesiología, neumología, medicina intensiva y enfermedades infecciosas, para decidir la inclusión o exclusión de cada paciente en la lista de espera de TP.

El día de la intervención, se obtuvieron muestras de las secreciones bronquiales de los pulmones donantes antes de ser implantados, y de los pulmones nativos del receptor una vez extraídos. Se realizaron cultivos para bacterias, micobacterias y hongos, con el fin de ajustar el tratamiento antimicrobiano postoperatorio.

El postoperatorio inmediato ha tenido lugar en la UCI, a la cual los pacientes se trasladaban de quirófano con ventilación mecánica y donde eran controlados por intensivistas y por el equipo de Cirugía Torácica. Tras el destete de la ventilación mecánica, el postoperatorio continuaba en la planta de hospitalización hasta el alta definitiva a domicilio.

Durante el ingreso hospitalario, se realizaron controles rutinarios mediante analíticas sanguíneas generales y control de la antigenemia del CMV semanalmente, niveles de inmunosupresión cada 2 días, radiografías de tórax y cultivos de secreciones respiratorias. Previo al alta hospitalaria, se solicitó una TC torácica, gammagrafía de ventilación - perfusión pulmonar, pruebas de función respiratoria (PFR) y fibrobroncoscopia de control para la revisión de las suturas bronquiales, obtener muestras de secreciones respiratorias y realizar una biopsia pulmonar transbronquial (BTB) para descartar rechazo del injerto.

Los cuidados postoperatorios de los pacientes trasplantados se han llevado a cabo por los servicios de Medicina Intensiva infantil y de adultos, Cirugía Torácica, Neumología de adultos y Neumología pediátrica, con el apoyo de otros servicios colaboradores como el servicio de Infecciosas, Radiología y Fisioterapia. 
Después del alta hospitalaria, los pacientes fueron controlados regularmente en la consulta externa de nuestro centro. La frecuencia de las visitas podía variar en función de las diferentes complicaciones surgidas en los pacientes. La cadencia básica fue cada 1 a 2 semanas durante los primeros 6 meses, cada 2 a 4 semanas entre los 6 meses y el año, y a partir del primer año cada 2 o 3 meses sin superar los 4 meses entre dos visitas. En cada visita se solicitaba una analítica sanguínea general con niveles sanguíneos de inmunosupresores, antigenemia o Reacción en cadena de la polimerasa (PCR) para CMV en sangre y unas PFR. Las muestras respiratorias para el cultivo de bacterias, micobacterias y hongos, se obtenían en caso sintomatología sugestiva de infección respiratoria. Se investigaba en cada control en consultas externa la presencia de efectos adversos relacionados con la medicación inmunosupresora o la profilaxis antimicrobiana.

El programa de vigilancia de la infección por CMV seguía un esquema similar al de las visitas en consulta externa. Hasta el año 2005 la monitorización de la viremia por CMV se realizaba mediante la prueba de antigenemia pp65, que consiste en la detección por inmunofluorescencia de la fosfoproteína de $65 \mathrm{kD}$ (pp65) en los leucocitos polimorfonucleares en sangre periférica. A partir del año 2005, se generalizó en nuestro centro la utilización del método molecular cuantitativo para la detección de secuencias de ADN del CMV por la técnica PCR. Los controles para la detección de viremia por CMV se ha solicitado cada 1 - 2 semanas hasta el día 180 y cada 2 - 4 semanas hasta el primer año. El tratamiento anticipado en caso de viremia se ha realizado a partir de las 10 células/100.000 leucocitos polimorfonucleares en la prueba de la antigenemia pp65. Se ha administrado ganciclovir IV a dosis de $5 \mathrm{mg} / \mathrm{Kg} / 12 \mathrm{~h}$ o valganciclovir oral a dosis de $900 \mathrm{mg} / 12 \mathrm{~h}(15 \mathrm{mg} / \mathrm{kg} / 12$ horas en los pacientes pediátricos) a partir del año 2003, durante 2 - 3 semanas.

En todos los pacientes en los que era posible, se ha realizado un fibrobroncoscopia de vigilancia entre la cuarta y sexta semana postrasplante, habitualmente previo al alta hospitalaria. Además, se realizaba una fibrobroncoscopia siempre que tuviera una indicación clínica de insuficiencia respiratoria no explicada por alguna causa, diminución de los valores de las PFR no justificada o sospecha de enfermedad pulmonar o bronquial. 
En cada fibrobroncoscopia se han obtenido muestras de aspirado bronquial, lavado broncoalveolar para examen celular, tinciones de Gram y de bacilos ácidoalcohol resistentes, cultivos de bacterias, micobacterias, hongos, Legionella spp y CMV. Así mismo, se obtenían BTB para el estudio anatomopatológico y realizar tinciones de inmunohistoquímica.

\subsubsection{Diagnóstico del rechazo agudo}

El rechazo agudo (RA) es una de las complicaciones más frecuentes del TP. Es una de las causas principales de insuficiencia respiratoria y deterioro clínico en el periodo postoperatorio temprano y lo que es más importante, se relaciona el RA como uno de los factores de riesgo para el desarrollo de DCI. ${ }^{191-193}$

La biopsia transbronquial (BTB) ha sido la prueba definitiva para el diagnóstico del RA. ${ }^{194-196}$ La lesión anatomopatológica principal es un infiltrado perivascular e intersticial de células mononucleares. Se han establecido cuatro grados de RA en función de la severidad del rechazo, basándose fundamentalmente en la intensidad del infiltrado y la extensión de las células mononucleares de la adventicia vascular hacia los septos alveolares. Para la clasificación del RA se han tenido en cuenta los criterios establecidos por las guías internacionales. Los grados son A1 (mínimo), A2 (leve), A3 (moderado) y A4 (severo). ${ }^{197}$

El tratamiento estándar para los episodios de RA presentados en los pacientes de nuestra serie ha sido metilprednisolona a dosis de 10 - $15 \mathrm{mg} / \mathrm{Kg} /$ día durante tres días consecutivos y posteriormente con dosis de $1 \mathrm{mg} / \mathrm{Kg} /$ día en pauta descendente.

\subsubsection{Diagnóstico de la disfunción crónica del injerto}

La DCI pulmonar se ha diagnosticado en base al funcionalismo pulmonar, de acuerdo a los criterios del consenso del año 2001 de la ISHLT $^{198}$. Se ha definido como una disminución permanente del $\mathrm{FEV}_{1}$ igual o mayor del $80 \%$ con respecto al valor basal, una vez descartadas otras posibles causas de alteración de los valores espirométricos.

Las complicaciones del injerto que más frecuentemente pueden alterar el $\mathrm{FEV}_{1}$ son el rechazo agudo, la infección respiratoria, una complicación bronquial o la recurrencia de la enfermedad de base. En caso de aparecer alguna de estas 
complicaciones, no se ha diagnosticado una DCI hasta considerar que la situación clínica aguda estaba superada y que la complicación estaba tratada correctamente.

Para considerar la caída del $\mathrm{FEV}_{1}$ como permanente, se ha exigido la existencia de al menos dos valores del $\mathrm{FEV}_{1}$ disminuidos separados por un mínimo de 3 semanas. Los valores del $\mathrm{FEF}_{25-75}$ también debían estar disminuidos de forma constante para confirmar el diagnóstico de DCI.

No se ha exigido la confirmación histológica para el diagnóstico de la DCI pero se han recogido todos los casos en los que la alteración del $\mathrm{FEV}_{1}$ se acompañara de hallazgos anatomopatológicos compatibles con una bronquiolitis obliterante, la lesión característica de la DCI.

\subsubsection{Variables del estudio}

Las variables del presente estudio se agrupan de acuerdo al momento de TP, variables previas a la realización del TP, variables del propio acto quirúrgico, la fase postoperatoria y las variables de seguimiento a largo plazo incluyendo el funcionalismo pulmonar.

Las variables previas al TP son las siguientes:

- La mutación genética de los pacientes TP por FQ $\left(\Delta \mathrm{F}_{508}, \mathrm{G} 542 \mathrm{X}\right.$, N1303K, R1066C, 2789+5G>A).

- $\quad$ El tiempo en lista de espera para trasplante, es el intervalo de tiempo entre la fecha de inicio de lista de espera y la fecha del TP.

- $\quad$ IMC es la relación entre el peso y la talla de los pacientes según la fórmula siguiente:

$$
\mathrm{IMC}=\frac{\text { Peso }(\mathrm{Kg})}{\operatorname{Talla}^{2}(\mathrm{~m})}
$$

- $\quad$ De acuerdo al IMC y según la clasificación de la $\mathrm{OMS}^{199}$ los pacientes se dividieron en:

$\begin{array}{ll}> & \text { Desnutrición severa }(<16) \mathrm{Kg} / \mathrm{m}^{2} \\ > & \text { Desnutrición moderada }(16-16.99) \mathrm{Kg} / \mathrm{m}^{2} \\ > & \text { Desnutrición leve }(17-18.49) \mathrm{Kg} / \mathrm{m}^{2} \\ >\quad & \text { Peso normal }(18.5-24.00) \mathrm{Kg} / \mathrm{m}^{2}\end{array}$


- $\quad$ Edad en años cumplidos en el momento del trasplante.

- $\quad$ El grupo sanguíneo (0, A, B o AB)

- $\quad$ El sexo de los receptores

- $\quad$ Diabetes Mellitus, presencia o ausencia de DM previo al TP

- Insuficiencia pancreática exocrina, presencia o ausencia de IPE previa al $\mathrm{TP}$

- $\quad \mathrm{PaO}_{2}$. Medida por gasometría arterial en la evaluación preoperatoria. Es la presión parcial de oxígeno medida en milímetros de mercurio $(\mathrm{mmHg})$.

- $\quad \mathrm{PaCO}_{2}$. Medida por gasometría arterial en la evaluación preoperatoria. Es la presión parcial de dióxido de carbono medida en $\mathrm{mmHg}$.

- $\quad \mathrm{FEV}_{1}$ pre trasplante. Es el $\mathrm{FEV}_{1}$ previo al TP medido en la evaluación preoperatoria. Se expresa en volumen absoluto (mililitros) y el porcentaje sobre el teórico.

- $\quad$ FVC pre trasplante. Es el FVC previo al TP medido en la evaluación preoperatoria. Se expresa en volumen absoluto (mililitros) y el porcentaje sobre el teórico.

- 6WT. Test realizado durante el preoperatorio. Mide la distancia máxima que puede recorrer el paciente en 6 minutos. Durante la prueba, se realiza una monitorización continua de la saturación de oxígeno con un pulsioximetro portátil. La distancia caminada durante 6 minutos fue registrada y se obtuvo el valor predicho en comparación con los valores normales de un adulto sano. La medición se realiza en metros. ${ }^{200}$

- VMNI. Presencia o ausencia de dicha terapia previa al TP. Según criterios de la Sociedad Española de Neumología y Cirugía Torácica. ${ }^{201}$

- Oxigenoterapia. Presencia o ausencia de requerimiento de oxígeno suplementario previo al trasplante. Criterio de oxigenoterapia: Hipoxemia grave $\left(\mathrm{PaO}_{2} \leq 60 \mathrm{mmHg}\right){ }^{202}$

- Aislamientos microbiológicos. Agentes microbiológicos aislados en cultivos de esputo previo a la realización del TP.

- Hospitalizaciones último año. Número de ingresos hospitalarios en los 12 meses previos al trasplante. 
Las variables relacionadas con el acto quirúrgico del TP son las siguientes:

- $\quad$ Era del trasplante. Periodo de tiempo en el que se realizó el TP. Se ha dividido el tiempo en 2 épocas, desde 1992 hasta 2002 y desde 2003 hasta 2011. La asignación de las dos épocas se realizó en base al cambio en la solución de preservación pulmonar de Euro-Collins ${ }^{\circledR}$ a Perfadex ${ }^{\circledR}$.

- Tiempo de isquemia. Se ha tenido en cuenta el tiempo de isquemia del pulmón derecho, pulmón izquierdo y tiempo de isquemia total desde el inicio de la solución de preservación en el donante hasta la reperfusión del injerto en el receptor.

- $\quad$ CEC. Se ha categorizado en función de la utilización o no de CEC en el acto quirúrgico del implante pulmonar. Según criterios definidos previamente. $^{190}$

- $\quad$ Tiempo de CEC. Es el tiempo en minutos desde el inicio de la circulación extracorpórea hasta la retirada completa del soporte extracorpóreo.

- Reducción del injerto. La presencia o ausencia de técnicas quirúrgicas destinadas a reducir el parénquima pulmonar por discrepancia de tamaños entre donante y receptor.

Se ha definido como "postoperatorio" al periodo de tiempo que comprende desde el acto quirúrgico hasta el alta hospitalaria.

Las variables relacionadas con el postoperatorio del TP son las siguientes:

- Re intervención. Presencia o ausencia de una nueva intervención en el postoperatorio del TP.

- Causa de re intervención. Definen cuales fueron los diagnósticos que motivaron la nueva cirugía después del TP.

- $\quad$ Días de VM. Los días transcurridos desde el TP hasta el día en el que se retira completamente el soporte ventilatorio.

- Días de estancia en UCI. Los días transcurridos desde el día del TP hasta la fecha de alta a planta de hospitalización.

- Ventilación mecánica prolongada. Ventilación mecánica > a 21 días. ${ }^{203}$

- Estenosis bronquial (EB). Presencia o ausencia de cualquier grado de disminución de la luz bronquial posterior al TP.

- Dehiscencia bronquial (DB) parcial. Presencia o ausencia de fallo que no compromete la totalidad de la sutura bronquial en el postoperatorio del TP. 
- DB total. Presencia o ausencia de fallo completo de la sutura bronquial en el postoperatorio del TP.

- Tratamiento de la complicación bronquial. En los pacientes que presentaron cualquier tipo de complicación bronquial, si el tratamiento fue conservador, dilataciones neumáticas para las estenosis +/- prótesis endobronquial y para los pacientes que presentaron dehiscencia de sutura si el tratamiento fue conservador o si requirió la colocación de prótesis endobronquial.

- $\quad \mathrm{FEV}_{1}$ pos trasplante. Es la primera determinación de $\mathrm{FEV}_{1}$ posterior al TP. Se expresa en volumen absoluto (mililitros) y el porcentaje sobre el teórico.

- $\quad$ FVC pos trasplante. Es la primera determinación de FVC posterior al TP. Se expresa en volumen absoluto (mililitros) y el porcentaje sobre el teórico.

- Infección respiratoria: Presencia o ausencia de infección del tracto respiratorio durante el ingreso hospitalario posterior al TP

- $\quad$ Rechazo agudo. Presencia o ausencia de rechazo diagnosticado durante el postoperatorio según los criterios establecidos por la ISHLT. ${ }^{197}$

- Método diagnóstico del RA. Si el diagnóstico se realizó mediante datos clínicos exclusivamente o si el diagnóstico fue mediante BTB, por la presencia de un infiltrado mononuclear peri vascular e intersticial. ${ }^{197}$

- $\quad$ Paresia frénica. Ausencia parcial o total de movimiento diafragmático.

- Rechazo crónico (RC). Síndrome clínico patológico caracterizado histológicamente por una bronquiolitis obliterativa según criterios previamente establecidos por la ISHLT. ${ }^{198}$

- Días hasta RC. El intervalo de tiempo transcurrido desde el TP hasta el diagnóstico de RC.

- $\quad$ Mejor funcionalismo pulmonar. El tiempo transcurrido desde el TP hasta que se obtiene el mejor registro de pruebas funcionales durante el seguimiento.

- Mejor $\mathrm{FEV}_{1}$ pos trasplante. Es la mayor determinación de $\mathrm{FEV}_{1}$ posterior al TP. Se expresa en volumen absoluto (mililitros) y el porcentaje sobre el teórico. 
- $\quad$ Mejor FVC pos trasplante. Es la mayor determinación de FVC posterior al TP. Se expresa en volumen absoluto (mililitros) y el porcentaje sobre el teórico.

\subsubsection{Recogida de datos}

Todos los datos fueron recogidos en una hoja de cálculo (Excel ${ }^{\circledR}$ 2016, Microsoft Corporation, Redmond, WA), que posteriormente se introdujeron en un programa informático (Stata 13.1, StataCorp ${ }^{\circledR}$ 2013) para su posterior análisis estadístico.

\subsubsection{Análisis estadístico}

Para la descripción de las variables nominales se utilizaron medidas de frecuencias absolutas y porcentajes. Las variables cuantitativas se expresaron mediante estadísticos de centralización (media) y de dispersión (desviación estándar). Las comparaciones entre las variables en diferentes grupos se realizó mediante las pruebas de t de Student, $\mathrm{X}^{2}$, U de Mann-Whitney o test exacto de Fisher según corresponda al tipo de variable. El análisis univariante se ha realizado mediante el modelo de regresión de riesgos proporcionales de Cox.

La estimación de probabilidad de supervivencia se realizó mediante el método de Kaplan-Meier. El tiempo de supervivencia se calculó desde la fecha del TP hasta la fecha de muerte o la fecha de último seguimiento.

El análisis multivariante de factores de riesgo de CEC y de muerte se ha llevado a cabo mediante el modelo de regresión proporcionales de Cox y se han incluido todas las variables del análisis univariante. Los modelos se han construido con el método de selección por pasos con introducción de las variables hacia adelante (forward stepwise).

El criterio de entrada de las variables ha sido un nivel de significación igual o superior a 0,1 en el contraste de verosimilitudes y para indicar significación se ha exigido una p menor 0,05 . El valor del riesgo para cada variable se expresa con el Hazard Ratio (HR) y el intervalo de confianza (IC) al $95 \%$. La HR se definió como la relación entre las posibilidades de muerte en el grupo con el factor de riesgo presente y las posibilidades de muerte en el grupo sin dicho factor de riesgo. 
Dado que la probabilidad de requerir CEC puede ser diferente entre los individuos y que los factores que condicionan la CEC también pueden condicionar la supervivencia, se ha utilizado un propensity score para controlar la posible confusión de éstos factores. A partir de un modelo de regresión logística se ha calculado para cada individuo la probabilidad de requerir CEC a partir de las variables de cada uno de los sujetos. De acuerdo a las predicciones del modelo logístico se obtuvieron pesos como el inverso de la probabilidad de la necesidad de CEC y se ajustó un modelo de Cox ponderado para evaluar el efecto de la CEC en la supervivencia.

El programa informático utilizado para el análisis estadístico ha sido el Stata 13.1 (StataCorp ${ }^{\circledR}$ 2013. Stata Statistical Software. College Station, TX.) 

5. RESULTADOS 



\subsection{ANÁLISIS DESCRIPTIVO DE LA SERIE GLOBAL}

Entre abril de 1992 y septiembre de 2011 se realizaron 66 TP por FQ en el Hospital Vall d'Hebron. Para el presente estudio se excluyeron 2 casos de retrasplantes pulmonares, por lo que la serie final analizada se basa en 64 pacientes. (Figura 11)

Se presentan los resultados del estudio descriptivo en la fase previa al TP, el propio acto quirúrgico y por último los resultados postoperatorios. El seguimiento medio de toda la serie fue de 59,6 meses.

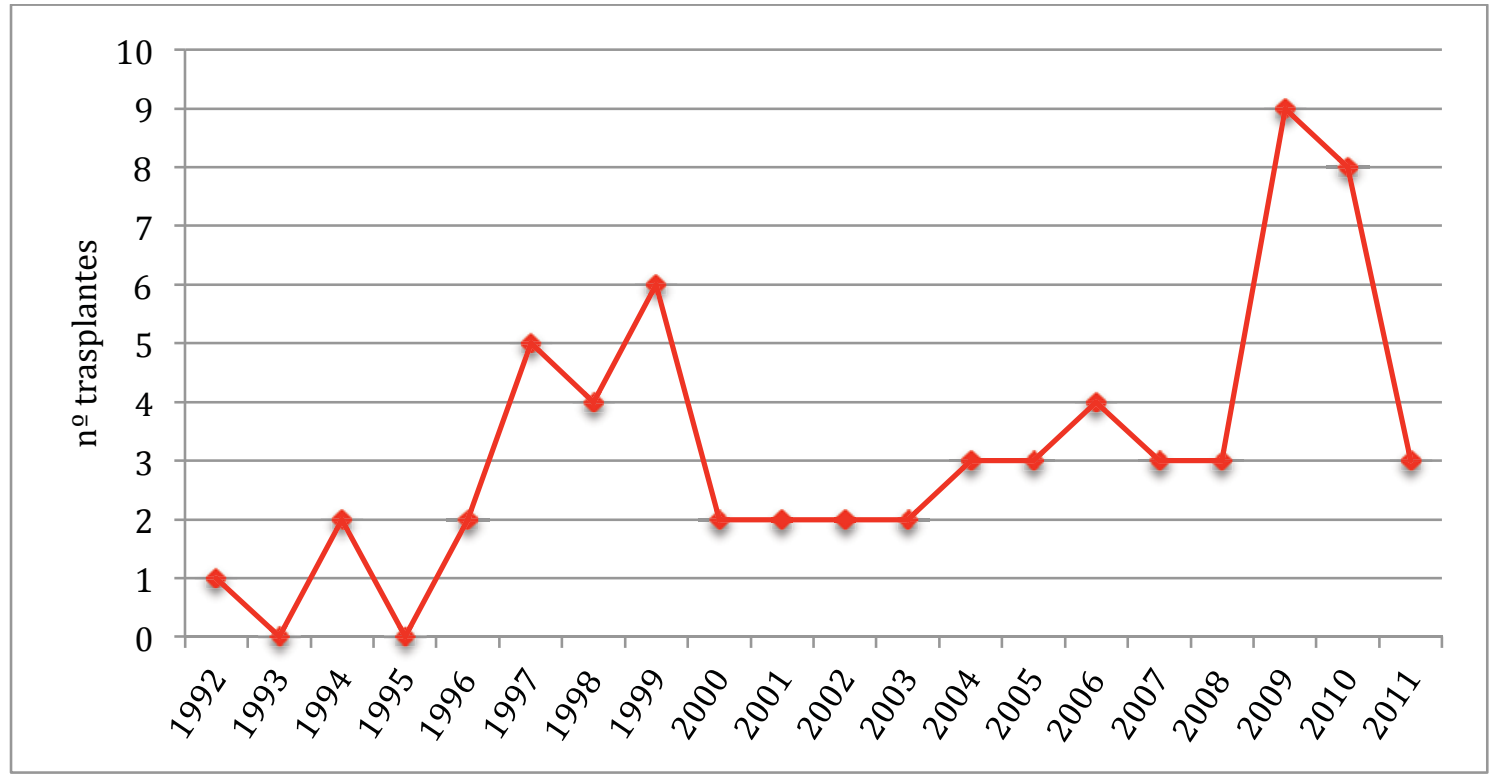

Figura 11. Evolución del número de trasplantes por FQ incluidos en el estudio. 


\subsubsection{Análisis descriptivo previo al trasplante pulmonar}

\section{Época del trasplante}

Durante la primera época se realizaron $26(40,3 \%)$ TP mientras que durante la segunda época dicho número aumentó a 38 (59,4\%). (Figura 12)

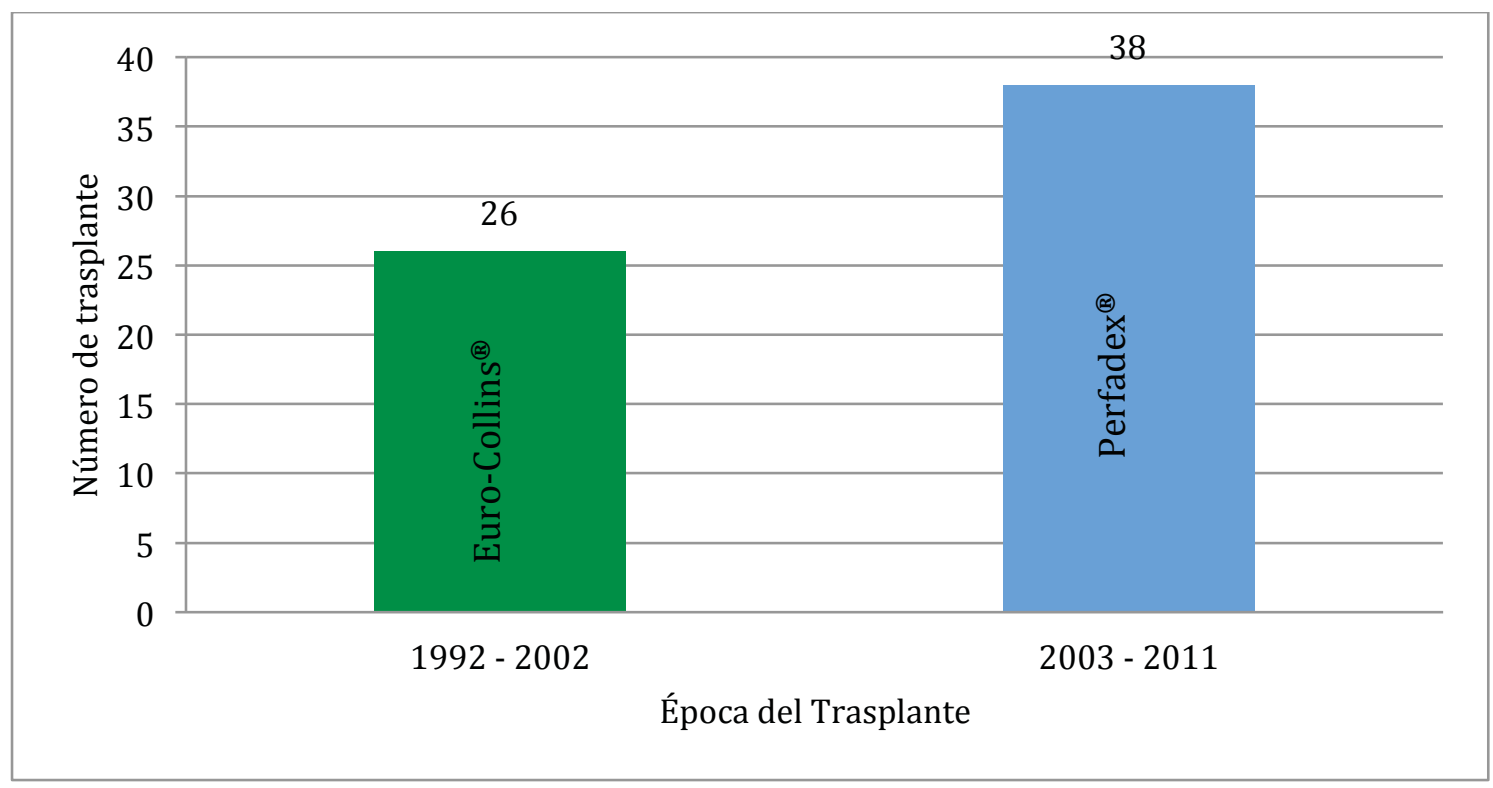

Figura 12. TP por FQ divididos por épocas según el año y la solución de preservación utilizada.

\section{Edad}

La edad media fue de 20,7 \pm 8 con un mínimo de 9 y un máximo de 49 años. Veintiséis (40,6\%) pacientes corresponden al programa de TP infantil (0 - 17 años) con una media de edad de 13,9 (r: 9 - 17) años. Los 38 pacientes restantes corresponden al programa de TP de adultos (18 - 49 años) con una media de edad de 35,3 (r: 18 - 49) años. (Figura 13) 


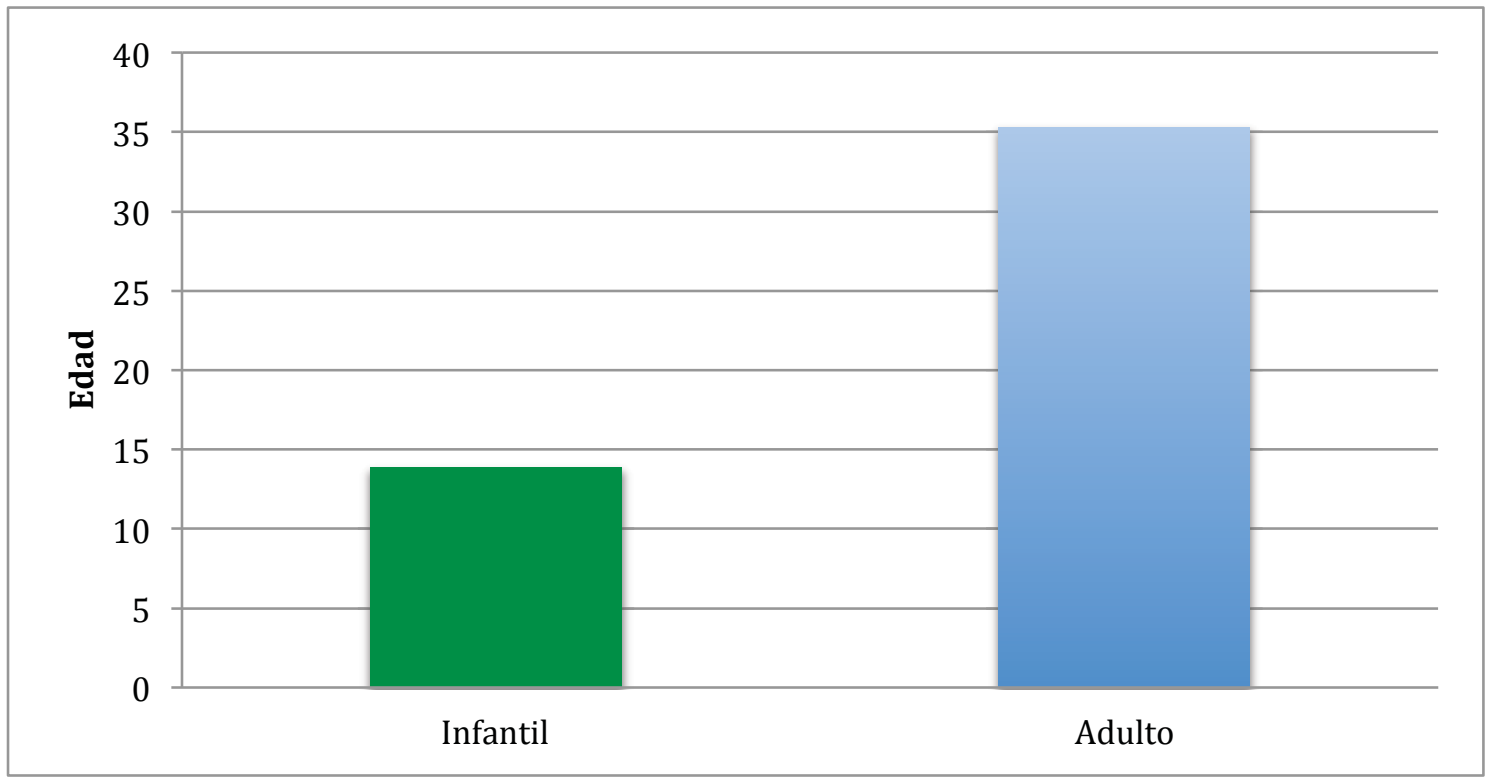

Figura 13. TP por FQ divididos por el grupo etario.

Sexo

De los 64 TP, 33 (51,5\%) eran del sexo masculino y 31 (48,5\%) del sexo femenino, dando lugar a una proporción hombre / mujer en el TP por FQ de 1,06/1. (Figura 14)

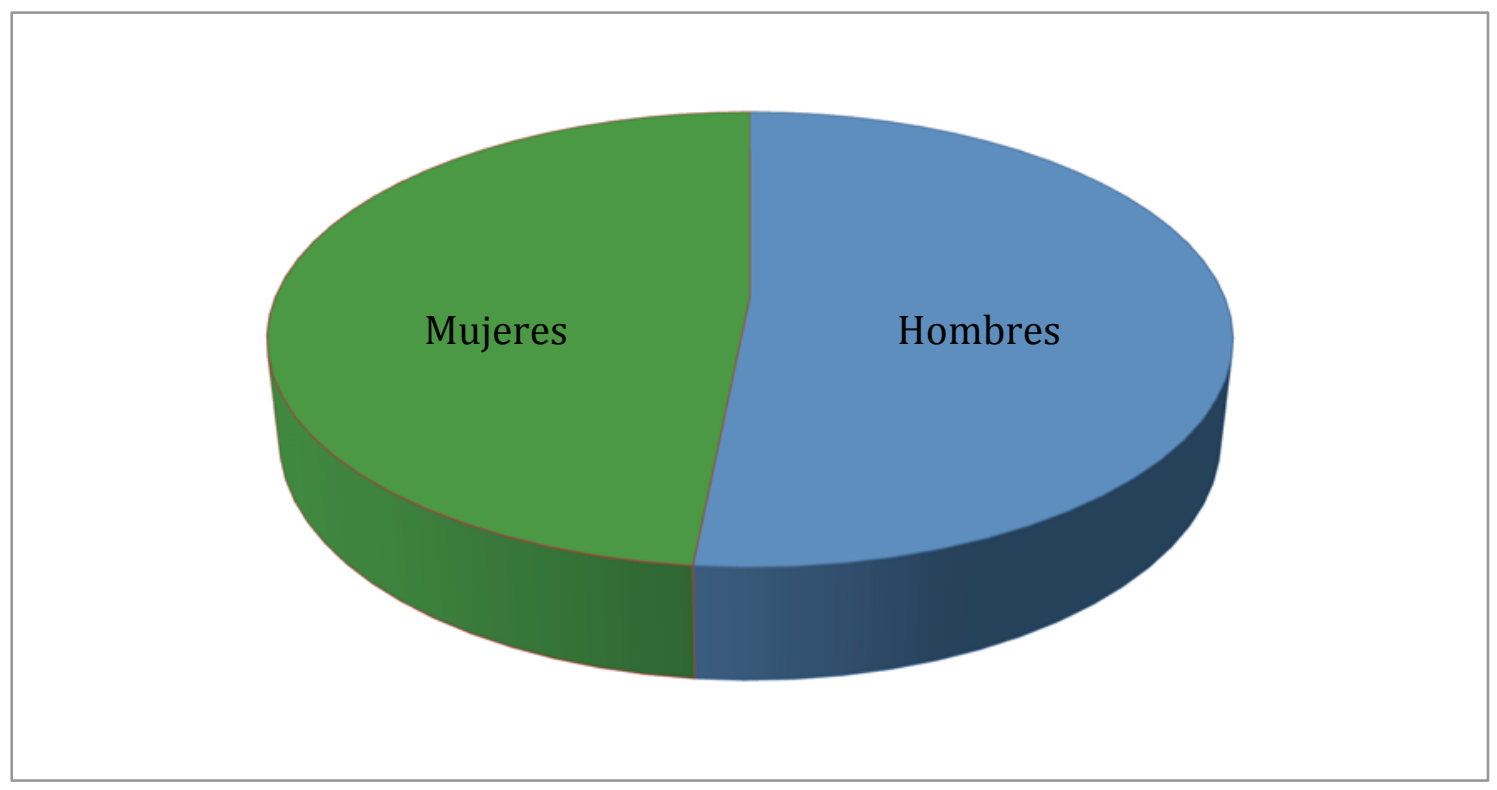

Figura 14. Número de receptores divididos por sexo. 


\section{Grupo sanguíneo}

El grupo sanguíneo más frecuente en los receptores fue el "A" (36 pacientes), seguido del grupo "0" (21 pacientes). (Figura 15)

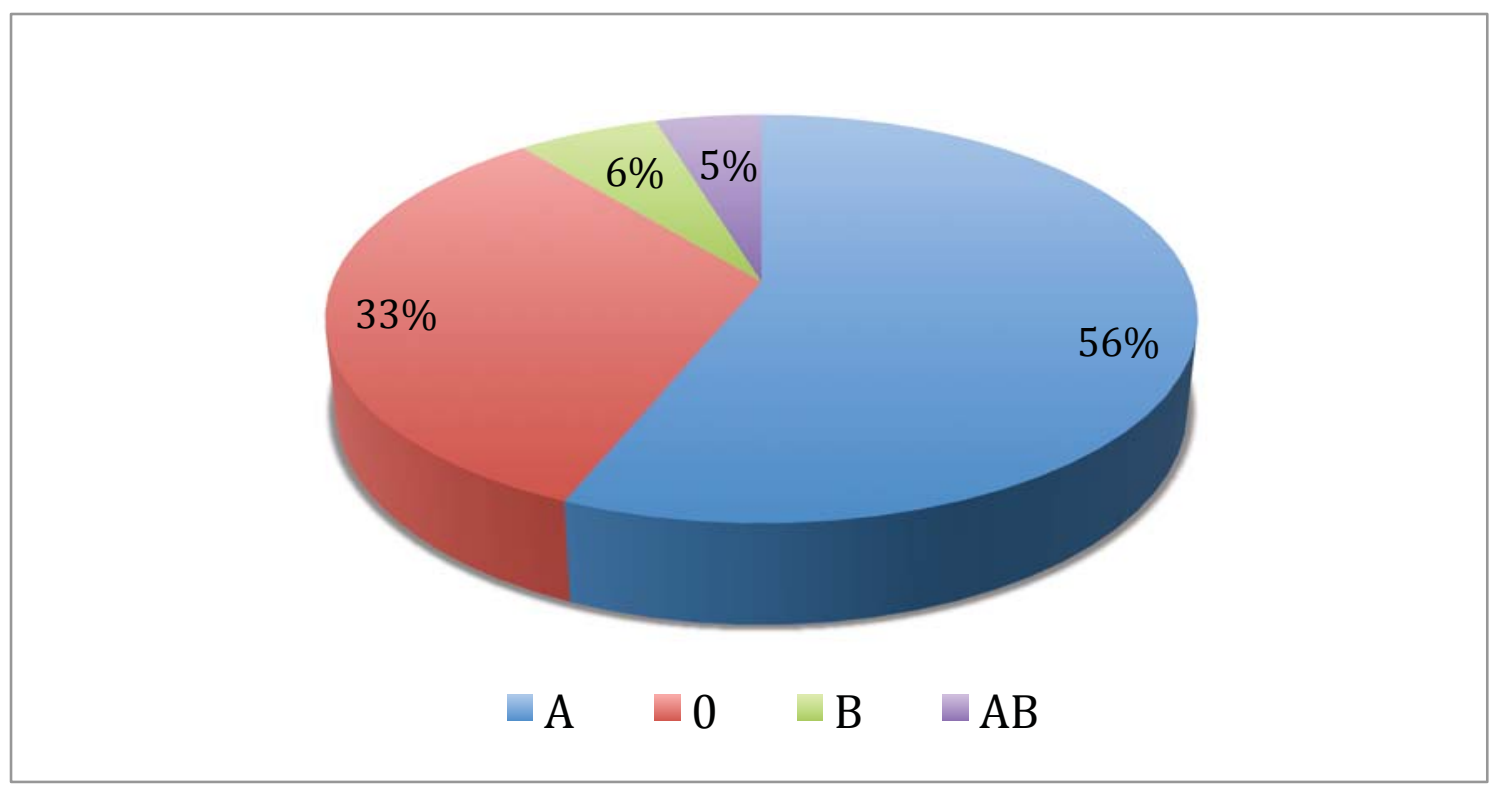

Figura 15. Distribución del grupo sanguíneo de los pacientes con FQ que recibieron un TP.

Antropometría e Índice de masa corporal (IMC)

El peso medio de los receptores fue de 41 con un mínimo de 13 y un máximo de $80 \mathrm{Kg}$. La talla media fue de 1,5 con un rango de 0,8 a 1,91 metros.

Respecto al IMC la media fue de 16,9 $\pm 2,7$ (r: 10 - 22,9) $\mathrm{Kg} / \mathrm{m}^{2}$. Según la clasificación de la $\mathrm{OMS}^{199}, 25$ pacientes presentaban desnutrición severa. (Tabla I)

\section{Mutación genética}

La mutación más frecuente de la serie fue la $\Delta \mathrm{F}_{508}$ en $36(56,2 \%)$ de los receptores y al momento del TP, 19 (29,6\%) pacientes no tenían registro del tipo de mutación genética. (Figura 16) 


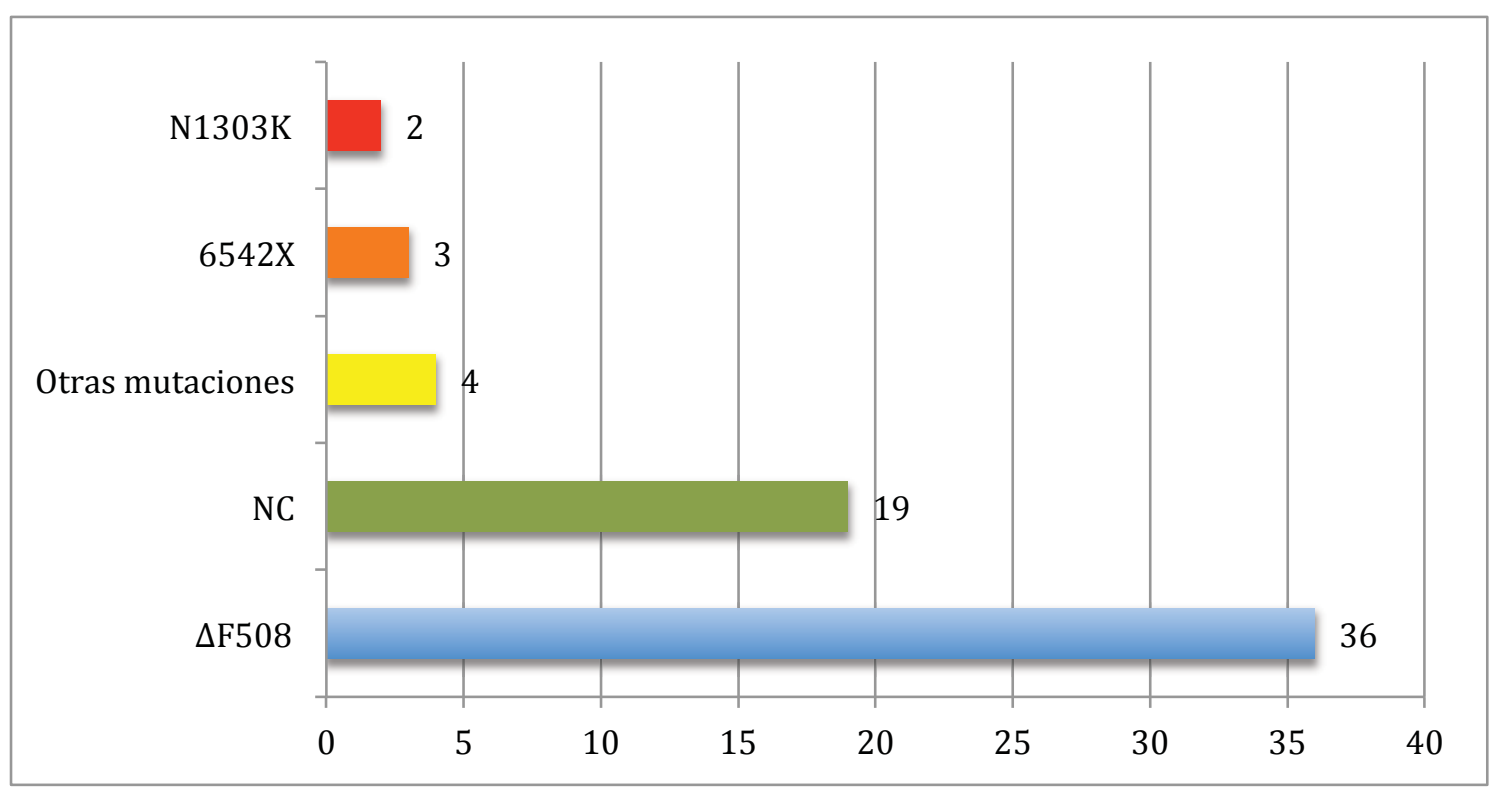

Figura 16. Mutaciones de la serie global de pacientes TP por FQ. $\Delta$ F508, Deleción de nucleótidos que codifican fenilalanina en la posición 508; NC, mutación no conocida.

\section{Tiempos de espera}

El tiempo transcurrido entre el diagnóstico clínico o genético de FQ y el TP fue de 181,7 $\pm 67,2$ (r: 12 - 322) meses, con un tiempo medio en lista de espera para TP de 9,3 $\pm 8,5$ (r: 0 - 34) meses. El grupo de trasplante infantil tuvo un tiempo medio de lista de espera de 9 (r: 0,7 - 34,7) meses mientras que la media del grupo de adulto fue de 10,5 (r: $0,1-30,2)$ meses.

\section{Patología previa y requerimiento de oxígeno}

Del total de la serie, $20(31,2 \%)$ tenían DM en el momento del TP y $50(78,1 \%)$ padecían de insuficiencia pancreática exocrina.

Respecto a la necesidad de oxígeno previo al TP, 51 (79,6\%) pacientes eran portadores de oxigenoterapia crónica domiciliaria y $13(20,3 \%)$ pacientes requerían VMNI previo al TP.

El tiempo medio de necesidad de oxigenoterapia previo al TP fue de 15,9 $\pm 21,4$ (r: 1 - 96) meses.

Aislamientos microbiológicos previos al trasplante. 
En el momento de la inclusión en lista de espera para TP, el 93,7\% de los receptores estaban colonizados por algún germen o múltiples combinaciones de bacterias y hongos.

De los colonizados, el $89 \%$ era por Pseudomonas aeruginosa y solo 2 (3.1\%) receptores no tenían ningún aislamiento microbiológico en el momento del trasplante. Cinco pacientes estaban colonizados por Burkhloderia cepacia $(7,8 \%)$ y uno por $M$. Abscessus. Durante el postrasplante, 4 pacientes con B. Cepacea y el paciente con $M$. Abscesus fallecieron. (Figura 17)

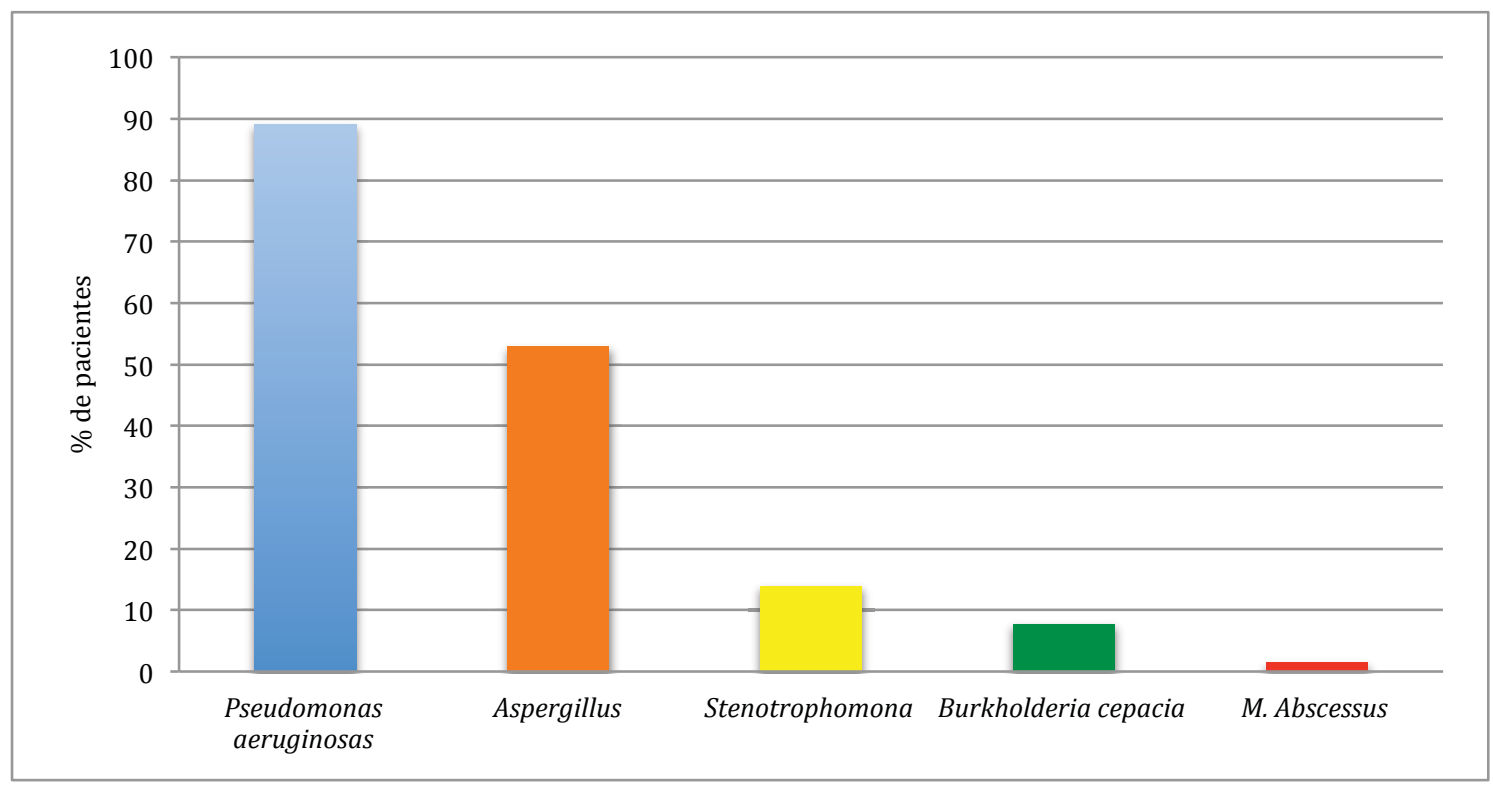

Figura 17. Aislamientos microbiológicos de los receptores previo al TP.

\section{Funcionalismo pulmonar}

En el momento del TP los pacientes presentaban insuficiencia respiratoria crónica grave con patrón de obstrucción severa con una media de $\mathrm{PaO}_{2}$ de $60 \pm 12$ (r: 27 - 85) mmHg y de $\mathrm{PaCO}_{2}$ de 47,8 \pm 13 (r: 30 - 84) mmHg. Respecto a las pruebas funcionales respiratorias (PFR), la media en porciento del predicho para FVC fue de 38,4 \pm 14 (r: 14 - 82) y de $\mathrm{FEV}_{1} 26 \pm 10$ (r: 13 - 60).

En el 6WT los pacientes recorrieron una distancia media de $323 \pm 111$ (r: $72-$ 636) metros. 
Hospitalizaciones durante el año previo al TP

Los receptores tuvieron una media de 2,5 $\pm 1,8$ ingresos hospitalarios en los 12 meses previos al TP. Con un mínimo de 0 y un máximo de 12 ingresos hospitalarios en un paciente de la serie.

\section{Relación de las diferentes variables respecto a la mortalidad}

De todas las variables analizadas, los pacientes con la mutación $\Delta \mathrm{F}_{508}$ tienen mayor mortalidad en comparación con el resto de mutaciones $(\mathrm{p}=0,040)$. Dicho resultado se puede explicar por la mayor prevalencia de dicha mutación en nuestra serie.

La segunda variable que alcanza la significación estadística es el tiempo en lista de espera de TP $(p=0,04)$. Los pacientes que permanecen menos tiempo en lista de espera tienen mayor mortalidad, probablemente por la mayor gravedad de dichos pacientes.

A continuación se presentan los resultados del análisis de las diferentes variables analizadas y su relación con la mortalidad. (Tabla I) 


\section{RESULTADOS}

Mortalidad

\begin{tabular}{|c|c|c|c|c|}
\hline \multirow[b]{2}{*}{ Variable $^{\mathrm{a}}$} & & \multirow[b]{2}{*}{ Total } & \multirow[b]{2}{*}{ Valor $\mathrm{p}$} \\
\hline & No & Si & & \\
\hline \multicolumn{5}{|l|}{ Era del TP } \\
\hline $1992-2002$ & $8(27,5 \%)$ & $18(51,4 \%)$ & $26(40,6 \%)$ & \multirow[t]{2}{*}{0,074} \\
\hline $2003-2011$ & $21(72,4 \%)$ & $17(58,5 \%)$ & $38(59,3 \%)$ & \\
\hline Edad & $20(7,2)$ & $21,31(8,7)$ & $20,72(8)$ & 0,710 \\
\hline \multicolumn{5}{|l|}{ Sexo } \\
\hline Mujer & $15(51,7 \%)$ & $16(45,7 \%)$ & $31(48,4 \%)$ & \multirow[t]{2}{*}{0,802} \\
\hline Hombre & $14(48,2 \%)$ & $19(54,2 \%)$ & $33(51,5 \%)$ & \\
\hline Peso (Kg) & $40,9(11,9)$ & $41,71(13,2)$ & $41,34(12,5)$ & 0,798 \\
\hline Talla (m) & $1,55(0,1)$ & $1,54(0,1)$ & $1,54(0,1)$ & 0,882 \\
\hline $\operatorname{IMC}\left(\mathrm{Kg} / \mathrm{m}^{2}\right)$ & $16,83(3)$ & $17,09(2,5)$ & $16,97(2,7)$ & 0,632 \\
\hline \multicolumn{5}{|l|}{ Grado nutricional $^{199}$} \\
\hline Desnutrición severa & $12(41,3 \%)$ & $13(37,1 \%)$ & $25(39 \%)$ & \multirow[t]{4}{*}{0,921} \\
\hline Desnutrición moderada & $3(10,3 \%)$ & $5(14,2 \%)$ & $8(12,5 \%)$ & \\
\hline Desnutrición leve & $6(20,6 \%)$ & $6(17,1 \%)$ & $12(18,7 \%)$ & \\
\hline Peso normal & $8(27,5 \%)$ & $11(31,4 \%)$ & $19(29,6 \%)$ & \\
\hline \multicolumn{5}{|l|}{ Mutación } \\
\hline$\Delta \mathrm{F}_{508}$ & $21(72,4 \%)$ & $15(42,8 \%)$ & $36(56,2 \%)$ & 0,040 \\
\hline $6542 \mathrm{X}$ & $0(0 \%)$ & $3(8,5 \%)$ & $3(4,6 \%)$ & \multirow[b]{5}{*}{0,609} \\
\hline N1303K & $1(4,4 \%)$ & $1(2,8 \%)$ & $2(3,1 \%)$ & \\
\hline Otras & $0(0 \%)$ & $4(11,4 \%)$ & $4(6,2 \%)$ & \\
\hline No conocido & $7(24,1 \%)$ & $12(34,2 \%)$ & $19(29,6 \%)$ & \\
\hline Diagnóstico - TP & $187,8(65,60)$ & $178,6(70,5 \%)$ & $181,7(67,2)$ & \\
\hline Lista de espera TP & $11,7(8,9)$ & $7,3(7,9)$ & $9,3(8,5)$ & 0,041 \\
\hline \multicolumn{5}{|l|}{ DM } \\
\hline No & $21(72,4 \%)$ & $23(65,7 \%)$ & $44(68,7 \%)$ & \multirow[t]{2}{*}{0,600} \\
\hline $\mathrm{Si}$ & $8(27,5 \%)$ & $12(34,2 \%)$ & $20(31,2 \%)$ & \\
\hline \multicolumn{5}{|l|}{$\overline{\mathrm{IPE}}$} \\
\hline No & $3(10,3 \%)$ & $11(31,4 \%)$ & $14(21,8 \%)$ & \multirow[t]{2}{*}{0,067} \\
\hline $\mathrm{Si}$ & $26(89,6 \%)$ & $24(68,5 \%)$ & $50(78,1 \%)$ & \\
\hline \multicolumn{5}{|l|}{ Oxigenoterapia } \\
\hline No & $8(27,5 \%)$ & $5(14,2 \%)$ & $13(20,3 \%)$ & \multirow[t]{2}{*}{0,224} \\
\hline $\mathrm{Si}$ & $21(72,4 \%)$ & $30(85,7 \%)$ & $51(79,6 \%)$ & \\
\hline \multicolumn{5}{|l|}{ VMNI } \\
\hline No & $23(79,3 \%)$ & $28(80 \%)$ & $51(79,6 \%)$ & \multirow[t]{2}{*}{1,000} \\
\hline $\mathrm{Si}$ & $6(20,6 \%)$ & $7(20 \%)$ & $13(20,3 \%)$ & \\
\hline $\mathrm{PaO}_{2}(\mathrm{mmHg})$ & $60,8(13)$ & $60,4(10,9)$ & $60,6(11,9)$ & 0,909 \\
\hline $\mathrm{PaCO}_{2}(\mathrm{mmHg})$ & $44,7(9,6)$ & $50,8(15,5)$ & $47,8(13,1)$ & 0,272 \\
\hline \multicolumn{5}{|l|}{ FVC } \\
\hline $\mathrm{mL}$ & $1460,8(563,6)$ & $1443,5(671,6)$ & $1452,7(617,2)$ & 0,919 \\
\hline$\%$ & $40(14,9)$ & $36,9(12,8)$ & $38,3(13,8)$ & 0,411 \\
\hline \multicolumn{5}{|l|}{$\mathrm{FEV}_{1}$} \\
\hline $\mathrm{mL}$ & $872,1(497,4)$ & $846,9(465,3)$ & $858,8(476,4)$ & 0,866 \\
\hline$\%$ & $27,3(10,8)$ & $25,6(9,3)$ & $26,4(9,9)$ & 0,730 \\
\hline 6WT (m) & $320,4(126,9)$ & $325,8(94,4)$ & $323(111,2)$ & 0,880 \\
\hline $\begin{array}{l}\text { Hospitalizaciones } \\
\text { último año }\end{array}$ & $2,3(1,3)$ & $2,6(2,3)$ & $2,5(1,8)$ & 0,916 \\
\hline
\end{tabular}

Tabla I. Comparativa de variables previas al trasplante respecto a la mortalidad. TP: Trasplante pulmonar; IMC: Índice de masa corporal; $\Delta \mathrm{F}_{508}$ : Deleción de nucleótidos que codifican fenilalanina en la posición 508; DM: Diabetes mellitus; IPE: Insuficiencia pancreática exocrina; VMNI: Ventilación mecánica no invasiva; PaO2: Presión parcial de oxígeno; PaCO2: Presión parcial de dióxido de carbono; FVC: Capacidad vital forzada; $\mathrm{FEV}_{1}$ : Volumen espiratorio forzado en el primer segundo; 6WT: Test de la marcha en 6 minutos.

${ }^{a}$ Las variables continuas se muestran con la media y la desviación típica entre paréntesis y las categóricas con el número absoluto y el porcentaje sobre el valor total de datos válidos entre paréntesis. 


\subsubsection{Análisis descriptivo del acto quirúrgico}

\section{Cirugía de reducción del injerto pulmonar}

En $6(9,3 \%)$ pacientes fue necesario realizar alguna forma de resección pulmonar para adaptar el injerto pulmonar al receptor. Las reducciones del injerto incluyeron resecciones segmentarias en 1 pulmón de 3 receptores, resección segmentaria y lobectomía contralateral en 1 receptor y lobectomías bilaterales en 2 pacientes. La reducción de los injertos pulmonares no se asociaron con un aumento de la mortalidad. (Tabla II)

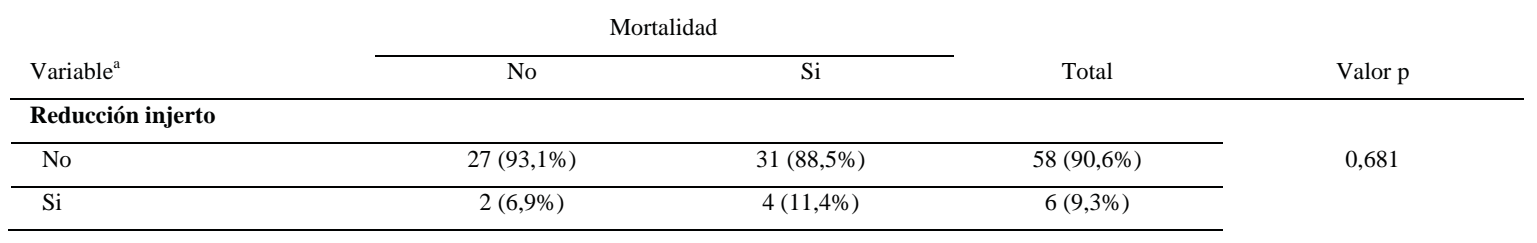

Tabla II. Comparativa de variables del acto quirúrgico respecto a la mortalidad

${ }^{a}$ Las variables continuas se muestran con la media y la desviación típica entre paréntesis y las categóricas con el número absoluto y el porcentaje sobre el valor total de datos válidos entre paréntesis.

\section{Tiempo de isquemia}

Respecto a los tiempos de isquemia, el pulmón derecho tuvo una media de $323 \pm 115$ (r: 110 - 540) minutos y el pulmón izquierdo de $290 \pm 106$ (r: 83 - 510) minutos.

La media del tiempo de isquemia del segundo pulmón fue de $375 \pm 101$ (r: 123 - 540) minutos. No se encontraron diferencias en los tiempos de isquemia del segundo pulmón entre los pacientes que fallecieron y los que no $(\mathrm{p}=0,362)$. (Tabla III) (Figura 18)

\begin{tabular}{lcccc} 
& \multicolumn{2}{c}{ Mortalidad } & \multirow{2}{*}{ Total } & \\
\cline { 2 - 4 } Variable $^{\mathrm{a}}$ & No & $\mathrm{Si}$ & \\
\hline Tiempo isquemia (min) & & & $322,71(115,3)$ & \multirow{2}{*}{0,581} \\
\hline Pulmón derecho & $312,7(112,3)$ & $332,71(120,2)$ & $290,14(106,0)$ \\
\hline Pulmón izquierdo & $266,14(101,1)$ & $314,14(107,7)$ & $374,63(100,6)$ & 0,362 \\
\hline Tiempo isquemia total & $360,5(99,3)$ & $388,05(102,3)$ & & \\
\hline
\end{tabular}

Tabla III. Comparativa de variables del acto quirúrgico respecto a la mortalidad

${ }^{\text {a }}$ Las variables continuas se muestran con la media y la desviación típica entre paréntesis y las categóricas con el número absoluto y el porcentaje sobre el valor total de datos válidos entre paréntesis. 


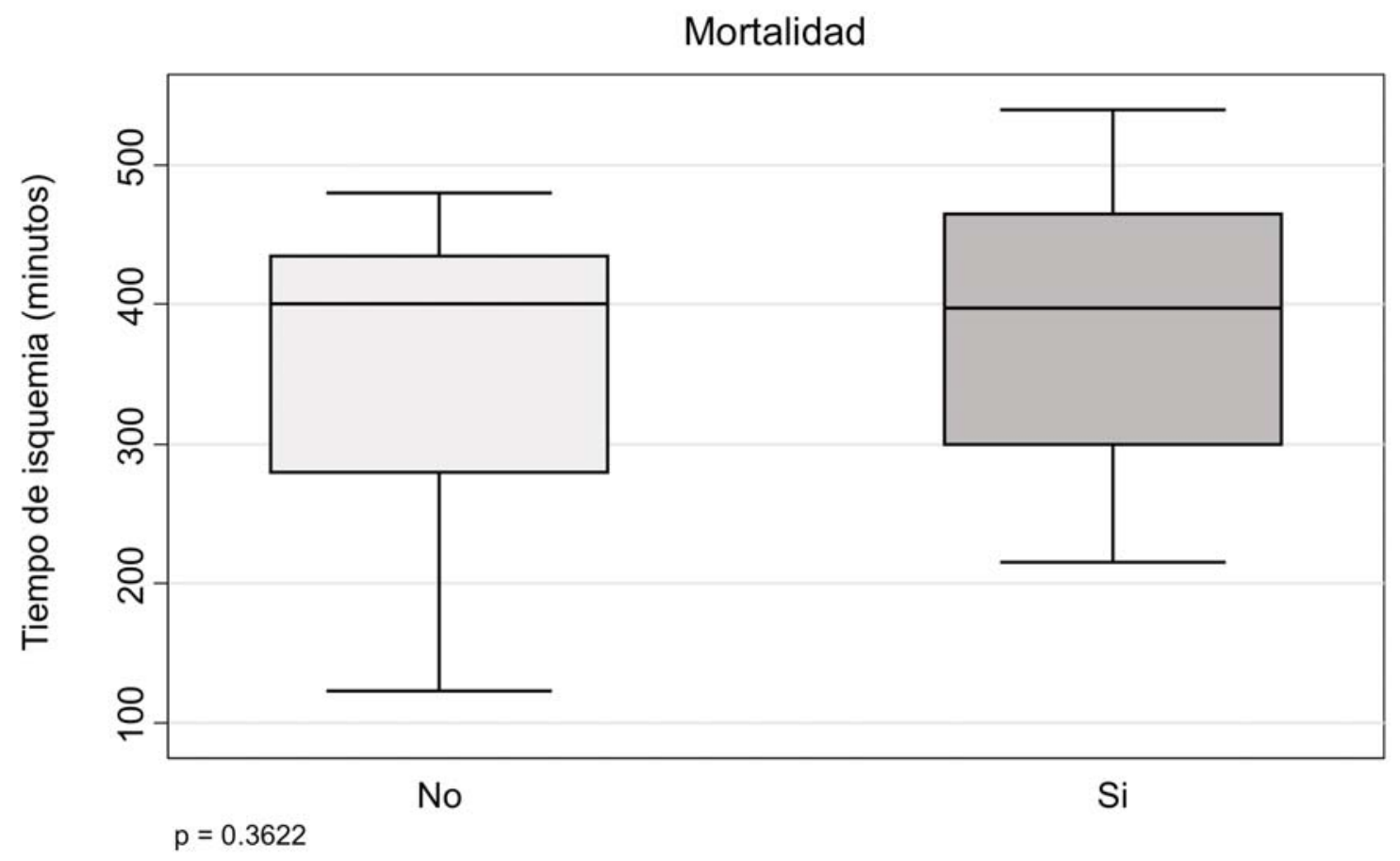

Figura 18. Diagrama de cajas del tiempo de isquemia respecto a la mortalidad. La línea de la caja representa la mediana y los límites el percentil 25 y 75.

\subsubsection{Análisis descriptivo del postoperatorio.}

\section{Ventilación mecánica y estancia en UCI}

Los receptores del TP estuvieron una media de 10 días con ventilación mecánica, con un mínimo de 1 día y un máximo de 60 días. Doce pacientes $(18,7 \%)$ requirieron VM prolongada.

La media de estancia en UCI fue de 17,7 $\pm 16,7$ (r: 1 - 90) días. Durante la estancia de los pacientes en UCI, $16(25,4 \%)$ presentaron paresia frénica temporal que revirtió previo al alta hospitalaria. Ninguno de los pacientes estudiados en la serie presentó parálisis frénica irreversible.

\section{Re intervención}

Cinco receptores $(7,8 \%)$ fueron re intervenidos posteriormente al TP. De éstos, 3 (60\%) fueron por sangrado, un paciente por sospecha de estenosis de anastomosis vasculares requirió re toracotomía de urgencia y un paciente se re intervino por fístula broncopleural precoz. Todos estos pacientes fallecieron en los primeros 7 días del postoperatorio de la re intervención, excepto uno del grupo de sangrado postoperatorio. 


\section{Infección respiratoria}

En cuanto a las infecciones respiratorias, la mayoría de los pacientes trasplantados $(62,5 \%)$ presentaron algún episodio de infección respiratoria durante el postoperatorio. El microorganismo causal más frecuente fue la Pseudomona aeruginosa en 26 (40,6\%) pacientes. (Figura 19)

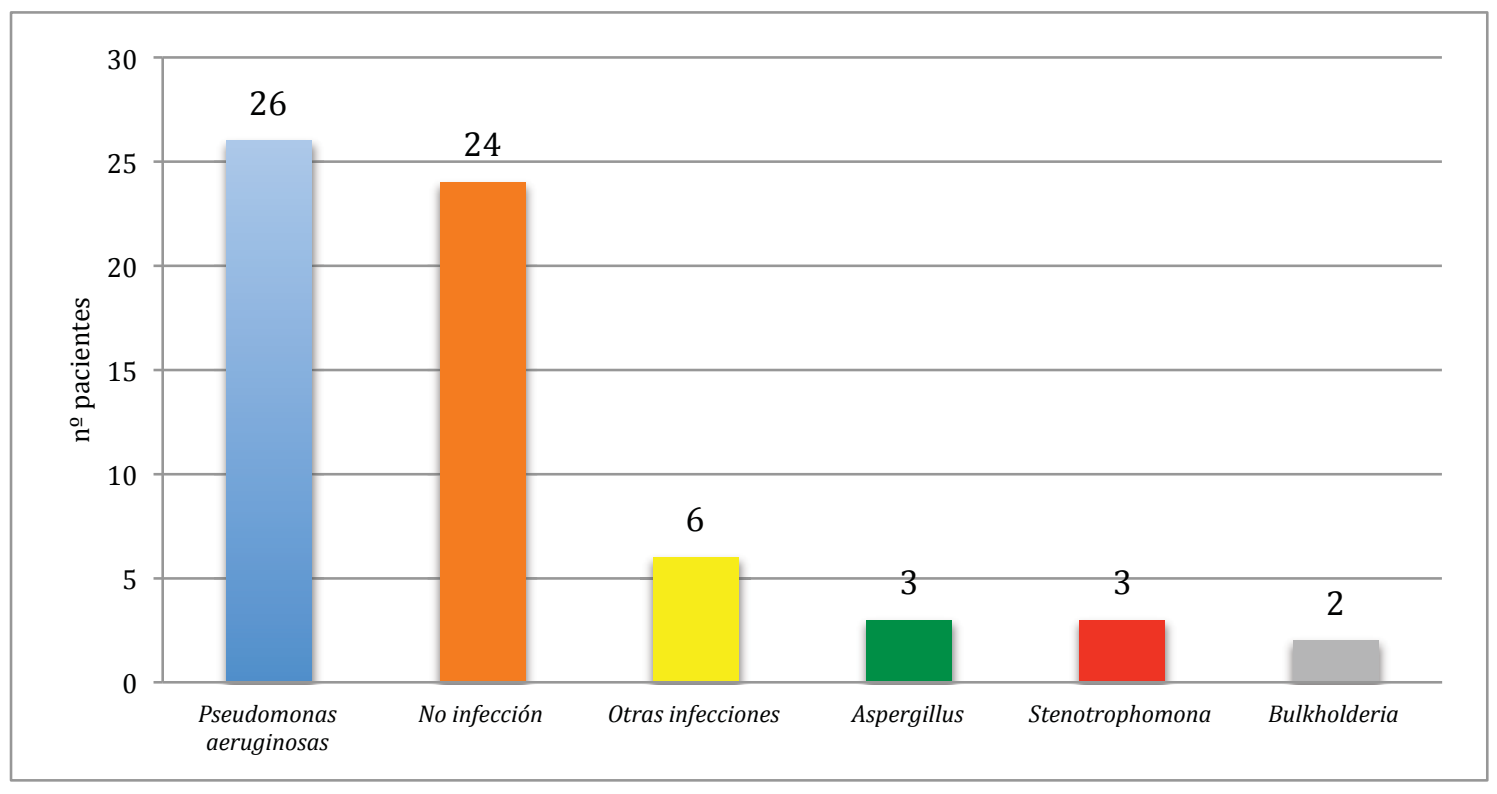

Figura 19. Aislamiento microbiológicos durante el postoperatorio del TP.

\section{Estenosis bronquial}

Del total de la serie, 6 pacientes $(9,4 \%)$ presentaron estenosis bronquial (EB) izquierda y $4(6,3 \%)$ EB derecha. El tratamiento de la EB fue conservador en 5 pacientes, 2 precisaron dilatación con balón de alta presión, 2 requirieron la colocación de una prótesis endobronquial y en un paciente fue necesario múltiples dilataciones más la colocación de una prótesis endobronquial. Sólo uno de los paciente que requirió dilataciones bronquiales y colocación de prótesis endobronquial falleció por causa directa de la complicación bronquial.

\section{Dehiscencia de sutura bronquial}

Un total de $4(6,2 \%)$ pacientes presentaron dehiscencia de sutura bronquial (DB) durante el postoperatorio, de los cuales 2 fue parcial y 2 pacientes presentaron dehiscencia completa de la sutura bronquial. Ninguno de los pacientes que presentaron algún tipo de dehiscencia de sutura sobrevivió. 


\section{Rechazo del injerto pulmonar}

Respecto al rechazo agudo (RA), $28(43,7 \%)$ pacientes presentaron algún episodio durante el seguimiento. El diagnóstico del RA fue por sospecha clínica en 10 (35,7\%) receptores y confirmados con BTB en $18(64,3 \%)$.

El rechazo crónico $(\mathrm{RC})$ se diagnostico en 21 (32,8\%) pacientes y el tiempo medio hasta el diagnóstico de RC fue de 37,4 $\pm 27,2$ (r: 12 - 109,5) meses.

\section{Mortalidad postoperatorio}

Durante el seguimiento, $29(45,3 \%)$ pacientes fallecieron. La causa de la mortalidad fue atribuida en 13 pacientes al RC; complicaciones del acto quirúrgico en 9 pacientes; shock séptico en 4 y otras causas (fallo respiratorio y/o multiorgánico) en 3 pacientes. (Tabla IV)

\begin{tabular}{|c|c|c|}
\hline & $\mathbf{N}=\mathbf{2 9}$ & $\%$ \\
\hline Rechazo crónico & 13 & 45 \\
\hline \multicolumn{3}{|l|}{ Complicaciones del acto quirúrgico } \\
\hline Dehiscencia de sutura bronquial & 4 & 13,8 \\
\hline Reintervención por sangrado & 2 & 6,9 \\
\hline Parada cardiaca tras implante del pulmón & 2 & 6,9 \\
\hline Estenosis de anastomosis arterial & 1 & 3,4 \\
\hline \multicolumn{3}{|l|}{ Shock séptico } \\
\hline SARM y Burkholderia cepacia & 1 & 3,4 \\
\hline SARM y Pseudomona aeruginosa & 1 & 3,4 \\
\hline Pseudomona, Stenotrophomona y aspergillus & 1 & 3,4 \\
\hline Acromobacter y Alcalygenes xilosoxidans & 1 & 3,4 \\
\hline \multicolumn{3}{|l|}{ Otras causas } \\
\hline Insuficiencia respiratoria & 1 & 3,4 \\
\hline Fallo multiorgánico & 2 & 6,9 \\
\hline
\end{tabular}

Tabla IV. Causas de mortalidad durante el seguimiento. SARM: Staphilococo aureus resistente a meticilina.

\section{Funcionalismo pulmonar}

Durante el postoperatorio se realizó una primera valoración del funcionalismo pulmonar que se repitió periódicamente. A continuación se detalla el funcionalismo pulmonar en el postoperatorio y el mejor funcionalismo pulmonar alcanzado durante el seguimiento. (Tabla V) 
La media de tiempo hasta conseguir el mejor funcionalismo pulmonar fue de 41,1 (r: 1,7 - 167,5) meses posteriores al TP. (Figura 20)

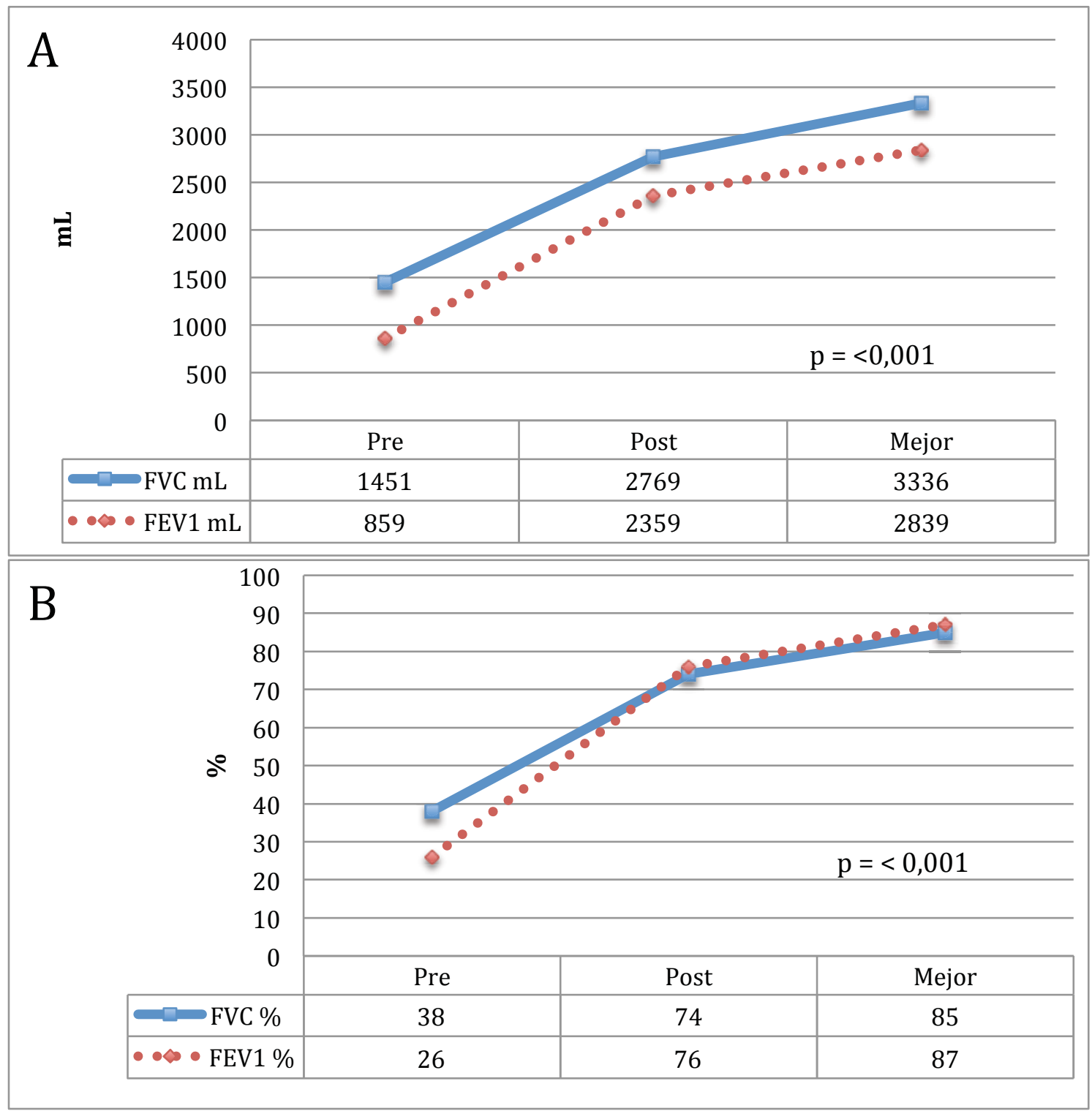

Figura 20. Evolución de los valores funcionales de los pacientes con FQ que recibieron un TP. Se muestra la media de cada valor, antes del TP, durante el postoperatorio y la media de los mejores valores alcanzados durante el seguimiento. A: Valores expresados en mililitros $(\mathrm{mL})$; B: Valores expresados en porcentaje de acuerdo al peso y talla de cada paciente.

FVC: Capacidad vital forzada; $\mathrm{FEV}_{1}$ : Volumen espiratorio forzado en el primer segundo 


\section{RESULTADOS}

Mortalidad

\begin{tabular}{|c|c|c|c|c|}
\hline \multirow[b]{2}{*}{ Variable $^{\mathrm{a}}$} & & \multirow[b]{2}{*}{ Total } & \multirow[b]{2}{*}{ Valor $\mathrm{p}$} \\
\hline & No & $\mathrm{Si}$ & & \\
\hline Tiempo VM (días) & $8,3(13,9)$ & $12(13,1)$ & $10,1(13,5)$ & 0,041 \\
\hline Tiempo UCI (días) & $17(19,4)$ & $18,39(13,7)$ & $17,7(16,6)$ & 0,321 \\
\hline \multicolumn{4}{|l|}{ Re intervención } & \multirow{3}{*}{0,366} \\
\hline No & $28(96,5 \%)$ & $31(88,5 \%)$ & $59(92,1 \%)$ & \\
\hline $\mathrm{Si}$ & $1(3,4 \%)$ & $4(11,4 \%)$ & $5(7,8 \%)$ & \\
\hline \multicolumn{4}{|l|}{ IR } & \multirow{3}{*}{0,438} \\
\hline No & $9(31 \%)$ & $15(42,8 \%)$ & $24(37,5 \%)$ & \\
\hline $\mathrm{Si}$ & $20(68,9 \%)$ & $20(57,1 \%)$ & $40(62,5 \%)$ & \\
\hline \multicolumn{4}{|l|}{ EB izquierda } & \multirow{3}{*}{1,000} \\
\hline No & $26(89,6 \%)$ & $32(91,4 \%)$ & $58(90,6 \%)$ & \\
\hline $\mathrm{Si}$ & $3(10,3 \%)$ & $3(8,5 \%)$ & $6(9,3 \%)$ & \\
\hline \multicolumn{4}{|l|}{ EB derecha } & \multirow{3}{*}{1,000} \\
\hline No & $27(93,1 \%)$ & $33(94,2 \%)$ & $60(93,7 \%)$ & \\
\hline $\mathrm{Si}$ & $2(6,9 \%)$ & $2(5,7 \%)$ & $4(6,2 \%)$ & \\
\hline \multicolumn{4}{|l|}{ DB parcial } & \multirow{3}{*}{0,497} \\
\hline No & $29(100 \%)$ & $33(94,2 \%)$ & $62(96,8 \%)$ & \\
\hline $\mathrm{Si}$ & $0(0 \%)$ & $2(5,7 \%)$ & $2(3,1 \%)$ & \\
\hline \multicolumn{4}{|l|}{ DB completa } & \multirow{3}{*}{0,497} \\
\hline No & $20(100 \%)$ & $33(94,2 \%)$ & $62(96,8 \%)$ & \\
\hline $\mathrm{Si}$ & $0(0 \%)$ & $2(5,7 \%)$ & $2(3,1 \%)$ & \\
\hline \multicolumn{4}{|l|}{ RA } & \multirow{3}{*}{0,576} \\
\hline No & $17(58,6 \%)$ & $19(54,2 \%)$ & $36(56,2 \%)$ & \\
\hline $\mathrm{Si}$ & $10(34,4 \%)$ & $15(42,8 \%)$ & $25(39 \%)$ & \\
\hline \multicolumn{4}{|l|}{$\mathbf{R C}$} & \multirow{3}{*}{0,439} \\
\hline No & $21(72,4 \%)$ & $22(62,8 \%)$ & $43(67,1 \%)$ & \\
\hline $\mathrm{Si}$ & $8(27,5 \%)$ & $13(37,1 \%)$ & $21(32,8 \%)$ & \\
\hline \multicolumn{4}{|l|}{ FVC posterior al TP } & \multirow[b]{2}{*}{0,288} \\
\hline $\mathrm{mL}$ & $2889,9(982,7)$ & $2580(907,6)$ & $2768,6(956,1)$ & \\
\hline$\%$ & $77,8(15,1)$ & $67,2(17,9)$ & $73,5(16,9)$ & 0,043 \\
\hline \multicolumn{4}{|l|}{$\mathrm{FEV}_{1}$ posterior al TP } & \multirow[b]{2}{*}{0,188} \\
\hline $\mathrm{mL}$ & $2498,1(937)$ & $2142,9(777,6)$ & $2359,1(886,5)$ & \\
\hline$\%$ & $81,4(18,3)$ & $67,84(20,8)$ & $75,96(20,3)$ & 0,015 \\
\hline \multicolumn{4}{|l|}{ FVC mejor post TP } & \multirow[b]{2}{*}{0,533} \\
\hline $\mathrm{mL}$ & $3387,7(538,2)$ & $3192,5(1172,3)$ & $3335,6(741,1)$ & \\
\hline$\%$ & $89,8(9,3)$ & $69,8(15,9)$ & $84,5(14,3)$ & 0,004 \\
\hline \multicolumn{4}{|l|}{$\mathrm{FEV}_{1}$ mejor post $\mathrm{TP}$} & \\
\hline $\mathrm{mL}$ & $2852,7(600,2)$ & $2801,2(976,8)$ & $2839(701,2)$ & 0,862 \\
\hline$\%$ & $91,4(13,4)$ & $75,63(19,3)$ & $87,23(16,4)$ & 0,017 \\
\hline
\end{tabular}

Tabla V. Comparativa de variables posteriores al trasplante respecto a la mortalidad. VM: Ventilación mecánica; UCI: Unidad de cuidados intensivos; IR: Infección respiratoria; EB: Estenosis bronquial; DB: Dehiscencia de la sutura bronquial; RA: Rechazo agudo; RC: Rechazo crónico; TP: Trasplante pulmonar; FVC: Capacidad vital forzada; FEV 1 : Volumen espiratorio forzado en el primer segundo.

${ }^{a}$ Las variables continuas se muestran con la media y la desviación típica entre paréntesis y las categóricas con el número absoluto y el porcentaje sobre el valor total de datos válidos entre paréntesis. 


\subsubsection{Análisis univariante}

En nuestra serie, e 1 análisis univariante de los factores que pueden afectar la supervivencia de nuestra serie no identificó ninguna variable que aumente la probabilidad de muerte excepto la $\mathrm{PaCO}_{2}$ preoperatoria (HR: 1,05; IC $95 \%$ : 1,02 $1,09)$.

El estado nutricional, el tiempo en lista de espera, el funcionalismo pulmonar (excepto lo mencionado previamente respecto a la $\mathrm{PaCO}_{2}$ ) y el número de hospitalizaciones previo al TP no parecen tener relación con la mortalidad.

Otros factores analizados como el tiempo de isquemia del injerto, los días de VM y los días de ingreso en la UCI tampoco parecen tener un impacto negativo en la supervivencia de nuestra serie. (Tabla VI)

\begin{tabular}{|c|c|c|c|}
\hline Variable & HR & IC $95 \%$ & Valor $\mathbf{p}$ \\
\hline Edad (años) & 1,02 & $0,97-1,07$ & 0,526 \\
\hline $\operatorname{IMC}\left(\mathrm{Kg} / \mathrm{m}^{2}\right)$ & 0,99 & $0,88-1,12$ & 0,955 \\
\hline Tiempo lista de espera (meses) & 0,97 & $0,93-1,02$ & 0,261 \\
\hline $\mathrm{PaO}_{2}(\mathrm{mmHg})$ & 0,99 & $0,96-1,03$ & 0,842 \\
\hline $\mathrm{PaCO}_{2}(\mathrm{mmHg})$ & 1,05 & $1,02-1,09$ & 0,003 \\
\hline \multicolumn{4}{|l|}{ FVC previo al TP } \\
\hline $\mathbf{m L}^{\mathrm{a}}$ & 1 & $0,99-1$ & 0,851 \\
\hline$(\%)^{\mathrm{b}}$ & 0,99 & $0,96-1,02$ & 0,561 \\
\hline \multicolumn{4}{|l|}{$\mathrm{FEV}_{1}$ previo al TP } \\
\hline $\mathbf{m L}^{\mathrm{a}}$ & 1 & $0,99-1$ & 0,972 \\
\hline$(\%)^{b}$ & 0,99 & $0,95-1,03$ & 0,883 \\
\hline 6WT previo al TP (metros) & 1 & $0,99-1$ & 0,658 \\
\hline Hospitalizaciones último año & 1,12 & $0,93-1,36$ & 0,228 \\
\hline Tiempo de isquemia (minutos) & 1 & $0,99-1$ & 0,782 \\
\hline Tiempo de VM (días) & 1,01 & $0,98-1,03$ & 0,570 \\
\hline Tiempo de estancia de UCI (días) & 1 & $0,97-1,02$ & 0,984 \\
\hline
\end{tabular}

Tabla VI. Análisis univariante de los factores de riesgo de mortalidad por el método riesgos proporcionales de Cox.

$\mathrm{HR}$, razón de tasas de riesgo; IC $95 \%$, intervalo de confianza al 95 \%; IMC, índice de masa corporal; PaO ${ }_{2}$, Presión parcial de

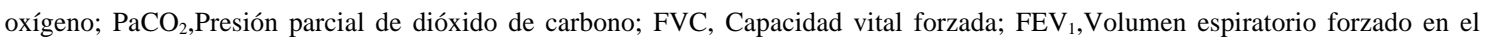
primer segundo; 6WT, Test de la marcha en 6 minutos; VM, Ventilación mecánica.

${ }^{\text {a }}$ FVC y $\mathrm{FEV}_{1}$ expresado en mililitros

${ }^{\mathrm{b}} \mathrm{FVC} \mathrm{y}_{\mathrm{FEV}}$ expresado como porcentaje sobre el teórico 
La supervivencia actuarial (Kaplan-Meier) de los pacientes trasplantados por FQ al año, tres, cinco y diez años fue de 71,8 \%, 62,4 \%, 56,7 \% y 41,3\% respectivamente, con una mediana de supervivencia de 5,7 años. Al finalizar el estudio, el paciente con mayor supervivencia había sido trasplantado hace 17 años. (Figura 21)

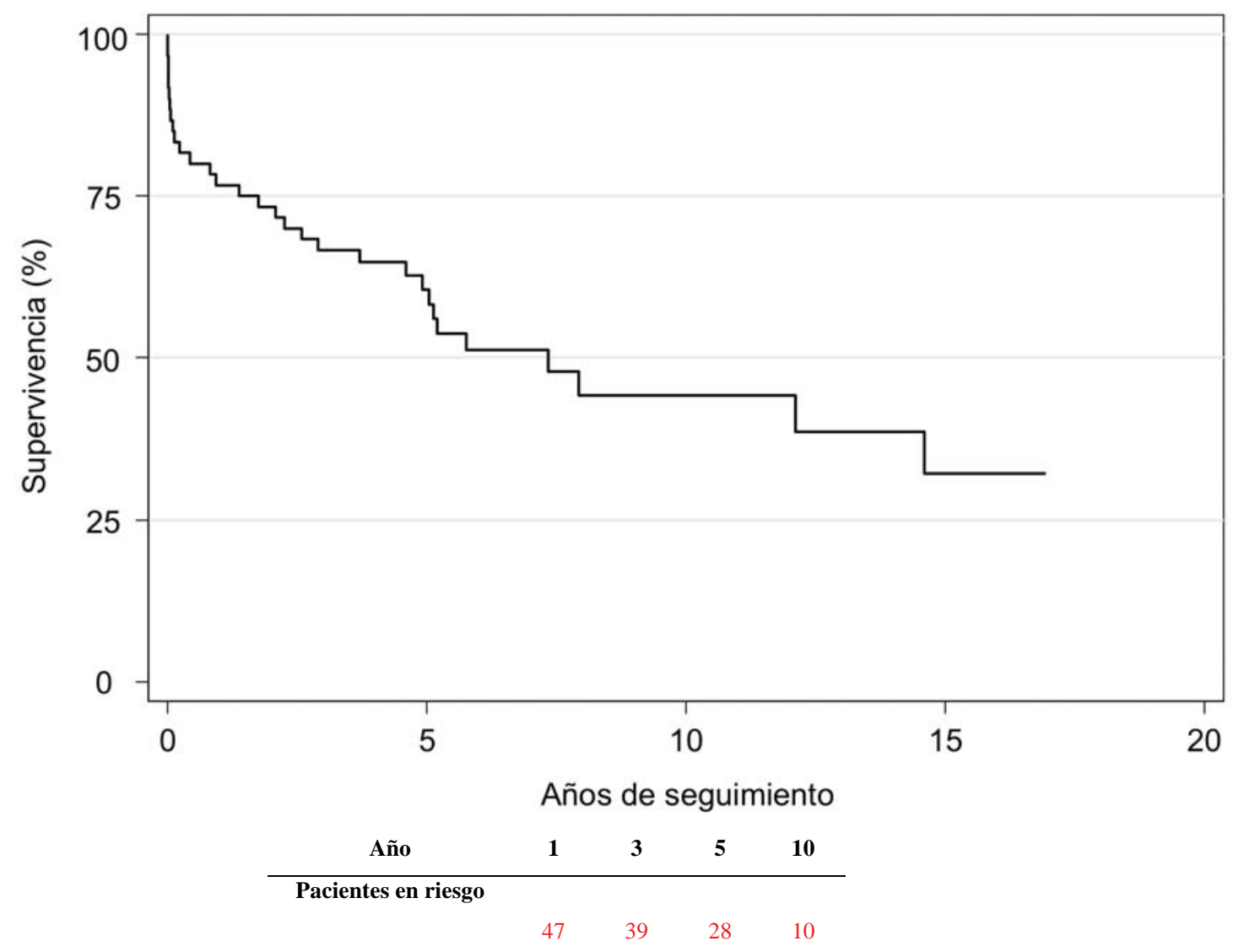

Figura 21. Supervivencia a largo plazo de la serie de TP por FQ. 
Respecto a la supervivencia de la serie dividida según la era de realización del TP se observó una supervivencia mayor durante la última era (2003 - 2011) aunque dicho aumento no alcanzó la significación estadística. Los pacientes trasplantados durante la segunda era parecen tener una mejor supervivencia los 5 primeros años del TP, aunque a larga plazo dicha diferencia no es significativa.

La supervivencia al año, tres, cinco y diez años fue de $61,5 \%, 50 \%, 50 \%$ y $37,7 \%$ respectivamente en los pacientes trasplantados entre 1992 y el 2002 y de 78,9 $\%, 70,9 \%, 60 \%$, y $42 \%$ respectivamente entre el año 2003 al 2011. (Figura 22)

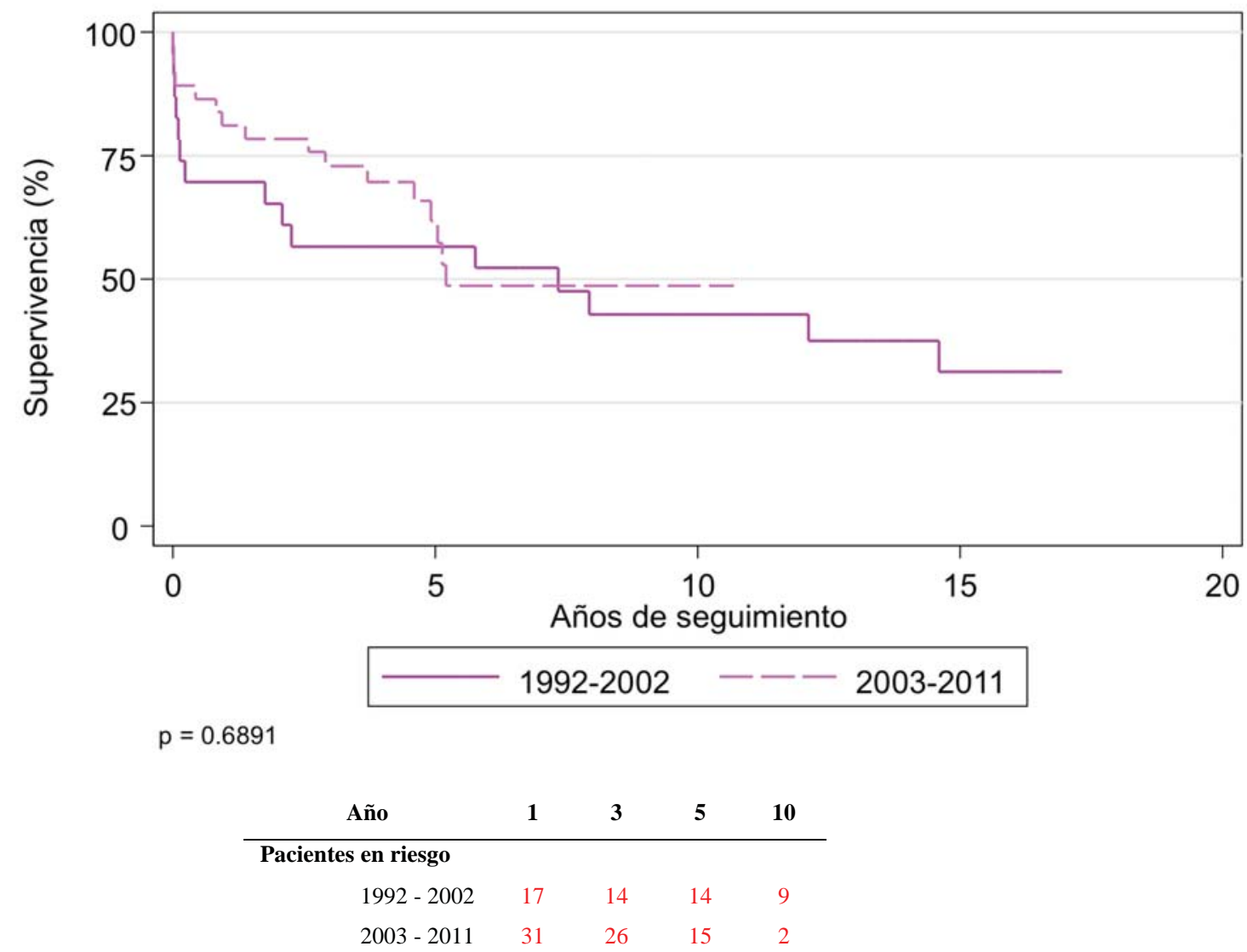

Figura 22. Supervivencia global estratificada de acuerdos a la era de realización del TP. Se observa una ligera mejoría no significativa de la curva de la era 2003 - 2011. 
El IMC preoperatorio no parece influir significativamente en la supervivencia global de la serie. La supervivencia estratificada por grados de desnutrición fue similar con una ligera mejoría no significativa del grupo con desnutrición severa a partir del quinto año del TP. (Tabla VII) (Figura 23)

\begin{tabular}{lccccc}
\multicolumn{1}{c}{ Grado nutricional (OMS) } & $\mathbf{1 0 4}$ & $\mathbf{3}$ & $\mathbf{5}$ & $\mathbf{1 0}$ & valor p \\
\hline Desnutrición severa (<16) & $76 \%$ & $59,7 \%$ & $59,7 \%$ & $51,2 \%$ & 0,970 \\
Desnutrición moderada (16-16,99) & $87,5 \%$ & $62,5 \%$ & $50 \%$ & $25 \%$ \\
\cline { 2 - 5 } Desnutrición leve (17-18,49) & $58,3 \%$ & $58,3 \%$ & $46,6 \%$ & $46,6 \%$ \\
Peso normal (18,5-24,99) & $68,4 \%$ & $68,4 \%$ & $62,2 \%$ & $34,5 \%$
\end{tabular}

Tabla VII. Supervivencia actuarial de acuerdo a los diferentes grados nutricionales. OMS: Organización mundial de la salud.

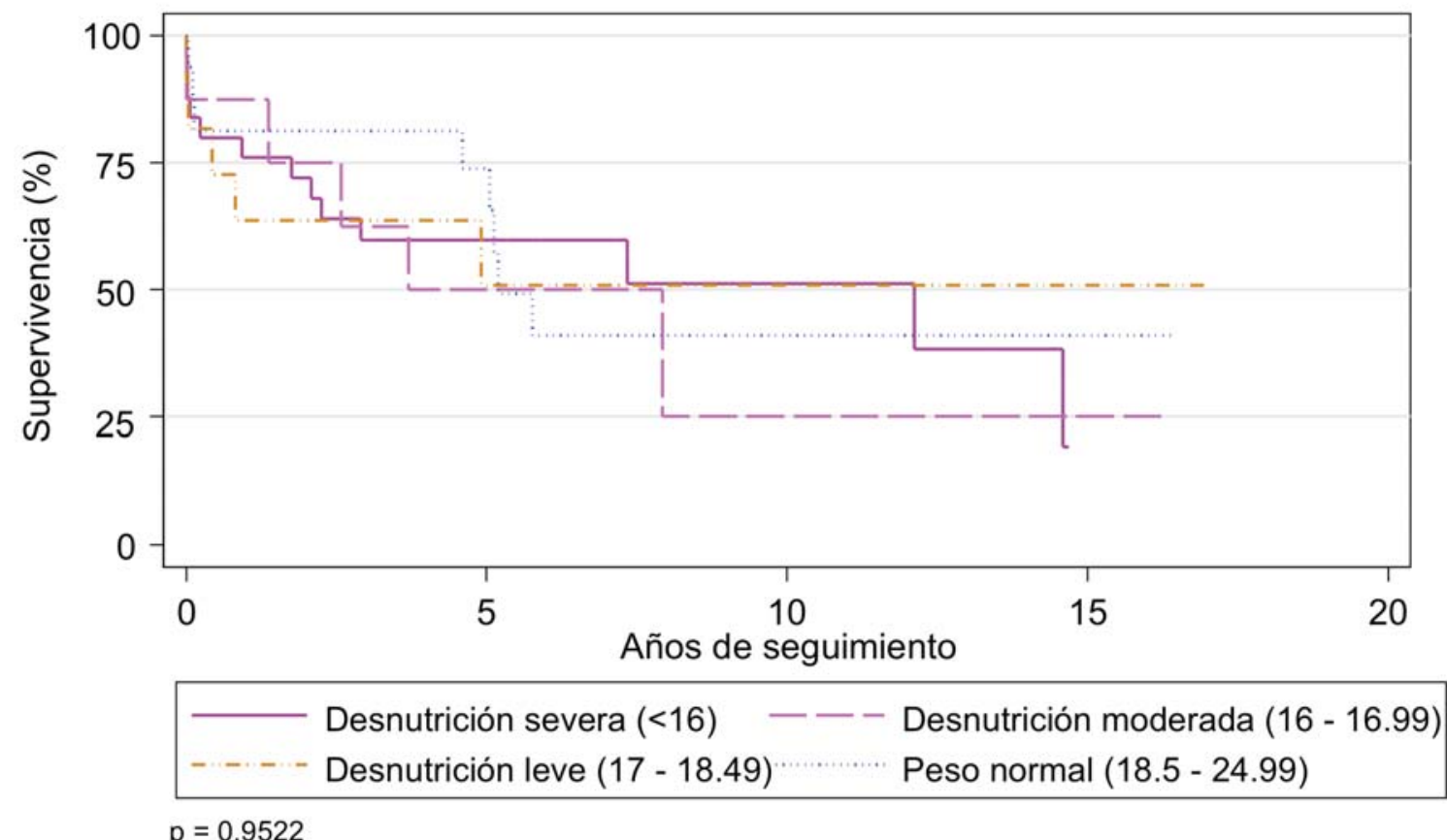

\begin{tabular}{ccccc} 
Año & $\mathbf{1}$ & $\mathbf{3}$ & $\mathbf{5}$ & $\mathbf{1 0}$ \\
\hline Pacientes en riesgo & & & & \\
Desnutrición severa & 20 & 14 & 12 & 5 \\
Desnutrición moderada & 8 & 6 & 4 & 2 \\
Desnutrición leve & 8 & 8 & 5 & 2 \\
Peso normal & 14 & 14 & 10 & 4
\end{tabular}

Figura 23. Supervivencia global estratificada de acuerdos a los grados de desnutrición. 
Debido a que la mayoría de los pacientes TP por FQ de nuestra serie tenían desnutrición severa (41,6\%), a continuación se analizan solamente dos grupos, comparando los pacientes con desnutrición severa con el resto global de pacientes.

El resultado es similar al análisis anterior; aunque la supervivencia parece ser mejor en el grupo de desnutrición severa a partir del quinto año del TP, las diferencias a largo plazo no son significativas. (Figura 24)

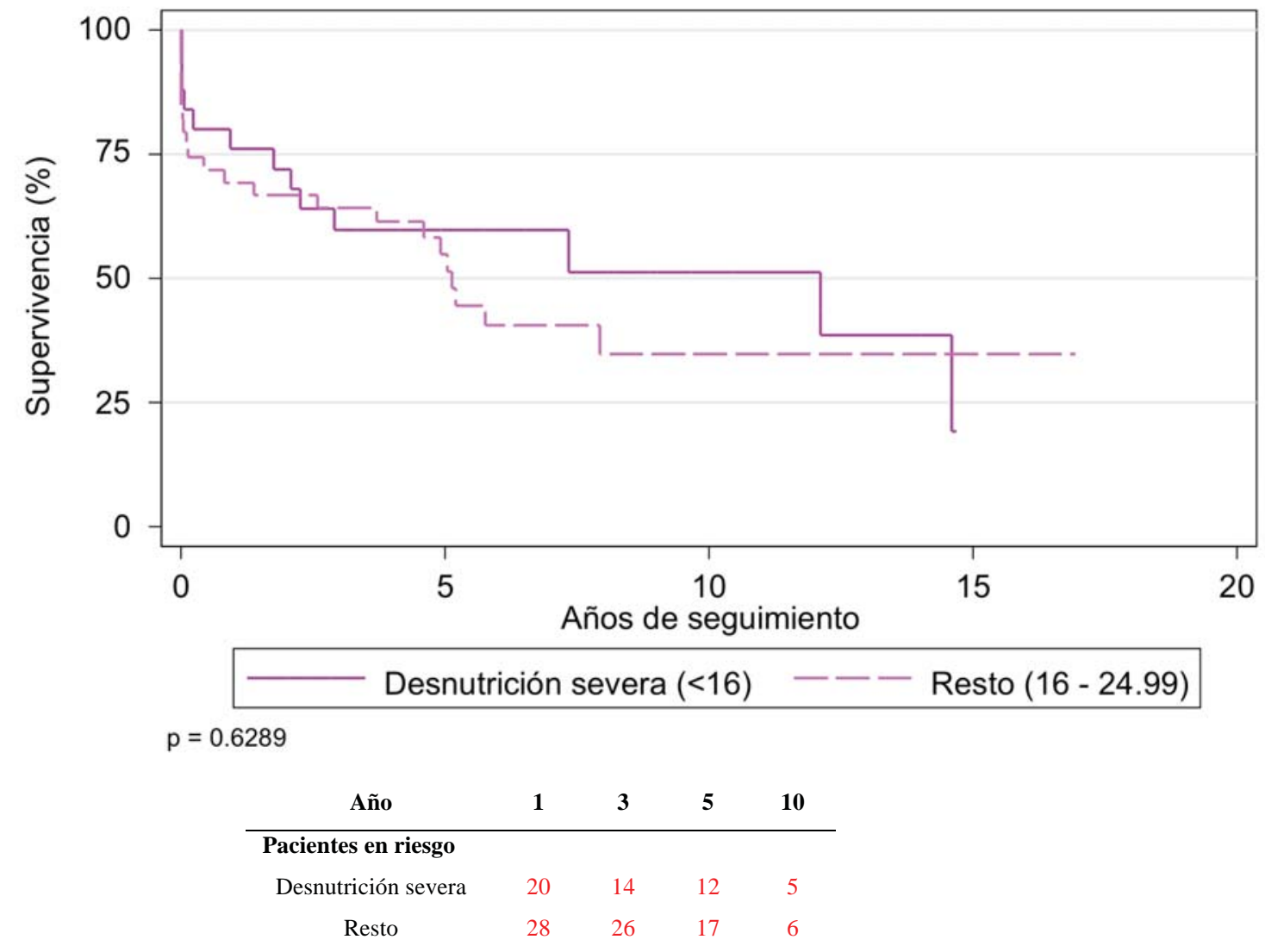

Figura 24. Supervivencia estratificada de acuerdos a Desnutrición severa y resto de estados nutricionales. 
El sexo del receptor no parece influir en la supervivencia a corto y largo plazo, siendo al año, 3, 5 y 10 años del 70,9 \%, $58 \%$, 58\% y 46,5\% para el sexo femenino respectivamente y del $72,7 \%, 66,5 \%, 55,6 \%$ y $36,4 \%$ para el sexo masculino respectivamente $(\mathrm{p}=0,50)$.

A partir del quinto año posterior al TP se aprecia una mejora en la curva de supervivencia para el sexo femenino que se mantiene durante todo el seguimiento, aunque dicha diferencia no alcanza la significación estadística. (Figura 25)

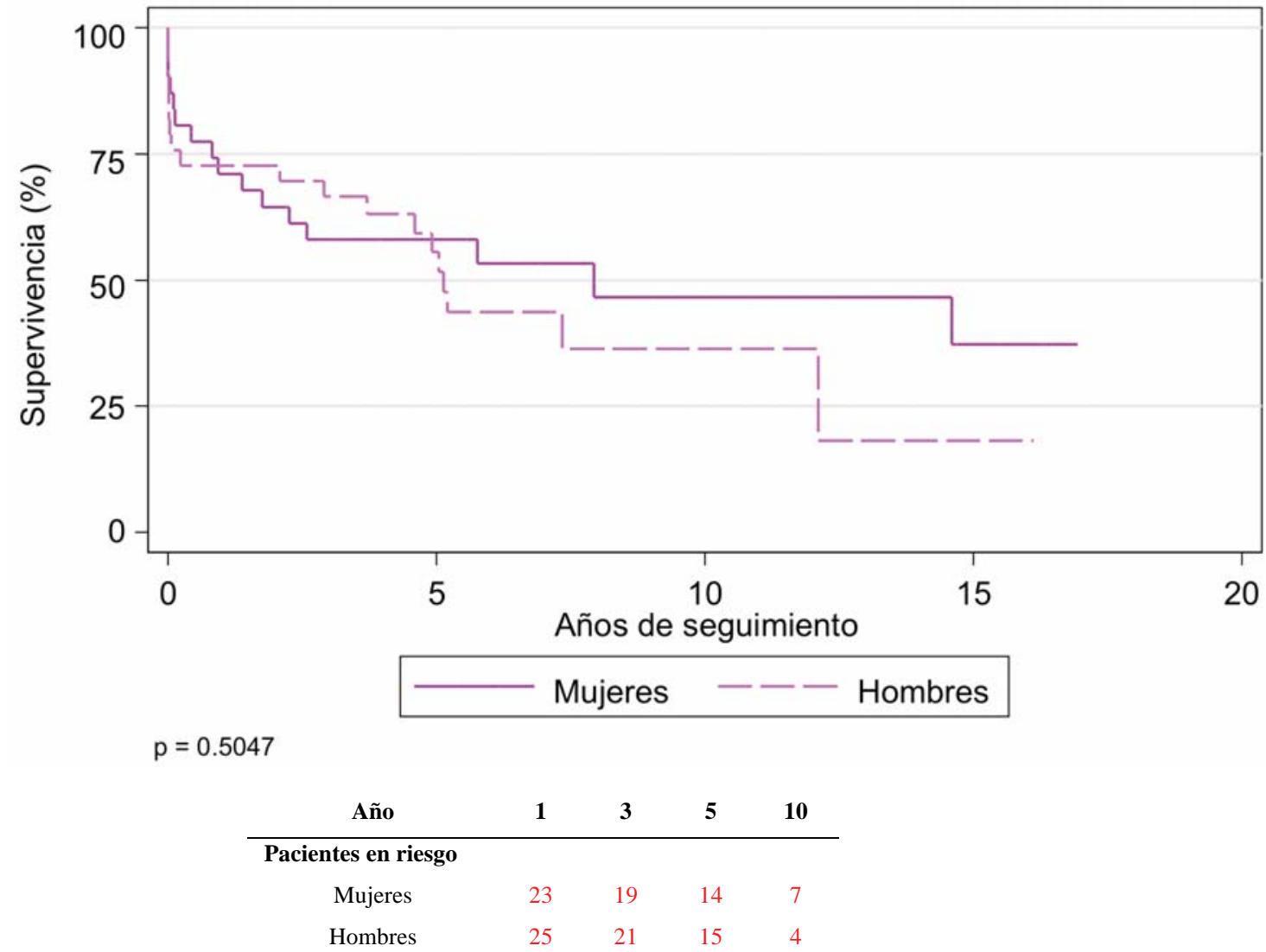

Figura 25. Supervivencia estratificada de acuerdo al sexo de los receptores. 
Respecto a la afectación pancreática en forma de DM, la supervivencia se mantiene similar, tanto si los receptores son diabéticos o no. Para los pacientes sin diagnostico de DM, la supervivencia al año, 3, 5 y 10 años fue del 72,7\%, 63,6\%, $58,1 \%$ y $43,4 \%$ respectivamente, mientras que para los pacientes diabéticos fue del $70 \%, 59,5 \%, 53,6 \%$ y $38,1 \%$ respectivamente $(\mathrm{p}=0,70)$. (Figura 26$)$

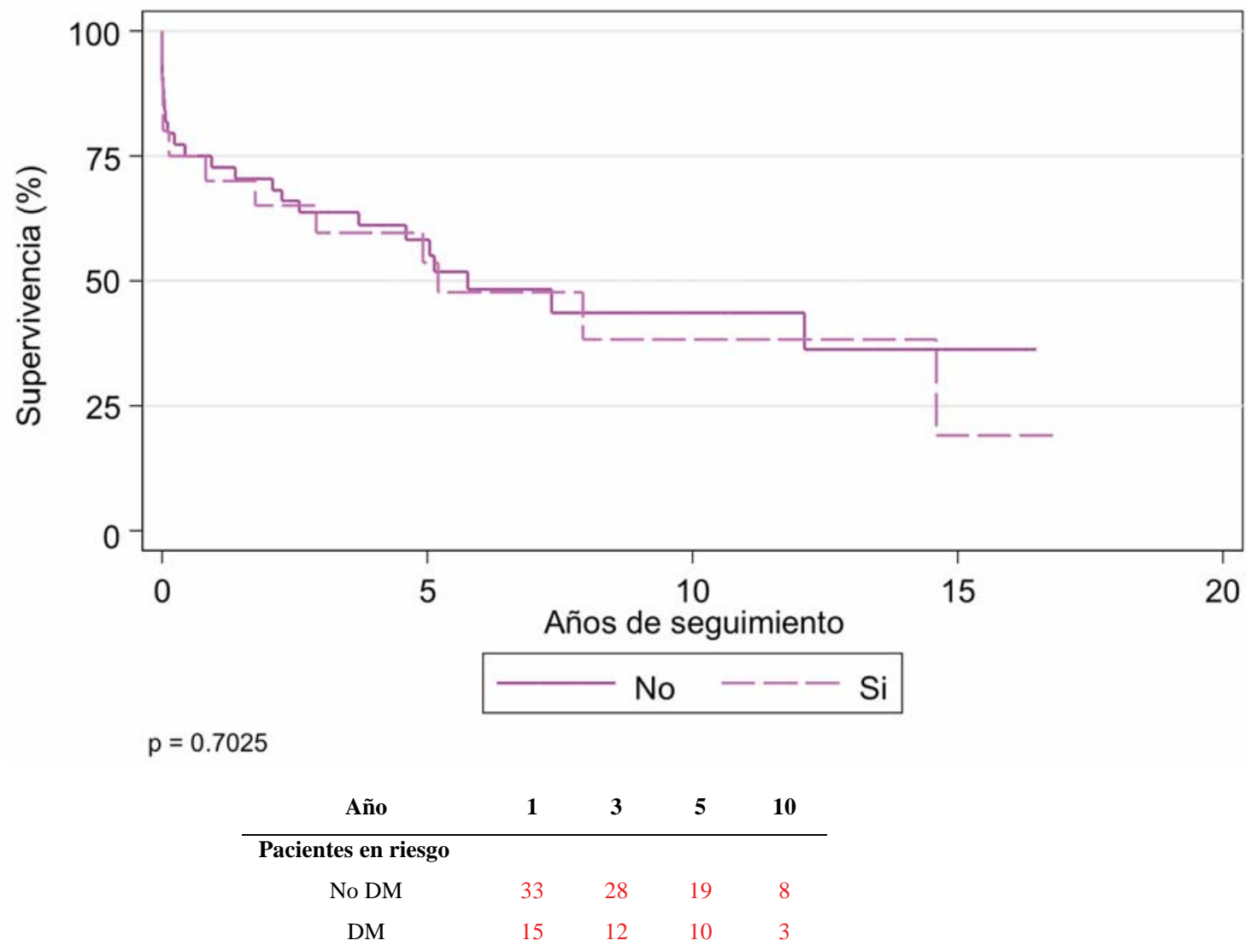

Figura 26. Supervivencia estratificada de acuerdo a la presencia o no de diabetes mellitus. 
Los receptores con IPE parecen tener una mejor supervivencia, siendo al año, 3, 5 y 10 años del 78\%, 67,9\%, 60,3\% y 45\% respectivamente en comparación con los pacientes que no tienen IPE con supervivencias del 50\%, 42,8\%, 42,8\% y del 28,5\% respectivamente $(\mathrm{p}=0,04)$. (Figura 27$)$

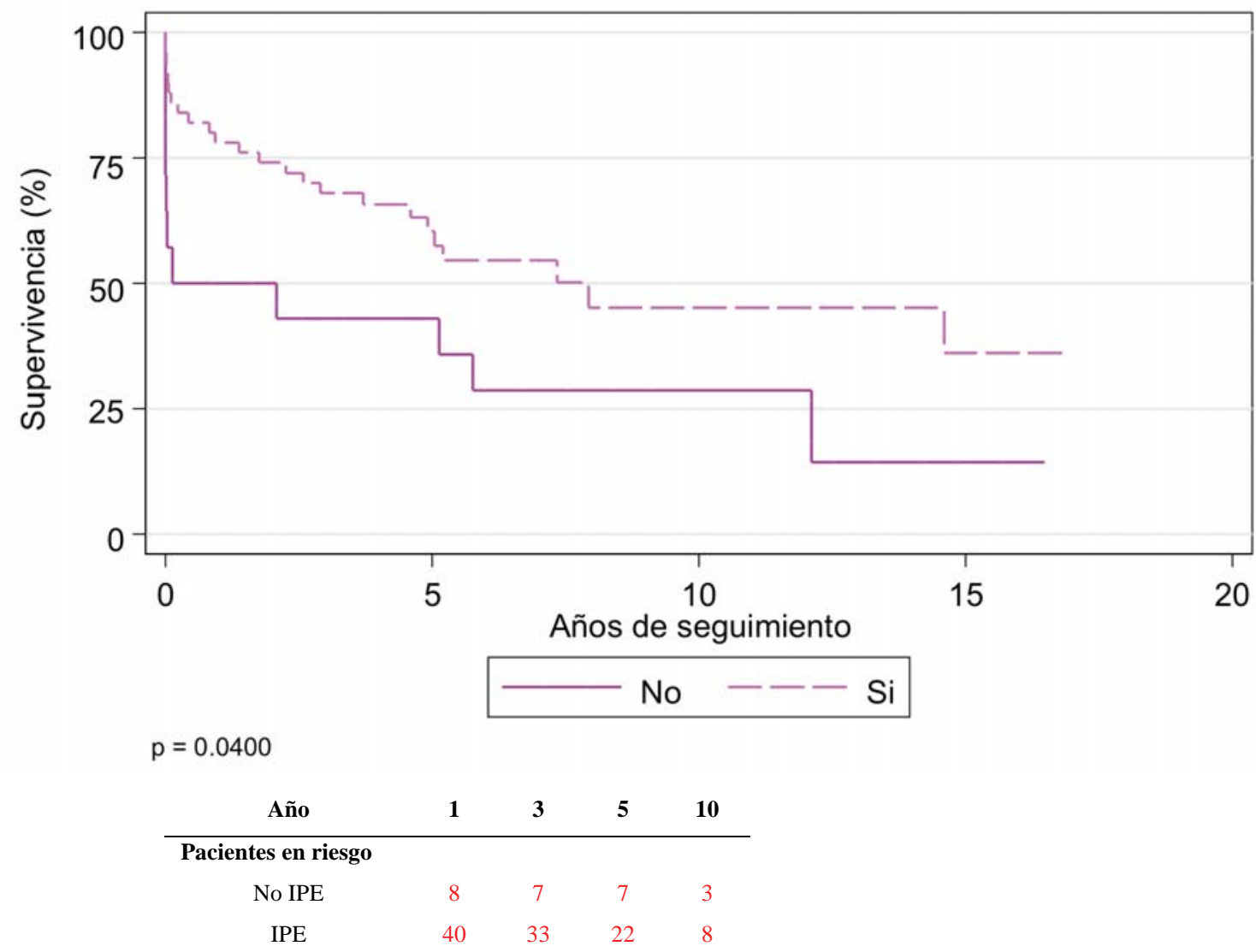

Figura 27. Supervivencia estratificada de acuerdo a la presencia o no de insuficiencia pancreática exocrina. 
El requerimiento o no de oxígeno suplementario no parece influir en la supervivencia de la serie. Los receptores que se trasplantaron con oxigenoterapia tuvieron una supervivencia al año, 3, 5 y 10 años del 72,5\%, 60,7\%, 53,8\% y $38 \%$ respectivamente en comparación con los que no requerían oxígeno suplementario con supervivencias del 69,2\%, 69,2\%, 69,2\% y 55,3\% respectivamente $(\mathrm{p}=0,44)$. (Figura 28)

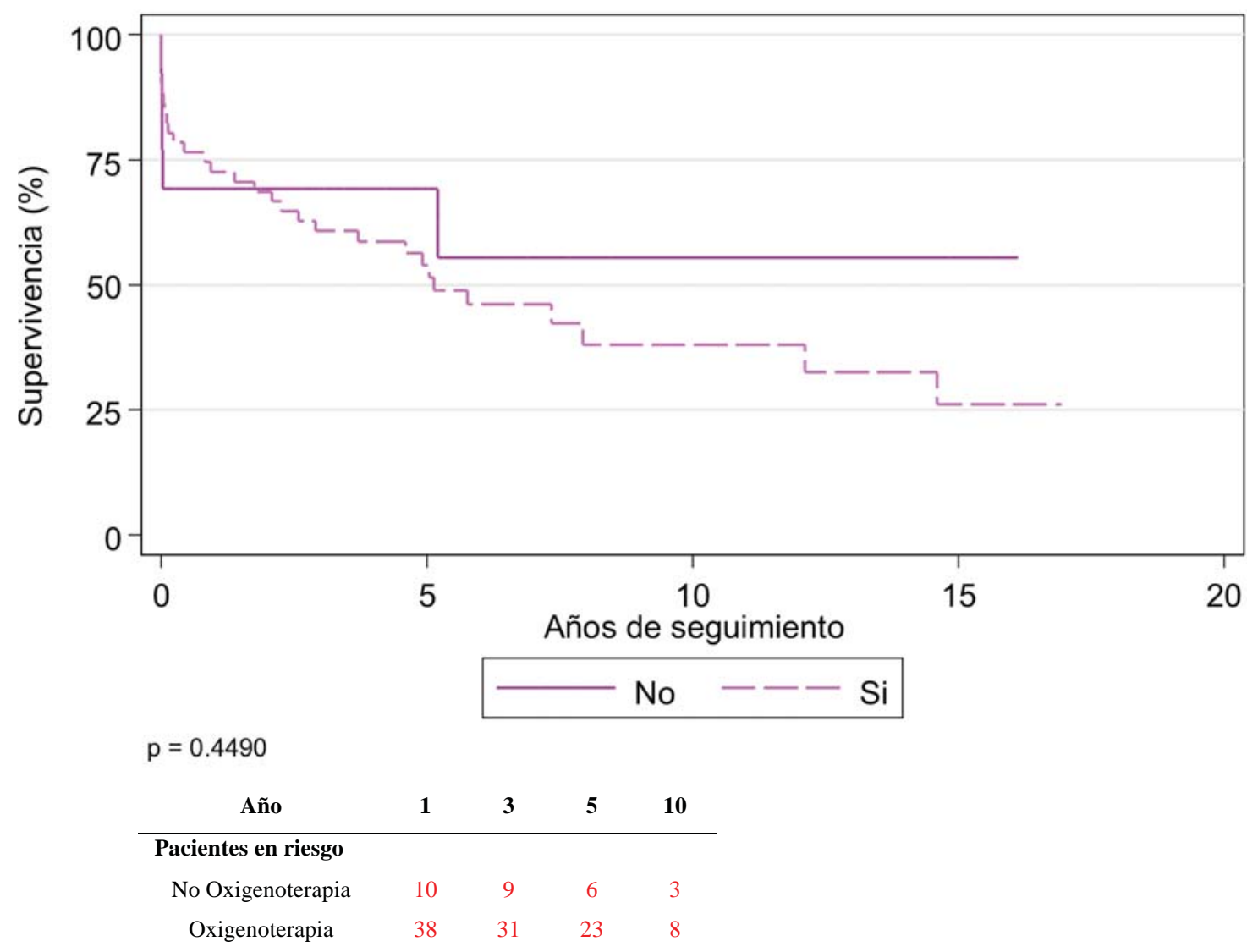

Figura 28. Supervivencia estratificada de acuerdo a la necesidad de oxigenoterapia previa al TP. 
En el análisis de los pacientes que se trasplantaron con VMNI no demostró diferencias con los pacientes que no utilizaban dicho tipo de terapia. Los pacientes trasplantados con VMNI tuvieron una supervivencia al año, 3, 5 y 10 años del 69,2\%, $53,8 \%, 43 \%$ y $43 \%$ y los que no requerían VMNI del 72,5\%, 64,7 \%, 60,1\% y 42,1\% respectivamente $(\mathrm{p}=0,63)$. (Figura 29$)$

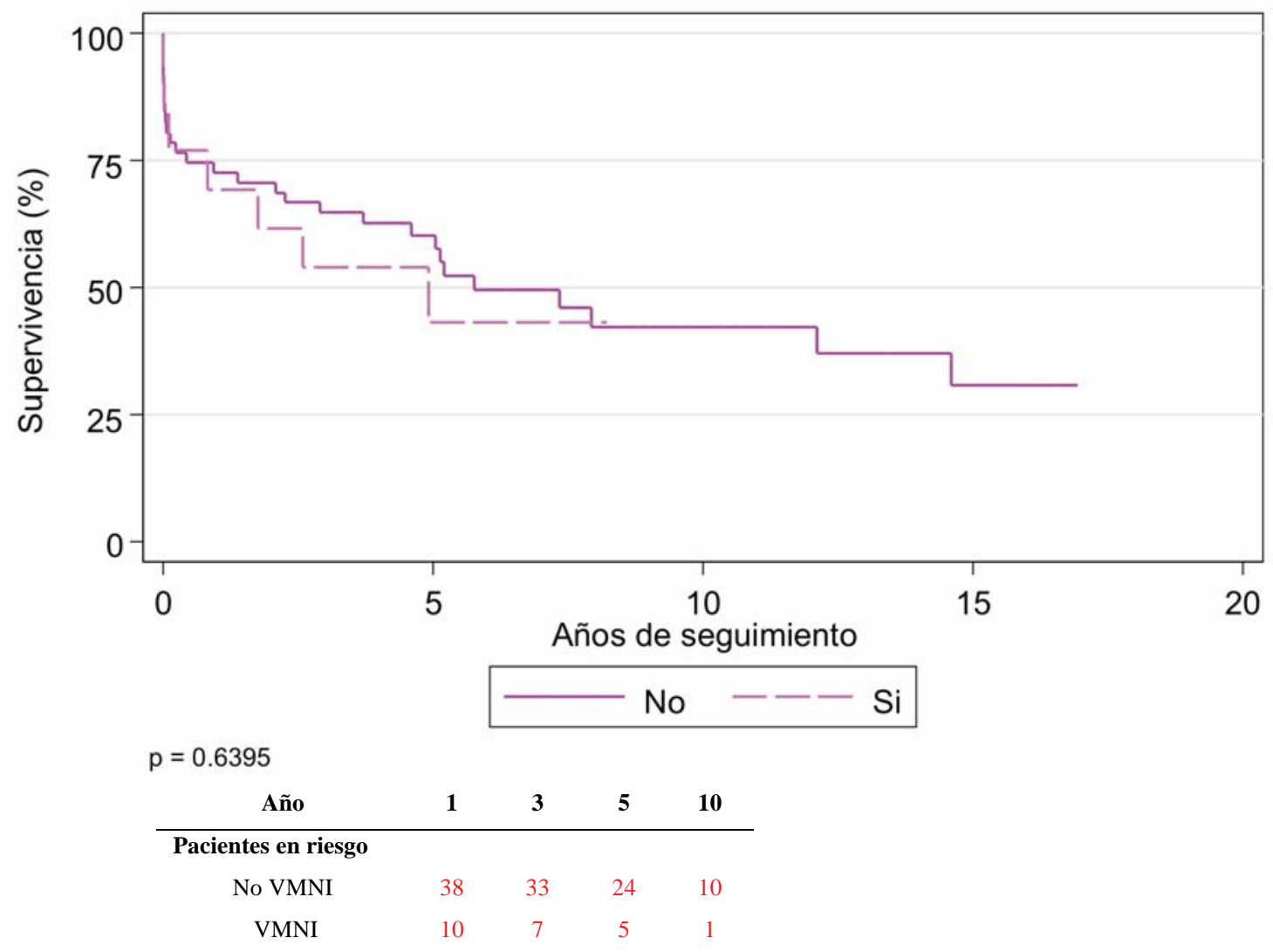

Figura 29. Supervivencia estratificada de acuerdo a la necesidad de ventilación mecánica no invasiva previa al TP. 


\subsection{INFLUENCIA DE FACTORES SOBRE LA PROBABILIDAD DE CEC}

A continuación se presentan los resultados de las variables analizadas en relación a la circulación extracorpórea.

Del total de la serie de 64 pacientes, 29 pacientes $(45,3 \%)$ fueron intervenidos bajo CEC con una tiempo medio de soporte extracorpóreo de $198 \pm 115$ (r: 53 - 410) minutos. (Figura 30)

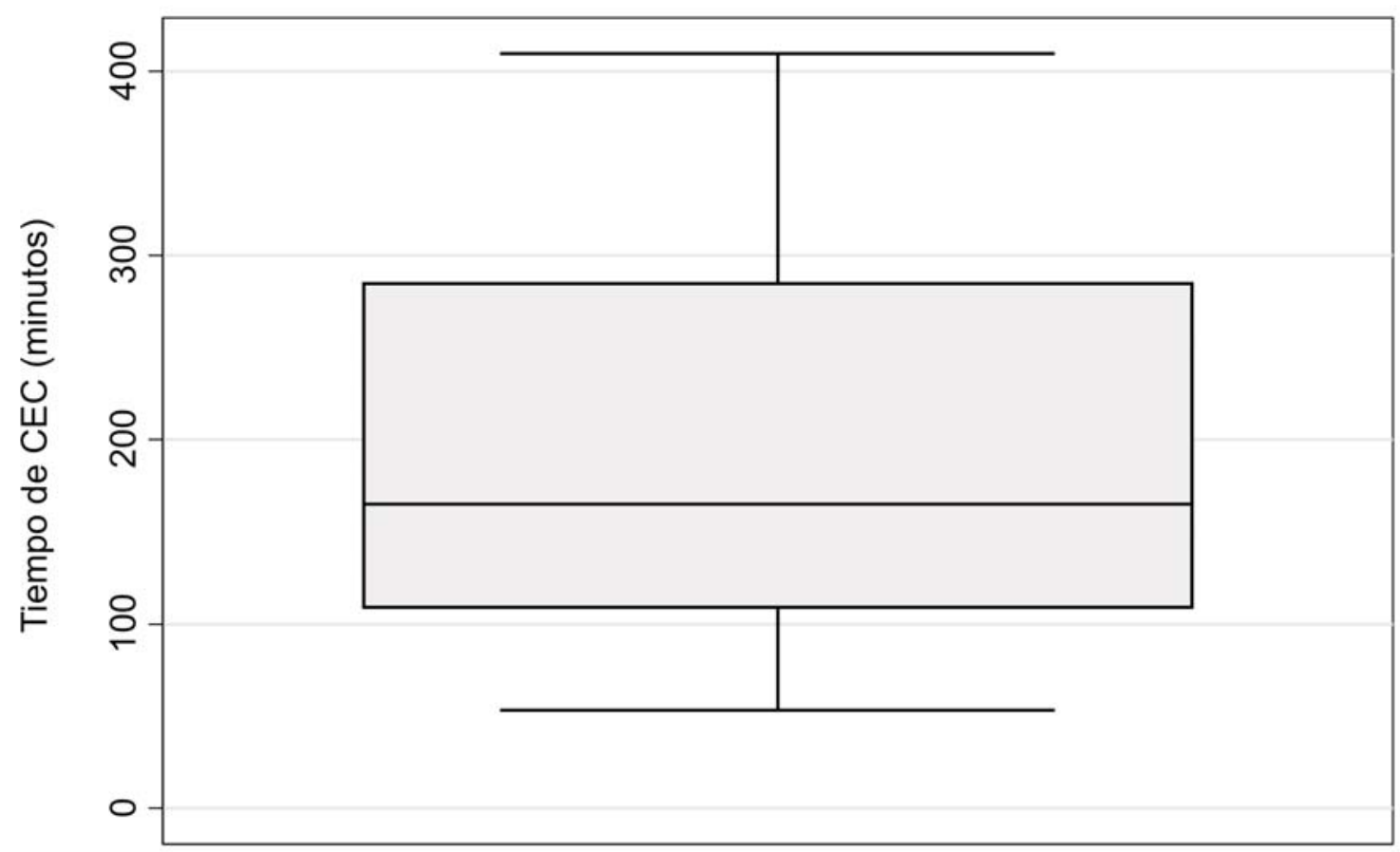

Figura 30. Diagrama de cajas del tiempo de circulación extracorpórea (CEC) expresada en minutos. La línea de la caja representa la mediana y los límites el percentil 25 y 75. 


\subsubsection{Análisis descriptivo previo al trasplante pulmonar}

\section{Época del trasplante}

En comparación con la primera época del TP de nuestra serie en que solo el $31 \%$ de los pacientes con FQ se trasplantaban sin necesidad de CEC, durante la segunda época, el $68 \%$ de lo pacientes se trasplantaron sin necesidad de CEC. (Figura 31)

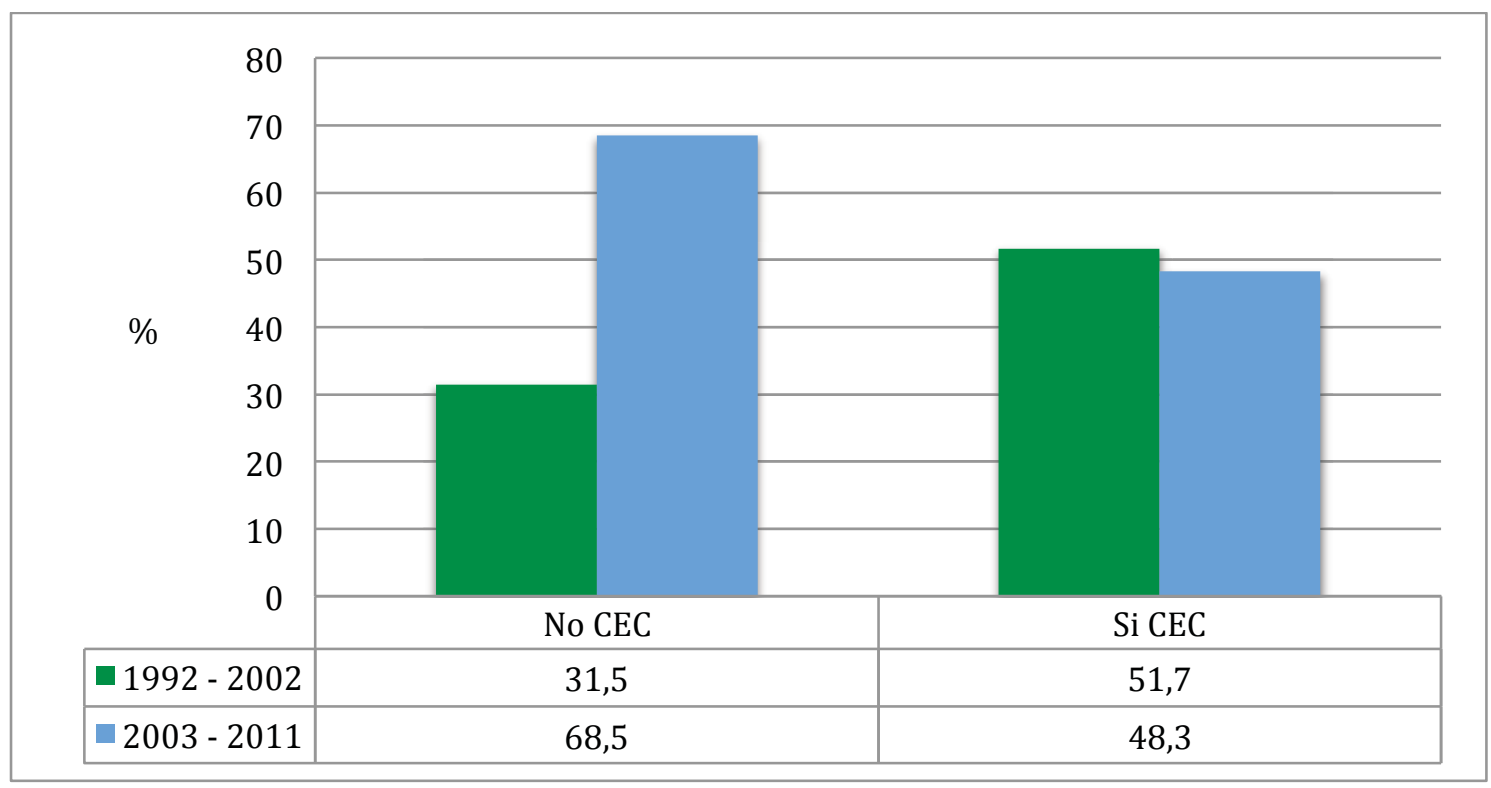

Figura 31. TP por FQ divididos por épocas según la necesidad de CEC. Los valores se expresan en porcentajes.

\section{Edad y sexo}

La media de edad de la serie global para los pacientes que requirieron CEC durante el TP fue de 20,7 \pm 9,6 vs. 20,6 \pm 6,6 de los pacientes en los que no fue necesario la CEC $(\mathrm{p}=0,97)$. La frecuencia de CEC respecto al grupo de edad se presenta en la figura 32. 


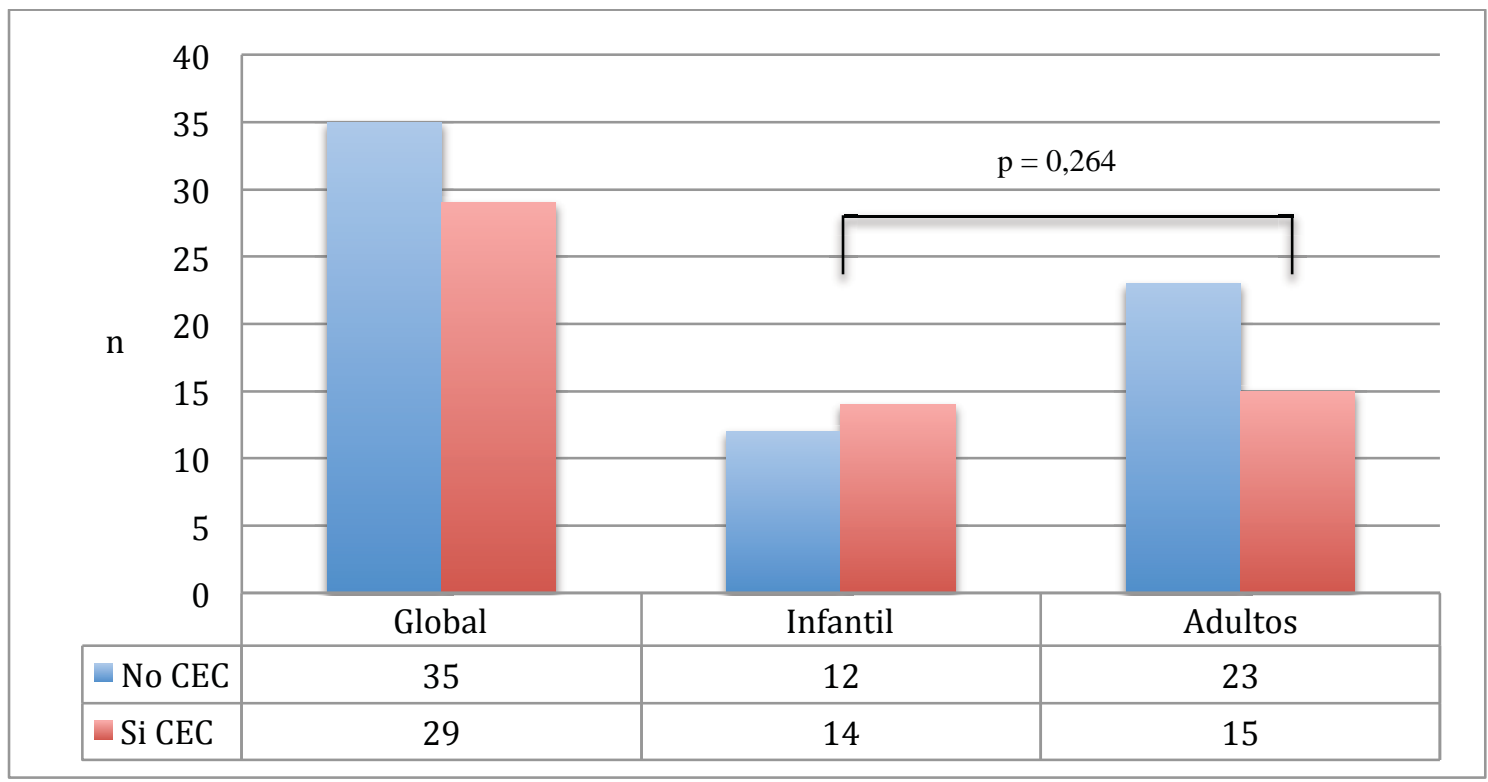

Figura 32. TP por FQ divididos grupo etario según la necesidad de CEC. Los valores se expresan en números absolutos.

Respecto al sexo de los receptores trasplantados bajo CEC, el $48 \%$ fueron del sexo masculino y el $52 \%$ del sexo femenino $(\mathrm{p}=0,80)$.

\section{Antropometría e IMC}

El peso medio de los receptores trasplantados bajo CEC fue de $41 \pm 13,4 \mathrm{Kg}$ con una talla media de $1,5 \pm 0,1$ metros.

Respecto al IMC, la media de los pacientes que necesitaron CEC fue de 16,89 \pm 2,55 vs. $17,05 \pm 3 \mathrm{Kg} / \mathrm{m}^{2}$ que no necesitaron el soporte extracorpóreo. No se encontraron diferencias entre los diferentes grupos de desnutrición. (Tabla VIII)

\begin{tabular}{lccc} 
& \multicolumn{2}{c}{ CEC } & Total \\
\cline { 2 - 4 } IMC & No & Si & $25(39,06 \%)$ \\
\hline Desnutrición severa & $14(49)$ & $11(37,93)$ & $8(12,5)$ \\
\hline Desnutrición moderada & $4(11,43)$ & $4(13,79)$ & $12(18,75)$ \\
\hline Desnutrición leve & $6(17,14)$ & $6(20,69)$ & $19(29,69)$ \\
\hline Peso normal & $11(31,43)$ & $8(27,59)$ & $64(100)$ \\
\hline Total & $35(54,69)$ & $29(45,31)$ & 0,984 \\
\hline
\end{tabular}

Tabla VIII. Grados de desnutrición de acuerdo a la necesidad de CEC. Los valores se expresan en números absolutos con porcentaje entre paréntesis. 
Tiempo entre el diagnóstico de FQ y el TP

Los receptores que necesitaron CEC para el TP, tuvieron una media de tiempo inferior desde el diagnóstico de FQ hasta el TP (195,10 vs. 234,83 meses, p = 0,025). (Figura 33)

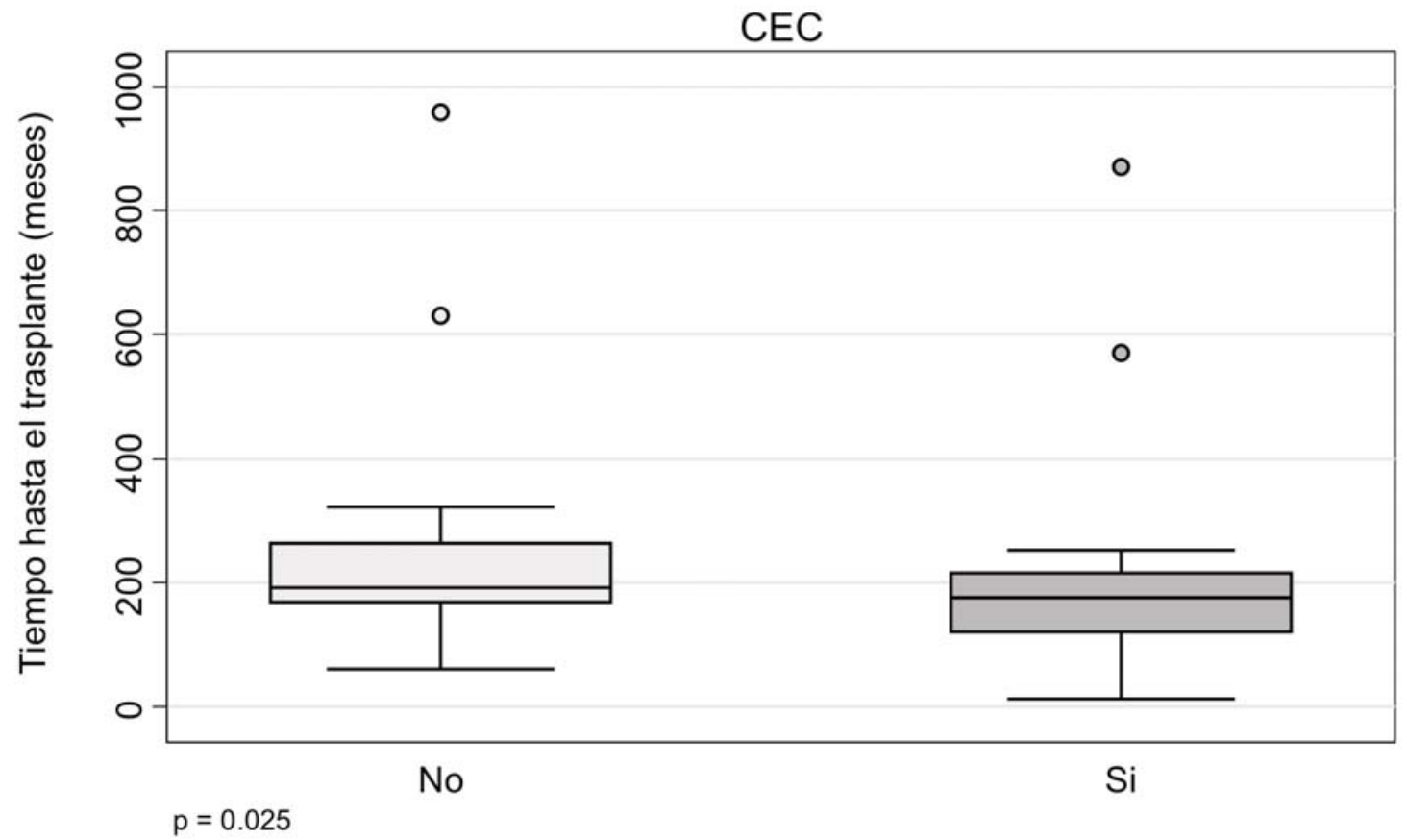

Figura 33. Comparativa de tiempo desde el diagnóstico de FQ hasta el TP divididos por la necesidad de CEC.

Tiempo en lista de espera de TP

Los pacientes que necesitaron CEC durante el TP estuvieron menos tiempo en lista de espera de TP $(7,86 \pm 8,7$ vs. $10,54 \pm 8,43$ meses, $p=0,20)$. (Figura 34 ) 


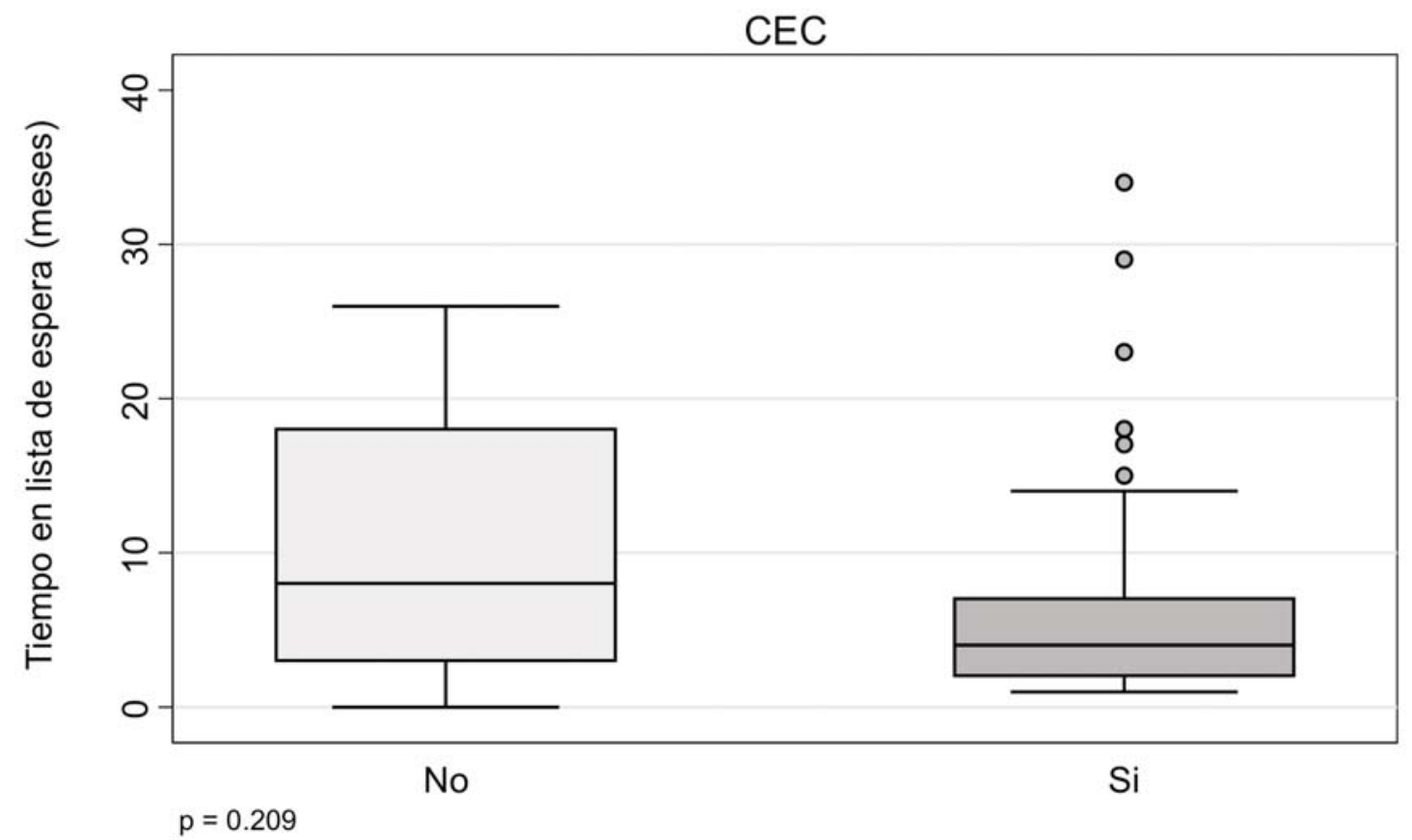

Figura 34. Comparativa de tiempo en lista de espera de TP divididos por la necesidad de CEC.

\section{Patología previa y requerimiento de oxígeno}

De los 20 pacientes de la serie global con diagnóstico previo al TP de DM, 10 fueron intervenidos bajo CEC ( $\mathrm{p}=0,787)$. Respecto a la IPE, de los 50 pacientes de la serie global con dicho diagnóstico, 21 fueron trasplantados bajo CEC $(p=0,372)$. (Figura 35)

Cincuenta y un pacientes de la serie fueron trasplantados mientras eran portadores de oxígeno domiciliario, de los cuales 25 , necesitaron soporte extracorpóreo durante la cirugía $(\mathrm{p}=0,351)$. Respecto a la VMNI, de los 13 pacientes trasplantados con dicho tratamiento, 9 necesitaron CEC durante el TP $(\mathrm{p}=0,052)$. (Figura 35) 


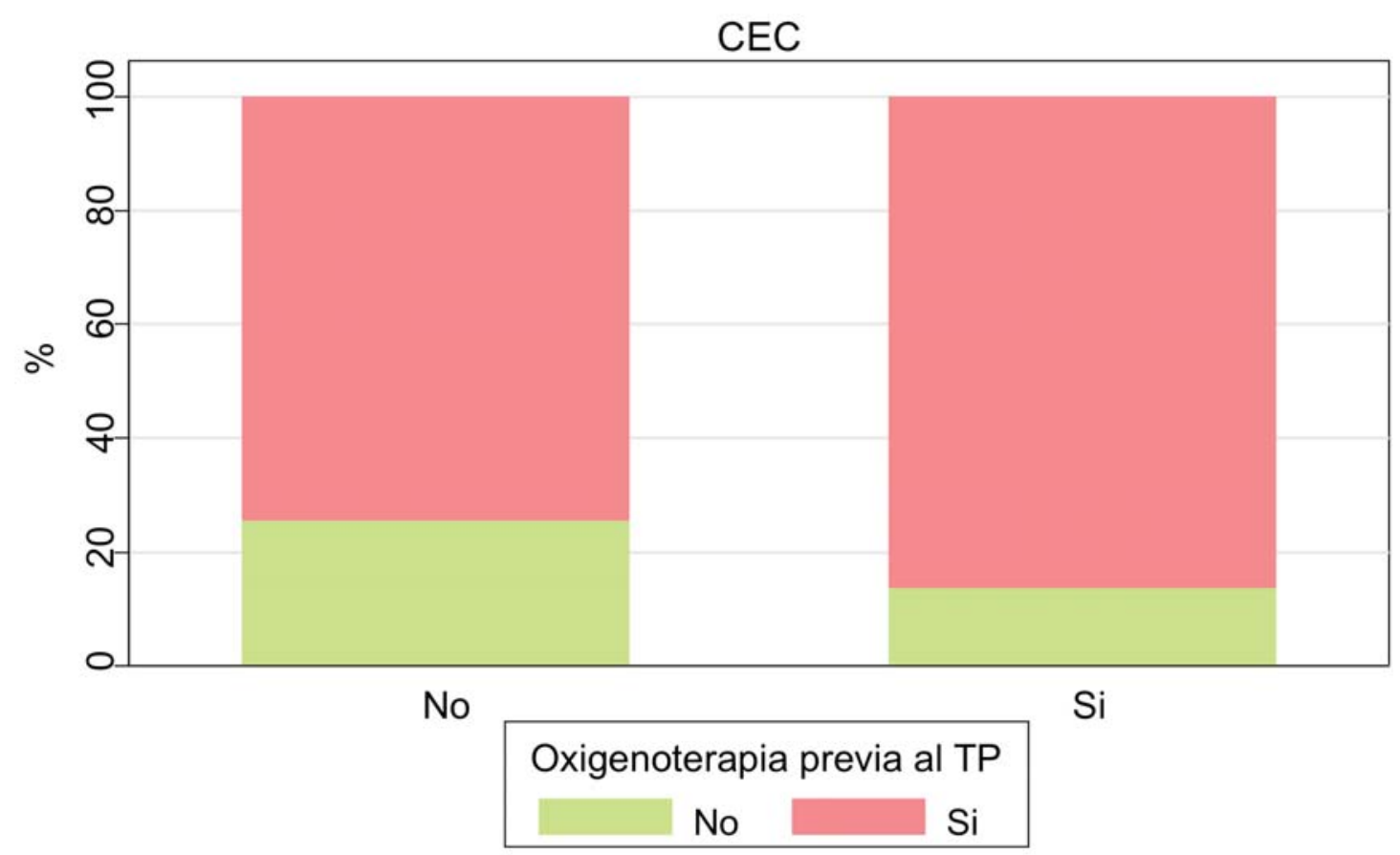

$p=0.351$

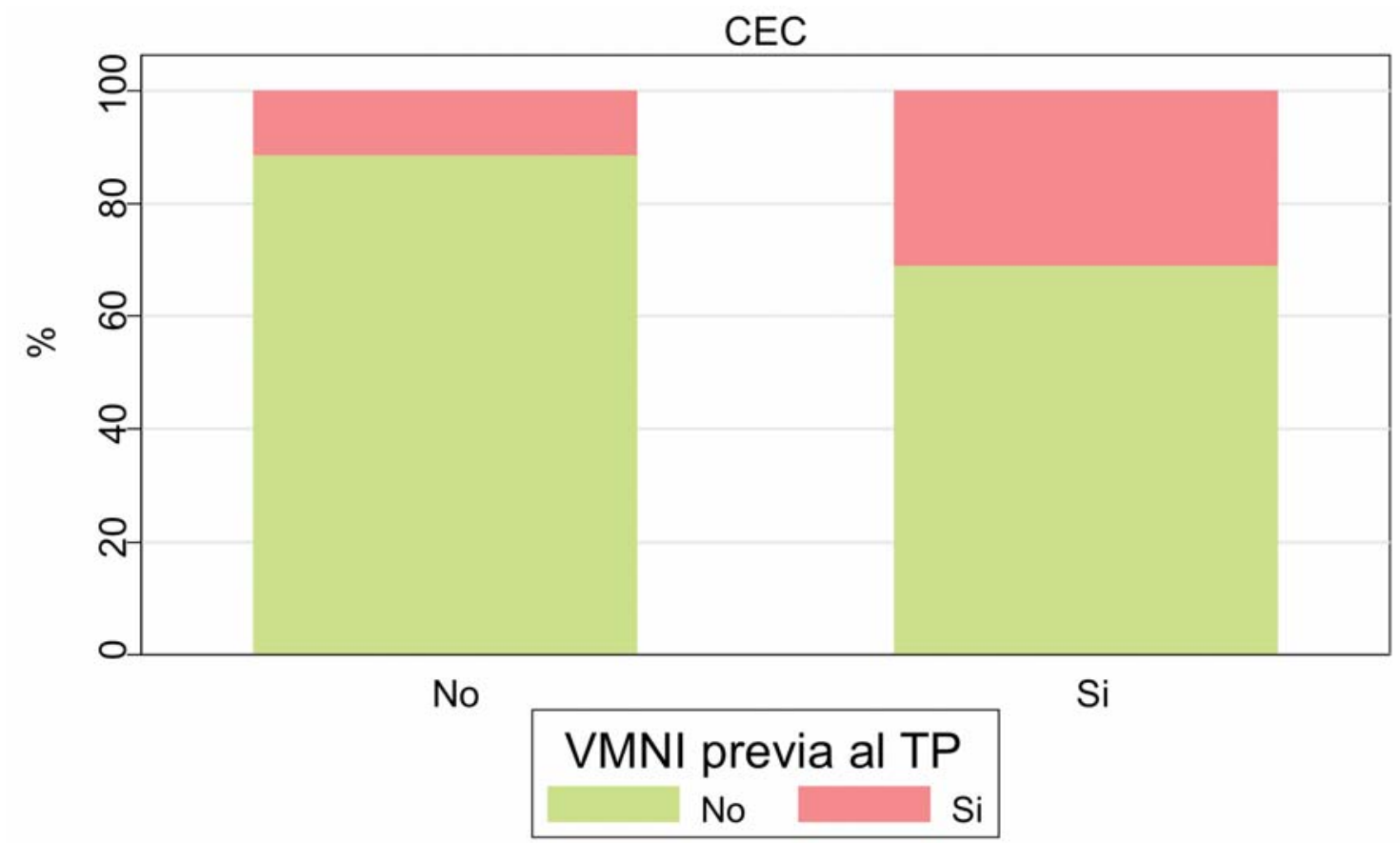

$p=0.052$

Figura 35. Proporción de pacientes con oxigenoterapia y VMNI trasplantados bajo CEC. 


\section{Funcionalismo pulmonar}

Al momento del TP, los pacientes que necesitaron CEC para la cirugía tenían medias de $\mathrm{PaO}_{2}$ de 58,2 mmHg y de $\mathrm{PaCO}_{2}$ de 53,7 mmHg, aunque los valores de $\mathrm{PaO}_{2}$ sean menores en los pacientes que requieren $\mathrm{CEC}$, dicho resultado no alcanza la significación estadística ( $\mathrm{p}=0,291)$, no así la $\mathrm{PaCO}_{2}$, que parece ser un factor que influye a favor de la necesidad de CEC ( $p=0,018)$. (Figura 36)
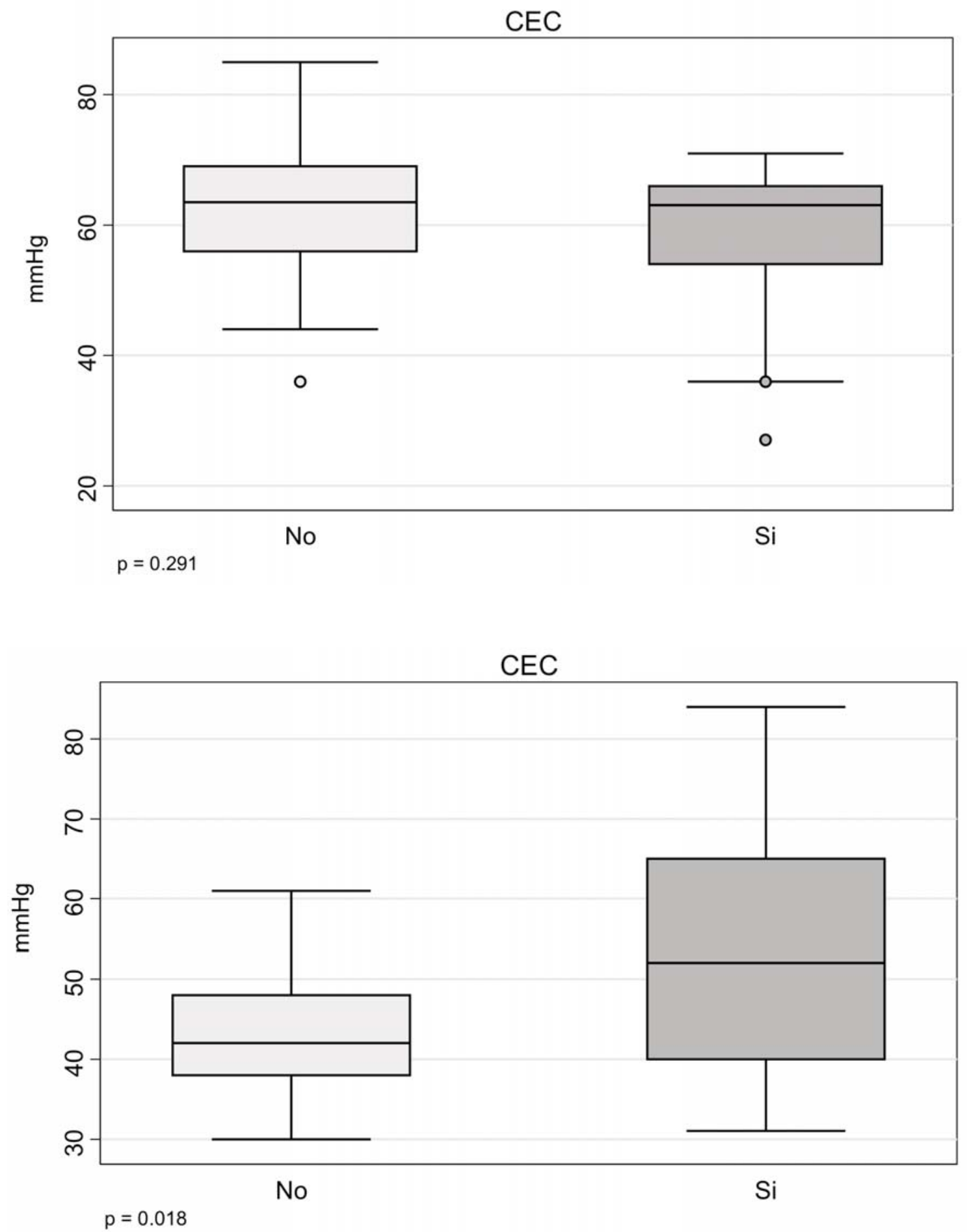

Figura 36. Comparativa de $\mathrm{PaO}_{2}$ y $\mathrm{PaCO}_{2}$ divididos por la necesidad de CEC. 
Respecto a las PFR determinadas antes del TP, en nuestra serie, todas las variables parecen influir en la necesidad de CEC excepto el $\mathrm{FEV}_{1}$ en porcentaje. (Tabla IX)

\begin{tabular}{|c|c|c|c|c|}
\hline \multirow[b]{2}{*}{ Variable $^{a}$} & \multicolumn{2}{|c|}{ CEC } & \multirow[b]{2}{*}{ Total } & \multirow[b]{2}{*}{ Valor $\mathbf{p}$} \\
\hline & No $(n=35)$ & $\mathrm{Si}(\mathrm{n}=29)$ & & \\
\hline FVC previo al TP $(\mathrm{mL})^{\mathrm{b}}$ & $1639(576,1)$ & $1191(587,7)$ & $1451,7(617,2)$ & $\mathbf{0 , 0 0 7}$ \\
\hline $\mathrm{FEV}_{1}$ previo al TP $(\mathrm{mL})^{\mathrm{b}}$ & $954,6(522,8)$ & $725,6(374,4)$ & $858,8(476,4)$ & 0,007 \\
\hline $\mathrm{FEV}_{1}$ previo al TP $(\%)^{\mathrm{c}}$ & $27,6(10,9)$ & $24,7(8,5)$ & $26,4(9,9)$ & 0,292 \\
\hline
\end{tabular}

Tabla IX. Características demográficas y clínicas de los pacientes incluidos en el análisis divididos en función de la CEC. CEC, circulación extracorpórea; FVC, Capacidad vital forzada; FEV1,Volumen espiratorio forzado en el primer segundo. ${ }^{a}$ Las variables continuas se muestran con la media y la desviación típica entre paréntesis y las categóricas con el número absoluto y el porcentaje sobre el valor total de datos válidos entre paréntesis.

${ }^{\mathrm{b}} \mathrm{FVC}_{\mathrm{y}} \mathrm{FEV}_{1}$ expresado en mililitros

${ }^{\mathrm{c}} \mathrm{FVC}_{\mathrm{y}} \mathrm{FEV}_{1}$ expresado como porcentaje sobre el teórico

En nuestra serie, una de las variables que parece tener relación con la necesidad de CEC es el 6WT (266,5 \pm 94,7 vs. 352,4 \pm 109 metros, $p=0,016)$. (Figura 37)

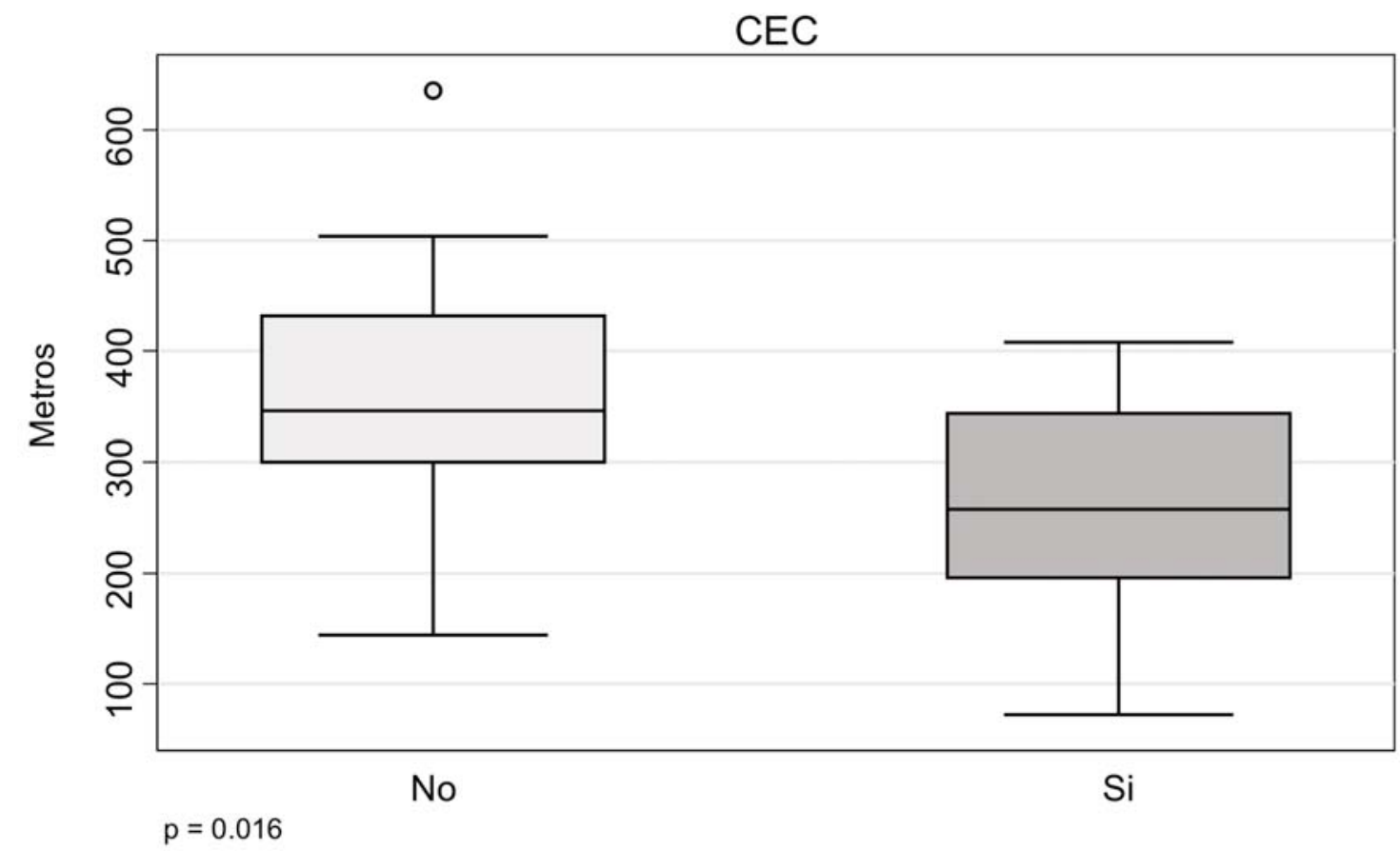

Figura 37. Comparativa de 6WT divididos por la necesidad de CEC.

\section{Hospitalizaciones durante el año previo al TP}

En el análisis de nuestra serie, no se encontraron diferencias entre el número de hospitalizaciones durante el año previo al TP entre los pacientes que requirieron CEC y los que no ( 2,91 vs. 2,19 hospitalizaciones, $\mathrm{p}=0,361$ ). 


\subsubsection{Análisis descriptivo del acto quirúrgico}

\section{Cirugía de reducción del injerto pulmonar}

De los $6(9,3 \%)$ pacientes de la serie global en los que fue necesario realizar alguna forma de resección pulmonar para adaptar el injerto pulmonar al receptor, 3 fueron realizados bajo CEC $(\mathrm{p}=0,808)$.

\section{Tiempo de isquemia}

El tiempo de isquemia medio del pulmón derecho trasplantado bajo CEC fue mayor en comparación al tiempo de isquemia sin el soporte extracorpóreo (338 \pm 115 vs. $309 \pm$ 111 minutos, $\mathrm{p}=0,411)$. El tiempo de isquemia del pulmón izquierdo también fue mayor en los pacientes que requirieron CEC $(320 \pm 127$ vs. $264 \pm 79$ minutos, $p=$ $0,172)$.

Al comparar las medias del tiempo de isquemia del segundo pulmón trasplantado con o sin CEC se aprecia que el soporte extracorpóreo aumenta significativamente dicho tiempo de isquemia (402 \pm 110 vs. $350 \pm 86$ minutos, $p=$ 0,046). (Figura 38)

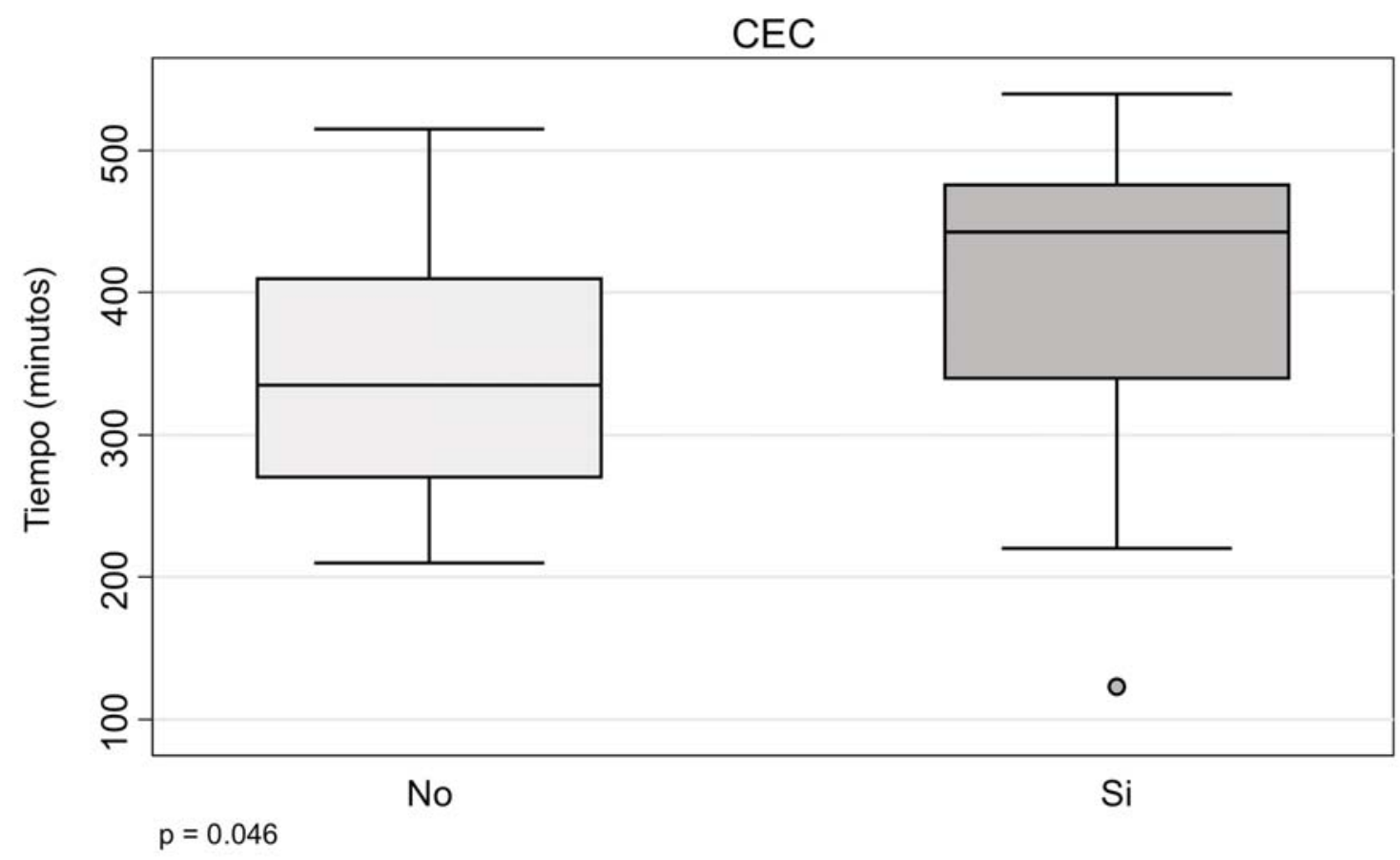

Figura 38. Comparativa de medias de tiempo de isquemia divididos por la necesidad de CEC. 


\subsubsection{Análisis descriptivo del postoperatorio.}

\section{Ventilación mecánica y estancia en UCI}

Los receptores que se trasplantaron con CEC estuvieron más tiempo con VM $(15,29 \pm$ 16,81 vs. $6,19 \pm 8,72$ días, $\mathrm{p}=0,012$ ) y requirieron más tiempo de ingreso en UCI $(22,56 \pm 20,20$ vs. $13,77 \pm 12,19$ días, $\mathrm{p}=0,049)$. (Figura 39)

Durante la estancia en UCI, de los $16(25,4 \%)$ pacientes de la serie global que presentaron paresia frénica, $5(7,8 \%)$ de los pacientes fueron trasplantados bajo CEC ( $\mathrm{p}$ $=0,25)$.

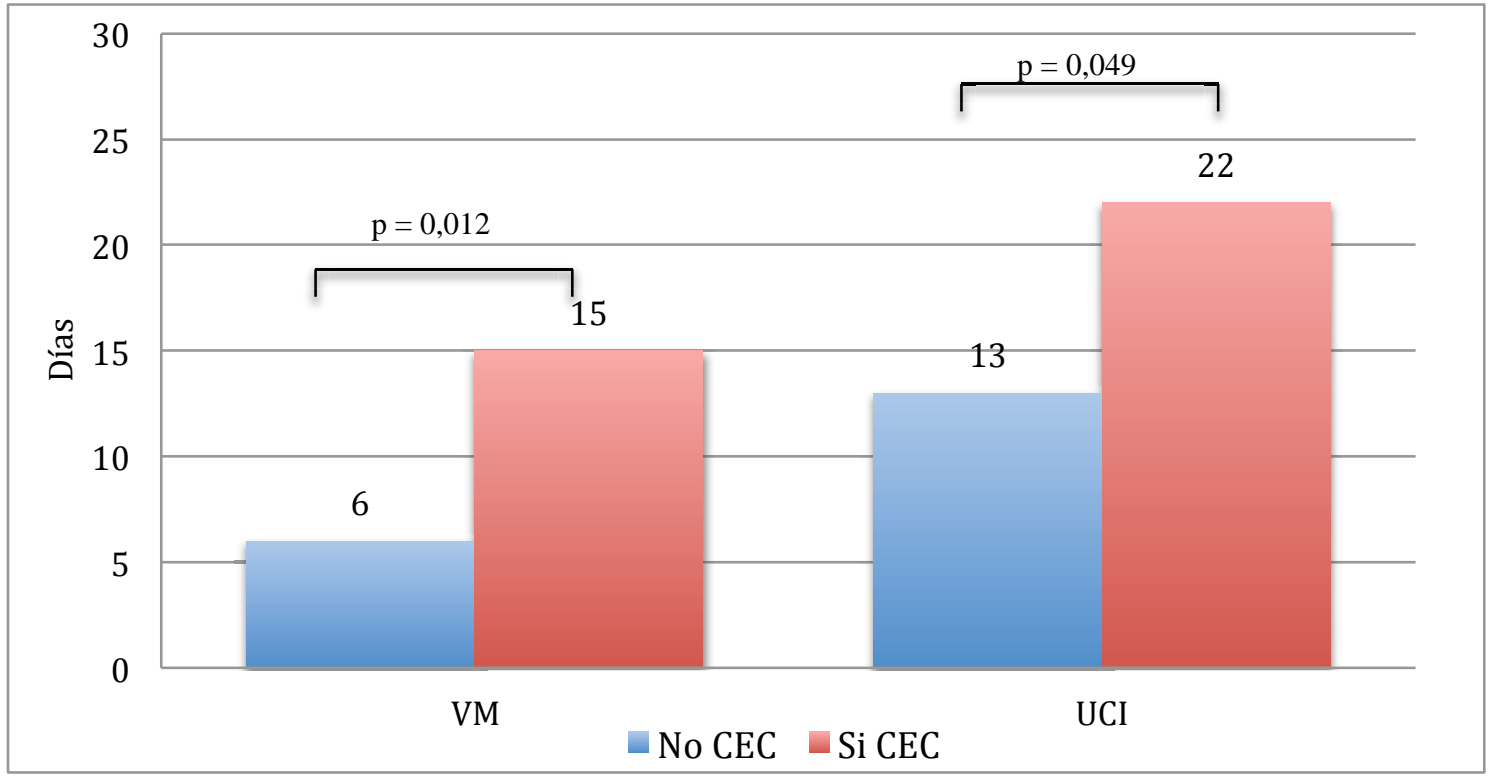

Figura 39. Comparativa de medias de días de VM y de ingreso en UCI divididos por la necesidad de CEC.

\section{Re intervención}

De los cinco receptores $(7,8 \%)$ de toda la serie que fueron re intervenidos posterior al trasplante, 4 (6,25\%) fueron trasplantados bajo CEC. En 2 casos, la causa de las re intervenciones fue por sangrado postoperatorio, sospecha de estenosis vasculares en 1 paciente y re sutura de anastomosis bronquial por fístula broncopleural precoz en otro paciente.

Todos los pacientes re intervenidos fallecieron en los primeros 7 días postoperatorios. 


\section{Infección respiratoria}

El número de pacientes con infecciones respiratorias posterior al TP no parece afectarse por la utilización de CEC ( $\mathrm{p}=0.43)$. (Tabla X)

\begin{tabular}{|c|c|c|c|c|}
\hline \multirow[b]{2}{*}{ Variable $^{\mathrm{a}}$} & \multicolumn{2}{|c|}{ CEC } & \multirow[b]{2}{*}{ Total } & \multirow[b]{2}{*}{ Valor $p$} \\
\hline & No $(n=35)$ & $\mathrm{Si}(\mathrm{n}=29)$ & & \\
\hline No IR & $15(42,8)$ & $9(31)$ & $24(37,5)$ & 0,438 \\
\hline Si IR & $20(57,2)$ & $20(69)$ & $40(62,5)$ & \\
\hline
\end{tabular}

Tabla X. Características demográficas y clínicas de los pacientes incluidos en el análisis divididos en función de la CEC. CEC, circulación extracorpórea; IR, Infección respiratoria.

${ }^{\text {a }}$ Las variables se muestran con el número absoluto y el porcentaje sobre el valor total de datos válidos entre paréntesis.

La Pseudomona aeruginosa se mantiene como el microorganismo más frecuente que se aísla en los pacientes con infecciones respiratorias posteriores al TP. (Figura 40)

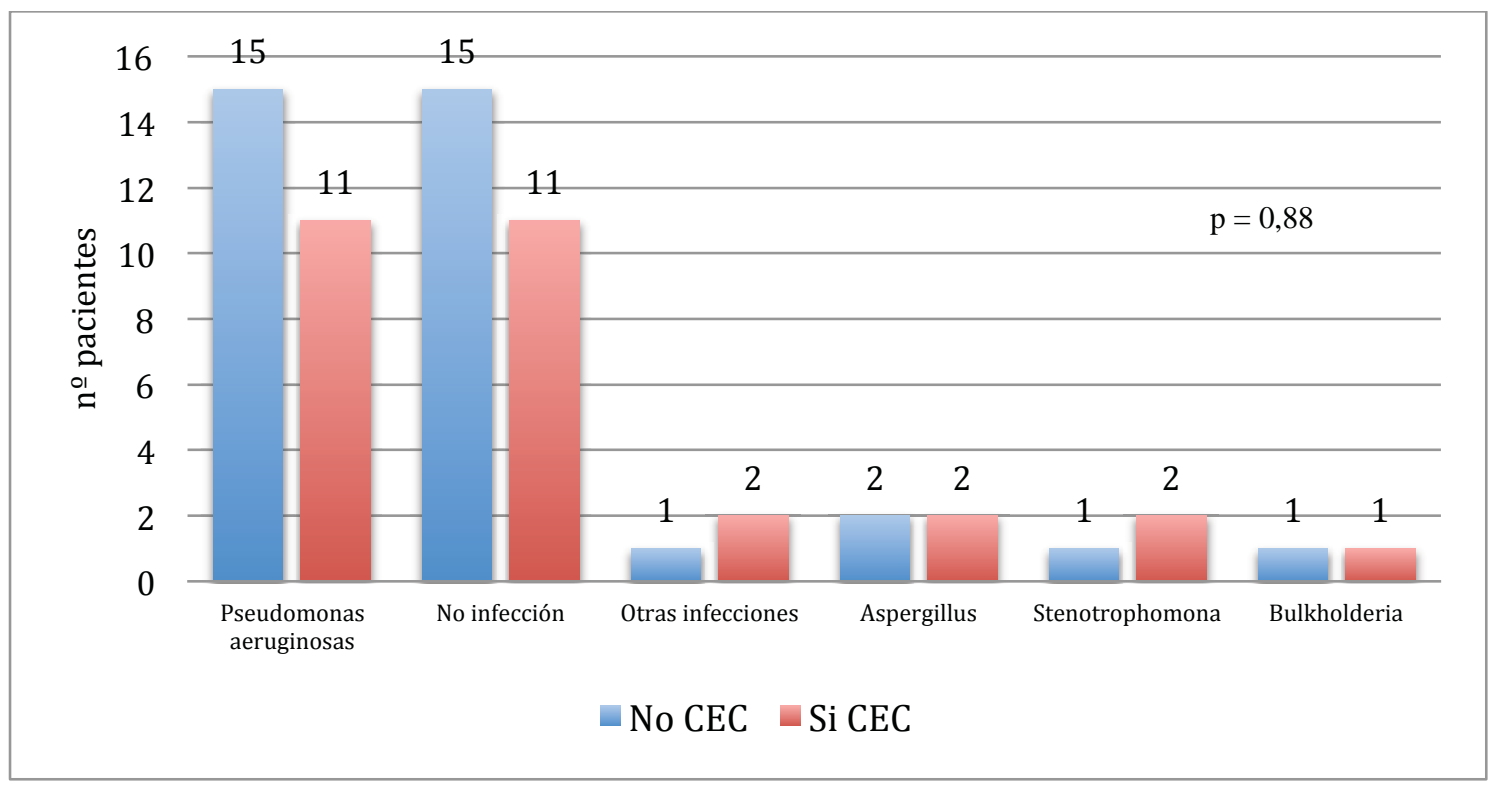

Figura 40. Etiología de las infecciones respiratorias posterior al TP de acuerdo a la CEC.

\section{Complicaciones de la anastomosis bronquial}

Respecto a la estenosis bronquial, del total de $10(15,6 \%)$ de la serie global, $3(4,6 \%)$ de las estenosis bronquiales izquierdas fueron en pacientes trasplantados bajo CEC ( $\mathrm{p}=$ 1,00). De los $2(3,1 \%)$ pacientes que presentaron dehiscencia parcial, uno de ellos fue del grupo de CEC $(\mathrm{p}=1,00)$. En cuento a la dehiscencia completa de la sutura bronquial, los $2(3,1 \%)$ pacientes que la presentaron, fueron del grupo de CEC ( $\mathrm{p}=$ $0,20)$. 


\section{Rechazo del injerto pulmonar}

El RA se diagnostico en 9 (14\%) pacientes trasplantados bajo CEC en comparación a 21 $(32,8 \%)$ pacientes con RA que fueron trasplantados sin CEC ( $\mathrm{p}=0,44)$. El diagnostico de los episodios de RA de los pacientes del grupo de CEC fue clínico en 5 (7,8\%) y con BTB en $6(9,3 \%)$.

El RC se diagnostico en 7 (10,9\%) pacientes del grupo de CEC en comparación a $14(21,8 \%)$ del grupo que no fueron trasplantados bajo CEC $(p=0,19)$.

\section{Funcionalismo pulmonar}

El funcionalismo pulmonar medido durante el postoperatorio no parece afectarse por la CEC. Resultados similares se presentan con los valores del mejor funcionalismo pulmonar medido durante el seguimiento. (Figura 41-42)

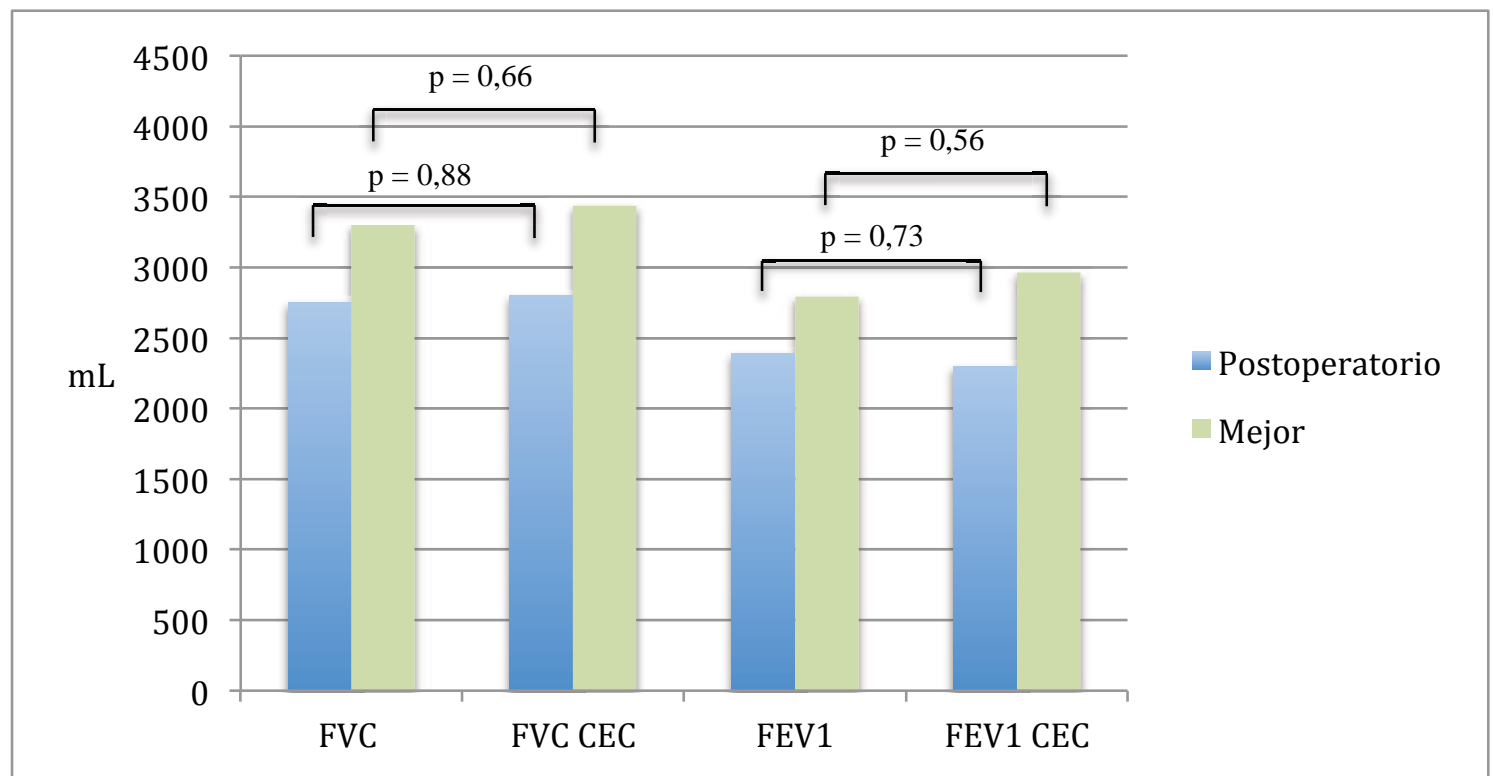

Figura 41. Comparativa de medias expresadas en mililitros $(\mathrm{mL})$ de valores funcionales respiratorios de acuerdo a la CEC. Se muestra la media de cada valor en el postoperatorio y la media de los mejores valores alcanzados durante el seguimiento.

FVC: Capacidad vital forzada; $\mathrm{FEV}_{1}$ : Volumen espiratorio forzado en el primer segundo 


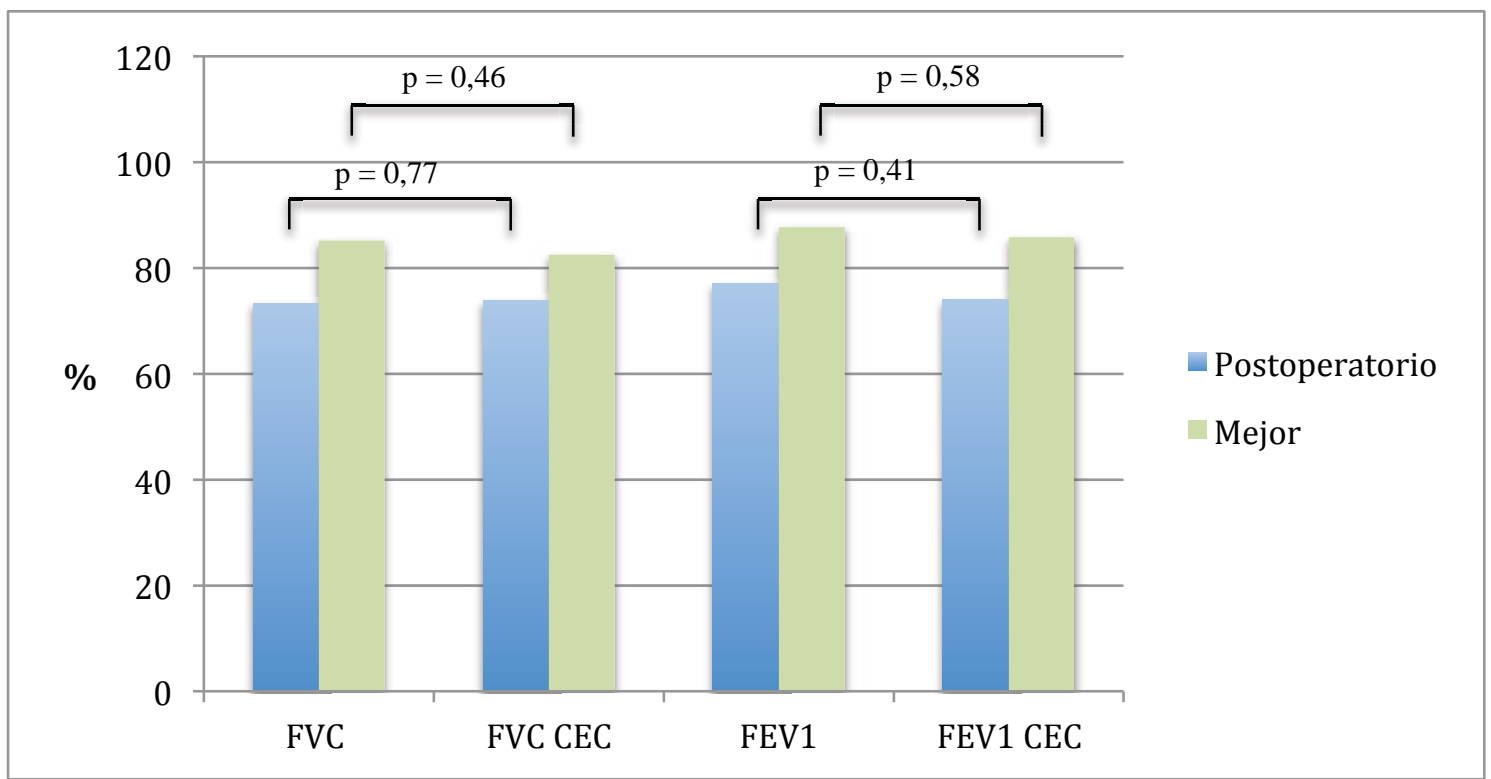

Figura 42. Comparativa de medias expresado en porcentaje (\%) de acuerdo al peso y la talla de los valores funcionales respiratorios de acuerdo a la CEC. Se muestra la media de cada valor en el postoperatorio y la media de los mejores valores alcanzados durante el seguimiento.

FVC: Capacidad vital forzada; $\mathrm{FEV}_{1}$ : Volumen espiratorio forzado en el primer segundo 


\subsubsection{Análisis univariante}

La supervivencia actuarial (Kaplan-Meier) de los pacientes trasplantados por FQ bajo CEC demuestra una disminución de la supervivencia de dichos pacientes. La supervivencia al año, 3, 5 y 10 años para los pacientes que no se trasplantan con CEC es del $91,43 \%, 82,86 \%, 75,69 \%$ y 49,06 \% respectivamente, mientras que los pacientes que se trasplantan bajo CEC tienen un supervivencia al año, 3, 5 y 10 años del 48,28 \%, $37,93 \%, 34,14 \%$ y $29,87 \%$ respectivamente $(\mathrm{p}=0,001)$. (Figura 43 )

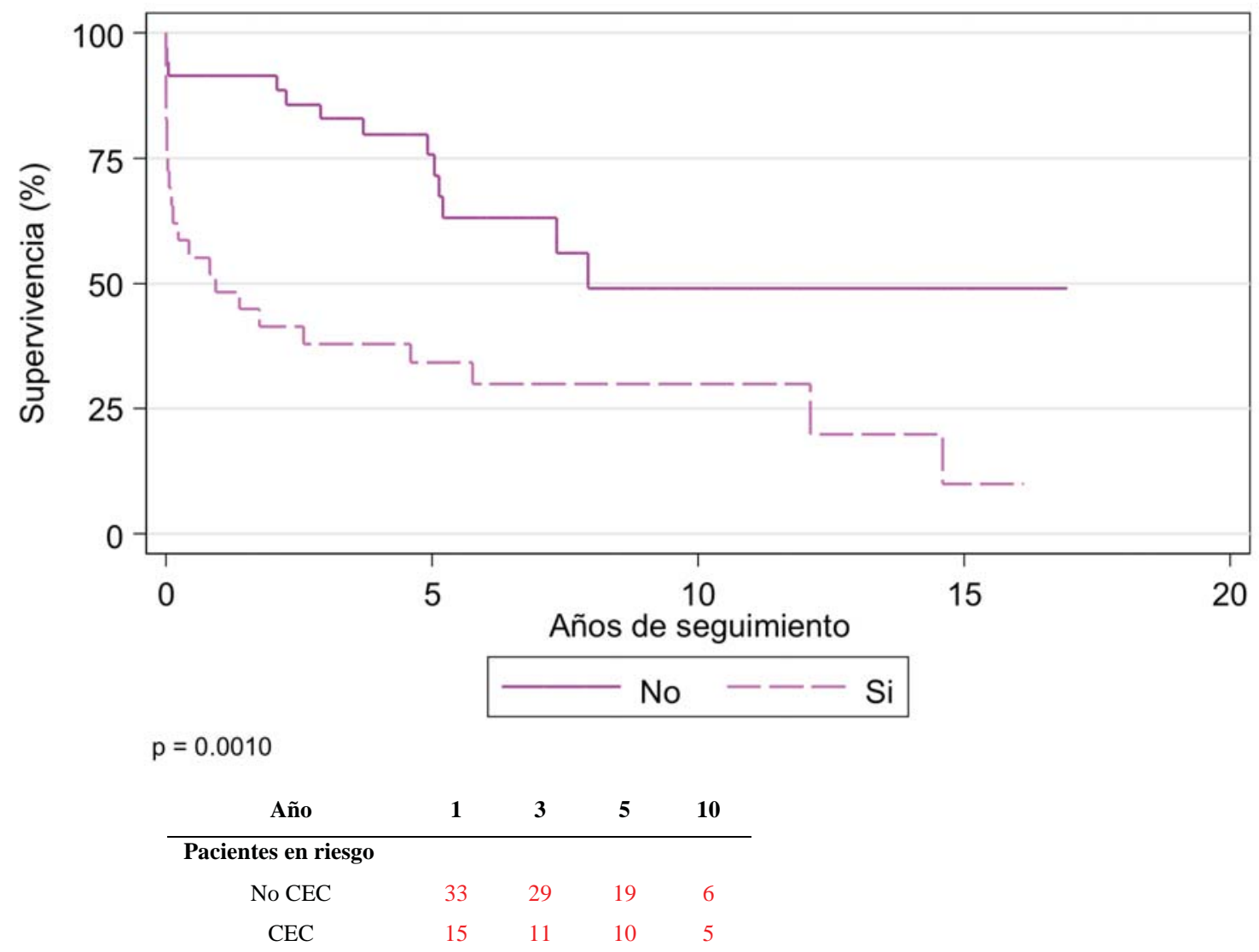

Figura 43. Supervivencia estratificada de acuerdo a la necesidad o no de CEC.

En el análisis univariante, para el posterior cálculo del Propensity Score, se han identificado 4 variables con significación estadística. (Tabla XI)

Las variables que alcanzaron la significación estadística corresponden al funcionalismo pulmonar previo al TP. $\mathrm{La} \mathrm{PaCO}_{2}$ (OR: 1,06; IC $95 \%$ : 1,01 - 1,12), el FVC mL (OR: 0,99; IC 95 \%: 0,99 - 1), el FVC \% (OR: 0,94; IC 95 \%: 0,9 - 0,99) y finalmente el 6WT (OR: 0,99; IC $95 \%$ : 0,98 - 1). 
RESULTADOS

\begin{tabular}{|c|c|c|}
\hline Variable & OR (IC 95\%) & Valor $\mathbf{p}$ \\
\hline Era & & 0,102 \\
\hline $1992-2002$ & 1 & \\
\hline $2003-2011$ & $0,43(0,15-1,19)$ & \\
\hline Edad (años) & $1(0,94-1,06)$ & 0,971 \\
\hline Sexo & & 0,632 \\
\hline Mujeres & 1 & \\
\hline Hombres & $0,79(0,29-2,11)$ & \\
\hline Peso (Kg) & $0,99(0,95-1,03)$ & 0,872 \\
\hline Talla (metros) & $0,62(0,03-12,08)$ & 0,753 \\
\hline $\mathrm{IMC}\left(\mathrm{Kg} / \mathrm{m}^{2}\right)$ & $0,98(0,82-1,17)$ & 0,818 \\
\hline IMC (Desnutrición) & & 0,965 \\
\hline Severa & 1 & \\
\hline Moderada & $1,27(6,26-6,27)$ & \\
\hline Leve & $1,27(0,32-5,06)$ & \\
\hline Peso normal & $0,93(0,28-3,09)$ & \\
\hline Mutación & & 0,677 \\
\hline$\Delta \mathrm{F}_{508}$ & 1 & \\
\hline $6542 X$ & $1(1-1)$ & \\
\hline N1303K & $1,77(0,10-30,7)$ & \\
\hline Otras & $1,77(0,22-14,09)$ & \\
\hline $\mathrm{NC}$ & $1,97(0,64-6,08)$ & \\
\hline Tiempo Diagnóstico - TP (meses) & $0,99(0,99-1)$ & 0,337 \\
\hline Tiempo lista de espera (meses) & $0,96(0,91-1,02)$ & 0,215 \\
\hline DM previo al TP & $1,32(0,46-3,80)$ & 0,611 \\
\hline IPE previa al TP & $0,54(0,16-1,80)$ & 0,318 \\
\hline Oxigenoterapia previa al TP & $2,16(0,59-7,93)$ & 0,244 \\
\hline VMNI previa al TP & $3,49(0,95-12,86)$ & 0,06 \\
\hline $\mathrm{PaO}_{2}(\mathrm{mmHg})$ & $0,97(0,92-1,02)$ & 0,287 \\
\hline $\mathrm{PaCO}_{2}(\mathrm{mmHg})$ & $1,06(1,01-1,12)$ & 0,027 \\
\hline FVC previo al TP $(\mathrm{mL})^{\mathrm{a}}$ & $0,99(0,99-1)$ & 0,013 \\
\hline FVC previo al TP $(\%)^{\mathrm{b}}$ & $0,94(0,9-0,99)$ & 0,024 \\
\hline $\mathrm{FEV}_{1}$ previo al TP $(\mathrm{mL})^{\mathrm{a}}$ & $0,99(0,99-1)$ & 0,110 \\
\hline $\mathrm{FEV}_{1}$ previo al TP $(\%)^{\mathrm{b}}$ & $0,97(0,91-1,03)$ & 0,285 \\
\hline 6WT previo al TP (metros) & $0,99(0,98-1)$ & 0,025 \\
\hline Hospitalizaciones último año & $1,27(0,87-1,86)$ & 0,217 \\
\hline
\end{tabular}

Tabla XI. Análisis univariante de los factores de riesgo de CEC por el método de riesgos proporcionales de Cox. OR, razón de riesgo; IC $95 \%$, intervalo de confianza al $95 \%$; IMC, índice de masa corporal; $\Delta$ F508, Deleción de nucleótidos que codifican fenilalanina en la posición 508; DM, diabetes mellitus; IPE, insuficiencia pancreática exocrina; VMNI, Ventilación mecánica no invasiva, $\mathrm{PaO}_{2}$, Presión parcial de oxígeno; $\mathrm{PaCO}_{2}$, Presión parcial de dióxido de carbono; FVC, Capacidad vital forzada; FEV1,Volumen espiratorio forzado en el primer segundo; 6WT, Test de la marcha en 6 minutos.

${ }^{\text {a }} \mathrm{FVC}_{\mathrm{y}} \mathrm{FEV}_{1}$ expresado en mililitros

${ }^{\mathrm{b}} \mathrm{FVC}_{\text {y }} \mathrm{FEV}_{1}$ expresado como porcentaje sobre el teórico 


\subsubsection{Análisis multivariante}

Con las variables que obtienes un resultado significativo en el estudio univariante, se realiza un modelo logístico para calcular la probabilidad de necesidad de CEC durante el TP. En el estudio multivariante, se aprecia que dichas variables tienen 3 veces más probabilidades de requerir CEC durante el TP en comparación con el resto de variables analizadas. (Tabla XII)

\begin{tabular}{lccc}
\hline Variable & HR & IC 95 \% & Valor $\mathbf{p}$ \\
\hline CEC & 1 & & $\mathbf{0 , 0 0 6}$ \\
\hline No & 3,11 & $1,38-7$ & \\
\hline $\mathrm{Si}$ & 1,04 & $1,01-1,04$ & $\mathbf{0 , 0 3 5}$ \\
\hline PaCO$(\mathbf{m m H g})$ & 1 & $1-1$ & 0,903 \\
\hline FVC previo al TP $(\mathbf{m L})^{\mathbf{a}}$ & 1 & $1-1$ & 0,064 \\
\hline 6WT previo al TP $($ metros $)$ & & & \\
\hline
\end{tabular}

Tabla XII. Análisis multivariante de los factores de riesgo de CEC. Modelo final de regresión de riesgos proporcionales de Cox con las variables estadísticamente significativas del estudio univariante.

HR, razón de tasas de riesgo; IC $95 \%$, intervalo de confianza al $95 \%$; $\mathrm{PaCO}_{2}$, Presión parcial de dióxido de carbono; FVC, Capacidad vital forzada; 6WT, Test de la marcha en 6 minutos.

${ }^{\mathrm{a}} \mathrm{FVC}$ expresado en mililitros 
6. DISCUSIÓN 

El TP se ha constituido en una terapéutica válida para el tratamiento de muchas enfermedades pulmonares en estadios finales. Desde el inicio del programa de TP una de sus indicaciones más frecuentes ha sido los pacientes afectos de FQ con enfermedad pulmonar avanzada.

El Hospital Universitario Vall d'Hebron, inicia su programa de TP en 1990, y hasta diciembre de 2016 se han realizado más de 900 TP en dicho centro. ${ }^{205,206}$

Según el registro Español de Trasplante Pulmonar ${ }^{189}$ entre los años 2006 a 2010 se han trasplantado a 950 pacientes en España, de los cuales $328(34,5 \%)$ han sido por EPOC, $261(27,5 \%)$ por FP y $117(12,3 \%)$ por FQ. Por lo tanto, la FQ se posiciona como la tercera patología más frecuente para el TP.

Según datos de la ONT, en el año 2016, la lista de espera para TP la constituían 668 pacientes, de los cuales $66(10 \%)$ eran pacientes con FQ. Durante el 2016 se realizaron 307 TP a nivel nacional, de los cuales 31 (10\%) fueron por FQ (Estadística de la ONT. Disponible en www.ont.es).

Desde el primer trasplante cardiopulmonar en pacientes con FQ en Norte América en 1983, las indicaciones y la técnica operatoria ha variado sustancialmente. ${ }^{207}$ En un inicio se utilizó el trasplante corazón-pulmón, técnica que se mantuvo hasta la década de los años 90. Actualmente la gran mayoría de pacientes con FQ reciben un TBP por lo que el corazón puede ser válido para otro receptor. La excepción son los pacientes con enfermedades cardíacas no subsidiarias de tratamiento médico/quirúrgico y por tanto la indicación en estos casos sería el trasplante de corazón y pulmón. Aunque según el reporte de la ISHLT, la FQ ha dejado de ser una de las indicaciones más 
importantes para el trasplante cardiopulmonar y actualmente, 2/3 de los pacientes que requieren este tipo de trasplante es por enfermedades cardíacas congénitas y la HTP. ${ }^{208}$

Los pacientes aceptados para TP en nuestra serie fueron evaluados y siguieron los criterios de inclusión propuestos por las guías internacionales ${ }^{45,99,104,209,210}$, sin embargo, también se adaptaron ciertos criterios individualizando cada paciente según el estado de su enfermedad y su calidad de vida, dichos parámetros se han comentado en publicaciones previas. ${ }^{211}$

\subsection{SERIE ANALIZADA}

La serie analizada en este estudio incluye a 64 paciente con FQ que recibieron un TP en el período de abril de 1992 - septiembre de 2011 en el Hospital Universitario Vall d'Hebron de Barcelona. El número anual de TP por FQ no ha sido constante, con un incremento en los años 2009 y 2010 con 9 y 8 TP respectivamente.

El número de TP por FQ varía notablemente entre las diferentes series publicadas, como también es variable el número de trasplantes anuales realizados por cada centro. ${ }^{56,184,185,212,213}$ Respecto a series nacionales, como la de Pablo y cols, ${ }^{186}$ que publica su serie de 27 pacientes trasplantados por FQ en un período de 11 años y el grupo de TP del Hospital Reina Sofía de Córdoba que ha publicado recientemente una serie de 120 pacientes TP por FQ en un período de 20 años. ${ }^{187}$

El tratamiento de un patología tan particular como la FQ y con características clínicas de afectación a múltiples órganos, obliga que dichos pacientes sean tratados en centros con amplia experiencia y con equipos multidisciplinares. Además, el TP sólo se realiza en pocos centros de nuestro territorio. Todo ello puede explicar las diferencias en el número de trasplantes reportados por cada centro. 


\subsection{SOLUCIÓN DE PRESERVACIÓN PULMONAR}

Durante los 10 primeros años de la serie (1992 - 2002), la solución de preservación pulmonar utilizada fue Euro-Collins ${ }^{\circledR}$ y a partir del año 2003, la solución de preservación utilizada en todos los TP por FQ fue el Perfadex ${ }^{\circledR}$.

Existen reportes de la utilización de Perfadex ${ }^{\circledR}$ desde mediados de $1990 .{ }^{214-216} \mathrm{~A}$ inicios de la década del año 2000, se observó una tendencia a nivel mundial a utilizar Perfadex ${ }^{\circledR}$ como única solución de preservación pulmonar, dicho cambio se vio respaldado por múltiples publicaciones científicas que confirmaban la mejor conservación del injerto pulmonar con Perfadex ${ }^{\circledR}$ frente a otras soluciones de preservación. $^{217-219-220,60,215,221-224}$

Nuestra serie coincide en años con dicho cambio en la solución de preservación al adoptar el Perfadex ${ }^{\circledR}$ como solución de preservación en todos los trasplantes pulmonares por FQ.

\subsection{CARACTERÍSTICAS DEMOGRÁFICAS}

En nuestra serie, la edad media de los receptores fue de 20,7 años. Los pacientes del programa de TP pediátrico (hasta los 17 años) tuvieron una media de edad al momento del TP de 13,9 años y los pacientes del grupo de adultos de 35,3 años. El paciente más joven de la serie tenía 9 años al momento del TP.

En la revisión de 8 años de TP por FQ en un solo centro, Wiebe y cols reportaron una edad media de 26 años, siendo el paciente pediátrico más joven de 12 años. ${ }^{54}$ La mayoría de series publicaciones de pacientes con FQ presentan resultados similares de acuerdo a la edad ${ }^{185,186,225-227}$.

La FQ ya no se considera actualmente una enfermedad de la edad pediátrica. La evolución en las mejoras de la terapia a permitido que los pacientes con FQ puedan sobrevivir hasta la edad adulta. La edad media de nuestros pacientes se corresponde con dicho comportamiento aunque muchos de los pacientes de la serie eran infantiles. 
Se sabe que existen genotipos de FQ que pueden ser más agresivos y condicionar que tratamientos como el TP se requiera en edades más tempranas. ${ }^{228-232}$

Respecto al sexo de los receptores, nuestra serie reporta una frecuencia ligeramente mayor del sexo masculino (51,5\%). En la serie publicada por Coloni y cols ${ }^{225}$ sobre 56 pacientes con FQ que recibieron un TP, el 46,4\% fueron del sexo masculino $(53,5 \%)$. Resultados similares presenta Quattrucci y cols en su serie de 55 pacientes con FQ, de los cuales el sexo masculino representa un $52,7 \% .^{212}$ Una de las series más amplias de pacientes con FQ en base a 176 trasplantados, reporta una ligera mayoría del sexo femenino $(51,7 \%){ }^{70}$

En nuestro medio, una de las series nacionales que incluye a 27 pacientes con FQ el número de pacientes de sexo masculino es ligeramente menor $(40,7 \%){ }^{186}$

Un estudio en base a 109 pacientes con FQ que evalúa la implicación del sexo en la actividad física habitual, concluye que el sexo femenino tiene menor actividad diaria y por tanto una disminución en el funcionalismo pulmonar que podría condicionar una peor supervivencia. ${ }^{233}$ Otras publicaciones también concluyen que la supervivencia del sexo femenino con FQ es menor en comparación con el sexo masculino. $^{234}$

No parece que exista un mayor número de trasplantes de acuerdo al sexo, aunque, como se ha comentado previamente, la disminución de la supervivencia en el sexo femenino puede ser un factor a tener en cuenta a la hora de incluir a dichos pacientes en las listas de espera. La ISHLT recomienda la inclusión en lista de espera para TP, entre otras, a una caída del $\mathrm{FEV}_{1}$ menor del 30\%, o disminución rápida del $\mathrm{FEV}_{1}$, sobretodo en el sexo femenino. ${ }^{104}$

El grupo sanguíneo de los pacientes incluidos en esta serie fueron en su mayoría, del grupo A $(56 \%)$.

No se han encontrado publicaciones que informen sobre el grupo sanguíneo de los receptores de TP por FQ. Si bien en el registro de la ONT se detalla que durante el año 2015, el 44,8\% de los receptores de TP en general fueron del grupo A (Grupo 0: 
38,4\%; Grupo B: 11,2\% y grupo AB: 5,44\%) (Estadística de la ONT. Disponible en www.ont.es).

\subsection{PREOPERATORIO}

El peso y la talla media de los pacientes de nuestra serie fue de $41 \mathrm{Kg}$ y $1,5 \mathrm{~m}$ respectivamente. En el reporte de Fulton y $\operatorname{cols}^{235}$ sobre pacientes pediátricos con FQ que fueron trasplantados pulmonares, la media de peso fue de $33,5 \pm 10,7 \mathrm{Kg}$ en el momento de la cirugía que aumentó a $35,4 \mathrm{Kg}$ a los 2 meses del TP.

Respecto a la talla, Bell y cols ${ }^{236}$ en su trabajo publicado en 1998 sobre una población general de 150 pacientes con $\mathrm{FQ}$, describen que la talla media tiende a ser menor en comparación a sujetos no-FQ con una media entre los 15 y los 19 años de 1,6 m. Otras series nacionales presentan datos muy similares a los nuestros con medias de peso de $47 \mathrm{Kg}$ y talla de $1,6 \mathrm{~m} .^{186}$

Los datos antropométricos de nuestros pacientes coinciden con los presentados en la literatura. Se trata pues, de un grupo de pacientes que no suelen pesar más de 50 $\mathrm{Kg}$ y cuya altura no suele exceder los 1,6 metros. La afectación metabólica que afecta a los pacientes con FQ condiciona los bajos valores de peso y talla. Se ha relacionado la baja estatura con un aumento en la mortalidad en la lista de espera fruto de la dificultad para encontrar donantes adecuados para el tamaño de la caja torácica de dichos pacientes. $^{237}$

El IMC de nuestra serie presenta una media de $16,9 \pm 2,7 \mathrm{Kg} / \mathrm{m}^{2}$, resultados muy similares a los publicados por una serie italiana de 55 pacientes con FQ que recibieron un TP $\left(\mathrm{IMC} 17,3 \pm 2,1 \mathrm{Kg} / \mathrm{m}^{2}\right) .{ }^{212}$

Hollander y cols ${ }^{238}$ publican un estudio sobre la evolución del IMC antes y después del TP, aunque no se valora la influencia del IMC sobre la mortalidad posterior al TP, describen que el grupo de pacientes $(n=75)$ analizados tenía una media de IMC de 19,2 (r: $15,3-28,4) \mathrm{Kg} / \mathrm{m}^{2}$. 
En la publicación de Calañas y $\operatorname{cols}^{239}$ en el que se valora el estado nutricional de los candidatos a TP se incluye a la FQ dentro de la categoría de enfermedades sépticas, junto con las bronquiectasias y sobre 47 pacientes evaluados en éste grupo, el IMC fue de $19,2 \pm 3,6 \mathrm{Kg} / \mathrm{m}^{2}$.

En el estudio publicado por Snell y cols ${ }^{240}$ sobre 45 pacientes trasplantados por FQ se concluye que el sexo femenino con IMC $<$ a $18 \mathrm{Kg} / \mathrm{m}^{2}$ tiene mayor riesgo de mortalidad a los 12 meses siguientes al inicio de la lista de espera para TP.

La implicación del IMC en la supervivencia del TP fue evaluado en una serie de casos del año 2002, que aunque no incluye pacientes con FQ, pone de manifiesto que los pacientes con IMC menor a $18,5 \mathrm{Kg} / \mathrm{m}^{2}$ tienen una mejor supervivencia a los 50 meses del TP, aunque posteriormente la supervivencia disminuye. ${ }^{241}$

Nuestra población de estudio presenta una IMC inferior al publicado en la literatura. Dicho resultado probablemente sea debido a que nuestros pacientes no fueran controlados en centros especializados de FQ y por lo tanto no puedan haber mantenido un correcto control del estado nutricional o que la decisión de incluir a los pacientes en la lista de espera de TP fue más permisiva en comparación a otros centros en los cuales el IMC juega un papel determinante a la hora de aceptar o rechazar a los pacientes para TP.

En nuestra serie se han dividido a los receptores en grupos de IMC de acuerdo a la clasificación nutricional de la OMS. ${ }^{199}$ No se encontraron diferencias respecto a la mortalidad independientemente de su grado nutricional $(\mathrm{p}=0,92)$. El grupo de trasplante pulmonar del Hospital General de Toronto publica en 2001 un trabajo que evalúa al IMC como factor de mortalidad a los 90 días del TP. Entre sus conclusiones, un $\mathrm{IMC}<$ a $17 \mathrm{Kg} / \mathrm{m}^{2}$ o $>$ a $25 \mathrm{Kg} / \mathrm{m}^{2}$ se asocia a un mayor riesgo de mortalidad a los 90 días. $^{242}$

El IMC bajo se ha relacionado con un peor funcionalismo pulmonar ${ }^{243,244}$ y es considerado por algunos autores como un predictor de mala evolución. ${ }^{245,246}$ 
Aunque el IMC bajo no es una contraindicación para el trasplante, es motivo de debate en los diferentes grupos trasplantadores a la hora de decidir cual es el punto de corte para iniciar la lista de espera. Nuestro estudio no encuentra diferencias en la mortalidad de los pacientes trasplantados de acuerdo al IMC, incluso en los casos de desnutrición severa $(\mathrm{p}=0,92)$.

En la serie analizada, la mutación más frecuente fue la $\Delta \mathrm{F}_{508}$ en $36(56,2 \%)$. A destacar que, un número significativo de pacientes de la serie, no tenían identificado el tipo de mutación $(29,6 \%)$.

En un estudio publicado sobre la relación entre el genotipo y fenotipo en la FQ, la prevalencia de la mutación $\Delta \mathrm{F}_{508}$ se encontró hasta en el $71 \%$ de los pacientes analizados $(\mathrm{n}=293){ }^{228}$

En el estudio publicado por de Gracia y cols ${ }^{247}$ sobre los tipos de mutaciones del gen RTFQ detectados en 111 pacientes, la mutación $\Delta \mathrm{F}_{508}$ estaba presente en $40,5 \%$ y eran desconocidas en $22,5 \%$. A pesar de la diferencia en la frecuencia de mutación más importante de FQ entre nuestro estudio y el mencionado, el número de casos con desconocimiento de perfil genético es también elevado. En nuestro estudio dicho resultado de casos desconocidos se podría atribuir a que en los años iniciales del estudio, los pacientes eran diagnosticados sobre una base clínico - laboratorial (test del sudor) en comparación a los casos más recientes, en que el diagnóstico genético se encuentra más extendido.

Los pacientes de nuestra serie con la mutación $\Delta \mathrm{F}_{508}$ tuvieron una menor mortalidad respecto al resto de mutaciones $(0,04)$. Un estudio sobre 183 pacientes adultos con FQ cuyo objetivo era identificar los factores de mortalidad, concluye que los pacientes con la mutación $\Delta \mathrm{F}_{508}$ no tienen afectación de la supervivencia. ${ }^{248}$

En el presente estudio, la media del tiempo entre el diagnóstico de FQ, independientemente de si el diagnóstico fue clínico - laboratorial o genético y el TP fue de 181,7 meses. 
El tiempo medio en lista de espera para TP de nuestra serie fue de 9,3 $\pm 8,5$ (r: 0 - 34) meses, resultado que se encuentra dentro de los tiempos en lista de espera publicados en la literatura según las diversas publicaciones; entre 6,8 y 47 meses. ${ }^{111,212,222,227,240,249,250}$

El tiempo en lista de espera general en España se encuentra en $20 \pm 18,4$ meses. (Estadística de la ONT. Disponible en www.ont.es). El menor tiempo de espera de los pacientes con FQ puede deberse a la relativa urgencia con la que algunos de éstos pacientes se tienen que trasplantar. Según el informe de la ONT, la FQ es una de las causas más importantes de trasplante preferente (28\% en el año 2014).

En nuestra serie, la proporción de pacientes con DM que fueron trasplantados fue del 31,2 \%. Según reportes del Reino Unido con valores de 10,5 \% y de los Estados Unidos de Norteamérica del $37,8 \%-41,4 \%{ }^{249}$, nuestro grupo poblacional se encuentra entre ambos. Un reporte de Holanda publica que un $63 \%$ de los pacientes con FQ tenían DM al momento de ser incluidos para lista de espera de $\mathrm{TP}^{238}$

Se ha visto que la DM es una factor que aumenta la mortalidad en los pacientes con FQ mayores de 30 años. ${ }^{251}$

Meachery y cols en la serie de 176 pacientes con FQ trasplantados, reporta una incidencia de DM del $40 \%$ previo al TP. Los autores mencionan también que posterior al TP, $20 \%$ de los pacientes fueron diagnosticados de DM. ${ }^{70}$ Lo que representa que aparte de que una gran proporción de pacientes ya son diabéticos al momento del TP, durante el postoperatorio, un gran porcentaje se volverá diabético.

Según algunos informes publicados, la DM aumenta el riesgo de muerte en la lista de espera, pero no parece afectar la supervivencia posterior al TP (HR, 1.0; 95\% CI, 0.82-1.2; $\mathrm{p}=0.98) .{ }^{252}$ En el estudio de Vizza y cols ${ }^{56}$ la DM se presenta como un factor de riesgo independiente de mortalidad en la lista de espera, al igual que el 6WT y la presión de la arteria pulmonar $(\mathrm{p}=0,001)$.

Nuestros datos no encuentran una relación entre la DM y un aumento en la mortalidad posterior al TP $(\mathrm{p}=0,6)$. La importancia de DM en la FQ se debe a que los 
pacientes que la padecen previo al TP pueden tener afectaciones renales derivadas de la diabetes y dicho estatus puede ser agravado posterior al TP por el tratamiento inmunosupresor. Los pacientes que no son diabéticos al momento del TP, es probable que lo sean posteriormente como se ha comentado previamente.

En nuestra serie, la gran mayoría de los receptores $(78,1 \%)$ tenían IPE al momento del TP. Reportes de otros grupos, refieren que la proporción se encuentra entre el 72,4 - $97 \%$ 238,253,254. Un correcto estado nutricional mejora la capacidad pulmonar y de ahí la importancia del correcto tratamiento con enzimas pancreáticas en los pacientes con FQ e IPE. ${ }^{255}$ Otros tratamientos descritos en la literatura, aunque en casos extremadamente seleccionados es el trasplante pulmonar y pancreático en pacientes con $\mathrm{FQ} .{ }^{256}$

Al igual que con la DM, nuestro estudio no encuentra una relación con una menor supervivencia de los pacientes afectos con IPE $(p=0,06)$.

En cuanto a la necesidad de oxigenoterapia previa al trasplante, nuestro trabajo identifica que un $79,6 \%$ de los receptores eran portadores de oxigenoterapia previo al TP. La publicación de Merlo y cols ${ }^{249}$, sobre la influencia de los seguros médicos en el TP por FQ, reporta que la necesidad de oxigenoterapia previa al TP es del $72.8 \%$ en los pacientes de Reino Unido y del 83,8\% en los Estados Unidos de Norteamerica.

Nuestros datos coinciden con los datos publicados en la literatura en cuanto a la necesidad de oxígeno previo al TP, lo cual indica a su vez, que los pacientes que llegan al TP se encuentran en una situación de insuficiencia respiratoria.

Un 20,3\% de los pacientes de nuestra serie, requerían VMNI previo al TP. Madden y cols publican una de las series más amplias en evaluar el estado de la VMNI en los pacientes con FQ. El tiempo medio de requerimiento de la VMNI para los pacientes que están en lista de espera de TP fue de 61 (r: 1 - 600 ) días y reportan que la VMNI mejora la hipoxia de éstos pacientes pero que no corrige la hipercapnia. Los autores concluyen que la VMNI es un tratamiento útil en los episodios de insuficiencia respiratoria. ${ }^{257}$ 
Meachery y cols en su serie de 176 pacientes FQ que recibieron un TP, no encuentran una mayor mortalidad en los pacientes portadores de VMNI $(p=0,89){ }^{70}$

Al igual que las publicaciones previas, nuestra serie no encuentra un aumento de mortalidad en los pacientes que requirieron VMNI previa al TP $(\mathrm{p}=1,00)$.

Una de las características más importantes de los pacientes con FQ son las colonizaciones previas al TP. Nuestra serie de pacientes presenta una amplia colonización por gérmenes $(93,7 \%)$ de los cuales hasta el $89 \%$ estaban colonizados por Pseudomona aeruginosa y algunos de los receptores presentaban colonizaciones por gérmenes multirresistentes como Stenotrophomonas, Burkhloderia cepacia y Micobacterium abscessus. La frecuencia de colonizaciones varía según las series publicadas siendo el germen más frecuente la Pseudomonas spp. que coloniza entre el $76 \%-100 \%$ de los receptores. ${ }^{54,185}$

Un 3,12\% (5 pacientes) de los pacientes de nuestra serie estaban colonizados por Burkhloderia cepacia, todos los pacientes colonizados por éste germen fallecieron durante el seguimiento, excepto uno. La incidencia de colonización por Burkhloderia cepacia de nuestro trabajo es inferior a lo publicado en otras series como la de Liou y cols que informan que un $7,7 \%$ de los receptores estaban colonizados por dicho gérmen. ${ }^{78}$ En la serie publicada por el grupo de Toronto ${ }^{184}$, el $52 \%$ de los receptores estaban colonizados por Burkhloderia cepacia y concluyen que la infección por éste germen aumenta la mortalidad posterior al TP.

La baja incidencia de pacientes con Burkhloderia cepacia de nuestra serie puede justificarse a que históricamente dicha infección estaba asociada a complicaciones infecciosas y una mala evolución posterior al $\mathrm{TP}^{258-267}$ y por tanto eran pacientes a los que no se solía ofrecer el TP como posibilidad terapéutica. Actualmente, se considera que el pronóstico después del TP depende del tipo de cepa de Burkhloderia, siendo los pacientes colonizados por Burkhloderia multivorans los de mejor pronóstico y la colonización por Burkhloderia gladioli los de peor pronóstico. ${ }^{268}$

Uno de los pacientes de nuestra serie estaba colonizado por M. abscessus que posterior al TP falleció por complicaciones derivadas de la infección. En la literatura 
existen múltiples reportes sobre la mala evolución de los pacientes FQ trasplantados y colonizados por M. abscessus. ${ }^{269-271}$

Algunos de los reportes informan sobre casos de diseminación sistémica del germen durante el postoperatorio con infecciones cutáneas y de la herida quirúrgica, ${ }^{272}$ líquido pleural y sangre, ${ }^{269}$ pared torácica y esputo ${ }^{271}$ y casos de dehiscencia de la sutura esternal. $^{273}$

Algunos reportes sobre la implicación de las micobacterias no tuberculosas en pacientes con FQ candidatos a TP informan que no debe ser una contraindicación, pero que debe tomarse una decisión conjunta entre el equipo médico y los pacientes, en cuanto existe un alto índice de recurrencia posterior al TP con muchos casos descrtios que han presentado una evolución desfavorable. ${ }^{274}$

Un estudio en base a 5.200 pacientes TP, la incidencia de $M$. abscessus. en el postoperatorio del trasplante fue del $0,33 \%$ con una tendencia a ser más frecuente en el sexo masculino $(\mathrm{M} / \mathrm{F}, 12: 5)$. Las conclusiones del estudio son; que aunque es una infección de muy difícil manejo, la estrategia de una terapia antimicrobiana combinada y desbridamientos quirúrgicos de las infecciones pueden dar lugar a una buena evolución. ${ }^{93}$

Según el documento de consenso para la selección de candidatos al $\mathrm{TP}^{45}$, los pacientes con especies de Burkhloderia y de Mycobacterium abscessus son considerados como contraindicaciones relativas, los posibles receptores deben ser tratados adecuadamente de forma preoperatoria y tener un adecuado control en el postoperatorio del TP. Además dichos pacientes deben ser evaluados por equipos médicos con experiencia en el manejo de éstas infecciones y que los posibles candidatos deben conocer el riesgo incrementado que existe con el TP y dar su consentimiento.

Al momento de ser incluidos en lista de espera, nuestros pacientes presentaban insuficiencia respiratoria con hipercapnia (Valores medios de $\mathrm{PaO}_{2}$ de $60 \mathrm{mmHg}$ y de $\mathrm{PaCO} 2$ de 47,8 $\mathrm{mm} \mathrm{Hg}$ ). En cuanto a los valores espirométricos medios, el FVC y FEV 1 fueron del 38,4\% y $26 \%$ respectivamente. Los resultados del funcionalismo pulmonar son similares a los publicados en la literatura. ${ }^{54,56,186,249,254,275}$ 
Quattrucci y cols, reportan que los pacientes de su serie trasplantados por FQ, tenían valores de FVC del $38 \%$ y de $\mathrm{FEV}_{1}$ del 25,4\%, ${ }^{212}$ valores muy similares a los presentados en nuestro trabajo.

En nuestra serie, la media de metros caminados en el 6WT fue de 323, resultado muy similar al de otra serie nacional. ${ }^{186} \mathrm{El}$ estudio publicado por Vizza y cols, el 6WT es considerado un factor de riesgo independiente de mortalidad previo al TP, siendo de 343 metros de media los pacientes que fallecieron mientras esperaban un TP. ${ }^{56}$

Dadas las características de la función respiratoria, los pacientes incluidos en nuestro estudio cumplían los criterios establecidos en los consensos nacionales para el TP. ${ }^{45}$ Aunque existen publicaciones en las cuales la decisión para incluir a los pacientes FQ en listas de espera de TP no se base exclusivamente en factores espirométricos como el $\mathrm{FEV}_{1}$ menor del $30 \%$, sino también, en otras consideraciones como la necesidad de oxígeno, el deterioro físico, la necesidad de antibióticos EV y la calidad de vida. $^{211}$

Los receptores de TP de nuestra serie requirieron una media de 2,5 ingresos hospitalarios en los 12 meses previos al TP, con un máximo en algún caso de hasta 12 ingresos.

En el consenso internacional de la ISHLT ${ }^{45}$ recomiendan que los pacientes con FQ y hospitalizaciones frecuentes, entre otros supuestos, sea una indicación para ser incluidos en una la lista de espera para TP, aunque no se especifica el número de episodios mínimos requeridos para sentar dicha indicación.

\subsection{INTRAOPERATORIO}

En nuestra serie, la cirugía de reducción del injerto pulmonar para acondicionarla a la caja de tórax del receptor fue necesaria en 6 pacientes (9,3\%). La necesidad de emplear ésta técnica varia significativamente según las series publicadas, del 3,3\% al 55\% $72,187,222$ 
La gran variabilidad de la frecuencia en la utilización de técnicas quirúrgicas de reducción de injerto pulmonar depende de la cantidad de donantes que tiene cada centro. La proporción de pacientes que necesitaron cirugía de reducción del injerto de nuestra serie se encuentra entre la frecuencia reportada en la literatura.

En nuestra serie, la cirugía de reducción de injerto pulmonar no parece aumentar la mortalidad postoperatoria $(\mathrm{p}=0,68)$, si bien hay que tener en cuenta el escaso número de pacientes que requirieron dicha técnica. Stanzi y cols reportan una serie de 74 pacientes con FQ trasplantados pulmonares de los cuales 8 fueron trasplantes lobares y concluyen que tienen una supervivencia y función pulmonar similar a los pacientes que reciben pulmones sin reducciones. ${ }^{276}$

El tiempo de isquemia de nuestra serie fue de $375 \pm 101$ minutos y no parecen influir en la mortalidad $(0,36)$. Los valores presentados en las distintas series son similares a los nuestros y al igual que nuestra serie, no parecen tener influencia sobre la mortalidad $187,222,249,277$.

\subsection{POSTOPERATORIO}

Los receptores de nuestro trabajo estuvieron una media de VM de 10 (r: 1 - 60) días y $12(18,7 \%)$ pacientes requirieron VM prolongada. Weill y cols en su estudio de VM prolongada en receptores de TP, entre los cuales se encuentra la FQ (total 690, FQ = 179), encuentran que casi el $12 \%$ de los pacientes con FQ son catalogados de VM prolongada (> 21 días de $\mathrm{VM}){ }^{278}$

El mayor porcentaje de VM prolongada de nuestra serie puede atribuirse a múltiples factores; diferentes protocolos de ventilación entre unidades de cuidados intensivos de adultos e infantiles, mayor deterioro funcional de nuestros pacientes al momento del trasplante y a la complejidad propia de los pacientes con FQ.

En nuestra serie, el tiempo medio de estancia de UCI durante el postoperatorio del TP fue de 17,7 $\pm 16,7$ (r: 1 - 90) días. Aunque no se ha diferenciado la estancia en UCI entre el grupo infantil y el de adultos, la estancia es similar a la presentada en otras 
series, con medias de estancia de $20 \pm 19$ para los infantiles y de $10 \pm 9$ para los adultos. $^{187}$

El estudio de Wiebe y cols ${ }^{54}$ presenta estancias en UCI de 4,7 \pm 3 (r: 1 - 13) días en su serie de 35 pacientes TP por FQ.

Un grupo italiano no detalla el tiempo medio de estancia de UCI en su publicación sobre una serie de 58 pacientes que recibieron una TP por FQ, sin embargo informan que el rango de estancia en UCI fue de 3 a 28 días. ${ }^{225}$

Aunque los tiempos de estancia en UCI de nuestra serie son mayores en comparación a los estudios mencionados previamente, en nuestro trabajo no hemos encontramos una asociación entre el tiempo en UCI y un aumento en la mortalidad postoperatoria $(\mathrm{p}=0,321)$.

En el presente trabajo, 7,8 \% de pacientes tuvieron que ser re intervenidos por diferentes causas, siendo el sangrado postoperatorio el más frecuente $(60 \%$ de los casos). En una serie sobre 35 pacientes con FQ que recibieron un TP, 8,5\% requieren re intervenciones por sangrado, todos los pacientes re operados fueron trasplantados bajo CEC. $^{54}$

En un artículo publicado sobre las complicaciones en el TP en base a 12,565 pacientes, la incidencia de re intervenciones fue del 19,9\%, aunque no se especifica el porcentaje de re intervenciones en los TP por FQ. ${ }^{279}$

La frecuencia de re intervenciones por sangrado se pueden atribuir a las características propias que tienen los pacientes con FQ. Al momento del TP muchos de los pacientes tienen antecedentes de procedimientos quirúrgicos previos en el tórax, procedimientos que varían desde la colocación de drenajes pleurales hasta resecciones pulmonares por destrucción del parénquima pulmonar.

En la serie presentada, hasta el $62 \%$ de los pacientes presentaron algún episodio de infección respiratoria posterior al TP, siendo la Pseudomona aeruginosa el germen 
más frecuente $(40,6 \%)$. De la serie general, $2(3,12 \%)$ de los pacientes presentaron aislamientos durante el postoperatorio para Burkholderia cepacea.

Una serie publicada en base a 60 pacientes trasplantados por FQ reportan que la etiología más frecuente de las infecciones en el postoperatorio es la Pseudomona aeruginosa en el 60,3\% de los pacientes y concluyen que el alto índice de infecciones respiratorias por Pseudomonas spp. en el postoperatorio del TP puede ser debido a defectos inmunitarios específicos de los pacientes con FQ. ${ }^{280}$

En el artículo publicado por de Pablo et al. en el que se estudia a los pacientes con enfermedades pulmonares supurativas que recibieron un TP, un 59\% de los presentaron aislamientos de gérmenes durante el postoperatorio. ${ }^{186}$

En otro estudio en base a 53 pacientes trasplantados por FQ se analiza la diferencia en cuanto a la supervivencia de los pacientes con Burkholderia vs. los receptores negativos a dicha infección y se concluye que existe una menor supervivencia de los pacientes portadores de Burkholderia $(\mathrm{p}=0,003) .{ }^{184}$

Una publicación en base a 528 paciente con FQ que recibieron un TP concluye que la mortalidad postoperatoria está influenciada por las diferentes subespecies de Burkholderia spp. y que tiene que formar parte en la decisión de incluir a estos pacientes en una lista de espera de TP, como ya se ha comentado previamente. ${ }^{268}$

Un trabajo reciente sobre pacientes trasplantados por FQ reporta que cuando se compara la supervivencia entre el grupo de pacientes colonizados por bacterias multirresistentes (Micobacterium abscessus y Bulkholderia spp.) con la del grupo FQ sin dichas colonizaciones, no se encuentran diferencias significativas $(\mathrm{p}=0,97){ }^{250}$

Egan y cols, reportan una menor supervivencia de los pacientes con Bulkholderia en comparación con los pacientes sin dicho aislamiento $(\mathrm{p}<0,006){ }^{72}$

La frecuencia y etiología de las infecciones respiratorias postoperatorias de nuestros pacientes son similares a los presentados en la literatura y el alto índice de infecciones postoperatorias es probable que sea debido a que, si bien se elimina el foco 
principal de la infección que son los pulmones, los gérmenes se mantienen en otras áreas corporales como los senos paranasales.

Un 15,6\% de los pacientes de nuestra serie presentaron EB y 6,2\% dehiscencia de la sutura bronquial. Los frecuencia de complicaciones de la anastomosis bronquial es similar a la publicada en otras series sobre TP en pacientes con $\mathrm{FQ} .{ }^{212}$

Sin embargo, en una serie nacional de 90 pacientes TP por diversas patologías, la frecuencia de EB es del 6,8\%. Específicamente sobre pacientes con FQ, reportan una incidencia de $2,2 \%$ de estenosis bronquiales. ${ }^{281}$

Un artículo publicado recientemente reporta que, cuando se diagnostica algún tipo de complicación bronquial, es un factor predictor de mortalidad al año en los pacientes con FQ (HR 1,22, $95 \%$ IC 1,08 - 1,36 p = 0,01). También detallan otros factores como el ingreso previo en UCI, mayor edad y antecedente de tabaquismo en el donante pulmonar. ${ }^{282}$

Un probable justificación de una mayor incidencia de estenosis bronquial de nuestra serie, es que al ser un diagnóstico estrictamente broncoscópico, pueden existir diferencias de criterios en cuanto a la disminución de la luz bronquial. Es probable que en algunas series presentadas, la disminución de la luz bronquial sea tan poco representativa, que no sean catalogados dichos pacientes como afectos de una estenosis bronquial. Cabe destacar que todos los pacientes que presentaron dehiscencia bronquial fallecieron en el postoperatorio del TP.

En la serie analizada, 43,7 \% de los pacientes presentaron RA durante el seguimiento, de los cuales, el diagnóstico se realizó por BTB en el 64,3\%. Respecto al $\mathrm{RC}$, se diagnostico en el $38,8 \%$ de los pacientes trasplantados con un tiempo medio hasta el diagnostico de 34,7 meses.

En una serie sobre 29 pacientes trasplantados por FQ, la frecuencia de RA fue del $20 \%$ y sugieren que la disminución en la frecuencia de RA se debe a la utilización de terapia de inducción con ATG previo al TP. Respecto al RC, reportan una incidencia del $20 \%$ durante el seguimiento. ${ }^{283}$ 
En una serie sobre 35 pacientes con $\mathrm{FQ}$ que recibieron un TP, 23\% de los pacientes desarrollaron RC durante el seguimiento. ${ }^{54}$ La supervivencia libre de RC se presenta en la literatura del $85 \%$ al año, $74 \%$ a los 5 años y del 38\% a los 10 años del TP. ${ }^{70}$

La frecuencia de RA y RC de nuestra serie es mayor a la presentada en la literatura. Un alto porcentaje de nuestros pacientes fueron diagnosticados por BTB. Pero el diagnóstico de RA también puede ser clínico, básicamente de exclusión. Es probable que una frecuencia elevada de biopsias haya permitido diagnosticar más pacientes del RA en nuestra serie.

En cuanto al RC, la frecuencia es muy similar a la presentada en otras series $(38,9$ $\%)^{284}$

En nuestro trabajo, 29 pacientes fallecieron durante el seguimiento. La causa de mortalidad temprana fue por complicaciones propias del acto quirúrgico (dehiscencia de sutura bronquial, re intervención por sangrado, etc.), complicaciones infecciosas y otras causas como el fracaso multiorgánico. La principal causa de mortalidad a largo plazo fue el RC. Las causas de mortalidad temprana es similar a la de otras series ${ }^{212}$ y está descrito que el RC causa más del $30 \%$ de las muertes postrasplante tras el tercer año. ${ }^{285}$

Aunque no específicamente del grupo de paciente FQ trasplantados, el registro internacional reporta factores similares de mortalidad postoperatoria, tanto temprana (propias del acto quirúrgico, fallo multiorgánico e infecciones) como tardías, siendo también la más importante, el RC del injerto. ${ }^{208}$

En una serie de 106 pacientes trasplantados por FQ, con una mortalidad de 15 pacientes los 2 primeros años del TP, las complicaciones infecciosas fueron la causa directa del $46,6 \%$ de la mortalidad. ${ }^{250}$

Las infecciones también son la causa más importante de mortalidad postoperatoria en una serie de 54 pacientes trasplantados por FQ, de los 18 pacientes que fallecieron en el postoperatorio, 11 de las muertes fueron atribuidas a las infecciones. ${ }^{275}$ 
En nuestra serie, previo al TP los pacientes tenían valores medios de FVC del $38 \%$ y del $\mathrm{FEV}_{1}$ del $26 \%$ y durante el seguimiento dichos parámetros aumentaron hasta el $85 \%$ y $87 \%$ respectivamente. Los mejores valores de funcionalismo pulmonares se registraron a los 41 meses del TP.

Una serie italiana sobre 55 pacientes con FQ que fueron trasplantados, reportan valores similares de $\mathrm{FEV}_{1}$ a los 2 años del TP $(82 \%){ }^{212}$

Aunque expresado en valores absolutos, un grupo alemán informa que después de un período de seguimiento de 39 meses, en su estudio en base a 35 pacientes con FQ que recibieron un TP, los pacientes tiene un $\mathrm{FEV}_{1}$ de $2800 \pm 1199 \mathrm{~mL}$, muy similares a los valores de nuestro trabajo $(2839 \pm 701 \mathrm{~mL}) .^{54}$

Así mismo, son interesantes los resultados de un estudio en base a 29 pacientes trasplantados con FQ que informa que el $\mathrm{FEV}_{1}$ mejora de un $20 \%$ de media antes del TP hasta un $78 \%$ (59 - 111\%) a los 6 meses del TP. Y menciona que entre los pacientes que sobreviven hasta los 5 años, el $\mathrm{FEV}_{1}$ se mantiene en valores elevados $\left(\mathrm{FEV}_{1} 71 \%\right.$, r: $19-118 \%, \mathrm{p}<0,0001)^{283}$

Algunas publicaciones que reportan sus resultados espirométricos, incluyen a pacientes que recibieron trasplantes cardiopulmonares además de receptores bipulmonares como la serie de Ganesh y cols ${ }^{111}$ sobre los resultados de 17 pacientes con $\mathrm{FEV}_{1}$ a los 4 años del trasplante de $2830 \mathrm{ml}$, resultado prácticamente igual al de nuestro grupo.

En una serie nacional, aunque no se especifica el número exacto y el objetivo final del estudio era comparar los resultados de los receptores FQ infantiles vs. adultos, los resultados espirométricos son muy similares a los de nuestra serie, con valores previos al TP de FVC alrededor del $40 \%$ y de $\mathrm{FEV}_{1}$ del 20 - 30\%. Los autores reportan que los mejores valores alcanzados durante el seguimiento del FVC\% fueron $>80 \%$ y del FEV 1 del $80 \% .{ }^{187}$ 
En un serie de 56 pacientes, reportan que el $\mathrm{FEV}_{1}$ previo al TP era de 20,4 $\pm 5 \mathrm{y}$ que a los 12 meses de la cirugía el $\mathrm{FEV}_{1}$ medio fue del $82 \%$, nuevamente, resultados muy similares a los presentados en nuestro trabajo. ${ }^{225}$

\subsection{SUPERVIVENCIA DE LA SERIE GENERAL}

La supervivencia de nuestra serie al año, tres, cinco y diez años fue del 71,8\%, 62,4\%, $56,7 \%$ y $41,3 \%$ respectivamente. Los resultados coindicen con la mayoría de series presentadas en la literatura. ${ }^{186,187,212,286}$ Aunque también hay que destacar que la supervivencia de nuestra serie varía respecto a otras series que obtienen supervivencias inferiores y algunas publicaciones incluso superiores. ${ }^{54,185,222}$

Un estudio publicado recientemente informa de supervivencias de 86,4\%, 73,7\% y $62,4 \%$ al año, 5 y 10 años respectivamente después del TP ${ }^{250}$, resultados similares de supervivencia a los 5 años que obtiene un grupo de Zurich $(72,7 \%){ }^{226}$

En 2014, la ISHLT publica los resultados de más de 47,000 receptores de TP. En dicho reporte la FQ representa al 16,4\% de todos los receptores con una supervivencia a los 5 años del $60 \%$ en comparación a la supervivencia del $50 \%$ cuando el diagnostico que motivó el TP no es la FQ. ${ }^{188}$

Los valores de supervivencia de nuestra serie coindicen con la mayoría de estudios publicados, aunque algunos reportan supervivencias mayores. Justificar dicha mejora en la supervivencia es difícil ya que pueden existir muchos factores que puedan condicionar dicha mejora como ser; inclusión en lista de espera de pacientes con deterioro de la función pulmonar pero no con insuficiencia respiratoria, adecuado control nutricional, unidades con gran experiencia en trasplante pulmonar, etc. 


\subsection{INFLUENCIA DE LA CEC}

El 45,3\% de los paciente de nuestra serie fueron trasplantados bajo CEC, la frecuencia varía entre los diferentes centros entre el 6,89 al 69\%. ${ }^{54,72,163,187,250,283,287,288}$

En nuestra serie el tiempo medio de soporte extracorpóreo fue de $198 \pm 115$ (r: 53 - 410) minutos, similar a los tiempos de CEC en el TP publicados en la literatura. ${ }^{289}$ También existen publicaciones con tiempos de CEC menores, como un estudio que evalúa la influencia de la CEC en el trasplante unipulmonar, con tiempos de CEC de 135,2 (r: 62 - 265) minutos, si bien, el diagnóstico principal de los receptores en esta serie fue de EPOC y FP. ${ }^{147}$

Szeto y cols reportan tiempos de CEC de 218,3 \pm 75,4 minutos en los TBP realizados en su estudio por EPOC. ${ }^{169}$ En una serie de 25 pacientes con FQ que recibieron un TP, la media de CEC fue de 231 (r: 90 - 375) minutos. ${ }^{185}$

Moreno y cols en su trabajo comparando adultos e infantiles con FQ que fueron trasplantados, informan de tiempos de CEC para el grupo infantil de $116 \pm 47$ minutos y del grupo de adultos de $107 \pm 55$, aunque no se especifica el tiempo de CEC para la serie general. ${ }^{187}$

En una serie de 94 TBP, en los que analizan la influencia de la CEC en la DPI, publican tiempos medios de CEC de $240 \pm 43$ minutos y que los pacientes que se trasplantan bajo CEC tienen un mayor tiempo de isquemia (CEC $346 \pm 75,4$ vs. No CEC $315 \pm 72, p=0,04) .{ }^{148}$ Nuestra serie obtiene resultados similares de tiempos medios de isquemia (CEC $402 \pm 110$ vs. $350 \pm 86, p=0,04$ ).

Los tiempos de CEC varían significativamente según las publicaciones. Esto se debe probablemente al protocolo quirúrgico que tiene cada centro trasplantador, por ejemplo, existen centros que realizan todos los trasplantes de los pacientes bajo CEC, independientemente del diagnostico. Nuestros tiempos de CEC se mantienen entre los rangos publicados en la literatura. 
El grupo de Newcastle presenta su serie de 259 pacientes que recibieron un TUP por diferentes diagnósticos, en los cuales se utilizó la CEC en el 20,5\% de los pacientes. Reportan que la VM no estuvo influenciada por la presencia de CEC $(p=0,15)$ con una media de VM de 31,3 (r: 6,2 - 78,3) horas, para los pacientes que necesitaron CEC. Sin embargo, si encuentran diferencias significativas respecto a la estancia en UCI, siendo de 5,2 días de media para los del grupo CEC y de 2,8 días para el grupo no CEC ( $\mathrm{p}=\leq$ $0,01) .{ }^{147}$ Resultados similares de otro estudio que publica una estancia mayor en UCI en los pacientes que requirieron $\mathrm{CEC}$ (5,2 vs. 2,8 días para los que no necesitan $\mathrm{CEC}, \mathrm{P}=$ $<0,01)^{290}$

Un aumento en el tiempo de VM $(\mathrm{p}=0,028)$ también está descrito por otros autores que comparan el efecto de la CEC en el TP. También dichos autores describen una mayor incidencia de daño alveolar difuso en las biopsias pulmonares. ${ }^{149}$

Sin embargo, otros autores no encuentran dichas diferencias en cuanto al tiempo de VM y el tiempo de ingreso en UCI como Szeto y cols que no encuentran dichas diferencias en el tiempo de VM $(p=0,76)$ ni en el tiempo de estancia en UCI $(p=$ $0,44){ }^{169}$

El uso de CEC durante el TP también se ha definido como factor de riesgo independiente para VM prolongada posterior al TP en la serie publicada por Gammie y cols en base a 94 pacientes que recibieron un TBP $\left(\mathrm{p}=0,0004\right.$, OR 6,2). ${ }^{148}$

Myles y cols en su serie sobre 64 pacientes de los cuales 20 se realizan bajo CEC, encuentran diferencias significativas en el tiempo de VM (No CEC $27 \mathrm{~h}$ vs. CEC electiva $50 \mathrm{~h}, \mathrm{p}=<0,001$ y CEC no planificada $50 \mathrm{~h}, \mathrm{p}=0,009)$ y la estancia en la UCI ( No CEC 3 días vs. CEC electiva 7 días, $\mathrm{p}=<0,001$ y CEC no planificada 6 días, $\mathrm{p}=$ 0,004), sin embargo no encuentran diferencias respecto a la estancia hospitalaria y a la supervivencia al año. ${ }^{291}$

El aumento en el tiempo de VM entre los pacientes operados bajo CEC también es reportado por Dalibon y cols en una serie de 140 TP (No CEC 6,6 \pm 5 días vs. CEC planificada $8,5 \pm 9$ vs. CEC no planificada $13,7 \pm 7, p=<0,05) .{ }^{173}$ 
En otra serie de 162 TP del grupo de Sant Louis, no se encontraron diferencias en cuanto al tiempo de VM ( CEC 4,2 $\pm 3,1$ vs. No CEC 2,8 $\pm 2,2$ días, $p=N S$ ) y al tiempo de estancia en UCI ( CEC 5,6 $\pm 3,8$ vs. No CEC 5,2 $\pm 6,5$ días, $p=N S$ ). ${ }^{292}$

Se describe en la literatura que los pacientes trasplantados pulmonares (incluidos entre otros diagnósticos, pacientes con FQ) sin $\mathrm{CEC}$ tienen mejor ratio $\mathrm{PaO}_{2} / \mathrm{FiO}_{2}$ postoperatoria, menos días de ventilación mecánica, tiempo en UCI y tiempo de hospitalización en comparación con los pacientes trasplantados bajo CEC. ${ }^{293}$

Nuestra serie también encuentra mayores tiempos de VM en los receptores trasplantados bajo CEC $(\mathrm{p}=0,012)$.

Respecto a las re intervenciones, en nuestra serie 4 (6,25\%) de los receptores que necesitaron una re intervención fueron trasplantados bajo CEC. Detterbeck y cols en su serie de 65 pacientes trasplantados por diversos diagnósticos, publica que el $6,15 \%$ de los trasplantes re operados por sangrado fueron realizados bajo CEC ( $\mathrm{p}=$ $0,007){ }^{294}$

Como se ha mencionado previamente, la utilización de la CEC con la consiguiente afectación de coagulación durante el intraoperatorio, puede predisponer al sangrado posterior al TP que requiere de re intervenciones para su control. Nuestros datos coinciden con la poca información presentada en la literatura de re intervenciones posteriores al TP.

En nuestra serie no apreciamos una influencia de la CEC entre los paciente que presentaron RA $(\mathrm{p}=0,44)$. El estudio del grupo de Trasplante Pulmonar de Newcastle tampoco encuentra una asociación entre CEC y RA $(p=0,99) .{ }^{147}$

Respecto al RC, nuestra serie tampoco encuentra una asociación respecto a los pacientes trasplantados bajo CEC (CEC 7 vs. No CEC 14, p = 0,19). En una publicación que evalúa los posibles factores de riesgo de $\mathrm{RC}$, la $\mathrm{CEC}$ tampoco alcanza la significación estadística ( RR 1,42, CI 95\% 0,98 - 2,06, p=0,07). ${ }^{160}$ 
Según lo descrito previamente, no parece que la CEC se relacione con alguna forma de rechazo en el TP por FQ.

\subsection{SUPERVIVENCIA EN BASE A LA CEC}

En nuestra serie, la supervivencia al año, 3, 5 y 10 años es del 91,43\%, 82,86\%, 75,69\% y 49,06\% respectivamente para los pacientes que no se trasplantan bajo CEC, mientras que los pacientes trasplantados bajo CEC tienen una supervivencia al año, 3, 5 y 10 años es del 48,28\%, 37,93\%, 34,14\% y $29,87 \%$ respectivamente $(\mathrm{p}=0,001)$.

Existen múltiples trabajos en los que se valora la supervivencia de los pacientes trasplantados en base a la CEC, pero la práctica totalidad de estos trabajos son en pacientes trasplantados por EPOC o FP. No se han encontrado trabajos que aborden específicamente el tema de la supervivencia en pacientes con FQ en base a la CEC. A continuación se presentan los trabajos en base a pacientes EPOC y FP.

En un estudio de 50 pacientes trasplantados por EPOC en el que se compara los pacientes trasplantados bajo CEC vs. los que no, se reporta que la supervivencia para los trasplantados bajo CEC al año y 3 años es del 85,7\% y 64,3\% respectivamente. ${ }^{169}$

Un estudio inglés sobre 125 pacientes TP por EPOC reporta supervivencia a los 5 años comparables entre los pacientes que fueron trasplantados bajo CEC y los que no (CEC $38 \%$ vs. No CEC 37\%, p= 0,89). ${ }^{295}$

Aunque por diversos diagnósticos, Mohite y cols publica un estudio sobre la influencia de la CEC en el TP. Define tres grupos de estudio; No CEC (86 pacientes), CEC electivo (162 pacientes) y Conversión a CEC (54 pacientes). Los autores especifican que el grupo CEC electivo se decide a preferencia del cirujano, algunos de los cuales prefieren realizar todos los TP bajo CEC independiente del diagnostico previo y que el grupo de Conversión a CEC es solo si es necesario durante el TP. Tomando en cuenta la supervivencia de los pacientes del grupo conversión (ya que la indicación es similar a la presentada en nuestro estudio), obtienen una supervivencia al año y 3 años del 61,9\%, y 39,8\% respectivamente en comparación del grupo No CEC 
que obtiene supervivencias al año, 3 y 5 años del 94,4\%, 78,1 y 51,4\% respectivamente $(\mathrm{p}=<0,001){ }^{293}$

En el estudio de Detterbeck y cols sobre el TP después de procedimientos quirúrgicos torácicos, los autores publican que los pacientes trasplantados bajo CEC requieren más días de VM $(\mathrm{p}=0,02)$, mayor ingreso hospitalario $(\mathrm{p}=0,05)$, mayor requerimiento de transfusiones de sangre $(\mathrm{p}=0,00005)$, re operaciones por sangrado $(\mathrm{p}=0,007)$, más complicaciones tempranas $(\mathrm{p}=0,001)$ y mayor mortalidad hospitalaria $(\mathrm{p}=0,007){ }^{294}$

Aunque no se ha encontrado en la literatura la supervivencia de los pacientes trasplantados bajo CEC en la FQ, la extrapolación de los datos de otras patologías como la EPOC coindice con la disminución en la supervivencia de los grupos con CEC. Las supervivencias de las diferentes series por otros diagnósticos es superponible a la supervivencia de nuestra serie.

\subsection{FACTORES DE RIESGO DE CEC}

Nuestro trabajo identifica tres factores que pueden considerarse como factores de riesgo de la necesidad de CEC durante el TP por FQ, estos son: la $\mathrm{PaCO}_{2}$, el FVC y el 6WT previo al trasplante.

Aunque en nuestra serie no se ha analizado cuales son los factores que pueden condicionar la mortalidad en la lista de espera, se ha sugerido que valores de la función pulmonar pueden jugar un papel importante en la estratificación del riesgo previo al TP.

En 1993, una serie de pacientes con FQ candidatos de trasplante cardiopulmonar evalúa diferentes parámetros que puedan condicionar la supervivencia en la lista de espera. Las dos variables que encuentra el estudio son el $\mathrm{FEV}_{1}$ y la $\mathrm{PaCO}_{2}$. Los pacientes que tienen valores de $\mathrm{FEV}_{1}$ superiores al $17 \%$ tienen la mitad de riesgo de morir en la lista de espera en comparación a los que tiene valores < al $17 \%$ (RR 0,47; 95\% CI, 0,23 - 0,97). Respecto a la $\mathrm{PaCO}_{2}$, mencionan que el riesgo relativo de 
mortalidad en lista de espera es de 1,44 (95\% CI, 1,17 - 1,77) por cada $7 \mathrm{mmHg}$ de aumento de $\mathrm{PaCO}_{2}{ }^{296}$

Ciriaco y cols también evalúan los variables de riesgo de los pacientes con FQ candidatos a TP y en su estudio comparando los pacientes que fueron trasplantados y los que fallecieron en la lista de espera, el $\mathrm{FEV}_{1}(21,2 \%$ vs. $16,5, \mathrm{p}=<0,02)$ y el $6 \mathrm{WT}$ (391,8 vs. 290,1 metros, $\mathrm{p}=<0,02)$ fueron las variables más significativas. También refieren la importancia de la $\mathrm{PaCO}_{2}$, aunque dicho resultado no alcanza la significación estadística ( 46 vs. $54 \mathrm{mmHg}, \mathrm{p}=\mathrm{NS}$ ). ${ }^{227}$

Vizza y cols publican una serie de pacientes con FQ y comparan 2 grupos, los pacientes que fallecen antes del trasplante y los pacientes que llegan al trasplante o se mantienen vivos al finalizar el estudio. Los autores encuentran 3 factores independientes de mortalidad en su estudio multivariante; el 6WT (RR 0,69. CI $95 \%$, 0,57 - 0,84, $\mathrm{p}=<0,001$ ), la presión sistólica de la arteria pulmonar (RR 1,41. CI $95 \%$, $1,11-1,80, \mathrm{p}=0,005)$ y la DM (RR 1,57 . CI $95 \%, 1,06-2,32, \mathrm{p}=0,023) .{ }^{56}$

En una serie de 68 pacientes de los cuales 26,5\% son trasplantados bajo CEC, no se encontró ningún parámetro preoperatorio que podría condicionar la necesidad de CEC. Los autores atribuyen dicha imposibilidad a la razón de que la necesidad de CEC durante el TP se debe sobre todo a causas intraoperatorias como la disfunción del injerto pulmonar. $^{292}$

El grupo de trasplante pulmonar del Hospital General de Toronto publica una serie de 122 pacientes trasplantados con el objetivo de definir posibles factores de riesgo de mortalidad peroperatoria, entre las conclusiones del estudio, una distancia de menor de 300 metros en el 6WT es considerado un factor de riesgo independiente. ${ }^{297}$

En 1993, de Hoyos y cols ${ }^{288}$ publican una serie de 109 pacientes trasplantados pulmonares, de los cuales 69 fueron trasplantados bajo CEC. Entre los pacientes que recibieron un TUP que requirieron CEC, todos con diagnóstico de FPI, el 6WT, la desaturación al esfuerzo y la fracción de eyección del ventrículo derecho diferían significativamente respecto al grupo que no requirió CEC $(\mathrm{p}<0.001)$. Entre los pacientes que recibieron un TBP, (pacientes con bronquiectasias, EPOC y FPI) no se 
encontraron parámetros preoperatorios que puedan predecir la utilización de la CEC.

Definir cuales son los factores de riesgo de mortalidad previos al TP fue el objetivo de un estudio multicéntrico en base a 343 pacientes con FQ en lista de espera para TP y entre los resultados del estudio multivariante el $\mathrm{FEV}_{1} \leq 30 \%$ (HR, 6.8; 95\% CI, 2.4-19.3, $\mathrm{p}=<0,01)$ y $\mathrm{PaCO} 2 \geq 50 \mathrm{mmHg}(\mathrm{HR}, 6.9 ; 95 \% \mathrm{CI}, 1.5-32.1, \mathrm{p}=0,01)$ fueron factores de riesgo de mortalidad. ${ }^{298}$

Aunque existen estudios que valoran la influencia del 6WT en pacientes con enfermedad coronaria y en el postoperatorio de cirugía cardíaca, ${ }^{299-304}$ no se han encontrado publicaciones que relacionen dicho parámetro con la necesidad de CEC durante el TP. Así mismo, tampoco se han encontrado publicaciones que relacionen la $\mathrm{PaCO}_{2}$ y el FVC como factores de riesgo para la necesidad de CEC durante el TP. 
7. CONCLUSIONES 

Las conclusiones de nuestro estudio son las siguientes:

1. Los pacientes TP por FQ tienen una supervivencia a los 5 y 10 años del $56,7 \%$ y $41,3 \%$ respectivamente. Se identifica que el tiempo de VM y el funcionalismo pulmonar se relacionan con la mortalidad en la evolución postoperatoria del TP. El valor preoperatorio de la $\mathrm{PaCO}_{2}$ es un factor de riesgo de mortalidad.

2. Los pacientes con FQ trasplantados bajo CEC tienen una menor supervivencia a corto y largo plazo en comparación a los pacientes que no precisan CEC. Así mismo, los pacientes del grupo de CEC requieren más días de VM y mayor estancia de la UCI. Sin embargo, otros factores como las complicaciones bronquiales, las infecciones respiratorias y el funcionalismo pulmonar postoperatorio no influye por la necesidad de CEC durante el TP.

3. Nuestro trabajo revela que los factores que afectan en la necesidad de CEC durante el TP por FQ son la $\mathrm{PaCO}_{2}$, el FVC preoperatorio y el 6WT. Aunque en el estudio multivariante, solo la $\mathrm{PaCO}_{2}$ alcanza la significación estadística. 

8. BIBLIOGRAFÍA 

1. de Gracia J, Mata F, Alvarez A, et al. Genotype-phenotype correlation for pulmonary function in cystic fibrosis. Thorax 2005;60:558-63.

2. Boucher RC. Airway surface dehydration in cystic fibrosis: pathogenesis and therapy. Annual review of medicine 2007;58:157-70.

3. Maiz L, Baranda F, Coll R, et al. [SEPAR (Spanish Society of Pneumology and Thoracic Surgery) Guidelines. Guideline for diagnosis and treatment of respiratory involvements in cystic fibrosis]. Archivos de bronconeumologia 2001;37:316-24.

4. Kumar V, Robbins SL. Robbins basic pathology. 8th ed. Philadelphia, PA: Saunders/Elsevier; 2007.

5. Greger R. Role of CFTR in the colon. Annual review of physiology 2000;62:467-91.

6. Schwiebert EM, Flotte T, Cutting GR, Guggino WB. Both CFTR and outwardly rectifying chloride channels contribute to cAMP-stimulated whole cell chloride currents. The American journal of physiology 1994;266:C1464-77.

7. Reddy MM, Light MJ, Quinton PM. Activation of the epithelial Na+ channel $(\mathrm{ENaC})$ requires CFTR Cl- channel function. Nature 1999;402:301-4.

8. Knowles MR, Boucher RC. Mucus clearance as a primary innate defense mechanism for mammalian airways. The Journal of clinical investigation 2002;109:5717.

9. Zeitlin PL. Cystic fibrosis and estrogens: a perfect storm. The Journal of clinical investigation 2008;118:3841-4. 
10. Zielenski J. Genotype and phenotype in cystic fibrosis. Respiration; international review of thoracic diseases 2000;67:117-33.

11. Davidson DJ, Porteous DJ. Genetics and pulmonary medicine. 1. The genetics of cystic fibrosis lung disease. Thorax 1998;53:389-97.

12. Noone PG, Knowles MR. 'CFTR-opathies': disease phenotypes associated with cystic fibrosis transmembrane regulator gene mutations. Respiratory research 2001;2:328-32.

13. FitzSimmons SC. The changing epidemiology of cystic fibrosis. The Journal of pediatrics 1993;122:1-9.

14. Wang SS, O'Leary LA, Fitzsimmons SC, Khoury MJ. The impact of early cystic fibrosis diagnosis on pulmonary function in children. The Journal of pediatrics 2002;141:804-10.

15. Smith JJ, Travis SM, Greenberg EP, Welsh MJ. Cystic fibrosis airway epithelia fail to kill bacteria because of abnormal airway surface fluid. Cell 1996;85:229-36.

16. Kopelman H, Durie P, Gaskin K, Weizman Z, Forstner G. Pancreatic fluid secretion and protein hyperconcentration in cystic fibrosis. The New England journal of medicine 1985;312:329-34.

17. Guy-Crotte O, Carrere J, Figarella C. Exocrine pancreatic function in cystic fibrosis. European journal of gastroenterology \& hepatology 1996;8:755-9.

18. Borowitz D. Update on the evaluation of pancreatic exocrine status in cystic fibrosis. Current opinion in pulmonary medicine 2005;11:524-7.

19. Baker SS, Borowitz D, Baker RD. Pancreatic exocrine function in patients with cystic fibrosis. Current gastroenterology reports 2005;7:227-33.

20. Cano Megias M, Gonzalez Albarran O. Cystic fibrosis-related diabetes: a distinct condition. Endocrinologia y nutricion : organo de la Sociedad Espanola de Endocrinologia y Nutricion 2014.

21. Kerem E, Viviani L, Zolin A, et al. Factors associated with FEV1 decline in cystic fibrosis: analysis of the ECFS Patient Registry. The European respiratory journal 2014;43:125-33.

22. Marshall BC, Butler SM, Stoddard M, Moran AM, Liou TG, Morgan WJ. Epidemiology of cystic fibrosis-related diabetes. The Journal of pediatrics 2005;146:681-7. 
23. Alves Cde A, Aguiar RA, Alves AC, Santana MA. Diabetes mellitus in patients with cystic fibrosis. Jornal brasileiro de pneumologia : publicacao oficial da Sociedade Brasileira de Pneumologia e Tisilogia 2007;33:213-21.

24. O'Loughlin EV, Hunt DM, Gaskin KJ, et al. Abnormal epithelial transport in cystic fibrosis jejunum. The American journal of physiology 1991;260:G758-63.

25. Kasper DL, Harrison TR. Harrison's principles of internal medicine. 16th ed. New York: McGraw-Hill, Medical Pub. Division; 2005.

26. Farrell PM, Rosenstein BJ, White TB, et al. Guidelines for diagnosis of cystic fibrosis in newborns through older adults: Cystic Fibrosis Foundation consensus report. The Journal of pediatrics 2008;153:S4-S14.

27. Comeau AM, Parad RB, Dorkin HL, et al. Population-based newborn screening for genetic disorders when multiple mutation DNA testing is incorporated: a cystic fibrosis newborn screening model demonstrating increased sensitivity but more carrier detections. Pediatrics 2004;113:1573-81.

28. Chmiel JF, Konstan MW. Inflammation and anti-inflammatory therapies for cystic fibrosis. Clinics in chest medicine 2007;28:331-46.

29. Konstan MW, Byard PJ, Hoppel CL, Davis PB. Effect of high-dose ibuprofen in patients with cystic fibrosis. The New England journal of medicine 1995;332:848-54.

30. Borowitz D, Goss CH, Limauro S, et al. Study of a novel pancreatic enzyme replacement therapy in pancreatic insufficient subjects with cystic fibrosis. The Journal of pediatrics 2006;149:658-62.

31. Konstan MW, Davis PB. Pharmacological approaches for the discovery and development of new anti-inflammatory agents for the treatment of cystic fibrosis. Advanced drug delivery reviews 2002;54:1409-23.

32. Curtis HJ, Bourke SJ, Dark JH, Corris PA. Lung transplantation outcome in cystic fibrosis patients with previous pneumothorax. The Journal of heart and lung transplantation : the official publication of the International Society for Heart Transplantation 2005;24:865-9.

33. Moran A, Brunzell C, Cohen RC, et al. Clinical care guidelines for cystic fibrosis-related diabetes: a position statement of the American Diabetes Association and a clinical practice guideline of the Cystic Fibrosis Foundation, endorsed by the Pediatric Endocrine Society. Diabetes care 2010;33:2697-708.

34. O'Riordan SM, Robinson PD, Donaghue KC, Moran A. Management of cystic fibrosis-related diabetes in children and adolescents. Pediatric diabetes 2009;10 Suppl 12:43-50. 
35. Demikhov VP. [Transplantation of the heart, lungs and other organs]. Eksperimental'naia khirurgiia i anesteziologiia 1969;14:3-8.

36. Metras D. Henri Metras: a pioneer in lung transplantation. The Journal of heart and lung transplantation : the official publication of the International Society for Heart Transplantation 1992;11:1213-5; discussion 5-6.

37. Hardy JD. The first lung transplant in man (1963) and the first heart transplant in man (1964). Transplantation proceedings 1999;31:25-9.

38. Hardy JD, Webb WR, Dalton ML, Jr., Walker GR, Jr. Lung Homotransplantation in Man. JAMA : the journal of the American Medical Association 1963;186:1065-74.

39. Derom F, Barbier F, Ringoir S, Rolly G, Versieck J. [Personal experience with lung transplantation]. Nederlands tijdschrift voor geneeskunde 1971;115:87-8.

40. Cooper JD, Pearson FG, Patterson GA, et al. Technique of successful lung transplantation in humans. The Journal of thoracic and cardiovascular surgery 1987;93:173-81.

41. Dark J, Cooper JD. Transplantation of the lungs. British journal of hospital medicine 1987;37:443-5.

42. Patterson GA, Cooper JD, Goldman B, et al. Technique of successful clinical double-lung transplantation. The Annals of thoracic surgery 1988;45:626-33.

43. Noirclerc MJ, Metras D, Vaillant A, et al. Bilateral bronchial anastomosis in double lung and heart-lung transplantations. European journal of cardio-thoracic surgery : official journal of the European Association for Cardio-thoracic Surgery 1990;4:314-7.

44. Low DE, Trulock EP, Kaiser LR, et al. Morbidity, mortality, and early results of single versus bilateral lung transplantation for emphysema. The Journal of thoracic and cardiovascular surgery 1992;103:1119-26.

45. Weill D, Benden C, Corris PA, et al. A consensus document for the selection of lung transplant candidates: 2014--an update from the Pulmonary Transplantation Council of the International Society for Heart and Lung Transplantation. The Journal of heart and lung transplantation : the official publication of the International Society for Heart Transplantation 2015;34:1-15.

46. De Soyza A, Archer L, Wardle J, et al. Pulmonary transplantation for cystic fibrosis: pre-transplant recipient characteristics in patients dying of peri-operative sepsis. The Journal of heart and lung transplantation : the official publication of the International Society for Heart Transplantation 2003;22:764-9. 
47. Noirclerc M, Chazalette JP, Metras D, et al. [Double lung transplantation. Report of the 1st French case and comments on the 5 subsequent cases]. Annales de chirurgie 1989;43:597-600.

48. Griffith BP, Hardesty RL, Armitage JM, et al. A decade of lung transplantation. Annals of surgery 1993;218:310-8; discussion 8-20.

49. Scott J, Higenbottam T, Hutter J, et al. Heart-lung transplantation for cystic fibrosis. Lancet 1988;2:192-4.

50. Scott JP, Dennis C, Mullins P. Heart-lung transplantation for end-stage respiratory disease in cystic fibrosis patients. Journal of the Royal Society of Medicine 1993;86 Suppl 20:19-22.

51. Christie JD, Edwards LB, Aurora P, et al. Registry of the International Society for Heart and Lung Transplantation: twenty-fifth official adult lung and heart/lung transplantation report--2008. The Journal of heart and lung transplantation : the official publication of the International Society for Heart Transplantation 2008;27:957-69.

52. Yankaskas JR, Mallory GB, Jr. Lung transplantation in cystic fibrosis: consensus conference statement. Chest 1998;113:217-26.

53. Adler FR, Aurora P, Barker DH, et al. Lung transplantation for cystic fibrosis. Proceedings of the American Thoracic Society 2009;6:619-33.

54. Wiebe K, Wahlers T, Harringer W, vd Hardt H, Fabel H, Haverich A. Lung transplantation for cystic fibrosis--a single center experience over 8 years. European journal of cardio-thoracic surgery : official journal of the European Association for Cardio-thoracic Surgery 1998;14:191-6.

55. Hosenpud JD, Bennett LE, Keck BM, Edwards EB, Novick RJ. Effect of diagnosis on survival benefit of lung transplantation for end-stage lung disease. Lancet 1998;351:24-7.

56. Vizza CD, Yusen RD, Lynch JP, Fedele F, Alexander Patterson G, Trulock EP. Outcome of patients with cystic fibrosis awaiting lung transplantation. American journal of respiratory and critical care medicine 2000;162:819-25.

57. Flume PA. Cystic fibrosis: when to consider lung transplantation? Chest 1998;113:1159-61.

58. Martin C, Hamard C, Kanaan R, et al. Causes of death in French cystic fibrosis patients: The need for improvement in transplantation referral strategies! Journal of cystic fibrosis : official journal of the European Cystic Fibrosis Society 2016;15:204-12.

59. Egan TM, Murray S, Bustami RT, et al. Development of the new lung allocation system in the United States. American journal of transplantation : official journal of the 
American Society of Transplantation and the American Society of Transplant Surgeons 2006;6:1212-27.

60. Oto T, Griffiths AP, Rosenfeldt F, Levvey BJ, Williams TJ, Snell GI. Early outcomes comparing Perfadex, Euro-Collins, and Papworth solutions in lung transplantation. The Annals of thoracic surgery 2006;82:1842-8.

61. DeCampos KN, Keshavjee S, Liu M, Slutsky AS. Optimal inflation volume for hypothermic preservation of rat lungs. The Journal of heart and lung transplantation : the official publication of the International Society for Heart Transplantation 1998;17:599-607.

62. Aoe M, Okabayashi K, Cooper JD, Patterson GA. Hyperinflation of canine lung allografts during storage increases reperfusion pulmonary edema. The Journal of thoracic and cardiovascular surgery 1996;112:94-102.

63. Haniuda M, Hasegawa S, Shiraishi T, Dresler CM, Cooper JD, Patterson GA. Effects of inflation volume during lung preservation on pulmonary capillary permeability. The Journal of thoracic and cardiovascular surgery 1996;112:85-93.

64. Wittwer T, Fehrenbach A, Meyer D, et al. Retrograde flush perfusion with lowpotassium solutions for improvement of experimental pulmonary preservation. The Journal of heart and lung transplantation : the official publication of the International Society for Heart Transplantation 2000;19:976-83.

65. Struber M, Hohlfeld JM, Kofidis T, et al. Surfactant function in lung transplantation after 24 hours of ischemia: advantage of retrograde flush perfusion for preservation. The Journal of thoracic and cardiovascular surgery 2002;123:98-103.

66. Kofidis T, Struber M, Warnecke G, et al. Antegrade versus retrograde perfusion of the donor lung: impact on the early reperfusion phase. Transplant international : official journal of the European Society for Organ Transplantation 2003;16:801-5.

67. Sakiyalak P, Vigneswaran WT. Postpneumonectomy syndrome in single lung transplantation recipient following previous pneumonectomy. The Annals of thoracic surgery $2003 ; 75: 1023-5$.

68. Le Pimpec-Barthes F, Thomas PA, Bonnette P, et al. Single-lung transplantation in patients with previous contralateral pneumonectomy: technical aspects and results. European journal of cardio-thoracic surgery : official journal of the European Association for Cardio-thoracic Surgery 2009;36:927-32.

69. Souilamas R, Mostafa A, Guillemain R, Boussaud V, Amrein C, Chevalier P. Single-lung transplantation for cystic fibrosis and metachronus pneumonectomy: case reports. Transplantation proceedings 2008;40:3594-5. 
70. Meachery G, De Soyza A, Nicholson A, et al. Outcomes of lung transplantation for cystic fibrosis in a large UK cohort. Thorax 2008;63:725-31.

71. Morrell MR, Pilewski JM. Lung Transplantation for Cystic Fibrosis. Clinics in chest medicine 2016;37:127-38.

72. Egan TM, Detterbeck FC, Mill MR, et al. Long term results of lung transplantation for cystic fibrosis. European journal of cardio-thoracic surgery : official journal of the European Association for Cardio-thoracic Surgery 2002;22:602-9.

73. Barr ML, Schenkel FA, Bowdish ME, Starnes VA. Living donor lobar lung transplantation: current status and future directions. Transplantation proceedings 2005;37:3983-6.

74. Couetil JP, Tolan MJ, Loulmet DF, et al. Pulmonary bipartitioning and lobar transplantation: a new approach to donor organ shortage. The Journal of thoracic and cardiovascular surgery 1997;113:529-37.

75. Couetil JP, Tolan MJ, Grousset A, et al. Experimental bilateral lobar lung transplantation and its application in humans. Thorax 1997;52:714-7.

76. Aigner C, Mazhar S, Jaksch P, et al. Lobar transplantation, split lung transplantation and peripheral segmental resection--reliable procedures for downsizing donor lungs. European journal of cardio-thoracic surgery : official journal of the European Association for Cardio-thoracic Surgery 2004;25:179-83.

77. Artemiou O, Birsan T, Taghavi S, et al. Bilateral lobar transplantation with the split lung technique. The Journal of thoracic and cardiovascular surgery 1999;118:36970 .

78. Liou TG, Adler FR, Cox DR, Cahill BC. Lung transplantation and survival in children with cystic fibrosis. The New England journal of medicine 2007;357:2143-52.

79. Allen J, Visner G. Lung transplantation in cystic fibrosis--primum non nocere? The New England journal of medicine 2007;357:2186-8.

80. Rosenbluth DB, Wilson K, Ferkol T, Schuster DP. Lung function decline in cystic fibrosis patients and timing for lung transplantation referral. Chest 2004;126:4129.

81. Kerem E, Reisman J, Corey M, Canny GJ, Levison H. Prediction of mortality in patients with cystic fibrosis. The New England journal of medicine 1992;326:1187-91.

82. Mayer-Hamblett N, Rosenfeld M, Emerson J, Goss CH, Aitken ML. Developing cystic fibrosis lung transplant referral criteria using predictors of 2-year mortality. American journal of respiratory and critical care medicine 2002;166:1550-5. 
83. Augarten A, Akons H, Aviram M, et al. Prediction of mortality and timing of referral for lung transplantation in cystic fibrosis patients. Pediatric transplantation 2001;5:339-42.

84. Liou TG, Adler FR, Cahill BC, et al. Survival effect of lung transplantation among patients with cystic fibrosis. JAMA : the journal of the American Medical Association 2001;286:2683-9.

85. Kadikar A, Maurer J, Kesten S. The six-minute walk test: a guide to assessment for lung transplantation. The Journal of heart and lung transplantation : the official publication of the International Society for Heart Transplantation 1997;16:313-9.

86. Tuppin MP, Paratz JD, Chang AT, et al. Predictive utility of the 6-minute walk distance on survival in patients awaiting lung transplantation. The Journal of heart and lung transplantation : the official publication of the International Society for Heart Transplantation 2008;27:729-34.

87. Venuta F, Rendina EA, Rocca GD, et al. Pulmonary hemodynamics contribute to indicate priority for lung transplantation in patients with cystic fibrosis. The Journal of thoracic and cardiovascular surgery 2000;119:682-9.

88. Venuta F, Tonelli AR, Anile M, et al. Pulmonary hypertension is associated with higher mortality in cystic fibrosis patients awaiting lung transplantation. The Journal of cardiovascular surgery 2012;53:817-20.

89. Esther CR, Jr., Esserman DA, Gilligan P, Kerr A, Noone PG. Chronic Mycobacterium abscessus infection and lung function decline in cystic fibrosis. Journal of cystic fibrosis : official journal of the European Cystic Fibrosis Society 2010;9:11723.

90. Flume PA, Mogayzel PJ, Jr., Robinson KA, et al. Cystic fibrosis pulmonary guidelines: pulmonary complications: hemoptysis and pneumothorax. American journal of respiratory and critical care medicine 2010;182:298-306.

91. Christie JD, Edwards LB, Kucheryavaya AY, et al. The Registry of the International Society for Heart and Lung Transplantation: twenty-seventh official adult lung and heart-lung transplant report--2010. The Journal of heart and lung transplantation : the official publication of the International Society for Heart Transplantation 2010;29:1104-18.

92. Lobo LJ, Chang LC, Esther CR, Jr., Gilligan PH, Tulu Z, Noone PG. Lung transplant outcomes in cystic fibrosis patients with pre-operative Mycobacterium abscessus respiratory infections. Clinical transplantation 2013;27:523-9.

93. Chernenko SM, Humar A, Hutcheon $\mathrm{M}$, et al. Mycobacterium abscessus infections in lung transplant recipients: the international experience. The Journal of 
heart and lung transplantation : the official publication of the International Society for Heart Transplantation 2006;25:1447-55.

94. De Soyza A, McDowell A, Archer L, et al. Burkholderia cepacia complex genomovars and pulmonary transplantation outcomes in patients with cystic fibrosis. Lancet 2001;358:1780-1.

95. De Soyza A, Corris PA. Lung transplantation and the Burkholderia cepacia complex. The Journal of heart and lung transplantation : the official publication of the International Society for Heart Transplantation 2003;22:954-8.

96. De Soyza A, Meachery G, Hester KL, et al. Lung transplantation for patients with cystic fibrosis and Burkholderia cepacia complex infection: a single-center experience. The Journal of heart and lung transplantation : the official publication of the International Society for Heart Transplantation 2010;29:1395-404.

97. Maurer JR, Frost AE, Estenne M, Higenbottam T, Glanville AR. International guidelines for the selection of lung transplant candidates. The International Society for Heart and Lung Transplantation, the American Thoracic Society, the American Society of Transplant Physicians, the European Respiratory Society. Transplantation 1998;66:951-6.

98. Varela A, Alvarez Kindelan A, Roman A, Ussetti P, Zurbano F, Grupo de Trabajo de la S. [SEPAR (Spanish Society of Pneumology and Thoracic Surgery) Guidelines. Lung transplantation]. Archivos de bronconeumologia 2001;37:307-15.

99. Orens JB, Boehler A, de Perrot $\mathrm{M}$, et al. A review of lung transplant donor acceptability criteria. The Journal of heart and lung transplantation : the official publication of the International Society for Heart Transplantation 2003;22:1183-200.

100. Mulligan MJ, Sanchez PG, Evans CF, et al. The use of extended criteria donors decreases one-year survival in high-risk lung recipients: A review of the United Network of Organ Sharing Database. The Journal of thoracic and cardiovascular surgery 2016;152:891-8 e2.

101. Soresi S, Zeriouh M, Sabashnikov A, et al. Extended Recipient Criteria in Lung Transplantation: Impact of Pleural Abnormalities on Primary Graft Dysfunction. The Annals of thoracic surgery 2016;101:2112-9.

102. Moreno P, Alvarez A, Santos F, et al. Extended recipients but not extended donors are associated with poor outcomes following lung transplantation. European journal of cardio-thoracic surgery : official journal of the European Association for Cardio-thoracic Surgery 2014;45:1040-7.

103. Somers J, Ruttens D, Verleden SE, et al. A decade of extended-criteria lung donors in a single center: was it justified? Transplant international : official journal of the European Society for Organ Transplantation 2015;28:170-9. 
104. Orens JB, Estenne M, Arcasoy S, et al. International guidelines for the selection of lung transplant candidates: 2006 update--a consensus report from the Pulmonary Scientific Council of the International Society for Heart and Lung Transplantation. The Journal of heart and lung transplantation : the official publication of the International Society for Heart Transplantation 2006;25:745-55.

105. Geddes DM, Hodson ME. The role of heart and lung transplantation in the treatment of cystic fibrosis. Journal of the Royal Society of Medicine 1989;82 Suppl 16:49-53.

106. Smyth RL, Higenbottam TW, Scott JP, et al. Early experience of heart-lung transplantation. Archives of disease in childhood 1989;64:1225-9; discussion 9-30.

107. Fradet G, Smyth RL, Scott JP, et al. Cystic fibrosis: a new challenge for cardiothoracic surgery. European journal of cardio-thoracic surgery : official journal of the European Association for Cardio-thoracic Surgery 1990;4:136-40; discussion 40-1.

108. Yacoub MH, Khaghani A, Miyamura H, Sono J. Heart-lung transplantation-Harefield experience. The Japanese journal of surgery 1990;20:247-51.

109. Griffith BP, Hardesty RL, Trento A, et al. Heart-lung transplantation: lessons learned and future hopes. The Annals of thoracic surgery 1987;43:6-16.

110. Vricella LA, Karamichalis JM, Ahmad S, Robbins RC, Whyte RI, Reitz BA. Lung and heart-lung transplantation in patients with end-stage cystic fibrosis: the Stanford experience. The Annals of thoracic surgery 2002;74:13-7; discussion 7-8.

111. Ganesh JS, Rogers CA, Bonser RS, Banner NR, Steering Group of the UKCTA. Outcome of heart-lung and bilateral sequential lung transplantation for cystic fibrosis: a UK national study. The European respiratory journal 2005;25:964-9.

112. Scheffert JL, Raza K. Immunosuppression in lung transplantation. Journal of thoracic disease 2014;6:1039-53.

113. Denton MD, Magee CC, Sayegh MH. Immunosuppressive strategies in transplantation. Lancet 1999;353:1083-91.

114. Felkel TO, Smith AL, Reichenspurner HC, et al. Survival and incidence of acute rejection in heart transplant recipients undergoing successful withdrawal from steroid therapy. The Journal of heart and lung transplantation : the official publication of the International Society for Heart Transplantation 2002;21:530-9.

115. Miller LW, Wolford T, McBride LR, Peigh P, Pennington DG. Successful withdrawal of corticosteroids in heart transplantation. The Journal of heart and lung transplantation : the official publication of the International Society for Heart Transplantation 1992;11:431-4. 
116. Opelz G, Dohler B, Laux G, Collaborative Transplant S. Long-term prospective study of steroid withdrawal in kidney and heart transplant recipients. American journal of transplantation : official journal of the American Society of Transplantation and the American Society of Transplant Surgeons 2005;5:720-8.

117. Punch JD, Shieck VL, Campbell DA, Bromberg JS, Turcotte JG, Merion RM. Corticosteroid withdrawal after liver transplantation. Surgery 1995;118:783-6; discussion 6-8.

118. Buchman AL. Side effects of corticosteroid therapy. Journal of clinical gastroenterology 2001;33:289-94.

119. Hachem RR, Chakinala MM, Yusen RD, et al. A comparison of basiliximab and anti-thymocyte globulin as induction agents after lung transplantation. The Journal of heart and lung transplantation : the official publication of the International Society for Heart Transplantation 2005;24:1320-6.

120. Swarup R, Allenspach LL, Nemeh HW, Stagner LD, Betensley AD. Timing of basiliximab induction and development of acute rejection in lung transplant patients. The Journal of heart and lung transplantation : the official publication of the International Society for Heart Transplantation 2011;30:1228-35.

121. Garrity ER, Jr., Villanueva J, Bhorade SM, Husain AN, Vigneswaran WT. Low rate of acute lung allograft rejection after the use of daclizumab, an interleukin 2 receptor antibody. Transplantation 2001;71:773-7.

122. van Loenhout KC, Groves SC, Galazka M, et al. Early outcomes using alemtuzumab induction in lung transplantation. Interactive cardiovascular and thoracic surgery 2010;10:190-4.

123. Shyu S, Dew MA, Pilewski JM, et al. Five-year outcomes with alemtuzumab induction after lung transplantation. The Journal of heart and lung transplantation : the official publication of the International Society for Heart Transplantation 2011;30:74354 .

124. McCurry KR, Iacono A, Zeevi A, et al. Early outcomes in human lung transplantation with Thymoglobulin or Campath-1H for recipient pretreatment followed by posttransplant tacrolimus near-monotherapy. The Journal of thoracic and cardiovascular surgery 2005;130:528-37.

125. Reams BD, Musselwhite LW, Zaas DW, et al. Alemtuzumab in the treatment of refractory acute rejection and bronchiolitis obliterans syndrome after human lung transplantation. American journal of transplantation : official journal of the American Society of Transplantation and the American Society of Transplant Surgeons 2007;7:2802-8. 
126. Hausen B, Morris RE. Review of immunosuppression for lung transplantation. Novel drugs, new uses for conventional immunosuppressants, and alternative strategies. Clinics in chest medicine 1997;18:353-66.

127. Keenan RJ, Konishi H, Kawai A, et al. Clinical trial of tacrolimus versus cyclosporine in lung transplantation. The Annals of thoracic surgery 1995;60:580-4; discussion 4-5.

128. Zuckermann A, Reichenspurner H, Birsan T, et al. Cyclosporine A versus tacrolimus in combination with mycophenolate mofetil and steroids as primary immunosuppression after lung transplantation: one-year results of a 2-center prospective randomized trial. The Journal of thoracic and cardiovascular surgery 2003;125:891-900.

129. Corris P, Glanville A, McNeil K, et al. One year analysis of an ongoing international randomized study of mycophenolate mofetil (MMF) vs azathioprine (AZA) in lung transplantation. The Journal of heart and lung transplantation : the official publication of the International Society for Heart Transplantation 2001;20:14950.

130. Collette S, Boucher A, Senécal L, Tran D, Leblond F, Pichette V. SP836PROSPECTIVE, 6 MONTH, OPEN LABEL, CONVERSION STUDY FROM MYCOPHENOLATE MOFETIL TO MYCOPHENOLIC ACID EVALUATING THE SEVERITY OF GASTRO-INTESTINAL SYMPTOMS AND MYCOPHENOLIC ACID URINARY METABOLITE AS A SURROGATE MARKER OF PLASMATIC AREA UNDER THE CURVE. Nephrology Dialysis Transplantation 2015;30:iii653-iii.

131. Snell GI, Levvey BJ, Chin W, et al. Sirolimus allows renal recovery in lung and heart transplant recipients with chronic renal impairment. The Journal of heart and lung transplantation : the official publication of the International Society for Heart Transplantation 2002;21:540-6.

132. Gullestad L, Iversen M, Mortensen SA, et al. Everolimus with reduced calcineurin inhibitor in thoracic transplant recipients with renal dysfunction: a multicenter, randomized trial. Transplantation 2010;89:864-72.

133. Patrucco F, Bellocchia M, Verri G, et al. The effect of everolimus on lung function and renal status in lung transplanted patients. Eur Respiratory Soc; 2016.

134. Machin D, Allsager C. Principles of cardiopulmonary bypass. Continuing Education in Anaesthesia, Critical Care \& Pain 2006;6:176-81.

135. Smith R. Inventions and inventors. Pasadena, Calif.: Salem Press; 2002.

136. RUBIO M. CIRCULACIÓN EXTRACORPÓREA. CONCEPTOS BÁSICOS. CONAREC:146. 
137. Giavarina D, Carta M, Fabbri A, Manfredi J, Gasparotto E, Soffiati G. Monitoring high-dose heparin levels by ACT and HMT during extracorporeal circulation: diagnostic accuracy of three compact monitors. Perfusion 2002;17:23-6.

138. Wildevuur CR, Jansen PG, Bezemer PD, et al. Clinical evaluation of Duraflo II heparin treated extracorporeal circulation circuits (2nd version). The European Working Group on heparin coated extracorporeal circulation circuits. European journal of cardiothoracic surgery : official journal of the European Association for Cardio-thoracic Surgery 1997;11:616-23; discussion 24-5.

139. Graves K. Perfusion safety in Europe: managing risks, learning from mistakes. Perfusion 2005;20:209-15.

140. Stoney WS. Evolution of cardiopulmonary bypass. Circulation 2009;119:284453.

141. Mehta RH, Castelvecchio S, Ballotta A, Frigiola A, Bossone E, Ranucci M. Association of gender and lowest hematocrit on cardiopulmonary bypass with acute kidney injury and operative mortality in patients undergoing cardiac surgery. The Annals of thoracic surgery 2013;96:133-40.

142. Voss B, Krane M, Jung C, et al. Cardiopulmonary bypass with physiological flow and pressure curves: pulse is unnecessary! European journal of cardio-thoracic surgery : official journal of the European Association for Cardio-thoracic Surgery 2010;37:223-32.

143. George TJ, Beaty CA, Kilic A, et al. Hemoglobin drift after cardiac surgery. The Annals of thoracic surgery 2012;94:703-9.

144. Khaladj N, Peterss S, Pichlmaier M, et al. The impact of deep and moderate body temperatures on end-organ function during hypothermic circulatory arrest. European journal of cardio-thoracic surgery : official journal of the European Association for Cardio-thoracic Surgery 2011;40:1492-9; discussion 9.

145. Lake CL, Booker PD. Pediatric cardiac anesthesia: Lippincott Williams \& Wilkins; 2005.

146. Méndez FJM. Fisiopatología de la circulación extracorpórea. Archivos de Cardiología de México 2004.

147. Burdett C, Butt T, Lordan J, Dark JH, Clark SC. Comparison of single lung transplant with and without the use of cardiopulmonary bypass. Interactive cardiovascular and thoracic surgery 2012;15:432-6; discussion 6.

148. Gammie JS, Cheul Lee J, Pham SM, et al. Cardiopulmonary bypass is associated with early allograft dysfunction but not death after double-lung transplantation. The Journal of thoracic and cardiovascular surgery 1998;115:990-7. 
149. Aeba R, Griffith BP, Kormos RL, et al. Effect of cardiopulmonary bypass on early graft dysfunction in clinical lung transplantation. The Annals of thoracic surgery 1994;57:715-22.

150. Fullerton DA, McIntyre RC, Jr., Mitchell MB, Campbell DN, Grover FL. Lung transplantation with cardiopulmonary bypass exaggerates pulmonary vasomotor dysfunction in the transplanted lung. The Journal of thoracic and cardiovascular surgery 1995;109:212-6; discussion 6-7.

151. Nagendran M, Maruthappu M, Sugand K. Should double lung transplant be performed with or without cardiopulmonary bypass? Interactive cardiovascular and thoracic surgery 2011;12:799-804.

152. Asimakopoulos G, Smith PL, Ratnatunga CP, Taylor KM. Lung injury and acute respiratory distress syndrome after cardiopulmonary bypass. The Annals of thoracic surgery 1999;68:1107-15.

153. McRae K. Con: lung transplantation should not be routinely performed with cardiopulmonary bypass. Journal of cardiothoracic and vascular anesthesia 2000;14:746-50.

154. Edmunds LH, Jr. Inflammatory response to cardiopulmonary bypass. The Annals of thoracic surgery 1998;66:S12-6; discussion S25-8.

155. Liu Y, Liu Y, Su L, Jiang SJ. Recipient-related clinical risk factors for primary graft dysfunction after lung transplantation: a systematic review and meta-analysis. PloS one 2014;9:e92773.

156. Diamond JM, Lee JC, Kawut SM, et al. Clinical risk factors for primary graft dysfunction after lung transplantation. American journal of respiratory and critical care medicine 2013;187:527-34.

157. Wan S, LeClerc JL, Vincent JL. Inflammatory response to cardiopulmonary bypass: mechanisms involved and possible therapeutic strategies. Chest 1997;112:67692.

158. Francalancia NA, Aeba R, Yousem SA, Griffith BP, Marrone GC. Deleterious effects of cardiopulmonary bypass on early graft function after single lung allotransplantation: evaluation of a heparin-coated bypass circuit. The Journal of heart and lung transplantation : the official publication of the International Society for Heart Transplantation 1994;13:498-507.

159. Khan SU, Salloum J, O'Donovan PB, et al. Acute pulmonary edema after lung transplantation: the pulmonary reimplantation response. Chest 1999;116:187-94.

160. Huang HJ, Yusen RD, Meyers BF, et al. Late primary graft dysfunction after lung transplantation and bronchiolitis obliterans syndrome. American journal of 
transplantation : official journal of the American Society of Transplantation and the American Society of Transplant Surgeons 2008;8:2454-62.

161. Christie JD, Kotloff RM, Ahya VN, et al. The effect of primary graft dysfunction on survival after lung transplantation. American journal of respiratory and critical care medicine 2005;171:1312-6.

162. Whitson BA, Prekker ME, Herrington CS, et al. Primary graft dysfunction and long-term pulmonary function after lung transplantation. The Journal of heart and lung transplantation : the official publication of the International Society for Heart Transplantation 2007;26:1004-11.

163. Christie JD, Bavaria JE, Palevsky HI, et al. Primary graft failure following lung transplantation. Chest 1998;114:51-60.

164. Barr ML, Kawut SM, Whelan TP, et al. Report of the ISHLT Working Group on Primary Lung Graft Dysfunction part IV: recipient-related risk factors and markers. The Journal of heart and lung transplantation 2005;24:1468-82.

165. Meyers BF, de la Morena M, Sweet SC, et al. Primary graft dysfunction and other selected complications of lung transplantation: A single-center experience of 983 patients. The Journal of thoracic and cardiovascular surgery 2005;129:1421-9.

166. Sommers KE, Griffith BP, Hardesty RL, Keenan RJ. Early lung allograft function in twin recipients from the same donor: risk factor analysis. The Annals of thoracic surgery 1996;62:784-90.

167. Marczin N, Royston D, Yacoub M. Pro: lung transplantation should be routinely performed with cardiopulmonary bypass. Journal of cardiothoracic and vascular anesthesia 2000;14:739-45.

168. Hlozek CC, Smedira NG, Kirby TJ, Patel AN, Perl M. Cardiopulmonary bypass (CPB) for lung transplantation. Perfusion 1997;12:107-12.

169. Szeto WY, Kreisel D, Karakousis GC, et al. Cardiopulmonary bypass for bilateral sequential lung transplantation in patients with chronic obstructive pulmonary disease without adverse effect on lung function or clinical outcome. The Journal of thoracic and cardiovascular surgery 2002;124:241-9.

170. de Boer WJ, Hepkema BG, Loef BG, et al. Survival benefit of cardiopulmonary bypass support in bilateral lung transplantation for emphysema patients. Transplantation 2002;73:1621-7.

171. Sheridan BC, Hodges TN, Zamora MR, et al. Acute and chronic effects of bilateral lung transplantation without cardiopulmonary bypass on the first transplanted lung. The Annals of thoracic surgery 1998;66:1755-8. 
172. Cassivi SD, Meyers BF, Battafarano RJ, et al. Thirteen-year experience in lung transplantation for emphysema. The Annals of thoracic surgery 2002;74:1663-9; discussion 9-70.

173. Dalibon N, Geffroy A, Moutafis M, et al. Use of cardiopulmonary bypass for lung transplantation: a 10-year experience. Journal of cardiothoracic and vascular anesthesia 2006;20:668-72.

174. Wang Y, Kurichi JE, Blumenthal NP, et al. Multiple variables affecting blood usage in lung transplantation. The Journal of heart and lung transplantation : the official publication of the International Society for Heart Transplantation 2006;25:533-8.

175. Quinlan JJ, Buffington CW. Deliberate hypoventilation in a patient with air trapping during lung transplantation. Anesthesiology 1993;78:1177-81.

176. Shigemura N, Orhan Y, Bhama JK, et al. Delayed chest closure after lung transplantation: techniques, outcomes, and strategies. The Journal of heart and lung transplantation : the official publication of the International Society for Heart Transplantation 2014;33:741-8.

177. Soresi S, Sabashnikov A, Weymann A, Zeriouh M, Simon AR, Popov AF. When the Battle is Lost and Won: Delayed Chest Closure After Bilateral Lung Transplantation. Med Sci Monit Basic Res 2015;21:222-5.

178. Meyers BF, Lynch JP, Trulock EP, Guthrie T, Cooper JD, Patterson GA. Single versus bilateral lung transplantation for idiopathic pulmonary fibrosis: a ten-year institutional experience. The Journal of thoracic and cardiovascular surgery 2000;120:99-107.

179. Estivill X, Bancells C, Ramos C. Geographic distribution and regional origin of 272 cystic fibrosis mutations in European populations. The Biomed CF Mutation Analysis Consortium. Human mutation 1997;10:135-54.

180. Mehta G, Macek M, Jr., Mehta A, European Registry Working G. Cystic fibrosis across Europe: EuroCareCF analysis of demographic data from 35 countries. Journal of cystic fibrosis : official journal of the European Cystic Fibrosis Society 2010;9 Suppl 2:S5-S21.

181. Lucotte G, Hazout S, De Braekeleer M. Complete map of cystic fibrosis mutation DF508 frequencies in Western Europe and correlation between mutation frequencies and incidence of disease. Human biology 1995;67:797-803.

182. McCormick J, Mehta G, Olesen HV, et al. Comparative demographics of the European cystic fibrosis population: a cross-sectional database analysis. Lancet 2010;375:1007-13. 
183. Bobadilla JL, Macek M, Jr., Fine JP, Farrell PM. Cystic fibrosis: a worldwide analysis of CFTR mutations--correlation with incidence data and application to screening. Human mutation 2002;19:575-606.

184. Chaparro C, Maurer J, Gutierrez C, et al. Infection with Burkholderia cepacia in cystic fibrosis: outcome following lung transplantation. American journal of respiratory and critical care medicine 2001;163:43-8.

185. Shennib H, Noirclerc M, Ernst P, et al. Double-lung transplantation for cystic fibrosis. The Cystic Fibrosis Transplant Study Group. The Annals of thoracic surgery 1992;54:27-31; discussion -2.

186. de Pablo A, Lopez S, Ussetti P, et al. [Lung transplant therapy for suppurative diseases]. Archivos de bronconeumologia 2005;41:255-9.

187. Moreno P, Alvarez A, Carrasco G, et al. Lung transplantation for cystic fibrosis: differential characteristics and outcomes between children and adults. European journal of cardio-thoracic surgery : official journal of the European Association for Cardiothoracic Surgery 2016;49:1334-43.

188. Yusen RD, Edwards LB, Kucheryavaya AY, et al. The registry of the International Society for Heart and Lung Transplantation: thirty-first adult lung and heart-lung transplant report--2014; focus theme: retransplantation. The Journal of heart and lung transplantation : the official publication of the International Society for Heart Transplantation 2014;33:1009-24.

189. Coll E, Santos F, Ussetti P, et al. The Spanish Lung Transplant Registry: first report of results (2006-2010). Archivos de bronconeumologia 2013;49:70-8.

190. DiNardo JA, Zvara DA. Anesthesia for cardiac surgery: Blackwell Pub.; 2008.

191. Bando K, Paradis IL, Similo S, et al. Obliterative bronchiolitis after lung and heart-lung transplantation. An analysis of risk factors and management. The Journal of thoracic and cardiovascular surgery 1995;110:4-13; discussion -4.

192. Girgis RE, Tu I, Berry GJ, et al. Risk factors for the development of obliterative bronchiolitis after lung transplantation. The Journal of heart and lung transplantation : the official publication of the International Society for Heart Transplantation 1996;15:1200-8.

193. Hachem RR, Khalifah AP, Chakinala MM, et al. The significance of a single episode of minimal acute rejection after lung transplantation. Transplantation 2005;80:1406-13.

194. Loubeyre P, Revel D, Delignette A, Loire R, Mornex JF. High-resolution computed tomographic findings associated with histologically diagnosed acute lung rejection in heart-lung transplant recipients. Chest 1995;107:132-8. 
195. Hopkins PM, Aboyoun CL, Chhajed PN, et al. Prospective analysis of 1,235 transbronchial lung biopsies in lung transplant recipients. The Journal of heart and lung transplantation : the official publication of the International Society for Heart Transplantation 2002;21:1062-7.

196. DeVito Dabbs A, Hoffman LA, Iacono AT, et al. Pattern and predictors of early rejection after lung transplantation. American journal of critical care : an official publication, American Association of Critical-Care Nurses 2003;12:497-507.

197. Stewart S, Fishbein MC, Snell GI, et al. Revision of the 1996 working formulation for the standardization of nomenclature in the diagnosis of lung rejection. The Journal of heart and lung transplantation : the official publication of the International Society for Heart Transplantation 2007;26:1229-42.

198. Estenne M, Maurer JR, Boehler A, et al. Bronchiolitis obliterans syndrome 2001: an update of the diagnostic criteria. The Journal of heart and lung transplantation : the official publication of the International Society for Heart Transplantation 2002;21:297-310.

199. Physical status: the use and interpretation of anthropometry. Report of a WHO Expert Committee. World Health Organization technical report series 1995;854:1-452.

200. Laboratories ACoPSfCPF. ATS statement: guidelines for the six-minute walk test. American journal of respiratory and critical care medicine 2002;166:111.

201. Bosch M, García S. Ventilación mecánica no invasiva. Manual SEPAR de procedimientos 2002:43.

202. Ortega RF, Díaz LS, Galdiz IJ, et al. Continuous home oxygen therapy. Archivos de bronconeumologia 2014;50:185-200.

203. Scheinhorn DJ, Chao DC, Stearn-Hassenpflug M. Liberation from prolonged mechanical ventilation. Critical care clinics 2002;18:569-95.

204. Stamm SJ, Docter J. Chest Measurements as an Aid in the Diagnosis of Cystic Fibrosis. Diseases of the chest 1965;47:98-101.

205. Astudillo Pombo J, Bravo Masgoret C, Margarit Creixell C, Guillermo Rodriguez ML, Tenorio Lopez L. [Sequential double-lung transplantation. Technique and results in the first 3 cases. Pulmonary Transplant Group]. Archivos de bronconeumologia 1994;30:348-53.

206. Roman A, Morell F, Astudillo J, et al. [Unilateral lung transplantation: the first 2 cases. Group of Lung Transplantation of the University General Hospital of the Vall d'Hebron]. Medicina clinica 1993;100:380-3. 
207. Frist WH, Fox MD, Campbell PW, Fiel SB, Loyd JE, Merrill WH. Cystic fibrosis treated with heart-lung transplantation: North American results. Transplantation proceedings 1991;23:1205-6.

208. Yusen RD, Edwards LB, Dipchand AI, et al. The Registry of the International Society for Heart and Lung Transplantation: Thirty-third Adult Lung and Heart-Lung Transplant Report-2016; Focus Theme: Primary Diagnostic Indications for Transplant. The Journal of heart and lung transplantation : the official publication of the International Society for Heart Transplantation 2016;35:1170-84.

209. Maurer JR, Frost AE, Estenne M, Higenbottam T, Glanville AR. International guidelines for the selection of lung transplant candidates. The International Society for Heart and Lung Transplantation, the American Thoracic Society, the American Society of Transplant Physicians, the European Respiratory Society. The Journal of heart and lung transplantation : the official publication of the International Society for Heart Transplantation 1998;17:703-9.

210. Shah PD, Orens JB. Guidelines for the selection of lung-transplant candidates. Current opinion in organ transplantation 2012;17:467-73.

211. Doershuk CF, Stern RC. Timing of referral for lung transplantation for cystic fibrosis: overemphasis on FEV1 may adversely affect overall survival. Chest 1999;115:782-7.

212. Quattrucci S, Rolla M, Cimino G, et al. Lung transplantation for cystic fibrosis: 6-year follow-up. Journal of cystic fibrosis : official journal of the European Cystic Fibrosis Society 2005;4:107-14.

213. Alexander BD, Petzold EW, Reller LB, et al. Survival after lung transplantation of cystic fibrosis patients infected with Burkholderia cepacia complex. American journal of transplantation : official journal of the American Society of Transplantation and the American Society of Transplant Surgeons 2008;8:1025-30.

214. Steen S, Kimblad PO, Sjöberg T, Lindberg L, Ingemansson R, Massa G. Safe lung preservation for twenty-four hours with Perfadex. The Annals of thoracic surgery 1994;57:450-7.

215. Wittwer T, Wahlers T, Fehrenbach A, Elki S, Haverich A. Improvement of pulmonary preservation with Celsior and Perfadex: impact of storage time on early post-ischemic lung function. The Journal of heart and lung transplantation : the official publication of the International Society for Heart Transplantation 1999;18:1198-201.

216. Ingemansson R, Massa G, Pandita RK, Sjöberg T, Steen S. Perfadex is superior to Euro-Collins solution regarding 24-hour preservation of vascular function. The Annals of thoracic surgery 1995;60:1210-4. 
217. Aziz TM, Pillay TM, Corris PA, et al. Perfadex for clinical lung procurement: is it an advance? The Annals of thoracic surgery 2003;75:990-5.

218. Miñambres E, González-castro A, Rabanal JM, et al. Perfadex Improves Early Lung Function In Bilateral Lung Recipients. Transplant International 2005;18:240-1.

219. Rega F, Verleden G, Vanhaecke J, Daenen W, Van Raemdonck D. Switch from euro-collins ${ }^{\circledR}$ to perfadex ${ }^{\circledR}$ for pulmonary graft preservation resulted in superior outcome in transplant recipients. The Journal of Heart and Lung Transplantation 2003;22:S111.

220. Rabanal JM, Ibanez AM, Mons R, et al. Influence of preservation solution on early lung function (Euro-Collins vs Perfadex). Transplantation proceedings 2003;35:1938-9.

221. Wittwer T, Franke U, Fehrenbach A, et al. Impact of retrograde graft preservation in Perfadex-based experimental lung transplantation. The Journal of surgical research 2004;117:239-48.

222. Inci I, Stanimirov O, Benden $\mathrm{C}$, et al. Lung transplantation for cystic fibrosis: a single center experience of 100 consecutive cases. European journal of cardio-thoracic surgery : official journal of the European Association for Cardio-thoracic Surgery 2012;41:435-40.

223. Nath DS, Walter AR, Johnson AC, et al. Does Perfadex affect outcomes in clinical lung transplantation? The Journal of heart and lung transplantation : the official publication of the International Society for Heart Transplantation 2005;24:2243-8.

224. Gohrbandt B, Simon AR, Warnecke G, et al. Lung Preservation With Perfadex or Celsior in Clinical Transplantation: A Retrospective Single-Center Analysis of Outcomes. Transplantation 2015;99:1933-9.

225. Coloni GF, Venuta F, Ciccone AM, et al. Lung transplantation for cystic fibrosis. Transplantation proceedings 2004;36:648-50.

226. Hofer M, Benden C, Inci I, et al. True survival benefit of lung transplantation for cystic fibrosis patients: the Zurich experience. The Journal of heart and lung transplantation : the official publication of the International Society for Heart Transplantation 2009;28:334-9.

227. Ciriaco P, Egan TM, Cairns EL, Thompson JT, Detterbeck FC, Paradowski LJ. Analysis of cystic fibrosis referrals for lung transplantation. Chest 1995;107:1323-7.

228. Kerem E, Corey M, Kerem BS, et al. The relation between genotype and phenotype in cystic fibrosis--analysis of the most common mutation (delta F508). The New England journal of medicine 1990;323:1517-22. 
229. Johansen HK, Nir M, Hoiby N, Koch C, Schwartz M. Severity of cystic fibrosis in patients homozygous and heterozygous for delta F508 mutation. Lancet 1991;337:631-4.

230. Santis G, Osborne L, Knight RA, Hodson ME. Independent genetic determinants of pancreatic and pulmonary status in cystic fibrosis. Lancet 1990;336:1081-4.

231. McKone EF, Emerson SS, Edwards KL, Aitken ML. Effect of genotype on phenotype and mortality in cystic fibrosis: a retrospective cohort study. Lancet 2003;361:1671-6.

232. McKone EF, Goss CH, Aitken ML. CFTR genotype as a predictor of prognosis in cystic fibrosis. Chest 2006;130:1441-7.

233. Schneiderman-Walker J, Wilkes DL, Strug L, et al. Sex differences in habitual physical activity and lung function decline in children with cystic fibrosis. The Journal of pediatrics 2005;147:321-6.

234. Rosenfeld M, Davis R, FitzSimmons S, Pepe M, Ramsey B. Gender gap in cystic fibrosis mortality. American journal of epidemiology 1997;145:794-803.

235. Fulton JA, Orenstein DM, Koehler AN, Kurland G. Nutrition in the pediatric double lung transplant patient with cystic fibrosis. Nutrition in clinical practice : official publication of the American Society for Parenteral and Enteral Nutrition 1995;10:67-72.

236. Bell SC, Bowerman AR, Davies CA, Campbell IA, Shale DJ, Elborn JS. Nutrition in adults with cystic fibrosis. Clinical nutrition 1998;17:211-5.

237. Sell JL, Bacchetta M, Goldfarb SB, et al. Short stature and access to lung transplantation in the United States. a cohort study. American journal of respiratory and critical care medicine 2016;193:681-8.

238. Hollander FM, van Pierre DD, de Roos NM, van de Graaf EA, Iestra JA. Effects of nutritional status and dietetic interventions on survival in Cystic Fibrosis patients before and after lung transplantation. Journal of cystic fibrosis : official journal of the European Cystic Fibrosis Society 2014;13:212-8.

239. Calanas-Continente AJ, Cervero Pluvins C, Munoz Gomariz E, et al. [Prevalence of malnutrition among candidates for lung transplantation]. Nutricion hospitalaria 2002;17:197-203.

240. Snell GI, Bennetts K, Bartolo J, et al. Body mass index as a predictor of survival in adults with cystic fibrosis referred for lung transplantation. The Journal of heart and lung transplantation : the official publication of the International Society for Heart Transplantation 1998;17:1097-103. 
241. Kanasky WF, Jr., Anton SD, Rodrigue JR, Perri MG, Szwed T, Baz MA. Impact of body weight on long-term survival after lung transplantation. Chest 2002;121:401-6.

242. Madill J, Gutierrez C, Grossman J, et al. Nutritional assessment of the lung transplant patient: body mass index as a predictor of 90-day mortality following transplantation. The Journal of heart and lung transplantation : the official publication of the International Society for Heart Transplantation 2001;20:288-96.

243. Steinkamp G, Wiedemann B. Relationship between nutritional status and lung function in cystic fibrosis: cross sectional and longitudinal analyses from the German CF quality assurance (CFQA) project. Thorax 2002;57:596-601.

244. Gozdzik J, Cofta S, Piorunek T, Batura-Gabryel H, Kosicki J. Relationship between nutritional status and pulmonary function in adult cystic fibrosis patients. Journal of physiology and pharmacology : an official journal of the Polish Physiological Society 2008;59 Suppl 6:253-60.

245. McCarthy C, Dimitrov BD, Meurling IJ, Gunaratnam C, McElvaney NG. The CF-ABLE score: a novel clinical prediction rule for prognosis in patients with cystic fibrosis. Chest 2013;143:1358-64.

246. Twisk JW, Arets H, van der Ent CK, Takken T. Prediction of mortality in adolescents with cystic fibrosis. 2014.

247. de Gracia J, Alvarez A, Mata F, et al. [Cystic fibrosis in adults: study of 111 patients]. Medicina clinica 2002;119:605-9.

248. Courtney JM, Bradley J, McCaughan J, et al. Predictors of mortality in adults with cystic fibrosis. Pediatric pulmonology 2007;42:525-32.

249. Merlo CA, Clark SC, Arnaoutakis GJ, et al. National Healthcare Delivery Systems Influence Lung Transplant Outcomes for Cystic Fibrosis. American journal of transplantation : official journal of the American Society of Transplantation and the American Society of Transplant Surgeons 2015;15:1948-57.

250. Gilljam M, Nystrom U, Dellgren G, Skog I, Hansson L. Survival after lung transplantation for cystic fibrosis in Swedendagger. European journal of cardio-thoracic surgery : official journal of the European Association for Cardio-thoracic Surgery 2017;51:571-6.

251. Lewis C, Blackman SM, Nelson A, et al. Diabetes-related mortality in adults with cystic fibrosis. Role of genotype and sex. American journal of respiratory and critical care medicine 2015;191:194-200.

252. Hayes D, Jr., Patel AV, Black SM, et al. Influence of diabetes on survival in patients with cystic fibrosis before and after lung transplantation. The Journal of thoracic and cardiovascular surgery 2015;150:707-13 e2. 
253. Stephenson AL, Sykes J, Berthiaume Y, et al. Clinical and demographic factors associated with post-lung transplantation survival in individuals with cystic fibrosis. The Journal of heart and lung transplantation : the official publication of the International Society for Heart Transplantation 2015;34:1139-45.

254. Sole A, Perez I, Vazquez I, et al. Patient-reported symptoms and functioning as indicators of mortality in advanced cystic fibrosis: A new tool for referral and selection for lung transplantation. The Journal of heart and lung transplantation : the official publication of the International Society for Heart Transplantation 2016;35:789-94.

255. Calvo-Lerma J, Martinez-Barona S, Masip E, Fornés-Ferrer V, Ribes-Koninckx C. 339 Pancreatic enzyme replacement therapy in cystic fibrosis: dose, variability and coefficient of fat absorption. Journal of Cystic Fibrosis 2017;16:S149-S50.

256. Barbas A, Dib M, Al-Adra D, et al. Combined lung-liver-pancreas transplantation in a recipient with cystic fibrosis. Journal of Cystic Fibrosis 2017.

257. Madden BP, Kariyawasam H, Siddiqi AJ, Machin A, Pryor JA, Hodson ME. Noninvasive ventilation in cystic fibrosis patients with acute or chronic respiratory failure. The European respiratory journal 2002;19:310-3.

258. Aris RM, Gilligan PH, Neuringer IP, Gott KK, Rea J, Yankaskas JR. The effects of panresistant bacteria in cystic fibrosis patients on lung transplant outcome. American journal of respiratory and critical care medicine 1997;155:1699-704.

259. Balfour-Lynn IM, Ryley HC, Whitehead BF. Subdural empyema due to Burkholderia cepacia: an unusual complication after lung transplantation for cystic fibrosis. Journal of the Royal Society of Medicine 1997;90 Suppl 31:59-64.

260. Noyes BE, Michaels MG, Kurland G, Armitage JM, Orenstein DM. Pseudomonas cepacia empyema necessitatis after lung transplantation in two patients with cystic fibrosis. Chest 1994;105:1888-91.

261. Snell GI, de Hoyos A, Krajden M, Winton T, Maurer JR. Pseudomonas cepacia in lung transplant recipients with cystic fibrosis. Chest 1993;103:466-71.

262. Egan JJ, McNeil K, Bookless B, et al. Post-transplantation survival of cystic fibrosis patients infected with Pseudomonas cepacia. Lancet 1994;344:552-3.

263. Thomassen MJ, Demko CA, Klinger JD, Stern RC. Pseudomonas cepacia colonization among patients with cystic fibrosis. A new opportunist. The American review of respiratory disease 1985;131:791-6.

264. Moss RB. Hypergammaglobulinemia in cystic fibrosis. Role of Pseudomonas endobronchial infection. Chest 1987;91:522-6. 
265. Tablan OC, Martone WJ, Doershuk CF, et al. Colonization of the respiratory tract with Pseudomonas cepacia in cystic fibrosis. Risk factors and outcomes. Chest 1987;91:527-32.

266. Tablan OC, Chorba TL, Schidlow DV, et al. Pseudomonas cepacia colonization in patients with cystic fibrosis: risk factors and clinical outcome. The Journal of pediatrics 1985;107:382-7.

267. Isles A, Maclusky I, Corey M, et al. Pseudomonas cepacia infection in cystic fibrosis: an emerging problem. The Journal of pediatrics 1984;104:206-10.

268. Murray S, Charbeneau J, Marshall BC, LiPuma JJ. Impact of burkholderia infection on lung transplantation in cystic fibrosis. American journal of respiratory and critical care medicine 2008;178:363-71.

269. Sanguinetti M, Ardito F, Fiscarelli E, et al. Fatal pulmonary infection due to multidrug-resistant Mycobacterium abscessus in a patient with cystic fibrosis. Journal of clinical microbiology 2001;39:816-9.

270. Aitken ML, Limaye A, Pottinger P, et al. Respiratory outbreak of Mycobacterium abscessus subspecies massiliense in a lung transplant and cystic fibrosis center. American journal of respiratory and critical care medicine 2012;185:231-2.

271. Gilljam M, Schersten H, Silverborn M, Jonsson B, Ericsson Hollsing A. Lung transplantation in patients with cystic fibrosis and Mycobacterium abscessus infection. Journal of cystic fibrosis : official journal of the European Cystic Fibrosis Society 2010;9:272-6.

272. Taylor JL, Palmer SM. Mycobacterium abscessus chest wall and pulmonary infection in a cystic fibrosis lung transplant recipient. The Journal of heart and lung transplantation : the official publication of the International Society for Heart Transplantation 2006;25:985-8.

273. Zaidi S, Elidemir O, Heinle JS, et al. Mycobacterium abscessus in cystic fibrosis lung transplant recipients: report of 2 cases and risk for recurrence. Transplant infectious disease : an official journal of the Transplantation Society 2009;11:243-8.

274. Chalermskulrat W, Sood N, Neuringer IP, et al. Non-tuberculous mycobacteria in end stage cystic fibrosis: implications for lung transplantation. Thorax 2006;61:50713.

275. Dobbin C, Maley M, Harkness J, et al. The impact of pan-resistant bacterial pathogens on survival after lung transplantation in cystic fibrosis: results from a single large referral centre. The Journal of hospital infection 2004;56:277-82. 
276. Stanzi A, Decaluwe H, Coosemans W, et al. Lobar lung transplantation from deceased donors: a valid option for small-sized patients with cystic fibrosis. Transplantation proceedings; 2014: Elsevier. p. 3154-9.

277. Saueressig MG, Pelluau S, Sermet I, Souilamas R. Urgent lung transplantation in cystic fibrosis patients: experience of a French center. European journal of cardiothoracic surgery : official journal of the European Association for Cardio-thoracic Surgery 2011;40:e101-6.

278. Hadem J, Gottlieb J, Seifert D, et al. Prolonged Mechanical Ventilation After Lung Transplantation-A Single-Center Study. American journal of transplantation : official journal of the American Society of Transplantation and the American Society of Transplant Surgeons 2016;16:1579-87.

279. Kilic A, George TJ, Beaty CA, Merlo CA, Conte JV, Shah AS. The effect of center volume on the incidence of postoperative complications and their impact on survival after lung transplantation. The Journal of thoracic and cardiovascular surgery 2012;144:1502-8; discussion 8-9.

280. Bonvillain RW, Valentine VG, Lombard G, LaPlace S, Dhillon G, Wang G. Post-operative infections in cystic fibrosis and non-cystic fibrosis patients after lung transplantation. The Journal of heart and lung transplantation : the official publication of the International Society for Heart Transplantation 2007;26:890-7.

281. Alvarez A, Algar J, Santos F, et al. Airway complications after lung transplantation: a review of 151 anastomoses. European journal of cardio-thoracic surgery : official journal of the European Association for Cardio-thoracic Surgery 2001;19:381-7.

282. Awori Hayanga JW, Aboagye JK, Shigemura N, et al. Airway complications after lung transplantation: Contemporary survival and outcomes. The Journal of heart and lung transplantation : the official publication of the International Society for Heart Transplantation 2016;35:1206-11.

283. Bech B, Pressler T, Iversen M, et al. Long-term outcome of lung transplantation for cystic fibrosis--Danish results. European journal of cardio-thoracic surgery : official journal of the European Association for Cardio-thoracic Surgery 2004;26:1180-6.

284. Sundaresan S, Trulock EP, Mohanakumar T, Cooper JD, Patterson GA. Prevalence and outcome of bronchiolitis obliterans syndrome after lung transplantation. Washington University Lung Transplant Group. The Annals of thoracic surgery 1995;60:1341-6; discussion 6-7.

285. Boehler A, Estenne M. Post-transplant bronchiolitis obliterans. European Respiratory Journal 2003;22:1007-18. 
286. Diso D, Anile M, Patella M, et al. Lung transplantation for cystic fibrosis: outcome of 101 single-center consecutive patients. Transplantation proceedings 2013;45:346-8.

287. Helmi M, Love RB, Welter D, Cornwell RD, Meyer KC. Aspergillus infection in lung transplant recipients with cystic fibrosis: risk factors and outcomes comparison to other types of transplant recipients. Chest 2003;123:800-8.

288. de Hoyos A, Demajo W, Snell G, et al. Preoperative prediction for the use of cardiopulmonary bypass in lung transplantation. The Journal of thoracic and cardiovascular surgery 1993;106:787-95; discussion 95-6.

289. Machuca TN, Collaud S, Mercier O, et al. Outcomes of intraoperative extracorporeal membrane oxygenation versus cardiopulmonary bypass for lung transplantation. The Journal of thoracic and cardiovascular surgery 2015;149:1152-7.

290. Clark SC. Single lung transplantation with cardiopulmonary bypass. Multimedia manual of cardiothoracic surgery : MMCTS / European Association for CardioThoracic Surgery 2011;2011:mmcts 2009004267.

291. Myles PS, Weeks AM, Buckland MR, Silvers A, Bujor M, Langley M. Anesthesia for bilateral sequential lung transplantation: experience of 64 cases. Journal of cardiothoracic and vascular anesthesia 1997;11:177-83.

292. Triantafillou AN, Pasque MK, Huddleston CB, et al. Predictors, frequency, and indications for cardiopulmonary bypass during lung transplantation in adults. The Annals of thoracic surgery 1994;57:1248-51.

293. Mohite PN, Sabashnikov A, Patil NP, et al. The role of cardiopulmonary bypass in lung transplantation. Clinical transplantation 2016;30:202-9.

294. Detterbeck FC, Egan TM, Mill MR. Lung transplantation after previous thoracic surgical procedures. The Annals of thoracic surgery 1995;60:139-43.

295. Jansz P, Ferguson J, Dhital K, Dunning J, Wallwork J, Large S. Cardiopulmonary bypass does not increase the morbidity associated with lung transplantation for chronic obstructive airway disease. The Journal of Heart and Lung Transplantation 2003;22:S190.

296. Sharples L, Hathaway T, Dennis C, Caine N, Higenbottam T, Wallwork J. Prognosis of patients with cystic fibrosis awaiting heart and lung transplantation. The Journal of heart and lung transplantation : the official publication of the International Society for Heart Transplantation 1993;12:669-74.

297. Sekine Y, Waddell TK, Matte-Martyn A, et al. Risk quantification of early outcome after lung transplantation: donor, recipient, operative, and post-transplant 
parameters. The Journal of heart and lung transplantation : the official publication of the International Society for Heart Transplantation 2004;23:96-104.

298. Belkin RA, Henig NR, Singer LG, et al. Risk factors for death of patients with cystic fibrosis awaiting lung transplantation. American journal of respiratory and critical care medicine 2006;173:659-66.

299. Cacciatore F, Abete P, Mazzella F, et al. Six-minute walking test but not ejection fraction predicts mortality in elderly patients undergoing cardiac rehabilitation following coronary artery bypass grafting. European journal of preventive cardiology 2012;19:1401-9.

300. Beatty AL, Schiller NB, Whooley MA. Six-minute walk test as a prognostic tool in stable coronary heart disease: data from the heart and soul study. Archives of internal medicine 2012;172:1096-102.

301. Fiorina C, Vizzardi E, Lorusso R, et al. The 6-min walking test early after cardiac surgery. Reference values and the effects of rehabilitation programme. European Journal of Cardio-thoracic Surgery 2007;32:724-9.

302. Oliveira GU, Carvalho VO, de Assis Cacau LP, et al. Determinants of distance walked during the six-minute walk test in patients undergoing cardiac surgery at hospital discharge. Journal of cardiothoracic surgery 2014;9:95.

303. Baptista VC, Palhares LC, Oliveira PPMd, et al. Six-minute walk test as a tool for assessing the quality of life in patients undergoing coronary artery bypass grafting surgery. Brazilian Journal of Cardiovascular Surgery 2012;27:231-9.

304. Zielińska D, Bellwon J, Rynkiewicz A, Elkady MA. Prognostic value of the sixminute walk test in heart failure patients undergoing cardiac surgery: a literature review. Rehabilitation research and practice 2013;2013. 